\title{
Desarrollos metodológicos en cromatografía de gases y electroforesis capilar
}

\section{Luis Ruano Miguel 2009}

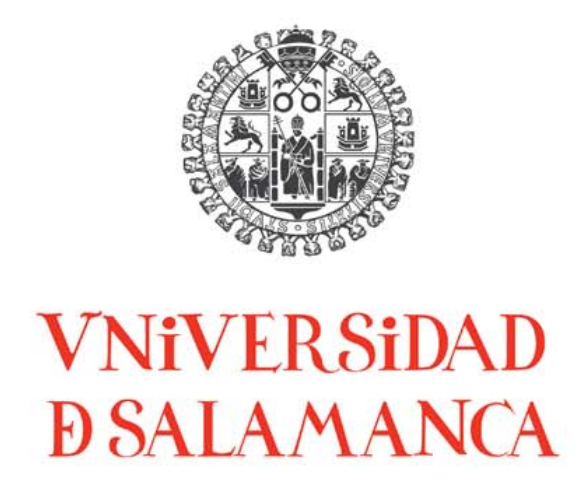

Facultad de Ciencias Químicas Departamento de Química Analítica, Nutrición y Bromatología 

FACULTAD DE CIENCIAS QUÍMICAS

Departamento de Química Analítica, Nutrición y Bromatología

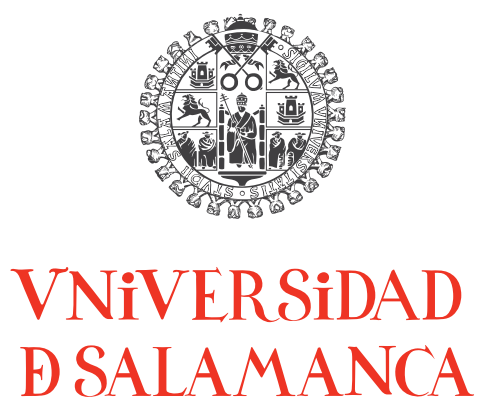

DESARROLLOS METODOLÓGICOS EN CROMATOGRAFÍA DE GASES Y ELECTROFORESIS CAPILAR

Memoria que para optar al grado de Doctor en Química presenta el licenciado

Luis Ruano Miguel

Salamanca, 15 de enero de 2009

Fdo.: Luis Ruano Miguel 

Da. Rita Carabias Martínez, Catedrática de la Universidad de Salamanca, y $D^{a}$. Encarnación Rodríguez Gonzalo, Profesora Titular de la Universidad de Salamanca, directoras del trabajo «Desarrollos metodológicos en cromatografía de gases y electroforesis capilar», realizado por D. Luis Ruano Miguel para optar al grado de Doctor en Química por la Universidad de Salamanca, autorizan la presentación del mismo, por considerar que se han alcanzado los objetivos inicialmente previstos.

Salamanca, 15 de enero de 2009

Fdo.: Rita Carabias Martínez

Fdo.: Encarnación Rodríguez Gonzalo 

Deseo expresar mi agradecimiento al Ministerio de Ciencia y Tecnología por la concesión de una beca de Formación de Personal Investigador durante el período 2003-2007.

El trabajo realizado ha sido financiado por los proyectos: BQU-2002-02314 y CTQ2005-00292 de la Dirección General de Investigación (Ministerio de Ciencia e Innovación), y SA-044/o2 y SAoo7Ao5 de la Junta de Castilla y León. 

Muchas gracias...

... a Rita y a Encarna, por tabajar intensamente para sacar esta tesis adelante, por vuestra paciencia, por confiar en mí y, sobre todo, por lo que me habéis transmitido a lo largo de estos años.

... al Dr. D. César García Hermida, codirector de mi trabajo de Grado de Salamanca, y a la postre primera parte de esta tesis, por tus sabios consejos y cordialidad durante todo este tiempo.

... al Dr. D. César Raposo Funcia por tu ayuda desinteresada, amable disposición y acertado asesoramiento durante la primera parte de la tesis.

... a toda el área de Química Analítica, tanto «los de arriba» como «los de abajo», especialmente a todos mis compañeros de laboratorio que he visto ir y venir, por los buenos ratos y por todo lo que me habéis enseñado tanto en el ámbito personal como profesional. Nunca olvidaré esta etapa de mi vida.

... a Norman W. Smith y todo su equipo del Micro Separations Group en el King's College London por vuestra excepcional acogida y todo lo aprendido durante mi estancia allí.

... a toda mi familia y amigos, en especial mis padres, por interesaros por lo que hago, por vuestro apoyo incondicional, continuo ánimo y por desearme siempre lo mejor. 



\section{ÍNDICE}

Acrónimos y abreviaturas

VIII

Objeto del trabajo

1. Introducción

1.1. Importancia de los plaguicidas carbámicos 4

1.2. Antecedentes bibliográficos 5

- 1.2.1. Análisis de plaguicidas carbámicos mediante GC 5

- 1.2.2. SPE aplicada a la preconcentración de plaguicidas carbámicos 8

- 1.2.3. SPME aplicada a la preconcentración de plaguicidas carbámicos 12

$\begin{array}{ll}\text { 1.3. Objetivo } & 14\end{array}$

$\begin{array}{ll}\text { 2. Parte experimental } & \mathbf{1 5}\end{array}$

$\begin{array}{ll}\text { 2.1. Instrumental } & 15\end{array}$

$\begin{array}{ll}\text { 2.2. } & \text { Reactivos y disoluciones } \\ \end{array}$

2.3. Procedimientos 17

- 2.3.1. Separación cromatográfica y detección mediante Ms 17

- 2.3.2. Determinación mediante GC-MS con SPME $\quad 18$

- 2.3.3. Determinación mediante GC-MS con SPE y SPME $\quad 19$

- 2.3.4. Determinación mediante GC-MS con SPE 20 


\section{Resultados y discusión}

3.1. Comportamiento de plaguicidas carbámicos en GC

- 3.1.1. Identificación de las señales cromatográficas generadas por inyección directa $\quad 21$

- 3.1.2. Reactividad de plaguicidas carbámicos en GC 26

3.2. Preconcentración mediante SPME 28

- 3.2.1. Identificación de las señales cromatográficas generadas después de SPME 28

- 3.2.2. Optimización del proceso de SPME 33

- 3.2.3. Optimización de la separación cromatográfica 43

3.3. Características analíticas de los métodos propuestos 44

-3.3.1. Determinación de plaguicidas carbámicos mediante GC-MS con SPME como etapa de preconcentración

- 3.3.2. Determinación de plaguicidas carbámicos mediante GC-MS con SPE y SPME como etapas de preconcentración

- 3.3.3. Determinación de plaguicidas carbámicos mediante GC-MS con SPE como etapa de preconcentración

\section{Separación de tocoferoles mediante CEC}

\section{Introducción}

5.1. Electrocromatografía capilar 59

- 5.1.1. Fases estacionarias con grupos polares incrustados 60

- 5.1.2. Fases estacionarias monolíticas 62

5.2. Analitos modelo: tocoferoles 68

- 5.2.1. Separación de vitamina E mediante CEC 70

5.3. Objetivo 72 


\section{Parte experimental}

6.1. Instrumental

6.2. Reactivos y disoluciones

6.3. Procedimientos

- 6.3.1. Fabricación de columnas capilares empaquetadas

75

- 6.3.2. Fabricación de columnas monolíticas

80

- 6.3.3. Separación de vitamina E mediante CEC con columnas empaquetadas

82

- 6.3.4. Separación de vitamina E mediante CEC con columnas monolíticas

83

\section{Resultados y discusión}

7.1. Separación con columnas empaquetadas

- 7.1.1. Efecto de la composición de la fase móvil en medios no acuosos

- 7.1.2. Separación de los isómeros $\beta$ y $\gamma$ en una fase estacionaria con grupos polares incrustados

7.1.3. Conclusiones

7.2. Separación en columnas poliméricas monolíticas

- 7.2.1. Optimización de la fabricación de las columnas

- 7.2.2. Características cromatográficas

- 7.2.3. Conclusiones

\section{Separación mediante CE de plaguicidas carbámicos y preconcentración en polímeros monolíticos}

\section{Introducción}

8.1. CE para el análisis de plaguicidas carbámicos

8.2. Extracción en fase sólida y $\mathrm{CE}$

- 8.2.1. Preconcentración en capilares abiertos

- 8.2.2. Preconcentración en columnas empaquetadas 
- 8.2.4. Preconcentración en columnas de CEC 128

$\begin{array}{lr}\text { 8.3. Objetivo } & 129\end{array}$

$\begin{array}{lr}\text { 9. Parte experimental } & 131\end{array}$

$\begin{array}{ll}\text { 9.1. Instrumental } & 131\end{array}$

9.2. Reactivos y disoluciones 131

9.3. Procedimientos 132

- 9.3.1. Separación de plaguicidas carbámicos mediante МЕкс 132

- 9.3.2. Separación de Pirimicarb y Carbendazima mediante CZE 133

- 9.3.3. Fabricación de polímeros monolíticos 134

- 9.3.4. Separación de plaguicidas carbámicos mediante мекC tras una etapa de preconcentración en un polímero monolítico 135

- 9.3.5. Separación de Pirimicarb y Carbendazima mediante CZE tras una etapa de preconcentración in-line

\section{Resultados y discusión}

10.1. Preconcentración y separación de plaguicidas carbámicos mediante MEKC

- 10.1.1. Separación mediante MEKC

- 10.1.2. Preconcentración y separación mediante MEKC

- 10.1.3. Características analíticas

10.2. Preconcentración y separación de plaguicidas carbámicos mediante CZE

- 10.2.1. Separación mediante CZE 173

- 10.2.2. Preconcentración in-line y separación mediante CZE 185

- 10.2.3. Características analíticas 193 


\section{Apéndices}

$\begin{array}{ll}\text { A. Plaguicidas estudiados } & 203\end{array}$

B. Monómeros empleados 205

$\begin{array}{ll}\text { C. Proveedores y marcas } & 207\end{array}$

D. Legislación $\quad 209$

\section{Publicaciones}

Behaviour of carbamate pesticides in GC and their determination with SPE and SPME as preconcentration steps

Use of a polar-embedded stationary phase for the separation of tocopherols by CEC

In-capillary preconcentration of pirimicarb and carbendazim with a monolithic polymeric sorbent prior to separation by CZE

In-capillary microextraction using monolithic polymers. Application to preconcentration of carbamate pesticides prior to their separation by MEKC 



\section{ACRÓNIMOS Y ABREVIATURAS}

$A, \mathrm{u} A$ Absorbancia, «unidad» de absorbancia

AIBN 2,2'-Azobis(2-metilpropionitrilo), Azobisisobutyronitrile

AMPS Ácido 2-acrilamido-2-metil-1propanosulfónico, 2-acrylamido-2methyl-1-propanesulfonic acid

BMA Metacrilato de butilo o butil metacrilato

BGE Electrolito de separación, Background electrolyte

CE Electroforesis capilar, Capillary electrophoresis

CEC Electrocromatografía capilar, Capillary electrochromatography

CMC Concentración micelar crítica

CZE Electoforesis capilar zonal, Capillary zone electrophoresis

DVB Divinilbenceno

EGDMA Dimetacrilalto de etileno, Ethylene glycol dimethacrylate

EOF Flujo electro-osmótico, Electroosmotic flow

ES, ESI Ionización mediante electro-esprái, Electro-spray ionisation

FID Detección de ionización por llama, Flame ionisation detector
GC Cromatografía de gases, Gas chromatography

HPLC Cromatografía líquida de alta eficacia, High performance liquid chromatography

LC Cromatografía líquida, Liquid chromatography

LD Límite de detección

$\gamma$-MAPs metacrilato de 3-(trimetoxisilil)propilo, $\gamma$-methacryloxypropyltrimethoxysilane

MS Espectrometría de masas, Mass spectrometry

мЕкс Cromatografía electrocinética micelar capilar, Micellar electrokinetic chromatography

NACE Electoforesis capilar en medios no acuosos, Non-aqueous capillary electophoresis

NPD Detector de nitrógeno-fósforo, Nitrogen-phosphorus detector

oDPVA octadecilo y alcohol polivinílico, octadecyl polyvinyl alcohol

PDMS-DVB Polidimetilsiloxanodivinilbenceno

PCA Análisis de componentes principales, Principal component analysis

PEEK Poliéter-éter-cetona, Polyetheretherketone 
PDVB Polidivinilbenceno

PFPS Sílice enlazada a fentafluorofenilo (pentafluorophenylsilica)

PM Peso molecular

PTV Inyección con rampa de temperatura, Programmed temperature vaporizing injector

$R_{\mathrm{S}}$ Resolución

RP Fase inversa, Reversed phase

RSD Desviación estándar relativa, Relative standard deviation

SFE Extracción con fluidos supercríticos, Supercritical fluid extraction

SLE Extracción sólido-líquido,

Solid-liquid extraction
SDS Dodecilsulfato sódico, Sodium dodecyl sulphate

SEM Microscopía de barrido electrónico, Scanning electron microscopy

sIM Seguimiento de iones seleccionados, Selected ion monitoring

SPE Extracción en fase sólida, Solid-phase extraction

SPME Microextracción en fase sólida, Solid-phase microextraction

Tris 2-amino-2-hidroximetil-1,3propanodiol, o tris-hidroximetil-aminometano

uHQ Calidad de agua ultrapura (Ultra high quality)

UV Ultravioleta 


\section{OBJETO DEL TRABAJO}

El trabajo que se presenta tiene por objeto el desarrollo de nuevos métodos de análisis basados en cromatografía de gases (GC) y electroforesis capilar (CE), con diferentes configuraciones de tratamiento de muestra para la determinación de diversos tipos de compuestos en muestras de interés medioambiental y alimentario. Los analitos estudiados son, por una parte, contaminantes orgánicos procedentes de la actividad agrícola (plaguicidas carbámicos), y por otro, vitaminas del grupo de los tocoferoles (vitamina E), para los cuales estas técnicas no han sido, hasta el momento, satisfactoriamente desarrolladas. Especial atención se dará al diseño de nuevos esquemas para la extracción y preconcentración de los analitos que, aplicados de forma individual o combinados entre sí, permitan determinar concentraciones adecuadas con el mínimo tratamiento de muestra posible.

El primer capítulo de la memoria trata del desarrollo de métodos analíticos para la separación, identificación y cuantificación de plaguicidas carbámicos mediante cromatografía de gases con espectrometría de masas (GC-MS). Debido a su inestabilidad térmica, los miembros de esta familia de plaguididas no son directamente analizables mediante GC, y requieren etapas previas de derivatización que incrementan el tiempo de análisis y pueden generar interferencias. Se pretende evitar la derivatización utilizando la técnica de microextracción en fase sólida (SPME) con objeto de conseguir una degradación controlada de estos analitos y obtener señales cromatográficas reproducibles de los productos de descomposición. Para tal fin se aprovechará la etapa de desorción térmica que tiene lugar tras la etapa de preconcentración.

Un segundo aspecto de especial importancia en esta tesis es la síntesis y el estudio de nuevas fases estacionarias para su uso en electrocromatografía capilar (CEC). En este sentido se estudiarán las posibilidades que presentan los 
materiales poliméricos monolíticos formados in situ en el interior del capilar como fases estacionarias y se compararán con otro tipo de fases estacionarias empaquetadas de sílice enlazada.

El uso de estos polímeros monolíticos como etapa de limpieza y preconcentración previa a una separación electroforética es el último aspecto de este trabajo y, quizá, el más innovador. Esta parte de la investigación se centrará en la aplicación de estos polímeros monolíticos como sorbentes eficaces y se estudiará su acoplamiento a la separación electroforética de plaguicidas carbámicos, los cuales serán separados por electroforesis capilar zonal en medios no acuosos o por cromatografía electrocinética micelar. 


\section{Parte I}

DETERMINACIÓN DE PLAGUICIDAS CARBÁMICOS MEDIANTE CROMATOGRAFÍA DE GASES CON DIFERENTES ETAPAS DE PRECONCENTRACIÓN 



\section{INTRODUCCIÓN}

Se define plaguicida o pesticida como cualquier producto químico destinado a matar, repeler, atraer, regular o interrumpir el crecimiento de seres vivos considerados plagas. Actualmente, más de 1.400 compuestos están registrados en todo el mundo como plaguicidas o sus metabolitos. Los plaguicidas se pueden clasificar según sus grupos funcionales o su estructura molecular (inorgánicos, organoclorados, organofosforados, carbámicos, etc.) o según su actividad biológica (insecticidas, herbicidas, acaricidas, etc.). Su uso más común es como herbicidas, seguido de insecticidas y fungicidas. Su empleo cada vez más frecuente y la contaminación adicional debida a emisiones durante su fabricación han dado como resultado la presencia de su residuos y de sus metabolitos en suelos, aguas y alimentos.

Debido a su uso en agricultura y posterior filtración, la contaminación por plaguicidas de aguas superficiales y acuíferos ha sido bien documentada y existen numerosas referencias del análisis de muestras de diferente complejidad como suelos, alimentos o fluidos biológicos. Por otra parte, los productos de transformación o los metabolitos que se forman como consecuencia de procesos tales como hidrólisis, biodegradaciones, oxidaciones, fotólisis, etc. son frecuentemente más tóxicos y persistentes en el medio ambiente que los plaguicidas de los que provienen. En las últimas décadas, el análisis de plaguicidas en muestras ambientales ha recibido una creciente atención, dando lugar a numerosos programas ambientales de control para una amplia variedad de estos productos. Su concentración y la de sus metabolitos en el medio ambiente es frecuentemente muy baja y su determinación puede presentar un gran número de interferencias. Por este motivo son necesarias técnicas 
muy sensibles y selectivas para la detección y cuantificación de dichos contaminantes a nivel de trazas.

\subsection{IMPORTANCIA DE LOS PLAGUICIDAS CARBÁMICOS}

Las probadas persistencia y toxicidad de los plaguicidas organofosforados y organoclorados justificó su sustitución por otros más fácilmente degradables, polares, lábiles y menos persistentes, como son los $N$-metil carbamatos. Los plaguicidas carbámicos comenzaron a aplicarse al principio de la década de 1950 y desde entonces se han usado extensamente en el control de plagas debido a su efectividad y amplio espectro de actividad biológica (insecticidas, fungicidas, herbicidas, etc.). En cuanto a su estructura, corresponde a la de ésteres de ácidos carbámicos $N$-sustituidos (Figuras 1.1 y A.1, pág. 203). La mayoría son ésteres de fenoles o anillos aromáticos heterocíclicos, con sustituyentes metílicos en el nitrógeno. La elevada polaridad, su solubilidad en agua y su inestabilidad térmica son características típicas de estos plaguicidas.<smiles>[R]OC(=O)N([R])[R]</smiles>

Figura 1.1. Estructura general de los plaguicidas carbámicos.

Su toxicidad aguda es elevada, su efecto a corto plazo es muy potente, y la rápida degradación dificulta su detección. Debido a ello, además de su uso apropiado, esta familia de compuestos se emplea como veneno para animales, en especial el Aldicarb y el Carbofurano, que han sido encontrados en cebos y cadáveres. Debido al incremento de su uso en agricultura, aunque su aplicación sea correcta, sus restos y los de sus metabolitos pueden encon- 
trarse en el suelo, en aguas de escorrentía, en alimentos y en cosechas, como consecuencia de su filtración y elevada solubilidad en agua.

Los plaguicidas carbámicos se absorben por inhalación, ingestión y, en menor medida, mediante absorción cutánea, aunque ésta sea la ruta menos tóxica. Actúan mediante un mecanismo de inhibición reversible de la acetilcolina, que es un neurotransmisor presente en las uniones nerviosas degradado continuamente por la acetilcolinesterasa. Causan una carbamilación de la enzima que ocasiona una acumulación de la acetilcolina y una estimulación excesiva de los receptores nerviosos caracterizada por cambios en el estado de conciencia, espasmos, debilidad muscular, falta de coordinación, excesiva actividad secretora $y$, en concentraciones altas, insuficiencia respiratoria y muerte. Son hidrolizados enzimáticamente por el hígado a los correspondientes alcoholes, y los productos de degradación (glucurónidos) se excretan por vía renal.

\subsection{ANTECEDENTES BibLIOGRÁficos}

\subsubsection{Análisis de plaguicidas carbámicos mediante cromatografía de gases}

Las técnicas analíticas más frecuentemente empleadas para la separación y cuantificación de plaguicidas son la cromatografía de gases (GC) y la cromatografía líquida de alta eficacia (HPLC). Sin embargo, los plaguicidas carbámicos y sus productos de transformación, al igual que las fenilureas, son térmicamente inestables, lo que limita el uso de la GC. Este inconveniente se evita mediante una etapa previa de derivatización, la cual implica un incremento del tiempo de análisis y puede introducir interferencias. Por este motivo, la técnica preferida para su determinación es HPLC con detección fluorimética $[1,2,3]$, de absorción UV $[4,5,6]$ o espectrometría de masas [7].

[1] Método US EPA 8318a. N-Methylcarbamates by HPLC, 2000. Rev. 1.

[2] Método AOAC 985.23. N-methylcarbamate insecticide and metabolite residues; liquid chromatographic method, 1986.

[3] Método AOAC 991.06. N-methylcarbamoyloximes and N-methylcarbamates in finished drinking water, 1993.

[4] Método US EPA 531.1. Measurement of N-methylcarbamoyloximes and N-methylcarbamates in water by direct aqueous injection HPLC with post column derivatization. 
No obstante, algunos investigadores han propuesto métodos para analizar esta familia de compuestos mediante GC.

En 1991 Stan y Klaffenbach [8] proponen una reacción con anhídrido acético de 10 plaguicidas carbámicos para conseguir derivados térmicamente estables y volátiles para su posterior análisis mediante GC-Ms. En 2006 Zhang y Lee [9] emplean una derivatización «en columna» para la determinación de 5 plaguicidas carbámicos en muestras acuosas tras una etapa de microextración en fase líquida.

Lambropoulou et al. [10] evaluaron la contaminación de plaguicidas en el río Kalamas (Grecia) mediante sPME y GC-Ms. Entre los compuestos estudiados se incluye el Carbofurano, para el cual el método propuesto tiene un límite de detección de $0,03^{\mu \mathrm{g} / \mathrm{L} \text {. }}$

Lu y Que Hee [11] estudian la permeabilidad de los guantes de nitrilo al Metomilo mediante GC-Ms. Con el fin de minimizar la descomposición del Metomilo se propone trabajar con temperaturas inferiores a $180^{\circ} \mathrm{C}$.

Algunos autores han propuesto dispositivos especiales para minimizar la degradación térmica de los plaguicidas carbámicos en GC. Por ejemplo, Wigfield et al. [12] recomiendan emplear columnas cortas (10 m), y un dispositivo

[5] Método AOAC 984.09. Benomyl in insecticidal formulations; RP liquid chromatographic method, 1984 .

[6] Método AOAC 995.14. Methomyl in insecticidal formulations; RP liquid chromatographic method, 1995.

[7] Método Us EPA 8321B. Solvent-extractable nonvolatile compounds by HPLC/Ts/MS or UV detection.

[8] H. J. Stan and P. Klaffenbach. Determination of carbamate pesticides and some urea pesticides after derivatization with acetic anhydride by means of GC-MSD. Fresenius J. Anal. Chem., 339:151-157, 1991.

[9] J. Zhang and H. K. Lee. Application of liquid-phase microextraction and on-column derivatization combined with GC-MS to the determination of carbamate pesticides. J. Chromatogr. A, 1117:31-37, 2006.

[10] D. A. Lambropoulou, V. A. Sakkas, D. G. Hela, and T. A. Albanis. Application of SPME in the monitoring of priority pesticides in the Kalamas River (N. W. Greece). J. Chromatogr. A, 963:107-116, 2002.

[11] X. Lu and S. S. Que Hee. Permeation of methomyl in Lannate $\mathrm{L}^{\mathrm{TM}}$ through nitrile gloves. J. Hazard. Mater., 59:279-285, 1998. 
de inyección con temperatura programada (PTV), el cual permite incrementar progresivamente la temperatura del inyector.

Zrostlíková et al. [13] comparan la técnica de inyección con PTV con otros modos de inyección usados en Gc. Comprueban que con PTV se evita la degradación de los compuestos térmicamente lábiles y lo aplican a la determinación de 26 plaguicidas de diferentes familias, entre ellos el Carbarilo.

Maštovská et al. [14] utilizan GC-MS a baja presión para evitar la degradación térmica de Metiocarb y Carbarilo. El vacío necesario lo suministraba la bomba del espectrómetro de masas que funcionaba como detector.

El grupo de Amirav et al. [15, 16] desarrolla una nueva técnica denominada GC-MS supersónica con la cual alcanzan una elevada sensibilidad para un número elevado de plaguicidas en matrices agrícolas complejas. Entre las principales ventajas de esta nueva técnica se encuentra la capacidad de analizar compuestos térmicamente lábiles mediante GC.

A pesar de los problemas que presenta el análisis de plaguicidas carbámicos mediante GC, existen muy pocas referencias que estudien el proceso de descomposición térmica y propongan cuáles son sus productos de degradación. Trehy et al. [17] muestran que el Aldicarb se degrada a su correspondiente nitrilo tanto térmicamente como en presencia de microorganismos anaero-

[12] Y. Y. Wigfield, R. Grant, and N. Snider. Gas chromatographic and mass spectrometric investigation of seven carbamate insecticides and one metabolite. J. Chromatogr., 657:219222, 1993 .

[13] J. Zrostlíková, J. Hajšlová, M. Godula, and K. Maštovská. Performance of PTv, pulsed splitless and on-column injection techniques in analysis of pesticide residues in plant matrices. J. Chromatogr. A, 937:73-86, 2001.

[14] K. Maštovská, S. J. Lehotay, and J. Hajšlová. Optimization and evaluation of low-pressure GC-MS for the fast analysis of multiple pesticide residues in a food commodity. J. Chromatogr. A, 926:291-308, 2001.

[15] M. Kochman, A. Gordin, P. Goldshlag, S. J. Lehotay, and A. Amirav. Fast, high-sensitivity, multipesticide analysis of complex mixtures with supersonic GC-MS. J. Chromatogr. A, 974:185-212, 2002.

[16] A. B. Fialkov, A. Gordin, and A. Amirav. Extending the range of compounds amenable for GC-mass spectrometric analysis. J. Chromatogr. A, 991:217-240, 2003.

[17] M. L. Trehy, R. A. Yost, and J. J. McCreary. Determination of Aldicarb, Aldicarb oxime, and Aldicarb nitrile in water by GC-Ms. Anal. Chem., 56:1281-1285, 1984. 
bios; comprueban que la degradación térmica se minimizaba mediante el uso de columnas capilares cortas (inferiores a $5 \mathrm{~m}$ ). Fialkov et al. [16] obtienen resultados similares con columnas cortas.

Santos Delgado et al. [18] realizan un estudio para conocer la estabilidad térmica de varios plaguicidas carbámicos, y proponen un método para su determinación mediante GC con detección FID y NPD. El método propuesto se ha aplicado de manera satisfactoria a la determinación en purés de patata precocinados de Propoxur, Carbofurano, Metiocarb y Carbarilo. Estos autores proponen que las variables que afectan a su estabilidad son: programa de temperatura del horno, longitud de la aguja de la jeringa, temperatura del inyector, concentración de plaguicida, volumen de aire al final de la aguja y edad de la columna. En las condiciones de trabajo y siempre que se inyectan concentraciones inferiores a $20 \mathrm{mg} / \mathrm{L}$, se obtienen las señales cromatográficas correspondientes a los analitos sin descomponer; sin embargo, si las concentraciones inyectadas son superiores, se detectan los productos de descomposición, cuya señal aumenta al incrementar la concentración de pesticida. Proponen que los compuestos con estructura de carbamato de fenilo se descomponen mediante un reordenamiento de McLafferty, y originan los compuestos fenólicos correspondientes.

\subsubsection{Extracción en fase sólida aplicada a la preconcentración de plaguicidas carbámicos}

En la mayoría de las ocasiones, los métodos de separación y detección por sí solos no son suficientemente sensibles como para determinar plaguicidas en los niveles en los que se encuentran en muestras ambientales; necesitan, como etapas previas al análisis, su aislamiento y preconcentración en diferentes tipos de muestras (aguas, alimentos, suelos, etc.). Mediante el aislamiento de los analitos se incrementa la selectividad y con la preconcentración se aumenta la sensibilidad del método. Las técnicas más empleadas habitualmente para la preconcentración de plaguicidas, son la extracción líquido-líquido, la extración en fase sólida (SPE) y la microextracción en fase sólida (SPME). 
La SPE es una de las técnicas más usadas para efectuar una preconcentración de contaminantes en muestras ambientales. En ella tiene lugar la distribución de los analitos entre un material adsorbente o absorbente sólido, y la fase líquida donde están disueltos. Los analitos quedan retenidos en el material, del cual son eluidos, tras una etapa de lavado, con un volumen relativamente pequeño de un disolvente adecuado. Las ventajas de la SPE son su selectividad (que depende del material y el extractante elegidos), el elevado factor de preconcentración, su fácil automatización, y el bajo consumo de disolventes orgánicos. Los fundamentos teóricos, así como los desarrollos experimentales de esta técnica de preconcentración han sido ampliamente recogidos en la literatura [19].

En cuanto a la aplicación concreta de SPE a la preconcentración de plaguicidas carbámicos, Soriano et al. [20] publicaron en 2001 una extensa revisión bibliográfica sobre la preconcentración de esta familia de compuestos $\mathrm{y}$ de sus metabolitos en aguas mediante SPE y posterior separación por LC, con 141 referencias que incluyen métodos de preconcentración on-line y off-line. En dicha recopilación queda patente que los materiales más empleados para la preconcentración de plaguicidas carbámicos son fases de

[18] M. J. Santos Delgado, S. Rubio Barroso, G. Toledano Fernández-Tostado, and L. M. PoloDíez. Stability studies of carbamate pesticides and analysis by GC with flame ionization and nitrogen-phosphorus detection. J. Chromatogr. A, 921:287-296, 2001.

[19] E. M. Thurman and M. S. Mills. Solid-phase Extraction: Principles and Practice. Wiley, 1998.

[20] J. M. Soriano, B. Jiménez, G. Font, and J. C. Moltó. Analysis of carbamate pesticides and their metabolites in water by SPE and LC: a review. Crit. Rev. Anal. Chem., 31:19-52, 2001.

[21] A. Di Corcia, R. Samperi, A. Marcomini, and S. Stelluto. Graphitized carbon black extraction cartridges for monitoring polar pesticides in water. Anal. Chem., 65:907-912, 1993.

[22] S. Chiron, A. Valverde, A. Fernández-Alba, and D. Barceló. Automated sample preparation for monitoring groundwater pollution by carbamate insecticides and their transformation products. J. AOAC Int., 78:1346-1352, 1995.

[23] K. M. Moore, S. R. Jones, and C. James. Multi-residue analytical method for uron and carbamate pesticides in water using SPE and LC-MS. Water Res., 29:1225-1230, 1995.

[24] A. Junker-Buchheit and M. Witzenbacher. Pesticide monitoring of drinking water with the help of SPE and HPLC. J. Chromatogr. A, 737:67-74, 1996.

[25] D. Giraud, A. Ventura, V. Camel, A. Bermond, and P. Arpino. Determination of traces of pesticides in water by SPE and LC-ionspray MS. J. Chromatogr. A, 777:115-125, 1997.

[26] I. Vassilakis, D. Tsipi, and M. Scoullos. Determination of a variety of chemical classes of pesticides in surface and ground waters by off-line SPE, GC with electron-capture and 
$\mathrm{C}_{18}[21,22,23,24,25,26,27,28]$, de carbono grafítico $[21,29,30,31,32,33,27]$ y materiales poliméricos basados en estireno-divinilbenceno [24, 34, 27].

Molina et al. [35] aplican una preconcentración on-line con cartuchos poliméricos a una separación multiresiduo mediante MEKc. Arráez-Román et al. [36] efectúan un paso previo de SPE antes de la separación por MEKC de Aldicarb y Carbofurano.

nitrogen-phosphorus detection, and HPLC with post-column derivatization and fluorescence detection. J. Chromatogr. A, 823:49-58, 1998.

[27] J. M. Soriano, B. Jiménez, M. J. Redondo, and J. C. Moltó. Comparison of different sorbents for on-line liquid-solid extraction followed by HPLC determination of nitrogencontaining pesticides. J. Chromatogr. A, 822:67-73, 1998.

[28] T. M. Primus, D. J. Kohler, M. Avery, P. Bolich, M. O. Way, and J. J. Johnston. Novel field sampling procedure for the determination of methiocarb residues in surface waters from rice fields. J. Agric. Food Chem., 49:5706-5709, 2001.

[29] A. Di Corcia and M. Marchetti. Multiresidue method for pesticides in drinking water using a graphitized carbon black cartridge extraction and liquid chromatographic analysis. Anal. Chem., 63:580-585, 1991.

[30] C. Crescenzi, A. Di Corcia, G. Passariello, R. Samperi, and M. I. T. Carou. Evaluation of two new examples of graphitized carbon blacks for use in SPE cartridges. J. Chromatogr. A, 733:41-55, 1996.

[31] A. Cappiello, G. Famiglini, and F. Bruner. Determination of acidic and basic/neutral pesticides in water with a new microliter flow rate LC/Ms particle beam interface. Anal. Chem., 66:1416-1423, 1994.

[32] J. Slobodník, Ö. Öztezkizan, H. Lingeman, and U. A. T. Brinkman. sPE of polar pesticides from environmental water samples on graphitized carbon and Empore-activated carbon disks and on-line coupling to octadecyl-bonded silica analytical columns. J. Chromatogr. A, 750:227-238, 1996.

[33] S. Guenu and M. C. Hennion. Prediction from liquid chromatographic data of obligatory backflush desorption from SPE cartridges packed with porous graphitic carbon. J. Chromatogr. A, 725:57-66, 1996.

[34] S. Guenu and M. C. Hennion. Evaluation of new polymeric sorbents with high specific surface areas using an on-line sPE-liquid chromatographic system for the trace-level determination of polar pesticides. J. Chromatogr. A, 737:15-24, 1996.

[35] M. Molina, D. Perez-Bendito, and M. Silva. Multi-residue analysis of $N$-methylcarbamate pesticides and their hydrolytic metabolites in environmental waters by use of SPE and мЕКс. Electrophoresis, 20:3439-3449, 1999.

[36] D. Arráez-Román, A. Segura-Carretero, C. Cruces-Blanco, and A. Fernández-Gutiérrez. Determination of Aldicarb, Carbofurano and some of their main metabolites in groundwater by application of MEKC with DAD and SPE. Pest Manage. Sci., 60:675-679, 2004. 
Otras aplicaciones más recientes incluyen el uso de polímeros impresos [37, 38] y SPE dispersiva [39, 40]. Del Carlo et al. [41] comparan la determinación de Carbarilo mediante un bioensayo electroquímico con la extracción en cartuchos de $C_{18}$ y separación mediante HPLC. Caballo-López et al. [42] comparan el método EPA 8318 [1] con la extracción con ultrasonidos y posterior limpieza on-line y separación.

Además de los trabajos mencionados, existen varias publicaciones recientes que incluyen etapas de SPE antes de una separación cromatográfica $[43,44$, 45].

[37] J. Hantash, A. Bartlett, P. Oldfield, G. Dénès, R. O'Rielly, and F. David. Application of an in-line imprinted polymer column in a potentiometric flow-injection chemical sensor to the determination of the carbamate pesticide carbaryl in complex biological matrices. Anal. Bioanal. Chem., 387:351-357, 2007.

[38] M. L. Mena, P. Martínez-Ruiz, A. J. Reviejo, and J. M. Pingarrón. Molecularly imprinted polymers for on-line preconcentration by SPE of Pirimicarb in water samples. Anal. Chim. Acta, 451:297-304, 2002.

[39] M. Liu, H. Yuki, Y. Song, and J. Lin. Determination of carbamate and organophosphorus pesticides in fruits and vegetables using LC-MS with dispersive SPE. Chinese J. Anal. Chem., 34:941-945, 2006.

[40] M. Liu, Y. Hashi, Y. Song, and J. M. Lin. Simultaneous determination of carbamate and organophosphorus pesticides in fruits and vegetables by LC-MS. J. Chromatogr. A, 1097:183187, 2005.

[41] M. Del Carlo, M. Mascini, A. Pepe, G. Diletti, and D. Compagnone. Screening of food samples for carbamate and organophosphate pesticides using an electrochemical bioassay. Food Chem., 84:651-656, 2004.

[42] A. Caballo-López and M. D. Luque de Castro. Continuous ultrasound-assisted extraction coupled to on line filtration-SPE-column LC-post column derivatisation-fluorescence detection for the determination of $\mathrm{N}$-methylcarbamates in soil and food. J. Chromatogr. A, 998:51-59, 2003.

[43] T. Pérez-Ruiz, C. Martínez-Lozano, and M. D. García. Determination of $\mathrm{N}$ methylcarbamate pesticides in environmental samples by an automated SPE and liquid chromatographic method based on post-column photolysis and chemiluminescence detection. J. Chromatogr. A, 1164:174-180, 2007.

[44] P. Morrica, P. Fidente, and S. Seccia. Liquid chromatographic determination of nine Nmethylcarbamates in drinking water. Biomed. Chromatogr., 19:107-110, 2005.

[45] G. Özhan, S. Topuz, and B. Alpertunga. A simple method for the determination of carbaryl and 1-naphthol in fruit juices by HPLC-DAD. J. Food Prot., 66:1510-1513, 2003. 


\subsubsection{Microextracción en fase sólida aplicada a la preconcentración de plaguicidas carbámicos}

Una técnica de preconcentración alternativa a la SPE, es la microextracción en fase sólida (SPME). Presenta las ventajas de no necesitar disolventes orgánicos, es relativamente barata, ya que las fibras son reutilizables (se pueden efectuar más de 50 extracciones por fibra), requiere pequeños volúmenes de muestra, se puede usar directamente en un gran número de matrices, y es posible su automatización.

Esta técnica consiste en la retención de los analitos en una fase extractante de naturaleza polimérica, dispuesta como revestimiento de una fibra de sílice fundida. La fase polimérica recubre un centímetro de longitud de la fibra de sílice, y puede exponerse o retraerse dentro de una aguja protectora de acero inoxidable. En la aplicación de la SPME se distinguen dos etapas:

1. La fibra se expone a la muestra y los analitos se reparten entre la matriz y el revestimiento polimérico.

2. Finalmente, la fibra con los analitos concentrados se coloca en el dispositivo de inyección de un cromatógrafo de gases, donde se desorben térmicamente, o bien se disuelven en un disolvente orgánico apropiado si la SPME se va a acoplar a una separación por HPLC.

Aunque la SPME ha sido muy empleada en el aislamiento y preconcentración de plaguicidas de diferente naturaleza (organoclorados, organofosforados, triazinas, fenilureas, etc.) en diferentes matrices (aguas, suelos y alimentos), en la revisión bibliográfica realizada se han encontrado escasas referencias sobre su aplicación a plaguicidas carbámicos. Dada su elevada polaridad, el tipo de recubrimiento polimérico empleado para la preconcentración de plaguicidas carbámicos es el poli(dimetilsiloxano-divinilbenceno) (PDMS-DVB) si la técnica de separación es HPLC, que es lo más habitual.

Blanco et al. [46] aplican la SPME a la preconcentración de Carbofurano en muestras de agua, encontrando que la fibra más adecuada es una de PDMs-

[46] M. C. López-Blanco, B. Cancho-Grande, and J. Simal-Gándara. Comparison of sPE and SPME for carbofuran in water analyzed by HPLC-DAD. J. Chromatogr. A, 963:117-123, 2002. 
DVB. Estudian el efecto que la temperatura y el efecto salino ejercen en el proceso de extracción y observan que la eficacia de la separación crece con la fuerza iónica y disminuye al aumentar la temperatura. El análisis se realizó mediante HPLC-DAD y presenta un límite de detección de 8,9 $\mu \mathrm{g} / \mathrm{L}$. Estos autores realizan un estudio comparativo utilizando SPME y SPE empleando una fase extractante de $C_{18}$. Las precisiones de ambos procedimientos de extracción son comparables, pero el límite de detección es inferior con SPE (o,o6 $\mu \mathrm{g} / \mathrm{L})$.

Volmer y Hui [47] encuentran unos límites de cuantificación entre o,3 y $1,9 \mathrm{\mu g} / \mathrm{L}$ para 9 plaguicidas carbámicos en aguas mediante SPME y HPLCMS/MS.

El grupo de Pawliszyn, quien introdujo la técnica de SPME, emplea una nueva modalidad (in-tube sPME o SPME intratubular) $[48,49,50,51]$. En esta metodología, en la etapa de preconcentración se pasa la muestra por el interior de un capilar de sílice fundida recubierto interiormente de la fase polimérica. La etapa de desorción se lleva a cabo pasando por el capilar un disolvente orgánico apropiado. La SPME intratubular permite su automatización, pues se puede acoplar en línea en una válvula de inyección de HPLc. Los límites de detección encontrados utilizando detección espectrofotométrica son

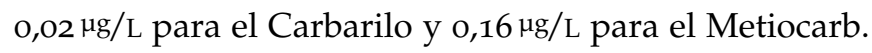

Möder et al. [52] proponen un método para la determinación de plaguicidas carbámicos y triazinas en muestras de suelos y lodos y los analizan mediante HPLC-MS. Sagratini et al. [53] analizan trazas de fenilureas y plaguicidas carbámicos en zumos de frutas preconcentrando $1 \mathrm{~mL}$ durante $90 \mathrm{~min}$ antes de su detección mediante HPLC-Ms/Ms.

[48] Y. Gou and J. Pawliszyn. In-tube sPME coupled to capillary LC for carbamate analysis in water samples. Anal. Chem., 72:2774-2779, 2000.

[49] Y. Gou, C. Tragas, H. Lord, and J. Pawliszyn. On-line coupling of in-tube spme to HPLC for analysis of carbamates in water samples: Comparison of two commercially available autosamplers. J. Microcolumn Sep., 12:125-134, 2000.

[50] Y. Gou, R. Eisert, and J. Pawliszyn. Automated in-tube SPME-HPLC for carbamate pesticide analysis. J. Chromatogr. A, 873:137-147, 2000.

[51] J. Wu, C. Tragas, H. Lord, and J. Pawliszyn. Analysis of polar pesticides in water and wine samples by automated in-tube sPME coupled with HPLC-Ms. J. Chromatogr. A, 976:357-367, 2002. 


\section{3. овJеTIVO}

El objetivo de la primera parte de esta memoria es la puesta a punto de métodos analíticos para la identificación y cuantificación de siete plaguicidas carbámicos mediante GC-Ms. Debido a que la mayoría de ellos son térmicamente inestables, se pretende conseguir una degradación controlada con el fin de obtener señales cromatográficas reproducibles de los productos de descomposición. Para lograr esta descomposición controlada se aprovechará la desorción térmica que tiene lugar tras una etapa de preconcentración mediante microextracción en fase sólida (SPME).

En primer lugar se ha estudiado el comportamiento de los plaguicidas carbámicos en GC-MS, en función de las condiciones de inyección y de si la introducción en el sistema cromatográfico se realiza directamente o por desorción térmica tras una etapa de sPME. Posteriormente se han optimizado los diferentes parámetros que afectan al proceso de extracción (SPME) y, en las condiciones óptimas encontradas, se han evaluado las características analíticas del método con una etapa de preconcentración mediante SPME. Finalmente, se comparan diversos métodos analíticos con diferentes configuraciones de preconcentración basados en SPME, SPE, o el uso conjunto de ambas técnicas de forma previa al análisis mediante GC-MS.

[52] M. Möder, P. Popp, R. Eisert, and J. Pawliszyn. Determination of polar pesticides in soil by sPMe coupled to HPLC-Es/Ms. Fresenius J. Anal. Chem., 363:680-685, 1999.

[53] G. Sagratini, J. Mañes, D. Giardiná, P. Damiani, and Y. Picó. Analysis of carbamate and phenylurea pesticide residues in fruit juices by SPME and LC-MS. J. Chromatogr. A, 1147:135-143, 2007. 


\section{PARTE EXPERIMENTAL}

\subsection{INSTRUMENTAL}

La separación cromatográfica se ha llevado a cabo en un equipo Shimadzu GC-17A equipado con detector de cuadrupolo Shimadzu QP500o. Se emplearon dos columnas capilares: una J\&W DB5 (5\% de polidifenilo y $95 \%$ de polidimetilsiloxano) de $30 \mathrm{~m}$ de longitud, $250 \mu \mathrm{m}$ de diámetro interno y $0,25 \mu \mathrm{m}$ de espesor de fase estacionaria, y otra columna de las mismas características usada intensamente durante dos años, con 1 um de espesor de fase estacionaria.

La preconcentración mediante SPME se realizó en una fibra de poliacrilato de $85 \mu \mathrm{m}$ de Supelco en viales de $12 \mathrm{~mL}$ con tapón de rosca y septo perforable de silicona recubierto de teflón. El vial con la muestra se mantuvo sobre un agitador magnético Jenway 1000, y a temperatura constante con la ayuda de un termostato de inmersión de la marca SBS (Figura 2.2).

Se usaron cartuchos Sep-Pak $\mathrm{tC}_{1} 8$ de Waters con $900 \mathrm{mg}$ de relleno para la preconcentración mediante SPE. Las muestras de agua fueron impulsadas con una bomba peristáltica Gilson Minipuls 2. Para la etapa de elución se utilizó una bomba de vacío acoplada a una urna de vidrio con capacidad para 20 cartuchos simultáneos de SPE de la marca Varian. Para redisolver el residuo seco se utilizó un equipo de agitación de tubos por vórtice. 


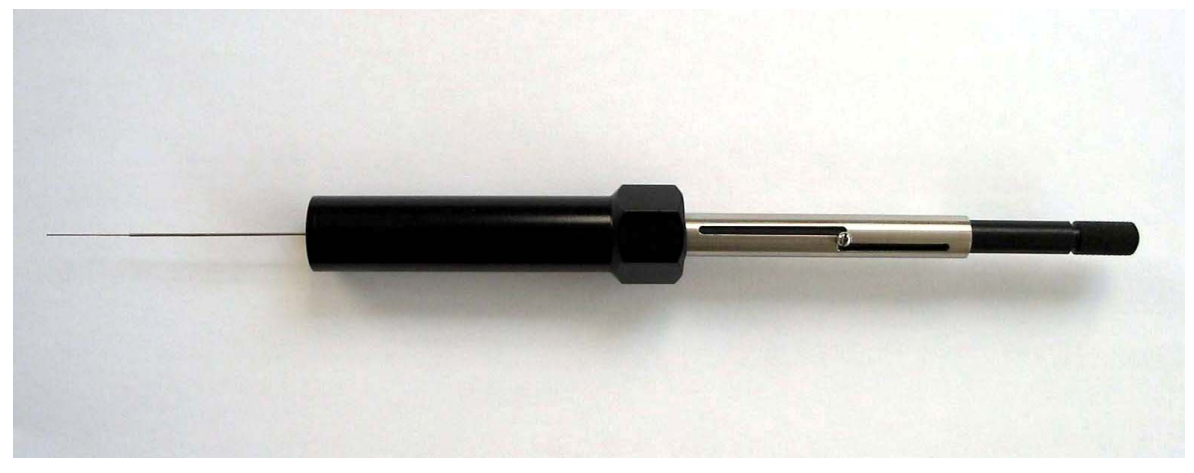

Figura 2.1. Dispositivo comercial de SPME.

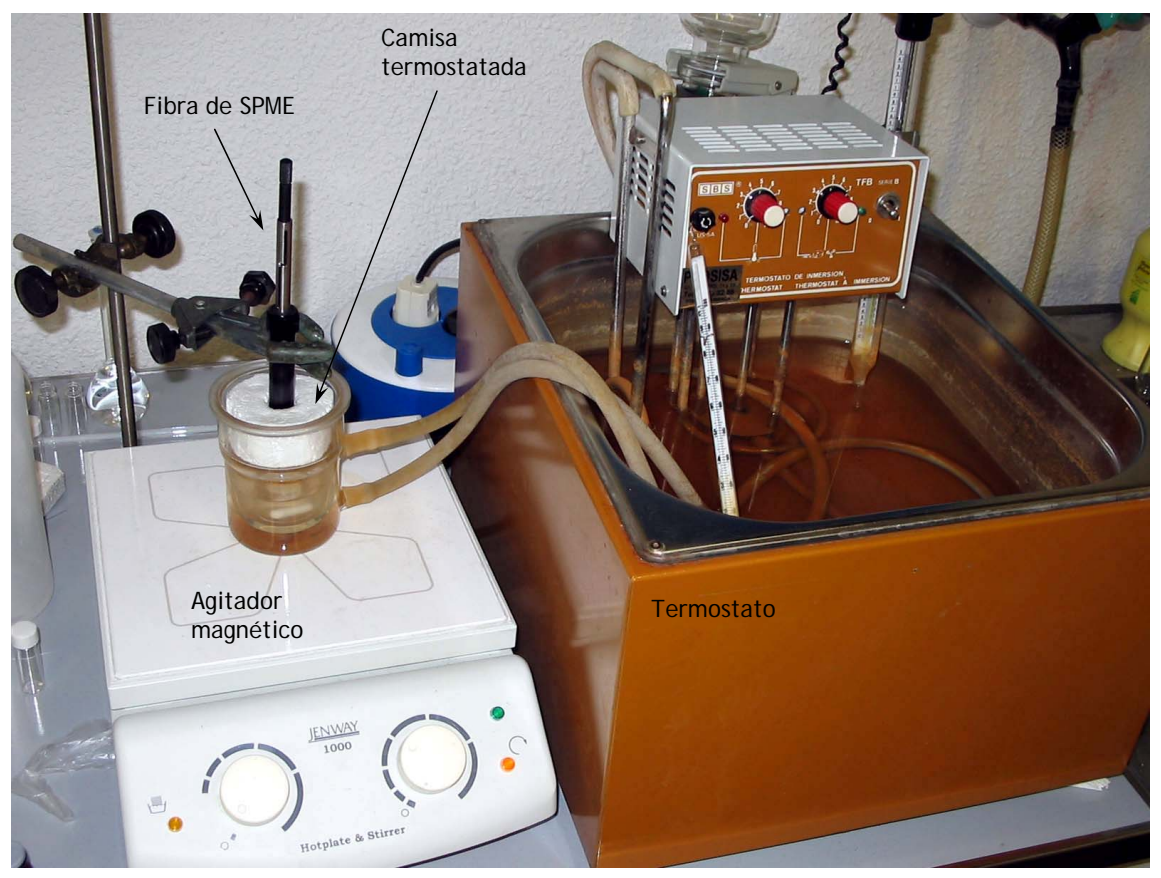

Figura 2.2. Montaje experimental para la SPME. 


\subsection{REACTIVOS Y DISOLUCIONES}

Los patrones de plaguicidas (Carbofurano, Propoxur, Metiocarb, Carbarilo, Carbetamida, Aldicarb y Pirimicarb) y metabolitos (Isopropoxifenol y 1Naftol) tuvieron un porcentaje mínimo de pureza superior al 98,5\%. Todos se obtuvieron de Dr. Ehrenstorfer excepto el Pirimicarb (Fluka).

Se prepararon disoluciones madre de todos los plaguicidas y sus metabolitos en metanol con una concentración de $200 \mathrm{mg} / \mathrm{L}$. A partir de estas disoluciones madre se obtuvieron por dilución las disoluciones de trabajo. Todas las disoluciones se almacenaron a $4{ }^{\circ} \mathrm{C}$ en ausencia de luz.

Los disolventes orgánicos empleados (acetonitrilo y metanol) fueron de Merck con calidad para HPLC. El agua se obtuvo mediante un sistema de purificación de agua Elgastat UHQ, de la marca Elga.

El resto de reactivos empleados para la preparación de disoluciones fueron de calidad «reactivo analítico».

\subsection{PROCEDIMIENTOS}

\subsubsection{Separación cromatográfica y detección mediante espectrometría de masas}

La temperatura de la interfase fue de $270^{\circ} \mathrm{C}$. La temperatura del inyector fue de $300^{\circ} \mathrm{C}$. El gas portador fue helio con un caudal de $1,7^{\mathrm{mL}} / \mathrm{min}$ y una velocidad lineal de $46,8 \mathrm{~cm} / \mathrm{min}$. El modo de inyección fue splitless (sin división de muestra). El programa de temperaturas óptimo se encuentra en la figura y tabla de la página 18 .

El modo de recogida de datos en los distintos métodos propuestos en este trabajo fue SIM, con una frecuencia de muestreo de $5 \mathrm{~Hz}$, adquiriendo datos desde el minuto 10 hasta el 18. Los estudios previos de identificación de picos fueron realizados en modo scan, con un muestreo de $2 \mathrm{~Hz}$ y división de muestra 1:50.

La identificación se realiza mediante el tiempo de retención y tres relaciones $m / z$ características para cada analito; un ion cuantificador (el más abundan- 


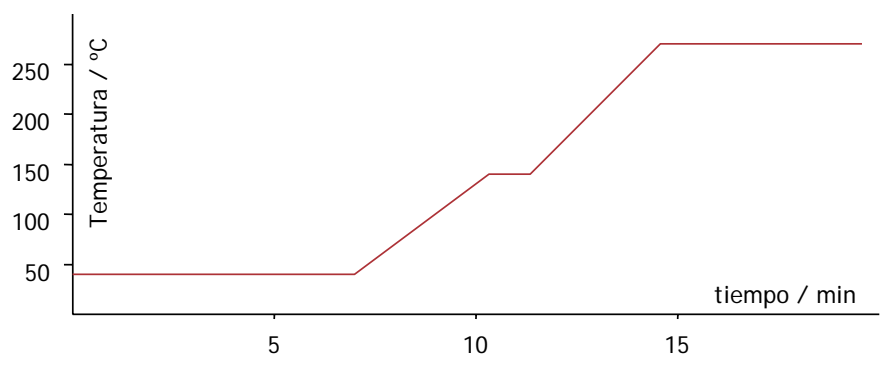

\begin{tabular}{|lll|}
\hline Velocidad $/{ }^{\circ} \mathrm{C} / \min$ & $\mathrm{T}$ objetivo $/{ }^{\circ} \mathrm{C}$ & Tiempo / min \\
\hline- & 40 & 7 \\
30 & 140 & 1 \\
40 & 270 & 5 \\
\hline
\end{tabular}

te) y dos cualificadores. En la Tabla 2.1 se muestran los compuestos detectados, los plaguicidas de los que provienen, las relaciones $m / z$ escogidas, sus tiempos de retención y los intervalos de tiempo seleccionados.

La cuantificación se realiza por el método del patrón externo. Debido a las variaciones de intensidad del detector entre días es necesario hacer un calibrado siempre que se analicen muestras.

\subsubsection{Determinación mediante cromatografía de gases y espectrometría de masas con microextracción en fase sólida}

Las fibras nuevas o que llevan mucho tiempo sin usarse han de ser acondicionadas según las instrucciones del fabricante, exponiéndolas como mínimo durante $2 \mathrm{~h}$ a $300^{\circ} \mathrm{C}$ en el inyector del cromatógrafo. Posteriormente se realizan ensayos en blanco hasta no obtener señales procedentes de los pegamentos empleados para fijar la fibra.

De una disolución multicomponente de los plaguicidas convenientemente diluida a partir de las disoluciones madre disponibles, se añaden $100 \mu \mathrm{L}$ en un matraz aforado de $10,0 \mathrm{~mL}$, se adicionan $6,0 \mathrm{~mL}$ de disolución saturada de $\mathrm{NaCl}$ y se completa el aforo con agua ultrapura; la composición resultan- 
Tabla 2.1. Compuestos detectados, plaguicidas de los que provienen y relaciones $m / z$ escogidas con sus abundancias relativas.

\begin{tabular}{|lllll|}
\hline Plaguicida & Compuesto detectado & $m / z(\%)$ & $t_{\mathrm{R}} /$ min & Intervalo / min \\
\hline \multirow{2}{*}{ Aldicarb } & Nitrilo de Aldicarb $\left(1^{a}\right)^{b}$ & $68(100), 100(53), 115(35)$ & 10,6 & $10,0-11,1$ \\
\cline { 2 - 5 } & No identificado (1') & $86(100), 87(98), 100(22)$ & 12,6 & $12,4-13,4$ \\
\hline \multirow{2}{*}{ Carbetamida } & Isocianato de fenilo (2) & $119(100), 91(83), 64(70)$ & 11,6 & $11,5-11,8$ \\
\cline { 2 - 5 } & Anilina (2') & $93(100), 66(54)$ & 11,9 & $11,8-12,4$ \\
\hline Propoxur & Isopropoxifenol (3) & $110(100), 152(10), 81(10)$ & 13,5 & $13,4-14,0$ \\
\hline Carbofurano & Fenol de Carbofurano (4) & $164(100), 149(93), 103(37)$ & 14,3 & $14,0-15,0$ \\
\hline Carbarilo & 1-Naftol (5) & $144(100), 115(89), 89(17)$ & 15,6 & $15,0-17,0$ \\
\hline Metiocarb & Fenol de Metiocarb (6) & $168(100), 109(79), 153(70)$ & 15,7 & \\
\hline Pirimicarb & Pirimicarb (7) & $72(100), 166(44), 238(10)$ & 17,4 & $17,0-18,0$ \\
\hline
\end{tabular}

${ }^{a}$ Para la identificación de las señales véanse los cromatogramas de la Figura 3.1.

${ }^{b}$ Compuesto elegido para cuantificar.

te es de $60 \%$ de disolución saturada de $\mathrm{NaCl}$ y 1 \% de metanol. Los 10,o mL se transfieren a un vial que contiene una barra agitadora magnética en su interior. El vial con la muestra se coloca en el interior de una camisa termostatada situada sobre un agitador magnético (Figura 2.2). Una vez perforada la tapa del vial con la aguja de SPME, y puesto en funcionamiento el agitador, se expone la fibra a la disolución, con cuidado de que ésta no resulte dañada por la barra magnética. Tras $2 \mathrm{~h}$ de preconcentración a $25^{\circ} \mathrm{C}$, la fibra se retrae, se saca del vial y se expone durante $6,5 \mathrm{~min}$ a $300^{\circ} \mathrm{C}$ en el inyector del cromatógrafo de gases.

\subsubsection{Determinación mediante cromatografía de gases y espectrometría de masas con extracción en fase sólida y microextracción en fase sólida}

250,o mL de muestra se hacen pasar con la ayuda de una bomba peristáltica con un caudal de $7 \mathrm{~mL} / \mathrm{min}$ por un cartucho de $\mathrm{C}_{18}$ acondicionado previamen- 
te con 10,0 mL de acetonitrilo y $10 \mathrm{~mL}$ de agua. Tras el paso de la muestra, el cartucho se seca durante $5 \mathrm{~min}$ aplicando vacío y los analitos se eluyen con 2,o mL de acetonitrilo directamente sobre el vial donde posteriormente se llevará a cabo la SPME. El acetonitrilo se evapora con una corriente de nitrógeno y el residuo se redisuelve con $8,0 \mathrm{~mL}$ de una disolución acuosa con $60 \%(\mathrm{v} / \mathrm{v})$ de disolución saturada de $\mathrm{NaCl}$. Al residuo redisuelto se le aplica la etapa de preconcentración con SPME indicada en la sección 2.3.2.

\subsubsection{Determinación mediante cromatografía de gases y espectrometría de masas con extracción en fase sólida}

250,o mL de muestra se preconcentran en un cartucho de SPE como en la sección 2.3.3. Los analitos retenidos se eluyen con 2,o mL de acetonitrilo y se recogen en un tubo de ensayo. El volumen recogido se evapora hasta sequedad con la ayuda de una corriente de nitrógeno y el residuo se redisuelve en $500 \mu \mathrm{L}$ de acetonitrilo con ayuda del agitador de tubos durante 10 s. $1 \mu \mathrm{L}$ de esta disolución se inyecta en el cromatógrafo de gases. 


\section{RESULTADOS Y DISCUSIÓN}

\subsection{COMPORTAMIENTO DE PLAGUICIDAS CARBÁMICOS \\ EN CROMATOGRAFÍA DE GASES}

El objetivo de esta sección es conocer el comportamiento en GC-Ms de los plaguicidas carbámicos objeto de estudio (Carbofurano, Propoxur, Metiocarb, Carbarilo, Carbetamida, Aldicarb y Pirimicarb), así como establecer las condiciones óptimas de resolución y sensibilidad.

\subsubsection{Identificación de las señales cromatográficas generadas por inyección directa}

Trabajando con el detector en el modo scan, se inyectó $1 \mu \mathrm{L}$ de una disolución de los 7 plaguicidas en metanol con una concentración de $10 \mathrm{mg} / \mathrm{L}$ para identificar por sus espectros de masas los picos obtenidos. El programa de temperatura fue: $40^{\circ} \mathrm{C}$ durante $10 \mathrm{~min} .5^{\circ} \mathrm{C} / \mathrm{min}$ hasta $140^{\circ} \mathrm{C}(2 \mathrm{~min}) \cdot 5^{\circ} \mathrm{C} / \mathrm{min}$ hasta $210^{\circ} \mathrm{C}(2 \mathrm{~min}) \cdot 7^{\circ} \mathrm{C} / \mathrm{min}$ hasta $260^{\circ} \mathrm{C}$ (hasta $80 \mathrm{~min}$ de análisis). Temperatura de inyección: $270^{\circ} \mathrm{C}$. El cromatograma obtenido se muestra en la Figura 3.1-A.

La Tabla 3.1 contiene todos los compuestos identificados en GC-MS confirmados por su espectro de masas, así como los plaguicidas de los que provienen y las etiquetas empleadas en los cromatogramas de esta parte de la memoria.

El Pirimicarb fue el único de los plaguicidas del que se encontró el pico correspondiente a su molécula sin descomponer (etiquetado como 7). Además de este pico se detecta el $N, N$-dimetil carbamato de metilo $\left(7^{\prime}\right)$, cuya única molécula precursora puede ser el Pirimicarb. 


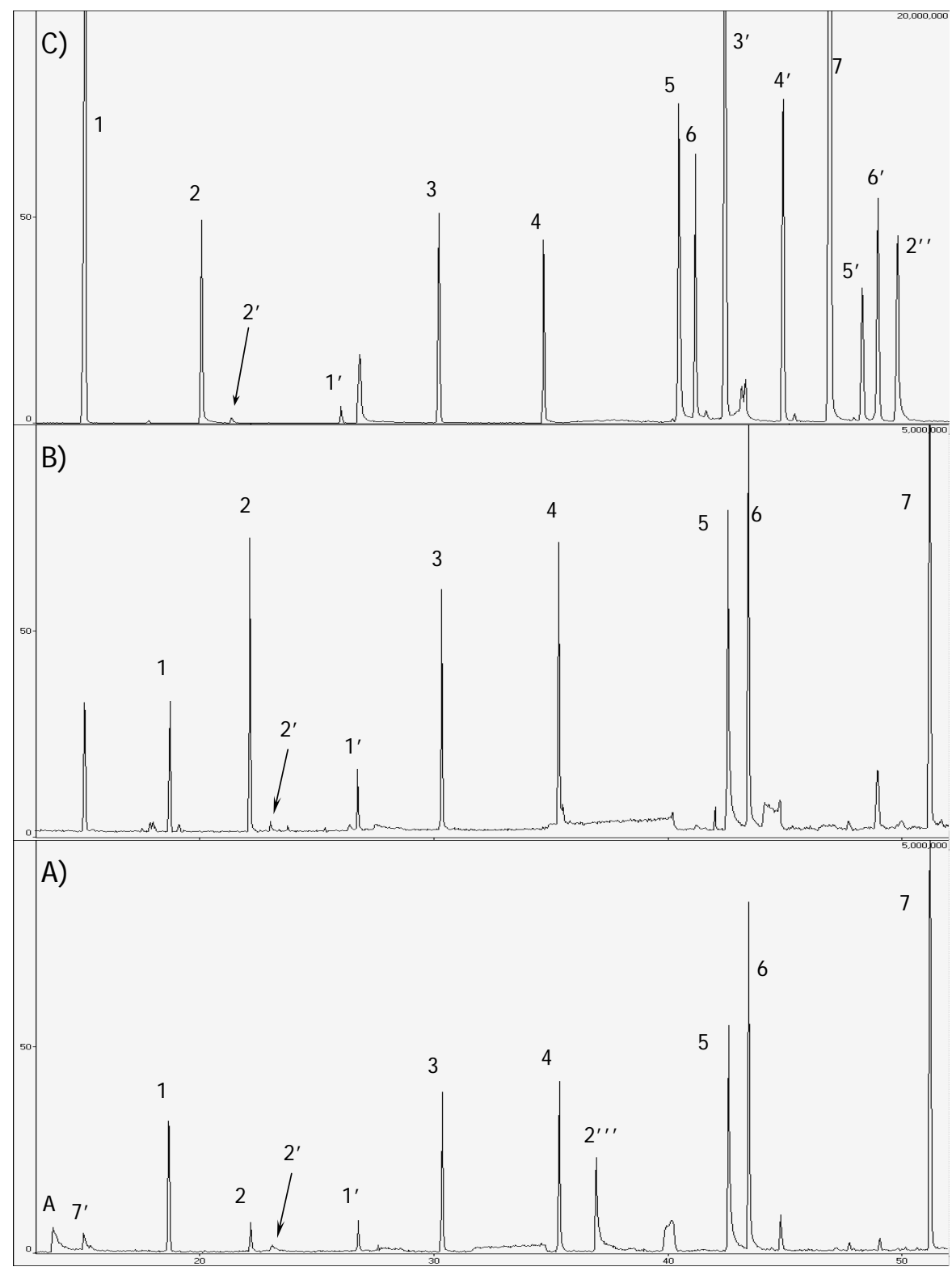

Figura 3.1. Cromatogramas en modo scan de los 7 plaguicidas estudiados en A) una columna muy usada cuando se inyectan disueltos en metanol, B) en una columna muy usada disueltos en acetato de etilo, y C) en una columna nueva disueltos en acetato de etilo.

Concentración: 10 mg/L. Identificación de los picos como en la Tabla 3.1 


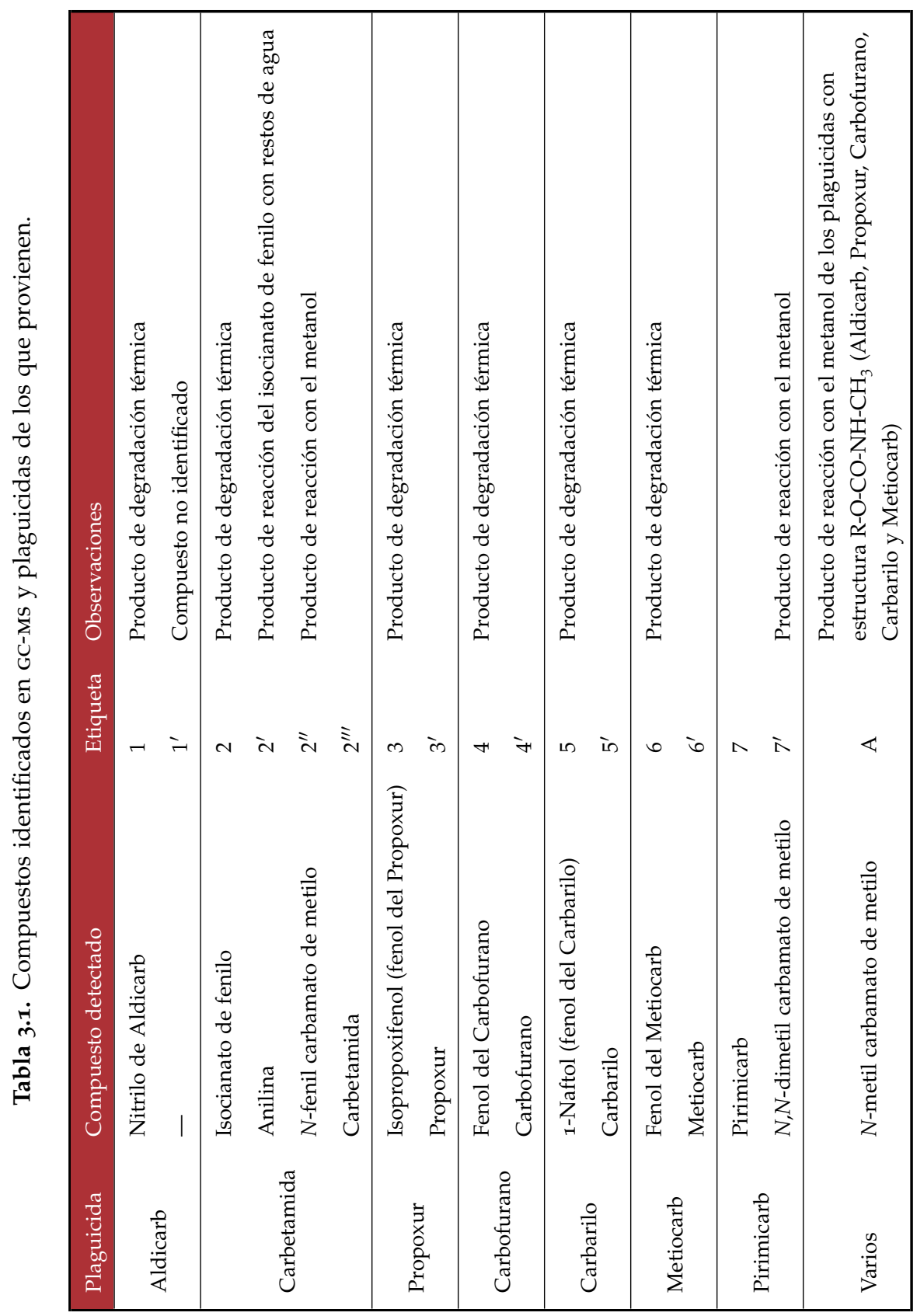


El Aldicarb originó dos picos, uno de los cuales corresponde al nitrilo de Aldicarb (1), y otra señal minoritaria identificada como Aldicarb por la búsqueda automática de la base de datos de espectros, pero con un grado de muy bajo de concordancia, que posiblemente es un compuesto de descomposición no identificado $\left(I^{\prime}\right)$.

La Carbetamida es precursora de isocianato de fenilo (2), anilina (2') y $\mathrm{N}$ fenil carbamato de metilo (2").

Los plaguicidas con estructura de $N$-metil carbamatos de fenilo, Propoxur, Carbofurano, Carbarilo y Metiocarb, originaron señales identificadas por la base de datos como las moléculas sin despomponer (3-7), a pesar de no poseer los iones moleculares. Según algunos autores [18] los carbamatos de fenilo se descomponen térmicamente para originar su forma fenólica, por ello cabe esperar que éstos sean los compuestos obtenidos. Para comprobar esta hipótesis se inyectó una disolución de 1-Naftol e Isopropoxifenol, y se pudo comprobar que las señales obtenidas coincidían en $t_{\mathrm{R}} \mathrm{y}$ espectro de masas con la inyección de Carbarilo y Propoxur, respectivamente.

Además de los picos ya indicados, aparece un pico correspondiente a $\mathrm{N}$ metil carbamato de metilo (etiquetado como «A»), cuyas posibles moléculas precursoras son aquellas con estructura de $N$-metil carbamatos (Aldicarb, Propoxur, Carbofurano, Carbarilo y Metiocarb), por su reacción con el metanol. Este compuesto es análogo a los obtenidos de la Carbetamida ( $N$-fenil carbamato de metilo) y del Pirimicarb ( $N, N$-dimetil carbamato de metilo).

\section{Influencia del disolvente}

Debido a que se detectaron diversos compuestos (2", A y $\left.7^{\prime}\right)$ como posibles productos de la reacción de algunos de los analitos con el metanol, se realizó un estudio utilizando acetato de etilo como disolvente. Para ello, se inyectó una disolución con la misma concentración (10 mg/L) manteniendo el resto de condiciones.

El cromatograma obtenido se representa en la Figura 3.1-B. Si se compara el cromatograma con el obtenido empleando metanol como disolvente se observa que: 
1. En la inyección directa de los 7 plaguicidas disueltos en acetato de etilo no se detectan las señales correspondientes al $N$-metil carbamato de metilo (A), N,N-dimetil carbamato de metilo $\left(7^{\prime}\right)$ ni $N$-fenil carbamato de metilo ( $\left.2^{\prime \prime}\right)$, lo que confirma que el metanol interviene en la descomposición de los analitos.

2. Las señales cromatográficas de los productos de degradación de los plaguicidas cuando la muestra se inyecta en acetato de etilo son superiores a los obtenidas cuando se inyectan en metanol.

3. La relación de intensidades entre la señal del isocianato de fenilo (2) y la de la anilina ( $2^{\prime}$ ) (ambos procedentes de la Carbetamida), es mucho mayor cuando se utiliza acetato de etilo en la inyección.

\section{Influencia del estado de la columna cromatográfica}

Según lo observado, existen diferencias notables en el comportamiento de los compuestos entre una columna cromatográfica nueva y una vieja.

Cuando se reemplazó la columna cromatográfica, que había sido usada intensamente durante dos años para identificación y análisis de pureza de productos de síntesis orgánica, se observó un cambio del comportamiento de los analitos estudiados. La principal diferencia fue que en la columna nueva se detectaron los picos de los plaguicidas sin descomponer: Carbetamida (2"'), Propoxur (3'), Carbofurano (4'), Carbarilo (5') y Metiocarb (6'), confirmados por la base de datos de espectros de masas.

La Figura 3.1-C muestra la inyección directa de $1 \mu \mathrm{L}$ de los 7 plaguicidas disueltos en acetato de etilo en una columna nueva.

La principal conclusión que se puede extraer de estos resultados es que los plaguicidas carbámicos no se degradan sólo en la etapa de inyección, como podría pensarse de los resultados obtenidos con la columna cromatográfica vieja. Con una columna muy usada, la porción de plaguicida que no se degrada en el inyector, lo hace en la columna. Este hecho es el responsable de la ausencia de los picos de las moléculas enteras y de la peor morfología (picos asimétricos) de sus productos de descomposición. Santos et al. [18] 
han comprobado también que el uso de columnas muy usadas favorece la degradación de compuestos térmicamente inestables.

El hecho de que las señales de los productos de degradación se observen siempre, indica que estas señales son más adecuadas para la cuantificación de los plaguicidas con cualquier columna, independientemente de su grado de desgaste.

\subsubsection{Reactividad de plaguicidas carbámicos en cromatografía de gases}

De acuerdo con sus estructuras, los analitos estudiados pueden dividirse en 4 grupos, cada uno con un comportamiento diferente según el disolvente empleado:

- Propoxur, Carbofurano, Carbarilo y Metiocarb son $N$-fenil carbamatos de fenilo. Santos et al. [18] concluyen que este tipo de compuestos se descomponen mediante un reordenamiento de McLafferty para originar el fenol y el isocianato de metilo. La presencia de $N$-metil carbamato de metilo cuando el disolvente es metanol se explica por la reacción de éste con el isocianato de metilo.

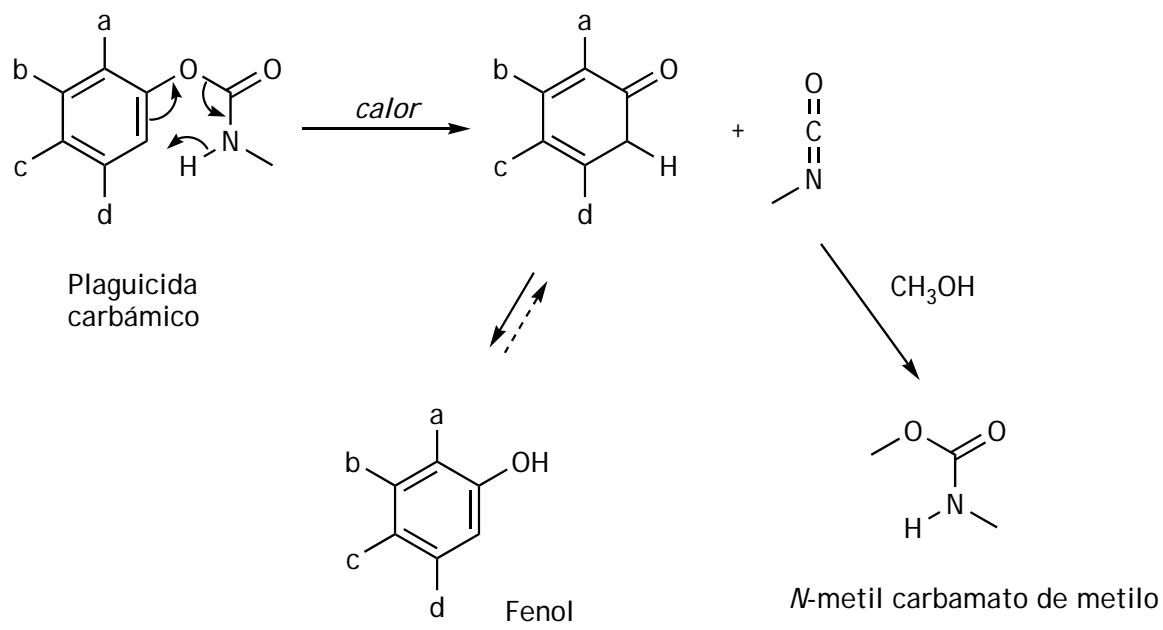


- El Pirimicarb tiene 2 grupos metilo unidos al nitrógeno del grupo carbámico y no puede tener lugar el reordenamiento anterior. La formación de $\mathrm{N}, \mathrm{N}$-dimetil carbamato de metilo cuando el disolvente es metanol sugiere una ruta alternativa de degradación, que es minoritaria en los plaguicidas en los que sí pueda tener lugar el reordenamiento.
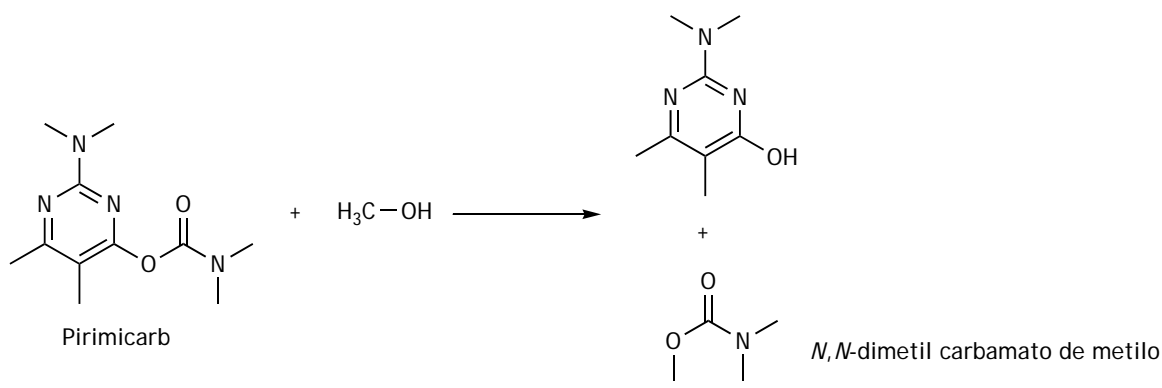

- La estructura del Aldicarb corresponde a la de un carbamato de una oxima y el producto de su descomposición térmica es su correspondiente nitrilo [17].<smiles>CNC(=O)O/N=C/C(C)(C)SC</smiles>

Aldicarb

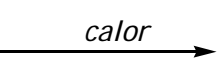

Nitrilo de Aldicarb

- La Carbetamida tiene estructura de $N$-fenil carbamato y durante su descomposición origina principalmente isocianato de fenilo. El resto de compuestos observados se deben a reacciones de éste que dependen del disolvente empleado y el estado de la columna. El compuesto detectado mayoritario es el $\mathrm{N}$-fenil carbamato de metilo cuando el disolvente es metanol, y el isocianato de fenilo cuando se usa un disolvente menos reactivo como el acetato de etilo. También se forma anilina, especialmente cuando se usa una columna muy gastada y existen 
trazas de agua en el medio. Este comportamiento de la carbetamida es similar al de otros plaguicidas de la familia de las fenilureas [54].

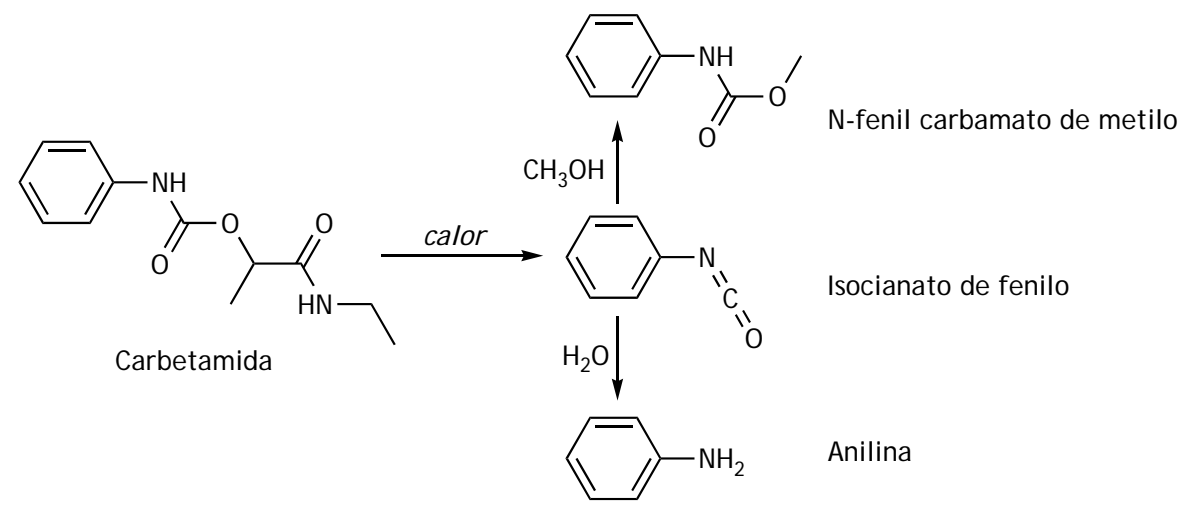

\subsection{PRECONCENTRACIÓN MEDIANTE}

MICROEXTRACCIÓN EN FASE SÓLIDA

\subsubsection{Identificación de las señales cromatográficas generadas después de microextracción en fase sólida}

El comportamiento en GC de compuestos térmicamente inestables es función de variables como el disolvente, el modo y la temperatura de inyeción, y el programa de temperaturas empleado. En un trabajo previo se ha podido comprobar que las fenilureas, que también son térmicamente lábiles, pueden determinarse mediante GC siempre que se utilice una etapa de preconcentración con SPME [54]. En dichas condiciones, la fragmentación se produce de una forma reproducible en la etapa de desorción de los analitos de la fibra. A la vista de estos antecedentes, en este trabajo se ha estudiado el comportamiento cromatográfico que presentan los analitos después de haber sido

[54] R. Carabias-Martínez, C. García-Hermida, E. Rodríguez-Gonzalo, F. E. Soriano-Bravo, and J. Hernández-Méndez. Determination of herbicides, including thermally labile phenylureas, by SPME and GC-MS. J. Chromatogr. A, 1002:1-12, 2003. 
preconcentrados en una fibra de poliacrilato, y posteriorente desorbidos en el inyector de un cromatógrafo de gases.

Se inyectó por triplicado $1 \mu \mathrm{L}$ de una disolución en acetato de etilo de los 7 analitos y se compararon los resultados con los obtenidos tras efectuar una preconcentración mediante SPME a una disolución con las mismas concentraciones durante 15 min y desorber térmicamente los compuestos a $270^{\circ} \mathrm{C}$ durante $5 \mathrm{~min}$. La concentración fue de $1 \mathrm{mg} / \mathrm{L}$ excepto para Aldicarb y Carbarilo (8 mg/L). El medio de preconcentración fue una disolución acuosa con $1 \%$ de metanol y $20 \%$ de disolución saturada de $\mathrm{NaCl}$. La recogida de datos fue en modo SIM con el ion más característico de cada compuesto para aumentar la sensibilidad y disminuir el ruido.

En las Figuras 3.2-A y 3.2-B se muestran los cromatogramas obtenidos con inyección directa y después de la preconcentración, respectivamente. En la Tabla 3.2 se muestran las áreas de los picos obtenidos y la variación en tanto por ciento entre las señales de los compuestos preconcentrados y sin preconcentrar.

Tabla 3.2. Áreas de pico mediante inyección directa y previa SPME para la misma concentración de plaguicidas.

\begin{tabular}{|c|c|c|c|c|c|}
\hline Plaguicida & Compuesto detectado & $m / z$ & $\begin{array}{c}\text { Área / } 10^{4} \text { c s } \\
\text { (Iny. directa) }\end{array}$ & $\begin{array}{c}\text { Área / } 10^{4} \text { c s } \\
\text { (SPME) }\end{array}$ & Variación (\%) \\
\hline Aldicarb & Nitrilo de Aldicarb (1) & 100 & 56 & 46 & -17 \\
\hline \multirow{2}{*}{ Carbetamida } & Isocianato de fenilo (2) & 119 & 9,6 & 1,7 & -83 \\
\hline & Anilina $\left(2^{\prime}\right)$ & 93 & 1,7 & 15 & 773 \\
\hline Propoxur & Isopropoxifenol (3) & 110 & 4,3 & 129 & 2015 \\
\hline Carbofurano & Fenol de Carbofurano (4) & 164 & 6,9 & 35 & 413 \\
\hline Carbarilo & 1-Naftol (5) & 144 & 142 & Saturado & - \\
\hline Metiocarb & Fenol de Metiocarb (6) & 168 & 11 & 162 & 1401 \\
\hline Pirimicarb & Pirimicarb (7) & 166 & 35 & 21 & -41 \\
\hline
\end{tabular}




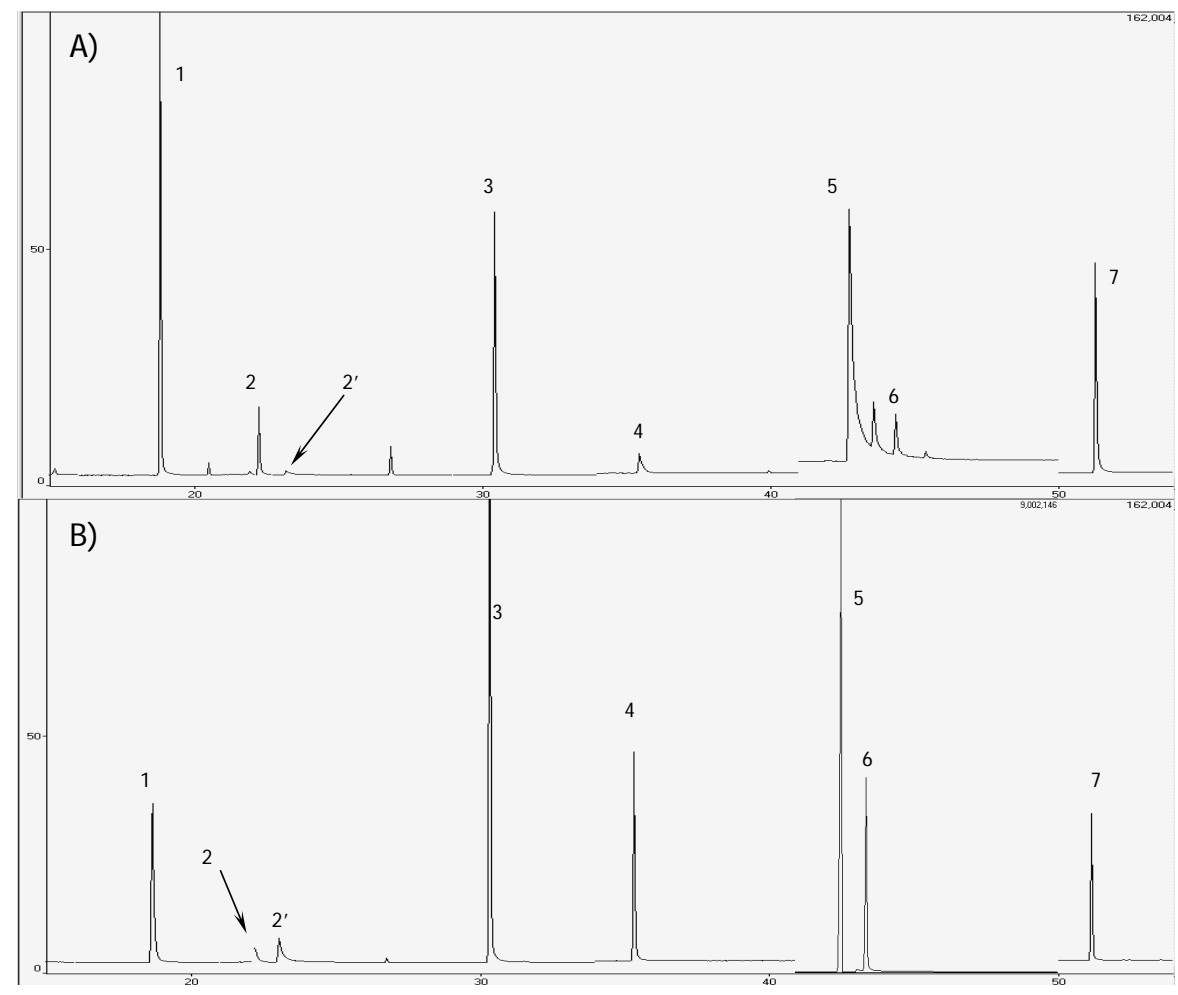

Figura 3.2. Cromatogramas en modo sIM de la misma concentración de plaguicidas

A) mediante inyección directa, y

B) tras SPME (15 min de preconcentración).

Identificación de los picos en Tabla 3.2 
Los analitos con una preconcentración más favorable son los carbamatos de fenilo, especialmente el Metiocarb, que es el menos polar de los estudiados. Además del aumento de sensibilidad, se aprecia para estos analitos una mejora notable de la forma de pico debido a su descomposición durante la desorción de la fibra en lugar de durante su elución en la columna. Cuando se inyectan los plaguicidas directamente se obtienen unas acusadas asimetrías de los picos de 1-Naftol y fenol de Carbofurano, procedentes de Propoxur y Carbofurano, respectivamente, hecho que dificulta la cuantificación de estos compuestos (Figuras 3.2 y 3.3).

En la Figura 3.4 se muestra la comparación de los picos obtenidos para los tres analitos que presentan menor sensibilidad con SPME que con inyección directa: Aldicarb, Carbetamida y Pirimicarb. El analito con peor preconcentración ha sido el Aldicarb, que es a su vez el plaguicida más polar. Por otra parte, no es posible conocer exactamente el grado de preconcentración de la Carbetamida, ya que se descompone en dos compuestos (anilina e isocianato de fenilo) que se encuentran en diferentes proporciones según el medio empleado (Figura 3.4-B); la formación de anilina es mayoritaria en presencia de agua (SPME).

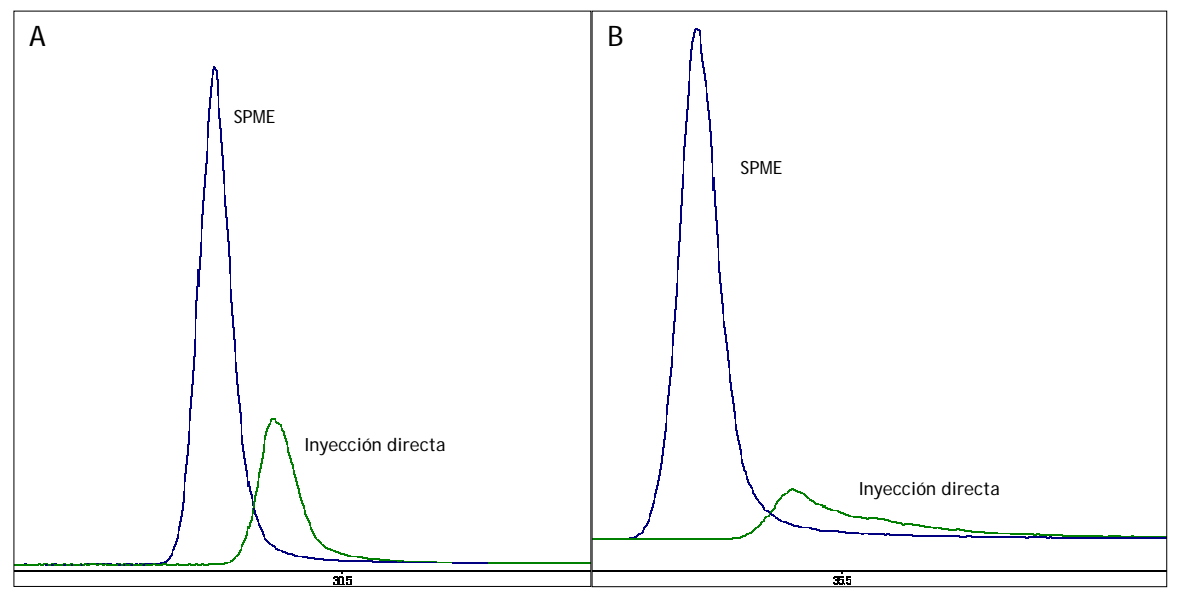

Figura 3.3. Comparación de los picos con inyección directa y mediante SPME de
A) Propoxur, y
B) Carbofurano. 


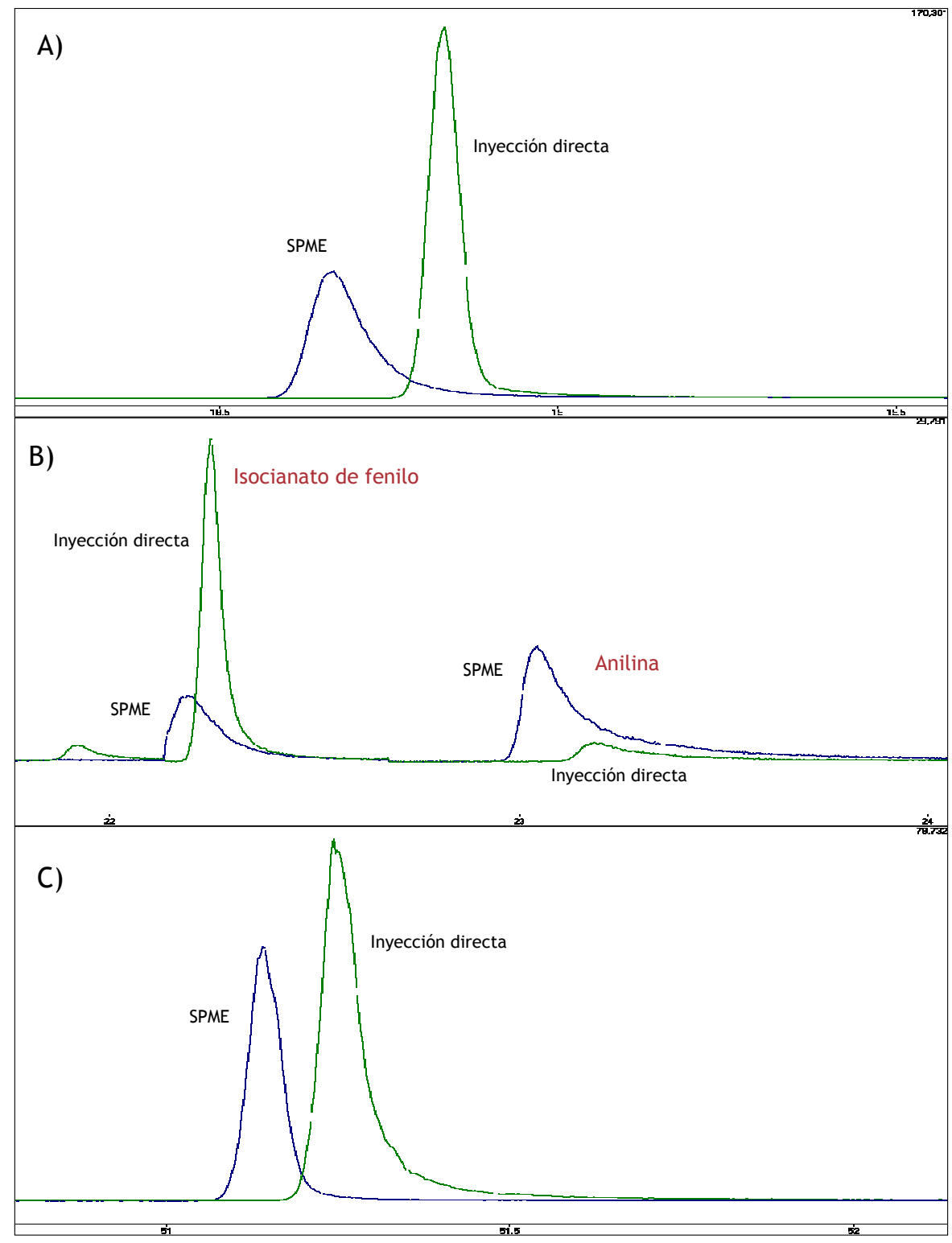

Figura 3.4. Superposición de los picos procedentes
A) del Aldicarb,
B) la Carbetamida, y
C) el Pirimicarb cuando se inyectan directamente y mediante SPME. 


\subsubsection{Optimización del proceso de microextracción en fase sólida}

La etapa de preconcentración mediante SPME fue optimizada por medio de una estrategia secuencial de experimentos. En general, una optimización bien diseñada necesita estudiar todos los factores simultáneamente para la comprensión de todos los efectos e interacciones, y además mantener el número de experimentos al mínimo. Existen varios trabajos publicados donde se ha optimizado los parámetros que afectan a la extracción y desorción de analitos en un fibra de sPME por medio de un diseño de experimentos $[55,56,57]$. El diseño de experimentos también se ha aplicado a la extracción de plaguicidas mediante SPME en muestras ambientales [58, 59].

En este caso, se realizó una etapa de criba de factores (diseño factorial fraccionado a 2 niveles) y un posterior diseño de superficie de respuesta de tres niveles. Las respuestas evaluada han sido lás áreas de pico de cada analito.

\section{Diseño factorial fraccionado}

En primer lugar, para establecer qué factores son significativos y qué niveles escoger en diseños posteriores más exhaustivos, se realizó un diseño inicial con las variables más influyentes: temperatura de extracción, fuerza iónica, tiempo de extracción y temperatura de desorción.

[55] J. Salafranca, C. Domeño, C. Fernández, and C. Nerín. Experimental design applied to the determination of several contaminants in Duero River by spme. Anal. Chim. Acta, 477:257-267, 2003.

[56] J. C. Penteado, R. E. Bruns, and L. R. F. de Carvalho. Factorial design optimization of SPME conditons for GC-MS analysis of linear alkylbenzenes in detergents. Anal. Chim. Acta, 562:152-157, 2006.

[57] Y. Zhou, Q. Jiang, Q. Peng, D. Xuan, and W. Qu. Development of a sPME-GC-Ms method for the determination of pentachlorophenol in human plasma using experimental design. Chemosphere, 70:256-262, 2007.

[58] V. Casas, M. Llompart, C. García-Jares, R. Cela, and T. Dagnac. Multivariate optimization of the factors influencing the SPME of pyrethroid pesticides in water. J. Chromatogr. A, 1124:148-156, 2006.

[59] A. Bouaid, L. Ramos, M. J. Gonzalez, P. Fernández, and C. Cámara. sPME method for the determination of atrazine and four organophosphorus pesticides in soil samples by GC. J. Chromatogr. A, 939:13-21, 2001. 
Del factor «tiempo de preconcentración» se sabe de antemano que siempre va a ser positivo, ya que la cantidad de analito extraída siempre aumenta con el tiempo hasta alcanzar un equilibrio. El hecho de incluir dicho factor en estos diseños tiene por objeto comprobar que no hay interacciones entre él y los demás factores, esto es, que el resto de variables influyan en la respuesta de manera independiente del tiempo empleado en la preconcentración.

El diseño escogido fue un diseño factorial fraccionado con 2 niveles para cada factor y 8 experimentos $\left(2^{4^{-1}}\right)$ más dos centros para evaluar la curvatura y el fallo de ajuste.

Los diseños con dos niveles sólo permiten calcular relaciones lineales entre los factores y la respuesta; sin embargo, no es posible comprobar si hay componentes no lineales (cuadráticas, por ejemplo). Si se sospecha que la relación no es lineal, se puede efectuar una prueba de curvatura, incluyendo uno o más experimentos en los que todos los factores están fijados en un valor intermedio. Tales experimentos se llaman centros, ya que están literalmente en el centro del diseño. Tras efectuar el análisis de los datos obtenidos, se compara la respuesta en estos puntos centrales con el valor medio del resto del diseño; si la media de las respuestas en el centro del diseño es significativamente diferente de la media del resto de experimentos del diseño, entonces hay razones para creer que la suposición de una relación lineal entre factores y respuesta no es cierta.

Por otra parte, el hecho de que existan medidas replicadas permite hacer una estimación de la significación del fallo de ajuste. La variabilidad de estas réplicas da información del error aleatorio de las medidas, y por tanto, permite separar el error experimental en sus dos componentes: el error debido a la variación aleatoria, llamado error puro, y el error debido al fallo de ajuste. Estas dos componentes se comparan mediante una prueba estadística F. Si el error debido al fallo de ajuste no resulta ser significativo (con una probabilidad mayor del $5 \%$ ) no hay suficiente evidencia para concluir que hay fallo de ajuste. Es decir, se comprueba si la relación entre la respuesta y los factores queda descrita adecuadamente por el modelo propuesto, o bien hay certeza para decir que faltan términos que necesitan ser incluidos en el modelo. 
Debido a que cada factor tiene unas unidades y oscila entre niveles diferentes, y para poder comparar más fácilmente los efectos, los coeficientes se calculan con los factores expresados en unidades codificadas ( -1 para los niveles bajos y 1 para los niveles altos). Los coeficientes así estimados representan el cambio en la respuesta cuando cada factor varía de o a 1 en unidades codificadas, mientras los otros factores permanecen en sus niveles intermedios. También se pueden expresar los efectos de cada factor estimando el cambio en la respuesta cuando cada factor oscila entre sus niveles mínimo y máximo.

La Tabla 3.3 muestra los niveles escogidos de cada factor y el efecto encontrado para cada uno (calculado con los factores codificados). Para establecer qué efectos se consideran significativos se ha determinado la desviación estándar de cada efecto y se ha multiplicado por la $t$ de Student para una significación del $5 \%$. De esta manera se conocen los intervalos de confianza de los efectos. Otra forma de establecer objetivamente qué efectos son significativos es mediante un análisis de varianza. De este modo es posible conocer si el modelo propuesto explica la variabilidad de la respuesta, y, en caso afirmativo saber qué probabilidad tiene cada efecto de ser significativo. Se considera que si la probabilidad de un efecto es menor del $5 \%$ ( $p$ calculado menor de 0,05 ), éste explica más de la variabilidad de la respuesta de la que podría esperarse de fenómenos aleatorios.

En todos los casos la probabilidad de fallo de juste es superior a 0,05. Estos resultados indican que la SPME de todos los plaguicidas se puede explicar con modelos sencillos en los que no es necesario incluir los efectos debidos a interacciones de dos factores. Los coeficientes de correlación son superiores a o,93 excepto el de la Carbetamida (o,84). Para este compuesto los intervalos de confianza son mayores debido a la falta de reproducibilidad en la relación de las señales procedentes de este plaguicida (anilina e isocianato de fenilo). Por este motivo, este analito no se ha incluido en estudios posteriores de optimización.

Se puede observar que la temperatura de extracción es una variable significativa para todos los analitos excepto el Carbarilo. La fuerza iónica ejerce un efecto significativo en la extracción de Aldicarb, Carbofurano y Pirimicarb. El tiempo de extracción, como es previsible, influye positivamente en la se- 


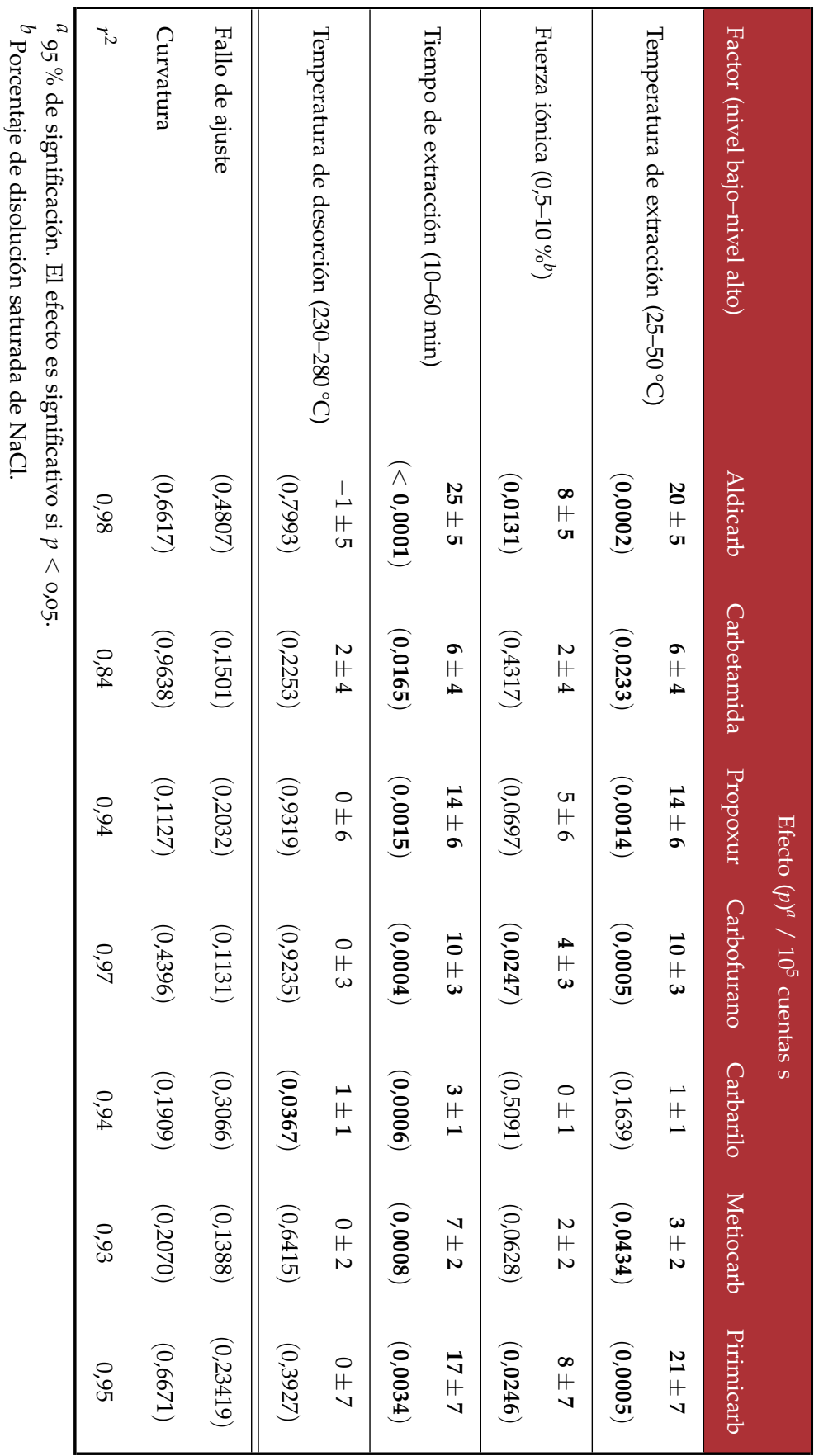

0
0
0
7 نّ . 규요 . ర్ర

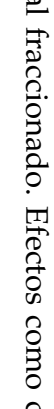
官.

2
0
0
09
0
0
0
0

0
0
0
0
0
0
0
0
0
$\infty$
0
0
0
0
0
0
0
0 罗

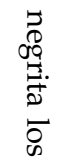



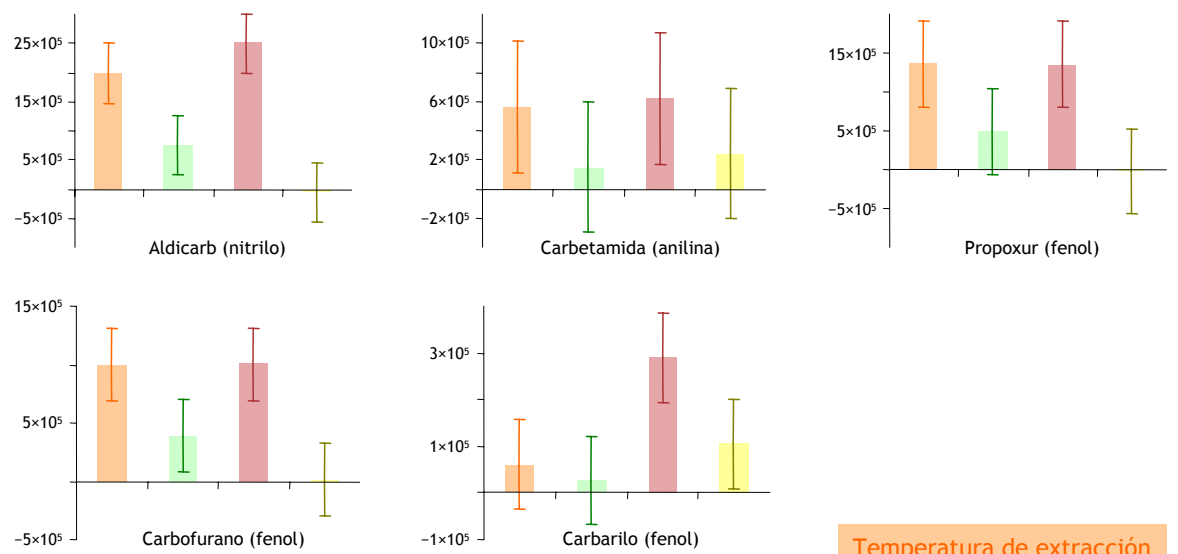

Temperatura de extracción Fuerza iónica
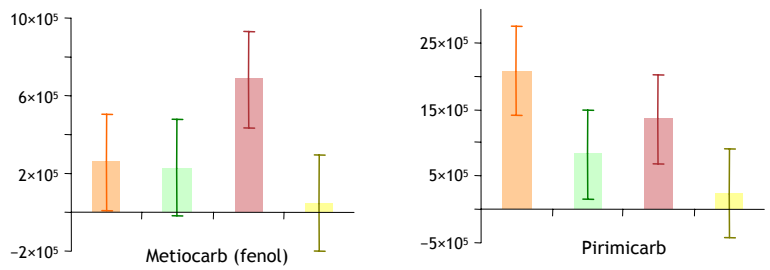

Tiempo de extracción

Temperatura de desorción

Figura 3.5. Diseño factorial fraccionado. Efectos en el área de la señal de los compuestos derivados de los 7 plaguicidas.

ñal de todos los analitos. La temperatura de desorción no es una variable significativa para ninguno de los plaguicidas excepto para el Carbarilo y se fijará en $300^{\circ} \mathrm{C}$ en diseños posteriores.

Mediante la prueba de curvatura se comprueba que para ningún compuesto se puede asegurar que las relaciones entre los factores y la respuesta tengan una relación no lineal. Este hecho significa que los máximos de respuesta están fuera del dominio experimental y por ello se aumentarán los niveles máximos del tiempo de extracción y la fuerza iónica hasta 120 min y 60\%, respectivamente. Estos valores se han fijado teniendo en cuenta que tiempos mayores son excesivos y una mayor concentración de sales puede dañar la fibra. 


\section{Diseño de superficie de respuesta}

Tras comprobar los efectos más importantes en la anterior etapa de criba (fuerza iónica, temperatura de extracción y tiempo de preconcentración), se llevó a cabo un diseño de superficie de respuesta para estudiar más a fondo el efecto de dichos factores. El diseño escogido fue un diseño Box-Behnken de 3 niveles. La presencia de 3 niveles por factor permite el cálculo de los efectos cuadráticos y la generación de superficies de respuesta. Este diseño ofrece una buena relación entre las conclusiones obtenidas y el esfuerzo experimental realizado.

Si no tenemos en cuenta las interacciones entre tres factores, el modelo al cual ajustar los resultados se puede expresar con la ecuación:

$$
\begin{aligned}
& \text { Área de pico }(A, B, C)=a+a_{A} x_{A}+a_{A^{2}} x_{A}^{2}+ \\
& \quad+a_{B} x_{B}+a_{B^{2}} x_{B}^{2}+a_{C} x_{C}+a_{C^{2}} x_{C}^{2}+ \\
& +a_{A B} x_{A} x_{B}+a_{A C} x_{A} x_{C}+a_{B C} x_{B} x_{C}
\end{aligned}
$$

donde:

- $A, B$ y $C$ son las variables independientes (factores) «temperatura de extracción», «fuerza iónica» y «tiempo de extracción», respectivamente,

- $x_{i}$ son los valores que toman dichos factores, $\mathrm{y}$

- $a_{i j}$ son los coeficientes de la regresión.

La Tabla 3.4 muestra los niveles escogidos de cada factor, la magnitud de cada efecto (coeficientes de regresión) y el fallo de ajuste calculado para el modelo propuesto.

Se comprueba que ninguno de los plaguicidas presenta fallo de ajuste con el modelo de términos lineales y cuadráticos, y que no es necesario incluir las interacciones entre dos factores. Aunque se observa que casi ningún término cuadrático es significativo y que para muchos de los plaguicidas tampoco existiría fallo de ajuste con un modelo puramente lineal, se han incluido los términos cuadráticos para mejorar los coeficientes de regresión y observar la curvatura de las superficies de respuesta. 


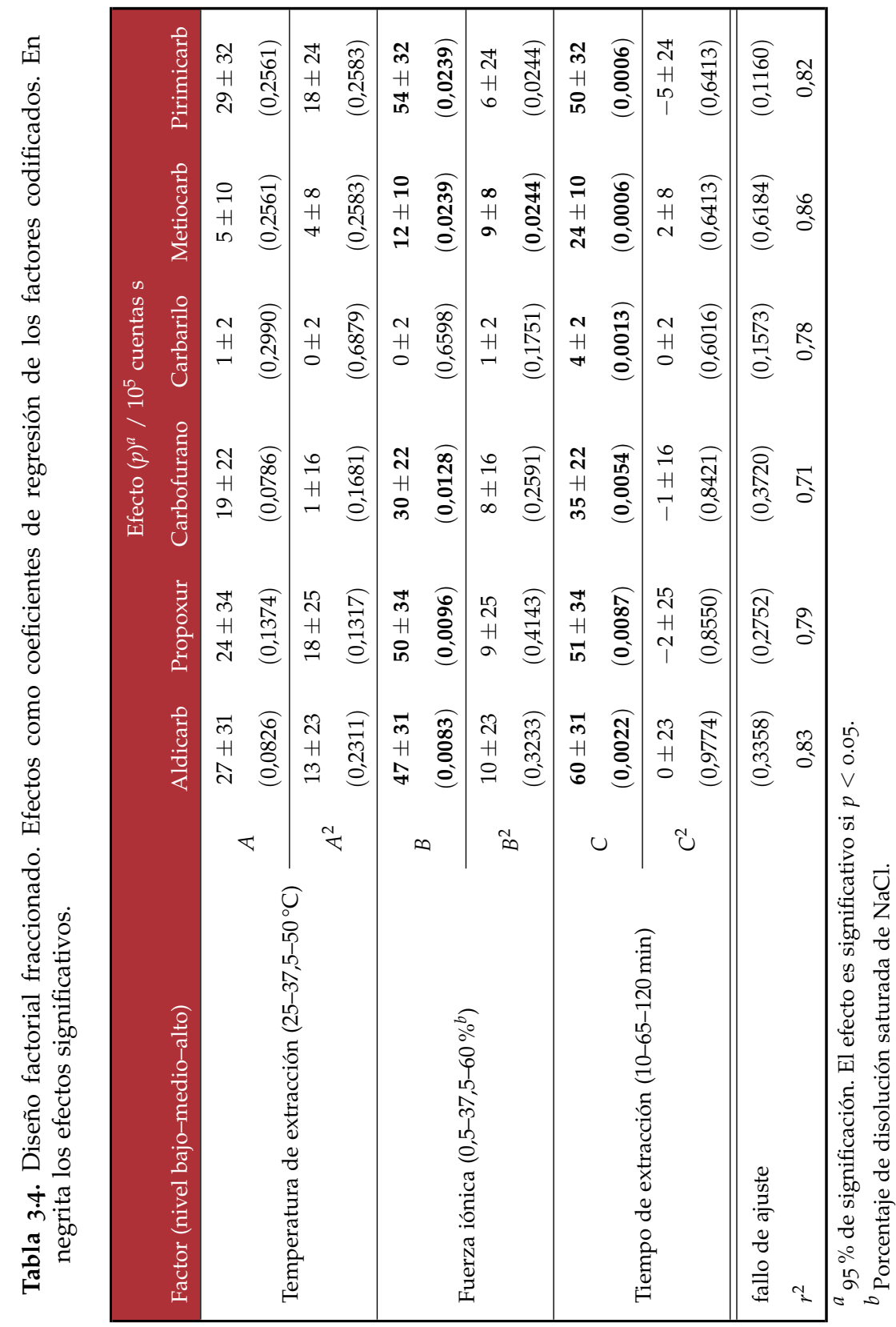




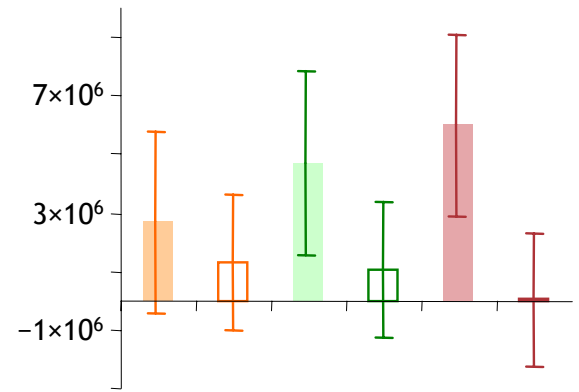

Aldicarb

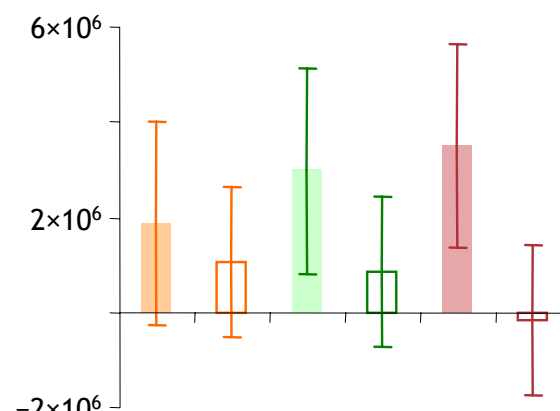

$-2 \times 10^{6}$

Carbofurano

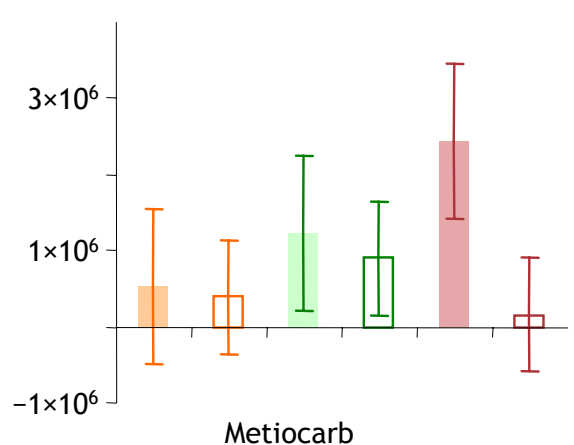

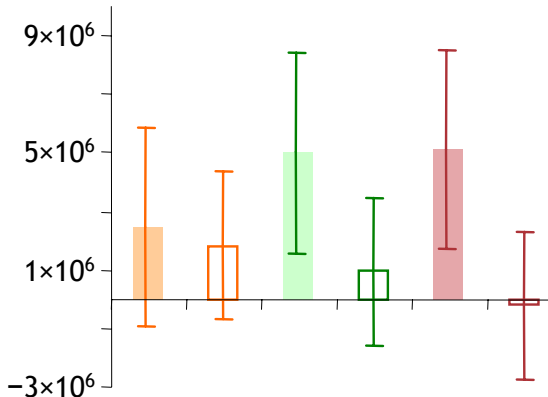

Propoxur
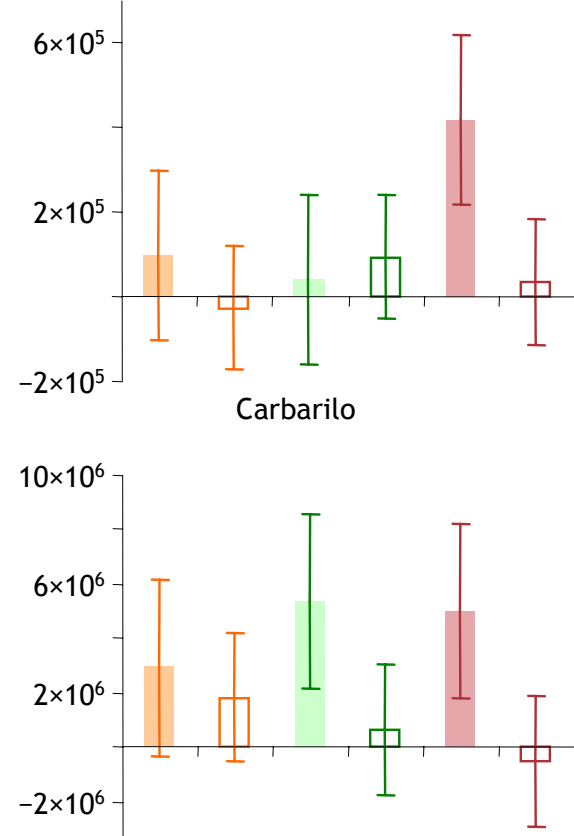

Pirimicarb

\begin{tabular}{|c|c|}
\hline Temperatura de extracción & $(\text { Temperatura de extracción })^{2}$ \\
\cline { 2 - 2 } Fuerza iónica & $(\text { Fuerza iónica })^{2}$ \\
\hline Tiempo de extracción & $(\text { Tiempo de extracción) })^{2}$ \\
\hline
\end{tabular}

Figura 3.6. Diseño Box-Behnken. Efectos lineales y cuadráticos en el área de la señal de los factores «temperatura de extracción», «fuerza iónica» y «tiempo de preconcentración». 
A pesar de que la temperatura de preconcentración era significativa para todos los compuestos en el diseño factorial, ha dejado de serlo cuando se han ampliado los intervalos entre los niveles de los factores «fuerza iónica»y «tiempo de extracción». Por ello, se establecerá la temperatura de extracción en $25^{\circ} \mathrm{C}$ como la temperatura más conveniente, debido al esfuerzo experimental que representa elevar la temperatura del baño a $50^{\circ} \mathrm{C}$.

Como era de esperar, el tiempo de extracción tiene un efecto positivo en todos los casos.

La fuerza iónica tiene un efecto positivo significativo en la SPME de todos los analitos, excepto para el carbarilo. Estos comportamientos están de acuerdo con la teoría de que los compuestos muy polares (por ejemplo, el Propoxur, $\log P_{\text {OW }}$ de 1,56) aumentan el rendimiento de su extracción al hacerlo la concentración de sales sin alcanzar un máximo y sin luego disminuir [6o]. El único término cuadrático significativo lo presenta el Metiocarb, que es el analito menos polar de los estudiados ( $\log P_{\mathrm{OW}}$ de 3,08$)$, para el que se aprecia que la extracción disminuye con la fuerza iónica tras alcanzar un máximo. Este comportamiento se puede explicar teniendo en cuenta dos procesos simultáneos. Con concentraciones bajas de electrolito aumenta la solubilidad de los analitos en la fibra por disminuir su solubilidad en el medio de extracción. Sin embargo, a medida que aumenta la concentración de sales, la interacción entre los iones y los analitos predomina y por lo tanto la capacidad de estos últimos para desplazarse hasta la fibra disminuye. En la Figura 3.7 se muestran las superficies de respuesta en función de los factores significativos («tiempo de extracción» y «fuerza iónica»), con la temperatura fijada en $25^{\circ} \mathrm{C}$.

Teniendo en cuenta los resultados obtenidos en esta etapa de optimización, se establecen las siguientes condiciones para efectuar la extracción de los plaguicidas carbámicos estudiados:

- Temperatura de extracción: $25^{\circ} \mathrm{C}$,

[6o] R. Eisert and K. Levsen. Determination of organophosphorus, triazine and 2, 6dinitroaniline pesticides in aqueous samples via SPME and GC with NPD. Fresenius J. Anal. Chem., 351:555-562, 1995. 


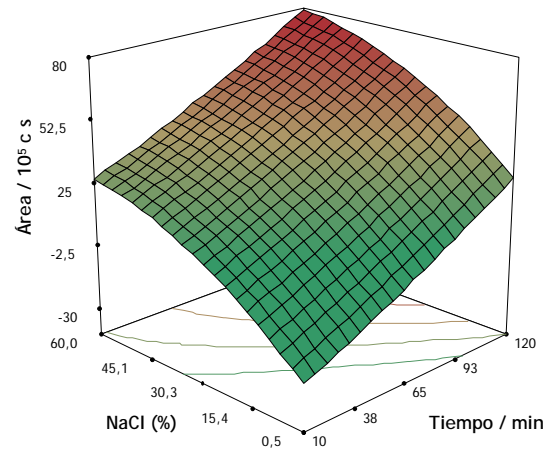

Aldicarb

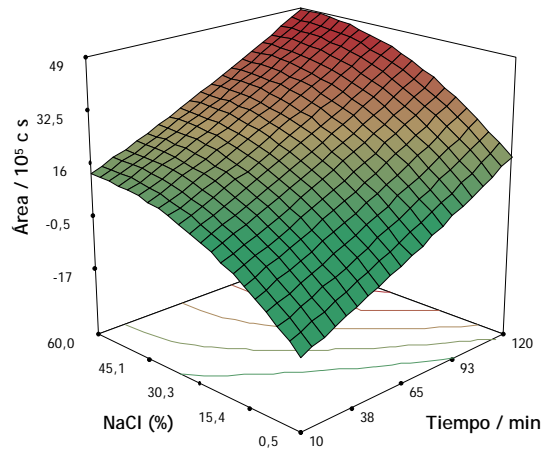

Carbofurano

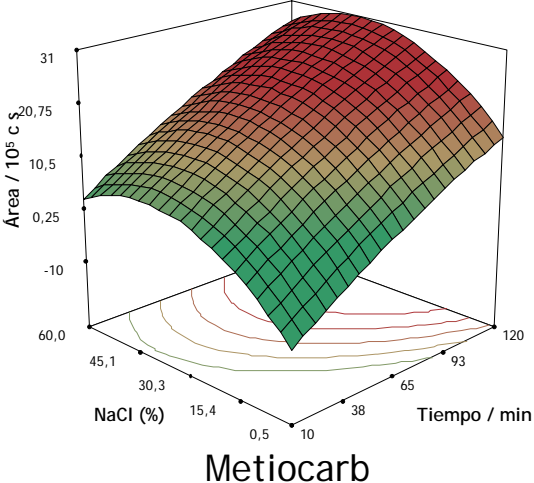

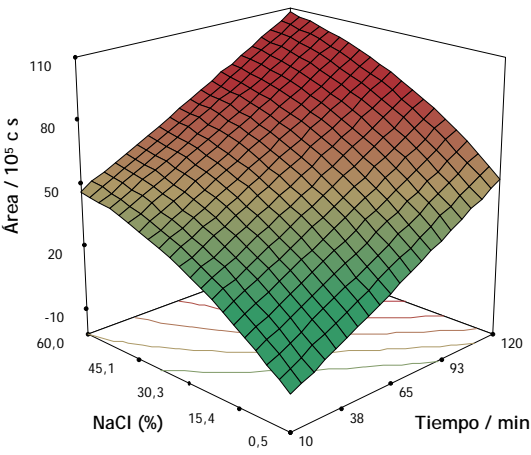

Propoxur

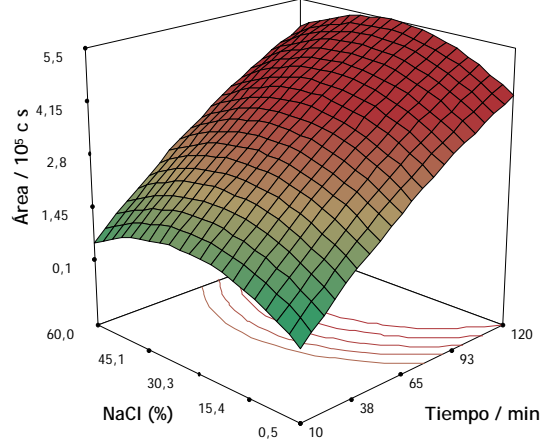

Carbarilo

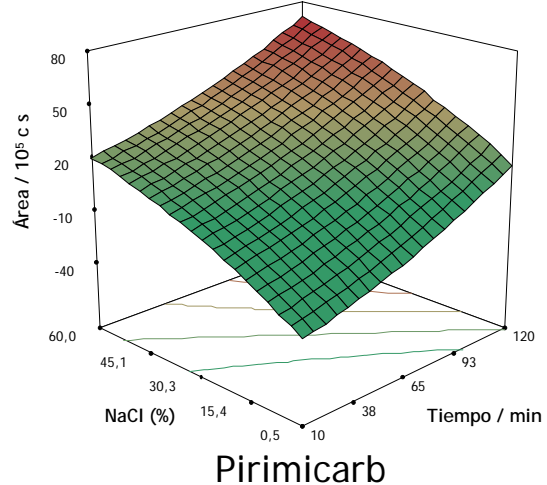

Pirimicarb

Figura 3.7. Superficies de respuesta (área de pico) en función de la fuerza iónica y el tiempo de extracción. Temperatura de extracción fijada en $25^{\circ} \mathrm{C}$. 
- Fuerza iónica: 6o \% de disolución saturada de $\mathrm{NaCl}$,

- Tiempo de preconcentración: 120 min, y

- Temperatura de desorción: $300^{\circ} \mathrm{C}$.

\subsubsection{Optimización de la separación cromatográfica}

Hasta ahora todos los cromatogramas han tenido un tiempo de análisis relativamente elevado (el Pirimicarb es el último analito detectado, con un tiempo de retencion de $51 \mathrm{~min}$ ). Se probaron diferentes gradientes de temperatura con objeto de disminur la duración del análisis sin reducir la resolución entre picos. Tras diversos ensayos se redujo el tiempo de análisis hasta 20 min (Figura 3.8). El programa de temperaturas final se encuentra en la sección 2.3.1 en la página 17.

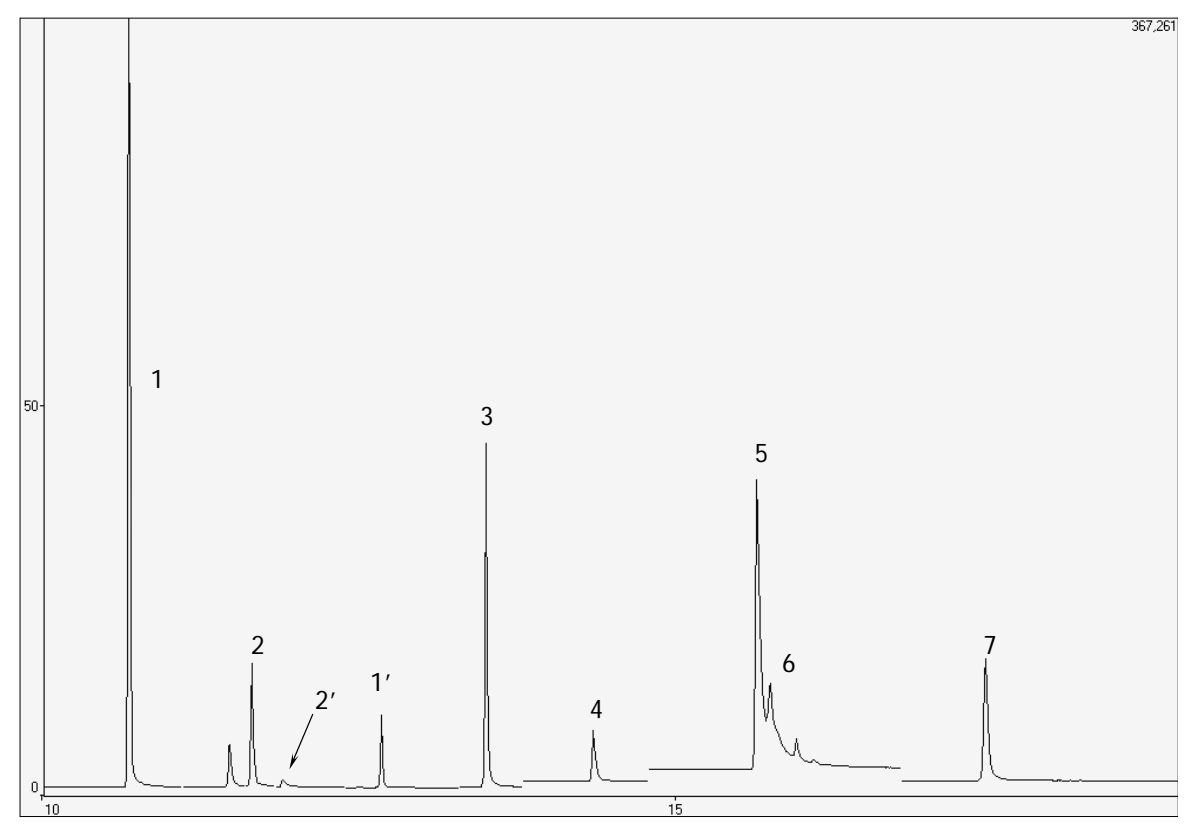

Figura 3.8. Cromatograma en modo SIM de los 7 plaguicidas disueltos en acetato de etilo. 


\subsection{CARACTERÍsticas anAlíticas de los métodos propuestos}

\subsubsection{Determinación de plaguicidas carbámicos mediante GC-MS con SPME como etapa de preconcentración}

Una vez optimizado el proceso de SPME y establecidas las condiciones óptimas de separación, se determinaron las características analíticas de la determinación por GC-MS de los plaguicidas carbámicos estudiados con SPME como etapa de preconcentración. Se evaluaron la linealidad de la señal con concentración, la precisión del procedimiento propuesto, y el límite de detección para cada analito.

\section{Linealidad}

Se prepararon disoluciones multianalito con diferentes concentraciones por dilución de las disoluciones madre en metanol. Se tomaron $100 \mu \mathrm{L}$ de cada una de estas disoluciones y se diluyeron con 6,0 mL de una disolución saturada de $\mathrm{NaCl}$ y agua ultrapura hasta 10,o $\mathrm{mL}$ en matraces aforados. Los intervalos de concentración son diferentes para cada plaguicida según la sensibilidad observada en los estudios previos. En la Tabla 3.5 aparecen reflejados los parámetros del ajuste por mínimos cuadrados a una línea recta.

\section{Precisión y límites de detección}

Para determinar la precisión del método se prepararon cuatro muestras con una concentración parecida a la más baja empleada en el estudio de linealidad. En la Tabla 3.6 se muestran las desviaciones estándar obtenidas en las áreas de las cuatro réplicas y sus valores relativos.

Se han utilizado dos criterios diferentes para establecer los límites de detección. Un método consiste en calcular la concentración de analito que produce una señal analítica equivalente a 3 veces el ruido de fondo. Esta concentración se calcula a partir de la expresión: $\mathrm{LD}=3 \times s_{\mathrm{B}} / b$, donde $s_{\mathrm{B}}$ representa la magnitud de la envolvente de las perturbaciones de la línea base en la zona del analito de interés, y $b$, la pendiente de la recta de regresión calculada 
Tabla 3.5. Linealidad y parámetros de regresión ${ }^{a}$ obtenidos con una etapa de preconcentración mediante SPME.

\begin{tabular}{|c|c|c|c|c|}
\hline Plaguicida & Intervalo / $\mu \mathrm{g} / \mathrm{L}$ & $a / 10^{4} \mathrm{c} \mathrm{s}$ & $b / 10^{3} \mathrm{c} \mathrm{s} \mathrm{L} / \mu \mathrm{g}$ & $r^{2}$ \\
\hline Aldicarb & $47,5-396$ & $1 \pm 1^{b}$ & $0,54 \pm 0,06$ & 0,999 \\
\hline Carbetamida & $52,3-436$ & $2 \pm 2$ & $0,77 \pm 0,08$ & 0,999 \\
\hline Propoxur & $1,6-16,4$ & $2 \pm 3$ & $13 \pm 3$ & 0,995 \\
\hline Carbofurano & $2,1-20,8$ & $0 \pm 1$ & $3,7 \pm 0,9$ & 0,994 \\
\hline Carbarilo & $2,6-25,6$ & $3 \pm 2$ & $59 \pm 11$ & 0,996 \\
\hline Metiocarb & $1,2-11,6$ & $1 \pm 12$ & $138 \pm 19$ & 0,998 \\
\hline Pirimicarb & $48,5-404$ & $25 \pm 52$ & $6 \pm 2$ & 0,984 \\
\hline
\end{tabular}

para alturas (criterio I). El otro criterio empleado consiste en medir una serie de muestras con una concentración próxima a la que se piensa que será el límite de detección. Las señales obtenidas se introducen en la ecuación de calibrado obtenida previamente y a la desviación estándar de las concentraciones así calculadas se le multiplica por una $t$ de Student para $n-1$ grados de libertad, donde $n$ es el número de réplicas (criterio II). Los resultados obtenidos se muestran también en la Tabla 3.6.

Los límites de detección encontrados trabajando con esta etapa de preconcentración mediante SPME son aún insuficientes para la aplicación del método propuesto al análisis de plaguicidas en aguas destinadas al consumo humano (valor máximo permitido por la legislación para plaguicidas individuales: o,1 $\mu \mathrm{g} / \mathrm{L}$ [61]), salvo para el Metiocarb si el límite de detección se calcula con el criterio I. Hay que señalar que los límites calculados mediante el criterio II son en general más elevados y realistas que los calculados utilizando el criterio I.

[61] Real decreto 140/2003, de 7 de febrero, por el que se establecen los criterios sanitarios de la calidad del agua de consumo humano. вов, 45:7228-7245, 21-2-2003. 
Tabla 3.6. Precisión expresada como desviación estándar relativa (RSD) y límites de detección obtenidos con una sola etapa de preconcentración mediante sPME.

\begin{tabular}{lccccc|}
\hline Plaguicida & Concentración / $\mu \mathrm{g} / \mathrm{L}$ & Área $/ 10^{4} \mathrm{c} \mathrm{s}$ & $\mathrm{RSD}(\%)$ & $\mathrm{LD}_{\mathrm{I}}^{a} / \mu \mathrm{g} / \mathrm{L}$ & $\mathrm{LD}_{\mathrm{II}}{ }^{b} / \mu \mathrm{gg} / \mathrm{L}$ \\
\hline Aldicarb & 47,5 & $2,3 \pm 0,3$ & 11 & 11 & 15 \\
Carbetamida & 43,6 & $4,4 \pm 0,4$ & 10 & 11 & 19 \\
Propoxur & 3,3 & $5,8 \pm 0,6$ & 10 & 0,89 & 1,4 \\
Carbofurano & 4,2 & $1,8 \pm 0,2$ & 13 & 2,9 & 2 \\
Carbarilo & 2,6 & $14 \pm 2$ & 17 & 0,53 & 1,2 \\
Metiocarb & 1,2 & $16 \pm 2$ & 13 & 0,06 & 0,63 \\
Pirimicarb & 12,1 & $0,40 \pm 0,06$ & 14 & 6,2 & 4,6 \\
\hline $\begin{array}{l}a \\
{ }_{\mathrm{LD}}=3 \times s_{\mathrm{B}} / b .\end{array}$ & & & & &
\end{tabular}

El método basado en SPME-GC-MS es adecuado para la determinación de Propoxur, Carbofurano, Carbarilo y Metiocarb en aguas superficiales destinadas a la producción de agua potable, ya que la legislación [62] establece un máximo de entre 1 y $5^{\mathrm{\mu g} / \mathrm{L}}$, dependiendo del tratamiento posterior de dichas aguas.

\subsubsection{Determinación de plaguicidas carbámicos mediante GC-MS con SPE y SPME como etapas de preconcentración}

Con objeto de proponer un método adecuado para la determinación de plaguicidas carbámicos en aguas potables, en este trabajo se estudia la posiblidad de aplicar una etapa de preconcentración mediante extracción en fase sólida (SPE) previa a la preconcentración mediante (SPME).

[62] Directiva del Consejo de 16 de junio de 1975 relativa a la calidad requerida para las aguas superficiales destinadas a la producción de agua potable en los Estados miembros (75/440/CEE). 
Estudio de la recuperación de la etapa de extracción en fase sólida

La fase utilizada ha sido $\mathrm{C}_{18}$ (cartuchos con $900 \mathrm{mg}$ de relleno). La elección de esta fase estacionaria se ha basado en los antecedentes bibliográficos existentes acerca del comportamiento de los compuestos estudiados en SPE $[21,22,23,24,25,26,27,28]$.

Se preconcentraron $250,0 \mathrm{~mL}$ de una disolución de todos los analitos de acuerdo con el procedimiento descrito en la Sección 2.3.4 (pág. 20). Los resultados se compararon con los obtenidos con la inyección directa de los mismos compuestos disueltos en acetato de etilo. En la Tabla 3.7 se muestran los valores de recuperación obtenidos (media de tres determinaciones) y su desviación estándar relativa.

Los valores de recuperación obtenidos son aceptables teniendo en cuenta el nivel de concentración al que se ha realizado la experimentación.

Tabla 3.7. Recuperaciones calculadas de cada uno de los analitos en cartuchos de SPE de tipo $\mathrm{tC}_{1} 8$

\begin{tabular}{|lccc|}
\hline Plaguicida & C puesta / mg/L & C encontrada/ mg/L & Recuperación (\%) \\
\hline Aldicarb & 0,3 & 0,26 & $85 \pm 12$ \\
Propoxur & 0,11 & 0,09 & $77 \pm 9$ \\
Carbofurano & 0,11 & 0,07 & $64 \pm 12$ \\
Carbarilo & 0,1 & 0,08 & $84 \pm 4$ \\
Metiocarb & 0,11 & 0,09 & $77 \pm 16$ \\
Pirimicarb & 0,25 & 0,2 & $78 \pm 6$ \\
\hline
\end{tabular}

\section{Linealidad}

El estudio de la linealidad de la señal analítica con la concentración se llevó a cabo para una serie de 4 muestras acuosas de 250,o mL, dopadas con diferentes intervalos de concentración según su sensibilidad. La preparación de 
las muestras se llevó a cabo por dilución de diferentes alícuotas de las disoluciones madre en metanol. La elución de los analitos tiene lugar mediante el paso de 2,o mL de acetonitrilo. Este volumen se evapora hasta sequedad con una corriente de nitrógeno y el residuo seco se redisuelve en el medio óptimo para la SPME $(8,0 \mathrm{~mL}$ de una disolución acuosa con un $60 \%$ de disolución saturada de $\mathrm{NaCl}$ ). En la Tabla 3.8 aparecen reflejados los parámetros de las rectas de regresión obtenidas.

Tabla 3.8. Linealidad y parámetros de regresión ${ }^{a}$ obtenidos con dos etapas de preconcentración consecutivas de SPE y SPME.

\begin{tabular}{|c|c|c|c|c|}
\hline Plaguicida & Intervalo / $\mu \mathrm{g} / \mathrm{L}$ & $a / 10^{4} \mathrm{c} \mathrm{s}$ & $b / 10^{4} \mathrm{c} \mathrm{s} L / \mu \mathrm{g}$ & $r^{2}$ \\
\hline Aldicarb & $0,59-4,8$ & $0,3 \pm 0,3^{b}$ & $0,5 \pm 0,1$ & 0,994 \\
\hline Carbetamida & $0,87-7,0$ & $1 \pm 3$ & $1,7 \pm 0,6$ & 0,987 \\
\hline Propoxur & $0,10-0,79$ & $0 \pm 2$ & $17 \pm 5$ & 0,991 \\
\hline Carbofurano & $0,10-0,83$ & $0,3 \pm 0,9$ & $5 \pm 2$ & 0,986 \\
\hline Carbarilo & $0,09-0,72$ & $2 \pm 8$ & $69 \pm 20$ & 0,991 \\
\hline Metiocarb & $0,07-0,56$ & $7 \pm 12$ & $104 \pm 37$ & 0,986 \\
\hline Pirimicarb & $0,32-2,59$ & $0 \pm 2$ & $7 \pm 21$ & 0,997 \\
\hline \multicolumn{5}{|c|}{$\begin{array}{l}a y=a+b x \text {, donde } y \text { es el área de pico (en cuentas por segundo, c s), y } x \\
\text { la concentración (en } \mu \mathrm{g} / \mathrm{L} \text { ). }\end{array}$} \\
\hline
\end{tabular}

\section{Precisión y límites de detección}

La precisión del método y sus límites de detección se determinaron del modo descrito en la Sección 3.3.1 (página 44). En la Tabla 3.9 se muestran los resultados obtenidos.

Para todos los analitos cuyo fenol es el producto de degradación térmica (Propoxur, Carbofurano, Carbarilo y Metiocarb), y para el Pirimicarb, los límites de detección, trabajando con dos etapas consecutivas de preconcen- 
Tabla 3.9. Precisión, desviaciones estándar relativas (RSD), y límites de detección obtenidos con dos etapas consecutivas de SPE y SPME.

\begin{tabular}{|lccccc|}
\hline Plaguicida & Concentración / $\mathrm{gg} / \mathrm{L}$ & Área $/ 10^{4} \mathrm{C} \mathrm{S}$ & $\mathrm{RSD}$ & $\mathrm{LD}_{\mathrm{I}}{ }^{a} / \mu \mathrm{g} / \mathrm{L}$ & $\mathrm{LD}_{\mathrm{II}}{ }^{b} / \mu \mathrm{g} / \mathrm{L}$ \\
\hline Aldicarb & 0,59 & $0,45 \pm 0,05$ & 10 & 0,28 & 0,29 \\
Carbetamida & 0,87 & $2,0 \pm 0,3$ & 13 & 0,22 & 0,46 \\
Propoxur & 0,10 & $2,0 \pm 0,3$ & 17 & 0,02 & 0,06 \\
Carbofurano & 0,10 & $0,7 \pm 0,1$ & 20 & 0,02 & 0,08 \\
Carbarilo & 0,09 & $6 \pm 2$ & 18 & 0,01 & 0,05 \\
Metiocarb & 0,07 & $8 \pm 2$ & 21 & 0,006 & 0,05 \\
Pirimicarb & 0,32 & $2,4 \pm 0,5$ & 20 & 0,06 & 0,23 \\
\hline $\begin{array}{l}{ }_{\mathrm{LD}}=3 \times s_{\mathrm{B}} / b . \\
{ }_{\mathrm{LD}}=t \times s, n=4 .\end{array}$ & & & & & \\
\end{tabular}

tración mediante SPE y SPME, son inferiores al valor máximo permitido por la legislación española $(0,1 \mu \mathrm{g} / \mathrm{L})$ para plaguicidas individuales en aguas potables. Sin embargo, los límites de detección de los plaguicidas Aldicarb, Carbetamida (y para el Pirimicarb según el criterio II) son aún insuficientes para el análisis de plaguicidas en aguas destinadas al consumo humano. Estos resultados se deben a que estos compuestos son los que poseen menor grado de preconcentración en la fibra de poliacrilato, según se pudo comprobar en el estudio previo realizado (Tabla 3.2), y por tanto para estos analitos no parece adecuado efectuar una doble preconcentración.

\subsubsection{Determinación de plaguicidas carbámicos mediante GC-MS con SPE como etapa de preconcentración}

Para Aldicarb, Carbetamida y Pirimicarb la preconcentración mediante SPME no es favorable, por lo que se procedió a evaluar las características analíticas del método con una sola etapa de preconcentración mediante SPE. 


\section{Precisión de las señales con inyección directa}

Una de las ventajas derivadas del uso de la fibra de SPME, es la degradación controlada de los plaguicidas térmicamente lábiles en el dispositivo de inyección del cromatógrafo de gases. Para la medida de muestras introducidas mediante su inyección directa es necesario llevar a cabo un estudio previo para asegurar que la descomposición se produce de manera reproducible. Se inyectaron 7 veces $2 \mu \mathrm{L}$ de una disolución de los plaguicidas estudiados disueltos en acetato de etilo y se calcularon las precisiones de las señales obtenidas como la desviación estándar relativa de sus áreas. Los resultados obtenidos se muestran en la Tabla 3.10.

Tabla 3.10. Precisión de la inyección directa de los 7 plaguicidas estudiados.

\begin{tabular}{|lcc|}
\hline Plaguicida & Concentración / $\mathrm{\mu g} / \mathrm{L}$ & $\mathrm{RSD}(\%)$ \\
\hline Aldicarb & 128 & 4 \\
Carbetamida & 262 & 11 \\
Propoxur & 164 & 14 \\
Carbofurano & 208 & 17 \\
Carbarilo & 768 & 25 \\
Metiocarb & 464 & 20 \\
Pirimicarb & 404 & 8 \\
\hline
\end{tabular}

Las señales de los plaguicidas que originan fenoles (Propoxur, Carbofurano, Carbarilo y Metiocarb) cuando se analizan mediante inyección directa no son reproducibles y presentan valores de desviación estándar comprendidos entre el $14 \%$ y el $25 \%$.

Se puede comprobar que la mayor reproducibilidad se obtiene para los tres compuestos que no se preconcentran de una forma favorable mediante SPME en una fibra de poliacrilato. Esta mayor precisión puede deberse a que, por una parte, el Pirimicarb no se degrada y, por otra, a que los mecanismos de 
degradación del Aldicarb y la Carbetamida son diferentes a los que presentan los $N$-metil carbamatos de fenilo.

\section{Linealidad}

El estudio de la influencia de la concentración de los plaguicidas Aldicarb, Carbetamida y Pirimicarb sobre la señal analítica se llevó a cabo para una serie de 7 muestras acuosas de 250,o mL, dopadas entre o,1 y 1 $\mu \mathrm{g} / \mathrm{L}$. La preparación de las muestras se llevó a cabo por dilución de diferentes alícuotas de las disoluciones madre en metanol. La retención y posterior elución de los analitos durante la etapa de SPE tiene lugar de la forma detallada anteriormente, con la diferencia de que el volumen recogido se evapora hasta sequedad con una corriente de nitrógeno y el residuo seco se redisuelve en $500 \mu \mathrm{L}$ de acetonitrilo. $1 \mu \mathrm{L}$ de esta disolución se inyecta directamente en el cromatógrafo. En la Tabla 3.11 aparecen los parámetros del análisis por regresión lineal de los datos obtenidos.

Tabla 3.11. Linealidad y parámetros de regresión ${ }^{a}$ obtenidos con preconcentración mediante SPE.

\begin{tabular}{|c|c|c|c|}
\hline Plaguicida & a / $10^{4} \mathrm{c} \mathrm{s}$ & $b / 10^{4} \mathrm{c} \mathrm{s} \mathrm{L/ \mu g}$ & $r^{2}$ \\
\hline Aldicarb & $-1 \pm 1$ & $16 \pm 6^{b}$ & 0,976 \\
\hline Carbetamida & $-1 \pm 2$ & $26 \pm 4$ & 0,986 \\
\hline Pirimicarb & $-2 \pm 3$ & $87 \pm 6$ & 0,998 \\
\hline
\end{tabular}




\section{Precisión y límites de detección}

La precisión del método se determinó a partir de los valores de desviación estándar relativa de 7 muestras con una concentración equivalente a la más baja empleada en el estudio de la linealidad del método. Los límites de detección se calcularon del modo indicado en la Sección 3.3.1 (página 44). En la Tabla 3.12 se muestran los valores de precisión y los límites de detección encontrados para los tres analitos.

Los límites de detección encontrados para los tres plaguicidas evaluados con este método, trabajando con preconcentración mediante SPE, son inferiores al valor máximo permitido por la legislación española para plaguicidas individuales $(0,1 \mu \mathrm{g} / \mathrm{L})$ en aguas potables.

Tabla 3.12. Precisión, desviaciones estándar relativas (RSD) y límites de detección obtenidos con una etapa de SPE.

\begin{tabular}{|lccccc|}
\hline Plaguicida & Concentración / $\mathrm{gg} / \mathrm{L}$ & Área $/ 10^{3} \mathrm{c} \mathrm{S}$ & $\mathrm{RSD}(\%)$ & $\mathrm{LD}_{\mathrm{I}}^{a} / \mu \mathrm{g} / \mathrm{L}$ & $\mathrm{LD}_{\mathrm{II}}^{b} / \mu \mathrm{g} / \mathrm{L}$ \\
\hline Aldicarb & 0,10 & $9 \pm 1$ & 15 & 0,019 & 0,020 \\
Carbetamida & 0,087 & $15 \pm 2$ & 15 & 0,038 & 0,038 \\
Pirimicarb & 0,097 & $66 \pm 10$ & 15 & 0,014 & 0,028 \\
\hline
\end{tabular}

${ }^{a} \mathrm{LD}=3 \times s_{\mathrm{B}} / b$.

${ }^{b} \mathrm{LD}=t \times s, n=4$. Datos obtenidos del estudio de precisión. 


\section{CONCLUSIONES}

\section{Comportamiento en cromatografía de gases de plaguicidas carbámicos}

En esta parte de la memoria se ha estudiado el comportamiento de diversos plaguicidas carbámicos en GC. Además se ha optimizado el proceso de SPME de estos plaguicidas, y se han propuesto métodos para su determinación en aguas mediante GC-MS con SPME y SPE como etapas de preconcentración.

\section{Comportamiento cromatográfico con inyección directa}

Los compuestos estudiados, con la excepción del Pirimicarb, se descomponen térmicamente con las temperaturas alcanzadas en GC. Esta degradación depende entre otros motivos del tipo de disolvente utilizado en su inyección directa. Cuando el disolvente es metanol, aparecen las señales cromatográficas correspondientes a los carbamatos de metilo. Esta reactividad desaparece cuando se utiliza acetato de etilo como disolvente.

Entre los carbamatos estudiados se distinguen 4 estructuras distintas con 4 reactividades diferentes en GC:

- Los N-metil carbamatos de fenilo (Propoxur, Carbofurano, Carbarilo y Metiocarb) se descomponen térmicamente para originar sus formas fenólicas correspondientes.

- La Carbetamida, con estructura de $N$-fenil carbamato, se descompone hacia isocianato de fenilo. Si existe agua, el isocianato reacciona con el agua para originar anilina. 
- El Aldicarb, que tiene estructura de carbamato de una oxima, se degrada térmicamente para dar el nitrilo de aldicarb.

- El Pirimicarb, cuya estructura es de $N, N$-dimetil carbamato no se degrada térmicamente, y siempre aparece la señal correspondiente a la molécula entera.

En este trabajo se ha comprobado que el comportamiento cromatográfico es diferente según sea el estado de uso de la columna cromatográfica utilizada. Una columna usada favorece la degradación de compuestos térmicamente lábiles en el interior de la columna. Los cromatogramas registrados por inyección directa de concentraciones elevadas de plaguicidas carbámicos en una columna capilar con dos años de uso, no presentan señales cromatográficas de las moléculas enteras de los analitos, salvo la del Pirimicarb, que no se degrada. En las mismas condiciones pero con una columna nueva, además de las de los productos de degradación, se observan las señales procedentes de todos los analitos sin descomponer.

\section{Comportamiento cromatográfico previa microextracción en fase sólida}

El uso de una fibra de poliacrilato permite efectuar la preconcentración de los analitos estudiados de manera que durante el proceso de desorción tenga lugar una degradación controlada de los compuestos térmicamente lábiles.

Para la cuantificación de bajas concentraciones de plaguicidas carbámicos se pueden utilizar las señales de los productos de degradación. Este procedimiento permite evaluar bajas concentraciones independientemente de la edad de la columna cromatográfica utilizada. La Carbetamida, que en una columna con una vida larga origina isocianato de fenilo y anilina en proporciones no reproducibles, produce sólo la señal del isocianato con una columna nueva. Este hecho indica que la anilina se produce por la reacción en la columna del isocianato con el agua presente. 


\section{Optimización de la etapa de microextracción en fase sólida}

Mediante un diseño de experimentos se han optimizado las variables que influyen en la microextracción en fase sólida: temperatura de extracción, fuerza iónica, tiempo de preconcentración y temperatura de desorción. En una primera etapa de criba mediante un diseño factorial fraccionado, se apartó del estudio la variable «temperatura de desorción» por resultar poco significativa. En un diseño posterior más completo de tres niveles (Box-Behnken) se establecieron los valores óptimos de fuerza iónica, temperatura de extracción y tiempo de preconcentración. La variable «temperatura de extracción» no resultó tener un efecto significativo en la extracción de los carbamatos y se fijó en $25^{\circ} \mathrm{C}$. Las variables «tiempo de extracción» y «fuerza iónica» tienen un efecto positivo en la extracción y se fijaron en 120 min y $60 \%$ de disolución saturada de $\mathrm{NaCl}$, respectivamente.

\section{Métodos propuestos}

GC-MS con SPME

En el método propuesto para la determinación de carbamatos con una etapa de preconcentración por SPME los límites de detección encontrados son superiores a los valores máximos establecidos por la legislación para este tipo de compuestos en aguas destinadas al consumo humano. Sin embargo, el método es válido para evaluar este tipo de plaguicidas en aguas superficiales.

GC-MS CON SPE $y$ SPME

Se ha desarrollado un método que incluye una etapa de preconcentración con sorbentes de $\mathrm{C}_{18}$, seguida de una etapa de preconcentración con SPME. Los límites de detección con este método son inferiores a los valores máximos establecidos por la legislación española para los plaguicidas que originan fenoles en GC: Propoxur, Carbofurano, Carbarilo y Metiocarb, y también para el Pirimicarb. Sin embargo, este método no poroporciona resultados adecuados para Aldicarb y Carbetamida. 
GC-MS con SPE

Para la determinación de los plaguicidas Aldicarb, Carbetamida y Pirimicarb se propone un método que tiene una sola etapa de preconcentración mediante SPE con cartuchos de $\mathrm{C}_{18}$. Los límites de detección con este método son inferiores a los valores máximos que establece la legislación española para este tipo de compuestos en aguas de consumo humano. 
Parte II

SEPARACIÓN DE TOCOFEROLES MEDIANTE ELECTROCROMATOGRAFÍA CAPILAR 



\section{INTRODUCCIÓN}

\subsection{ELECTROCROMATOGRAFÍA CAPILAR}

La electrocromatografía capilar (CEC) es una técnica de separación en la que se trabaja con tubos capilares de sílice rellenos de fase estacionaria. Fue introducida por primera vez por Pretorious et al. en 1974 [63]. Es una técnica híbrida que combina las interacciones entre analitos y fase estacionaria características de la cromatografía líquida (HPLC) con el formato capilar y electrocinético de la electroforesis capilar (CE), combinando las ventajas de ambas técnicas (selectividad y elevada eficacia, respectivamente) con un consumo mínimo de disolventes.

El método clásico de fabricación de columnas para CEC consiste en empaquetar una suspensión de partículas de fase estacionaria en un capilar de sílice fundida haciéndolas fluir a gran velocidad por su interior; el capilar tiene una frita en un extremo que deja pasar el disolvente (normalmente acetona), pero retiene las partículas que van quedando perfectamente empaquetadas debido a las elevadas presiones empleadas (unos 70obar). En este procedimiento [64] está basado el seguido en esta memoria (pág. 75). Es una etapa complicada y que necesita instrumental apropiado y no muy habitual (una sonda de ultrasonidos, una cámara de acero para mantener la suspensión de fase estacionaria, etc.). Las fases estacionarias empaquetadas hacen indispensable el uso de fritas en ambos extremos del lecho cromatográfico para

[63] V. Pretorius, B. J. Hopkins, and J. D. Schieke. Electroosmosis: A new concept for highspeed LC. J. Chromatogr., 99:23-30, 1974.

[64] R. J. Boughtflower, T. Underwood, and J. Maddin. The production of packed capillaries using a novel pressurised ultrasound device. Chromatographia, 41:398-402, 1995. 
mantener retenida la fase estacionaria en el interior de la columna capilar. Existen varios inconvenientes asociados al uso de fritas: la dificultad de su construcción, su falta de reproducibilidad, su posible contribución al ensanchamiento de los picos, su efecto sobre el flujo electro-osmótico (EOF), y la adsorción de los analitos, además de ser un punto de formación de burbujas.

\subsubsection{Fases estacionarias con grupos polares incrustados}

Desde hace algunos años existen en el mercado un nuevo tipo de fases estacionarias para LC llamadas polar embedded (con grupos polares incrustados). Su principal diferencia con las fases alquílicas lineales habituales es que incluyen grupos funcionales polares en su estructura (Figura 5.1). El grupo polar, que puede ser muy diverso (un grupo amido, carbamato, urea, sulfonamida o fenil-éter), se une a la partícula de sílice por un espaciador que suele ser una cadena de 2 a 4 átomos de carbono, y por otra parte a una cadena alquílica que varía de $\mathrm{C}_{8}$ a $\mathrm{C}_{18}$, que le proporciona su carácter hidrofóbico.

Sus características, selectividad y comparación con las fases alquílicas habituales han sido descritas ampliamente $[65,66,67,68,69]$. Sus principales características son:

1. Simetría mejorada de analitos básicos como resultado de la desactivación de la interación de éstos con los grupos silanol superficiales de la

[65] J. Layne. Characterization and comparison of the chromatographic performance of conventional, polar-embedded, and polar-endcapped reversed-phase LC stationary phases. $J$. Chromatogr. A, 957:149-164, 2002.

[66] M. R. Euerby and P. Petersson. Chromatographic classification and comparison of commercially available RP liquid chromatographic columns containing polar embedded groups/amino endcappings using PCA. J. Chromatogr. A, 1088:1-15, 2005.

[67] K. Le Mapihan, J. Vial, and A. Jardy. RP LC testing; Role of organic solvent through an extended set of columns. J. Chromatogr. A, 1088:16-23, 2005.

[68] P. A. Tate and J. G. Dorsey. Column selection for liquid chromatographic estimation of the $k_{\mathrm{w}}^{\prime}$ hydrophobicity parameter. J. Chromatogr. A, 1042:37-48, 2004.

[69] A. Marín and C. Barbas. Systematic comparison of different functionality columns for a classical pharmaceutical problem. J. Pharm. Biomed. Anal., 40:262-270, 2006. 

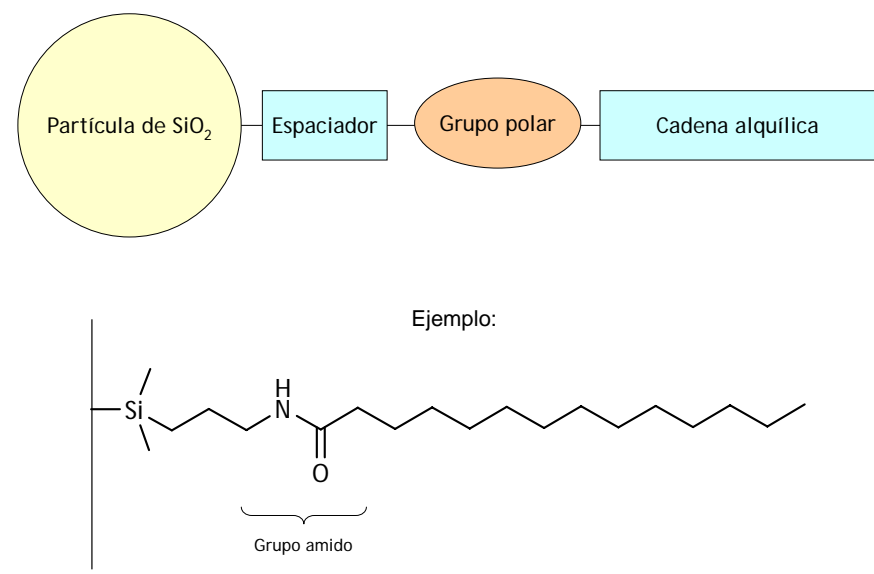

Figura 5.1. Estructura general de fases estacionarias con grupos polares incrustados.

fase estacionaria; los grupos silanol interaccionan preferentemente formando puentes de hidrógeno con el grupo polar, en lugar de con los analitos $[65,70]$. Si estos grupos polares están cargados positivamente en medio ácido, pueden provocar la repulsión de las bases protonadas lejos de la superficie de la sílice.

2. Muestran diferente selectividad que las fases habituales de $C_{8}$ y $C_{18}$. Esto es debido a las diferentes atracciones y repulsiones de ácidos y bases por interacciones electrostáticas entre la fase estacionaria y los analitos. Se sabe que este tipo de fases estacionarias ejercen una retención adicional en los compuestos fenólicos debido a su capacidad de formar puentes de hidrógeno [70, 71].

[7o] J. E. O'Gara, B. A. Alden, T. H. Walter, J. S. Petersen, C. L. Niederlaender, and U. D. Neue. Simple preparation of a $\mathrm{C}_{8}$ HPLC stationary phase with an internal polar functional group. Anal. Chem., 67:3809-3813, 1995.

[71] N. S. Wilson, J. Gilroy, J. W. Dolan, and L. R. Snyder. Column selectivity in reversedphase LC vi. Columns with embedded or end-capping polar groups. J. Chromatogr. A, 1026:91-100, 2004. 
3. Tienen menor carácter hidrofóbico debido al grupo polar que incluyen. Dan la oportunidad de usarlas con fases móviles totalmente acuosas sin riesgo de colapsar las cadenas alquílicas [72, 73].

\subsubsection{Fases estacionarias monoliticas}

Debido a los inconvenientes de las fases estacionarias empaquetadas para CEC, se buscaron métodos alternativos que evitaran la dificultad de la etapa de empaquetamiento y eliminaran el uso de fritas de retención. Una respuesta a todos los problemas planteados está en el uso de columnas rígidas de una sola pieza, llamadas comúnmente monolíticas. Este tipo de columnas se pueden clasificar en dos categorías principales: monolitos basados en polímeros orgánicos, y monolitos de sílice.

Las fases estacionarias monolíticas basadas en sílice se fabrican mediante el método «sol-gel», introducido en 1996 para HPLC [74] y adaptado posteriormente a su uso en CEC $[75,76,77,78]$. Mediante este método se forma un monolito poroso de sílice con una estructura uniforme como resultado de una policondensación hidrolítica de alcoxisilanos acompañada de una separación de fases en presencia de polímeros orgánicos solubles en agua. La estructura de sílice puede ser funcionalizada posteriormente de acuerdo con la selectividad requerida en la separación.

[72] R. E. Majors and M. Przybyciel. Columns for RP LC separations in highly aqueous mobile phases. LC GC North America, 20:584-593, 2002.

[73] J. E. O'Gara, D. P. Walsh, C. H. Phoebe, B. A. Alden, E. S. P. Bouvier, P. C. Iraneta, M. Capparella, and T. H. Walter. Embedded-polar-group bonded phases for HPLC. LC GC North America, 19:632-642, 2001.

[74] H. Minakuchi, K. Nakanishi, N. Soga, N. Ishizuka, and N. Tanaka. Octadecylsilylated porous silica rods as separation media for RP LC. Anal. Chem., 68:3498-3501, 1996.

[75] Q. Tang, B. Xin, and M. L. Lee. Monolithic columns containing sol-gel bonded octadecylsilica for CEC. J. Chromatogr. A, 837:35-50, 1999.

[76] J. D. Hayes and A. Malik. Sol-gel open tubular ods columns with reversed electroosmotic flow for CEC. Anal. Chem., 73:987-996, 2001.

[77] J. Kang, D. Wistuba, and V. Schurig. A silica monolithic column prepared by the sol-gel process for enantiomeric separation by CEC. Electrophoresis, 23:1116-20, 2002.

[78] W. Li, D. P. Fries, and A. Malik. Sol-gel stationary phases for CEC. J. Chromatogr. A, 1044:23-52, 2004. 


\section{Polímeros orgánicos monolíticos}

Sin embargo, la mayoría de las columnas monolíticas para CEC están construidas por la polimerización in situ de una mezcla de monómeros orgánicos y la formación una de una red rígida porosa. El modo general para la fabricación de este tipo de columnas es el siguiente:

1. En primer lugar se prepara una mezcla con las cantidades deseadas de monómeros, una mezcla de disolventes porogénicos y un reactivo iniciador. Un capilar se rellena con esta disolución, una vez desgasificada mediante ultrasonidos o con una corriente de $\mathrm{N}_{2}$.

2. A continuación el capilar se sella y tiene lugar la descomposición, bien térmicamente o mediante radiación uv, de la molécula de iniciador, que genera radicales libres que comienzan una reacción de polimerización en cadena. A medida que las moléculas de polímero van aumentando su tamaño son cada vez menos solubles y precipitan de un modo más o menos homogéneo dejando atrapado el disolvente en pequeños intersticios que formarán los poros.

3. Una vez que la polimerización se ha completado, la columna se lava con una bomba (normalmente son necesarias presiones elevadas) para arrastrar disolventes y moléculas de monómeros e iniciador que han quedado sin reaccionar. También es posible el lavado de la columna empleando el EOF como bomba.

El resultado es un monolito poroso con una distribución de tamaño de poro muy estrecha. Este tipo de fases estacionarias para CEC representan una alternativa a las columnas empaquetadas debido a su facilidad de preparación, la ausencia de fritas, la homogeneidad del lecho, y la amplia variedad de monómeros disponibles para la síntesis de fases estacionarias con funcionalidades muy diferentes. Desde su introducción por Hjertén et al. [79]

[79] S. Hjertén, J. L. Liao, and R. Zhang. HPLC on continuous polymer beds. J. Chromatogr., 473:273-275, 1989. 
para HPLC y su posterior desarrollo por Svec et al. [80, 81], se han investigado en profundidad diferentes tipos de monómeros y reactivos, aunque las fases más habituales están basadas en el ácido metacrílico y sus ésteres $[82,83,84,85,86,87]$, acrilamida [88, 89, 90], y estireno y divinilbenceno [91, 92, 93], debido a ventajas como su rigidez, su facilidad de derivatización y su estabilidad en un intervalo amplio de $\mathrm{pH}$.

[8o] F. Svec and J. M. J. Fréchet. Continuous rods of macroporous polymer as HPLC separation media. Anal. Chem., 64:820-822, 1992.

[81] Q. C. Wang, K. Hosoya, F. Svec, and J. M. J. Fréchet. Polymeric porogens used in the preparation of novel monodispersed macroporous polymeric separation media for HPLC. Anal. Chem., 64:1232-1238, 1992.

[82] F. Svec and J. M. J. Fréchet. New designs of macroporous polymers and supports: from separation to biocatalysis. Science, 273:205-211, 1996.

[83] E. C. Peters, M. Petro, F. Svec, and J. M. J. Fréchet. Molded rigid polymer monoliths as separation media for Cec. Anal. Chem., 69:3646-3649, 1997.

[84] S. Zhang, X. Huang, J. Zhang, and C. Horváth. CEC of proteins and peptides with a cationic acrylic monolith. J. Chromatogr. A, 887:465-477, 2000.

[85] F. M. Okanda and Z. El Rassi. Cec with monolithic stationary phases. 4. Preparation of neutral stearyl-acrylate monoliths and their evaluation in CEC of neutral and charged small species as well as peptides and proteins. Electrophoresis, 26:1988-1995, 2005.

[86] N. Delaunay-Bertoncini, C. Demesmay, and J. L. Rocca. Development and in situ synthesis of monolithic stationary phases for electrochromatographic separations. Electrophoresis, 25:3204-15, 2004.

[87] Z. Jiang, N. W. Smith, P. D. Ferguson, and M. R. Taylor. Preparation and characterization of long alkyl chain methacrylate-based monolithic column for capillary chromatography. J. Biochem. Biophys. Methods, 70:39-45, 2007.

[88] A. Palm and M. V. Novotny. Macroporous polyacrylamide/poly(ethylene glycol) matrixes as stationary phases in CEC. Anal. Chem., 69:4499-4507, 1997.

[89] D. Hoegger and R. Freitag. Acrylamide-based monoliths as robust stationary phases for CEC. J. Chromatogr. A, 914:211-222, 2001.

[9o] D. Hoegger and R. Freitag. Investigation of mixed-mode monolithic stationary phases for the analysis of charged amino acids and peptides by CEC. J. Chromatogr. A, 1004:195-208, 2003.

[91] I. Gusev, X. Huang, and C. Horváth. Capillary columns with in situ formed porous monolithic packing for $\mu$ HPLC and CEC. J. Chromatogr. A, 855:273-290, 1999.

[92] N. W. Smith. Advances in CEC and $\mu$-HPLC monolithic columns for separation science. Electrophoresis, 24:917-944, 2003.

[93] B. Xiong, L. Zhang, Y. Zhang, H. Zou, and J. Wang. Cec with monolithic poly (styreneco-divinylbenzene-co-methacrylic acid) as the stationary phase. J. High Res. Chromatogr., 23:67-72, 2000 . 
Los capilares de sílice fundida pueden usarse directamente sin ninguna modificación de la pared interna, pero frecuentemente es necesario su tratamiento con un reactivo bifuncional que sirva de anclaje para fijar el polímero creado y evitar su expulsión durante el lavado o las separaciones. Del mismo modo, los monómeros pueden utilizarse directamente, aunque es conveniente su purificación por destilación o con columnas de sílice o alúmina para eliminar conservantes y mejorar la reproducibilidad.

Al igual que en el caso de la cEC con columnas empaquetadas, el movimiento de la fase móvil es electrocinético; en el caso de que los polímeros no posean cargas eléctricas de forma nativa (como por ejemplo, el ácido metacrílico), el EOF es generado normalmente incorporando a la mezcla inicial una pequeña proporción de monómeros con una función ionizable. En el caso de polímeros basados en ésteres acrílicos y metacrílicos, se suelen emplear monómeros con un grupo sulfónico, que permanece ionizado en todo el intervalo de $\mathrm{pH}$. Los monómeros funcionalizados más empleados son el ácido 2-acrilamido2-metil-1-propanosulfónico (AMPS) y el metacrilato de 3-sulfopropilo (como sal potásica). Los generadores de radicales libres más usados como iniciadores son el peróxido de benzoílo o el azobisisobutironitrilo (AIBN), cuyas disoluciones pueden manejarse fácilmente a temperatura ambiente y conservarse durante varios días en un refrigerador sin riesgo de polimerización de la mezcla. Su concentración suele ser de un 1 \% con respecto a la suma total de monómeros.

La composición de la mezcla porogénica es la variable que más afecta al comportamiento de la posterior fase estacionaria. La proporción de disolventes y monómeros altera la estructura y eficacia de los monolitos resultantes de un modo notable; la elección cuidadosa de su justa proporción permite conseguir fases estacionarias con una elevada eficacia. Destacan los trabajos de Peters et al. [83, 94, 95], quienes desarrollan una mezcla ternaria de disolventes que les permite el control de las propiedades y tamaño de los poros

[94] E. C. Peters, M. Petro, F. Svec, and J. M. J. Fréchet. Molded rigid polymer monoliths as separation media for CEC. 1. Fine control of porous properties and surface chemistry. Anal. Chem., 70:2288-2295, 1998.

[95] E. C. Peters, M. Petro, F. Svec, and J. M. J. Fréchet. Molded rigid polymer monoliths as separation media for CEC. 2. Effect of chromatographic conditions on the separation. Anal. Chem., 70:2296-2302, 1998. 
en un amplio intervalo, empleando pequeñas variaciones de la relación entre 1-propanol y 1,4-butanodiol en el disolvente porogénico. Un cambio de tan solo $2,5 \%$ en la proporción entre estos disolventes permite controlar con precisión el tamaño de poro entre 255 y $9.000 \mathrm{~nm}$.

En el caso de fases estacionarias empaquetadas la eficacia de la separación aumenta a medida que el tamaño de partícula del empaquetamiento disminuye; sin embargo, en fases estacionarias monolíticas no se puede hablar de tamaños de partícula, y es el tamaño de los poros, controlado por las condiciones de polimerización la variable que afecta a la eficacia. En general, una disminución del tamaño de los poros implica un aumento en la eficacia de las separaciones debido a la mayor superficie específica en contacto con la fase móvil.

En realidad, los monolitos porosos tienen dos niveles estructurales. En primer lugar están formados por canales que permiten el flujo de la fase móvil. Las paredes de estos canales contienen a su vez poros más pequeños y microcanales que proporcionan la capacidad de adsorción y son los responsables de la superficie específica de la columna. A estos microcanales sólo se puede llegar mediante difusión molecular [91]. La formación de esta doble estructura necesita el uso de más de un disolvente porogénico, y su composición es crítica para conseguir un comportamiento óptimo de la fase estacionaria.

En general se trata de construir columnas fabricadas con la menor cantidad de disolvente posible, ya que la dispersión de Eddy (término $C$ en la ecuación de Van Deemter) es menor y la transferencia de masa entre fase estacionaria y fase móvil es más rápida, dando lugar a mayores eficacias y curvas de Van Deemter con una pendiente menor por encima de la velocidad óptima [96]. No obstante, experimentalmente se comprueba que el caudal disminuye de-

[96] A. M. Siouffi. About the $C$ term in the Van Deemter's equation of plate height in monoliths. J. Chromatogr. A, 1126:86-94, 2006.

[97] E. F. Hilder, F. Svec, and J. M. J. Fréchet. Polymeric monolithic stationary phases for CEC. Electrophoresis, 23:3934-53, 2002.

[98] M. Bedair and Z. El Rassi. Recent advances in polymeric monolithic stationary phases for electrochromatography in capillaries and chips. Electrophoresis, 25:4110-4119, 2004.

[99] K. W. Ro, R. Nayak, and D. R. Knapp. Monolithic media in microfluidic devices for proteomics. Electrophoresis, 27:3547-3558, 2006. 
bido a la resistencia al flujo de los microcanales y a la solapamiento de la doble capa eléctrica cuando el tamaño de poro es muy pequeño. En realidad, la relación a priori entre la composición de la mezcla porogénica y la posterior estructura del polímero es compleja y sólo pueden relacionarse de manera puramente experimental.

Algunas revisiones recientes recogen la preparación y los usos de este tipo de fases estacionarias así como los progresos realizados para controlar su morfología y superficie [97, 98, 99, 100, 101, 102, 103, 104, 105, 106].

A pesar del creciente interés en los últimos años, el uso habitual y la explotación comercial de este tipo de columnas para CEC y HPLC aún está por desarrollarse. La mayoría de trabajos caracterizan las fases creadas mediante la separación de pequeños compuestos neutros, aunque cada vez más publicaciones amplían su uso a otro tipo de aplicaciones, entre las que se encuentra el uso de polímeros impresos [107, 108, 109], separaciones de in-

[100] D. Schaller, E. F. Hilder, and P. R. Haddad. Monolithic stationary phases for fast ion chromatography and CEC of inorganic ions. J. Sep. Sci., 29:1705-1719, 2006.

[101] K. Štulík, V. Pacáková, J. Suchánková, and P. Coufal. Monolithic organic polymeric columns for capillary LC and electrochromatography. J. Chromatogr. B, 841:79-87, 2006.

[102] S. Eeltink and F. Svec. Recent advances in the control of morphology and surface chemistry of porous polymer-based monolithic stationary phases and their application in CEC. Electrophoresis, 28:137-147, 2007.

[103] E. G. Vlakh and T. B. Tennikova. Preparation of methacrylate monoliths. J. Sep. Sci., 30:2801-2813, 2007.

[104] M. R. Buchmeiser. Polymeric monolithic materials: Syntheses, properties, functionalization and applications. Polymer, 48:2187-2198, 2007.

[105] N. W. Smith and Z. Jiang. Developments in the use and fabrication of organic monolithic phases for use with HPLC and CEC. J. Chromatogr. A, 1184:416-440, 2007.

[106] R. Wu, L. Hu, F. Wang, M. Ye, and H. Zou. Recent development of monolithic stationary phases with emphasis on microscale chromatographic separation. J. Chromatogr. A, 1184:369-92, 2008.

[107] Z. S. Liu, C. Zheng, and C. Yan. Molecularly imprinted polymers as a tool for separation in CEC. Electrophoresis, 28:127-136, 2006.

[108] M. Quaglia, B. Sellergren, and E. De Lorenzi. Approaches to imprinted stationary phases for affinity CEC. J. Chromatogr. A, 1044:53-66, 2004.

[109] L. Schweitz, P. Spegel, and S. Nilsson. Approaches to molecular imprinting based selectivity in CEC. Electrophoresis, 22:4053-63, 2001. 
tercambio iónico [110, 111], de compuestos quirales [112, 113], proteómica [114, 115], etc. Además del uso de capilares, se ha ampliado su formato hacia otro tipo de dispositivos como los de microfluidos llamados comúnmente chips $[116,117,118]$, que poseen ventajas como el empleo de una menor cantidad de muestra, menor consumo de disolventes, tiempos de análisis muy cortos, y facilidad de transporte para análisis de campo.

\subsection{ANALitos MODELO: TOCOFEROLES}

La vitamina E pertenece al grupo de las liposolubles y es considerada uno de los mejores antioxidantes biológicos. No se conocen con exactitud todas sus funciones biológicas, pero sus efectos antioxidantes en medios grasos son debidos a la presencia del grupo fenólico. Previene la oxidación de las membranas citoplasmáticas y protege otras vitaminas fácilmente oxidables, como el retinol y el ácido ascórbico. Se encuentra principalmente en aceites y

[110] E. F. Hilder, C. W. Klampfl, and P. R. Haddad. Pressurized-flow anion-exchange cec using a polymeric ion-exchange stationary phase. J. Chromatogr. A, 890:337-345, 2000.

[111] M. Lämmerhofer, F. Svec, J. M. J. Fréchet, and W. Lindner. CEC in anion-exchange and normal-phase mode using monolithic stationary phases. J. Chromatogr. A, 925:265-277, 2001.

[112] Q. L. Deng, Z. H. Lun, R. Y. Gao, L. H. Zhang, and W. B. Zhang. (S)-ibuprofen-imprinted polymers incorporating $\gamma$-methacryloxypropyl-trimethoxysilane for CEC separation of ibuprofen enantiomers. Electrophoresis, 27:4351-4358, 2006.

[113] M. G. Schmid, N. Grobuschek, C. Tuscher, G. Gübitz, Á. Végvári, E. Machtejevas, A. Maruška, and S. Hjertén. Chiral separation of amino acids by ligand-exchange CEC using continuous beds. Electrophoresis, 21:3141-4, 2000.

[114] R. Shediac, S. M. Ngola, D. J. Throckmorton, D. S. Anex, T. J. Shepodd, and A. K. Singh. RP electrochromatography of amino acids and peptides using porous polymer monoliths. J. Chromatogr. A, 925:251-263, 2001.

[115] A. R. Ivanov. Separation methods in proteomics, chapter Polymeric monolithic capillary columns in proteomics, pages 419-438. CRC Press, 2006.

[116] M. Pumera. Microchip-based electrochromatography: designs and applications. Talanta, 66:1048-1062, 2005.

[117] Y. Yang, C. Li, J. Kameoka, K. H. Lee, and H. G. Craighead. A polymeric microchip with integrated tips and in situ polymerized monolith for ES-MS. Lab Chip, 5:869-876, 2005.

[118] F. E. Regnier, B. He, S. Lin, and J. Busse. Chromatography and electrophoresis on chips: critical elements of future integrated, microfluidic analytical systems for life science. Trends Biotechnol., 17:101-106, 1999. 
margarinas vegetales procedentes de semillas, así como en frutos secos como almendras, avellanas y nueces. Los tejidos animales como hígado, leche y huevos tienen niveles más bajos de vitamina E.

La vitamina $\mathrm{E}$ pertenece a una familia de 8 compuestos estructuralmente relacionados: 4 tocoferoles y 4 tocotrienoles. Los compuestos de mayor actividad vitamínica son los tocoferoles, cuya estructura se muestra en la Figura 5.2. Los tocotrienoles análogos contienen 3 dobles enlaces en la cadena hidrocarbonada. Los 4 tocoferoles difieren en el número y la posición de los sustituyentes metílicos del anillo aromático: $\alpha, \beta, \gamma$ y $\delta$-tocoferol. Aunque a esta familia de compuestos se la denomine usualmente «isómeros», únicamente las formas $\beta$ y $\gamma$ son isómeros de posición.

Las diferentes formas tienen distinta actividad biológica, siendo la forma $\alpha$ la de mayor capacidad antioxidante, seguido del $\beta, \gamma$ y el $\delta$-tocoferol. Debido a su diferente actividad y a sus diferentes proporciones en distintos alimentos, es importante disponer de metodologías analíticas capaces de distinguir entre los diferentes isómeros en muestras alimentarias muy variadas.

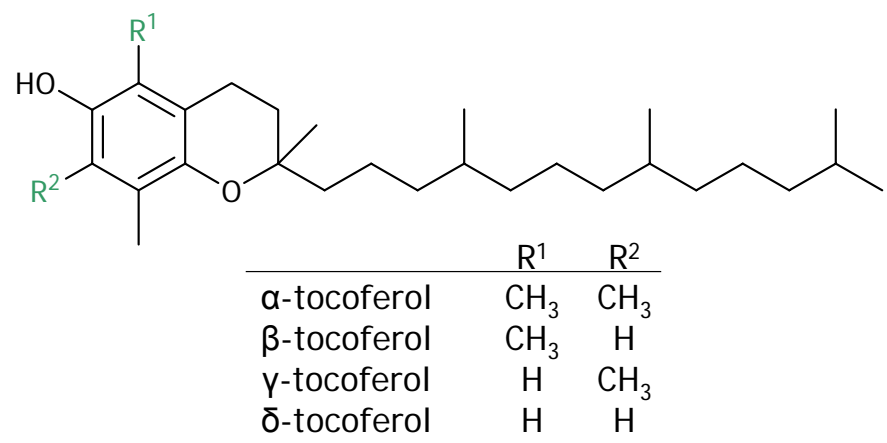

Figura 5.2. Estructura de las diferentes formas de vitamina $E$ 


\subsubsection{Separación de vitamina E mediante electrocromatografía capilar}

\section{Columnas empaquetadas}

Debido a su naturaleza, la separación mediante cromamatografía líquida de alta eficacia (HPLC) puede llevarse a cabo tanto en fase normal como en fase inversa, si bien los sistemas de fase inversa tienen un uso más extendido dadas su robustez y mayor resolución [119, 120, 121]. Las fases normales son menos usadas, a pesar de su mayor selectividad, que permite la separación de isómeros estructurales ( $\beta$ y $\gamma$ ), que no es posible separar con las fases habituales de $\mathrm{C}_{18}$ [122].

La separación de isómeros de vitamina E mediante CEC con fases estacionarias empaquetadas de sílice enlazada ha sido un campo investigado durante los últimos años [123, 124, 125, 126, 127]. Sin embargo, al igual que ocurre en HPLC cuando se emplean fases estacionarias de $\mathrm{C}_{18}$, no se obtiene la selectividad suficiente para resolver los isómeros posicionales $\beta$ y $\gamma$.

[119] S. L. Abidi and T. L. Mounts. RP high-performance liquid chromatographic separations of tocopherols. J. Chromatogr. A, 782:25-32, 1997.

[120] A. Gliszczyńska-Świgło and E. Sikorska. Simple RP LC method for determination of tocopherols in edible plant oils. J. Chromatogr. A, 1048:195-198, 2004.

[121] Directiva 2000/45/Ce de la Comisión, de 6 de julio de 200o, por la que se fijan métodos de análisis comunitarios para la determinación de vitamina A, vitamina E y triptófano en los piensos. Diario Oficial de las Comunidades Europeas, 174:32-50, 13-7-2000.

[122] Norma UNE-EN 12822:2000. Productos alimenticios. Determinación de vitamina E mediante cromatografía líquida de alta resolución. Medición de los tocoferoles alfa-, beta-, gamma- y delta, 2000.

[123] S. L. Abidi and K. A. Rennick. Capillary electrochromatographic evaluation of vitamin E-active oil constituents: tocopherols and tocotrienols. J. Chromatogr. A, 913:379-386, 2001.

[124] C. W. Henry III, C. A. Fortier, and I. M. Warner. Separation of tocopherol isomers using CEC: comparison of monomeric and polymeric $\mathrm{C}_{30}$ stationary phases. Anal. Chem., 73:6077-82, 2001.

[125] S. L. Abidi, S. Thiam, and I. M. Warner. Elution behavior of unsaponifiable lipids with various capillary electrochromatographic stationary phases. J. Chromatogr. A, 949:195-207, 2002.

[126] S. Fanali, P. Catarcini, M. G. Quaglia, E. Camera, M. Rinaldi, and M. Picardo. Separation of $\delta$-, $\gamma$ - and $\alpha$-tocopherols by CEC. J. Pharm. Biomed. Anal., 29:973-979, 2002.

[127] Z. Aturki, G. D'Orazio, and S. Fanali. Rapid assay of vitamin E in vegetable oils by reversed-phase CEC. Electrophoresis, 26:798-803, 2005. 


\section{Columnas monolíticas poliméricas}

Existen pocas referencias que traten de la separación de tocoferoles mediante CEC con columnas monolíticas poliméricas.

Lerma-García et al. [128] optimizan la separación de $\alpha,(\beta+\gamma)$, $\delta$-tocoferol y acetato de $\alpha$-tocoferol en un polímero de lauril metacrilato. Empleann EGDMA como entrecruzador variando la cantidad de 1,4-butanodiol en la mezcla porogénica de disolventes. Utilizan una longitud relativamente corta de fase estacionaria $(8,5 \mathrm{~cm})$, con una fase móvil compuesta por $\mathrm{MeOH} /$ Tris $5 \mathrm{~mm}$ (99/1).

Chaisuawan et al. [129] consiguen la separación de los cuatro tocoferoles y acetato de $\alpha$-tocoferol en 25 min utilizando un monolito basado en estearato de pentaeritritol-diacrilato. Al igual que las fases estacionarias con grupos polares incrustados, el polímero contiene en su estructura cadenas hidrocarbonadas de 17 átomos de carbono junto con grupos polares correspondientes al grupo -OH del pentaeritritol. En su trabajo, el disolvente de la fase móvil desempeña un papel muy importante en la resolución y el orden de retención de los compuestos. Estos autores logran regular la hidrofobicidad de la fase estacionaria por el enmascaramiento del grupo polar debido a los puentes de hidrógeno que forma con el metanol variando la cantidad de metanol en fases móviles formadas por acetonitrilo. La máxima selectividad se obtiene con fases de acetonitrilo sin metanol, con las que se consiguen mayor selectividad y retención de los tocoferoles debido a interacciones hidrofílicas con la fase estacionaria. La resolución para los isómeros $\beta$ y $\gamma$ es muy superior a la que se obtiene con fases estacionarias de $C_{18}$.

[128] M. J. Lerma-García, E. F. Simo-Alfonso, G. Ramis-Ramos, and J. M. Herrero-Martínez. Determination of tocopherols in vegetable oils by CEC using methacrylate ester-based monolithic columns. Electrophoresis, 28:4128-4135, 2007.

[129] P. Chaisuwan, D. Nacapricha, P. Wilairat, Z. Jiang, and N. W. Smith. Separation of $\alpha-$, $\beta-, \gamma-, \delta$ and $\alpha$-tocopherol acetate on a pentaerythritol diacrylate monostearate-ethylene dimethacrylate monolith by CEC. Electrophoresis, 29:2301-2309, 2008. 


\subsection{OBJetivo}

Durante el desarrollo de esta tesis se estudió la utilidad de una fase estacionaria con grupos polares incrustados, llamada comercialmente ULTIMA $\mathrm{C}_{1} 8$, para la separación y resolución de los 4 «isómeros» de vitamina E mediante CEC. Además los resultados se han comparado con los obtenidos con fases enlazadas de $\mathrm{C}_{18}$ y $\mathrm{C}_{30}$. Los resultados y conclusiones de esta investigación se encuentran en la Sección 7.1, «Separación de tocoferoles con columnas empaquetadas» (páginas 85-96).

En esta parte de la memoria también se muestran los resultados obtenidos en la investigación de la síntesis y uso de diferentes fases estacionarias poliméricas monolíticas encaminadas a la separación de tocoferoles. Se empleó BMA como monómero principal, EGDMA como entrecruzador, y una mezcla ternaria de 1,4-butanodiol, 1-propanol y agua como disolvente porogénico, composición basada en los trabajos de Peters et al. [83, 94, 95]. Los resultados y conclusiones de este apartado se encuentran recogidos en la Sección 7.2, «Separación de tocoferoles en columnas poliméricas monolíticas» (páginas 97-112). 


\section{PARTE EXPERIMENTAL}

\subsection{INSTRUMENTAL}

Las separaciones electrocromatográficas se han llevado a cabo en un equipo $\mathrm{HP}{ }^{3 \mathrm{D}} \mathrm{CE}$ de Hewlett Packard, refrigerado por aire, con muestreador automático y detector de absorción Uv-visible de diodos (DAD). El sistema se controla mediante el programa Chemstation (Hewlett Packard), que permite el manejo de todas las funciones del aparato y la recogida de datos del detector. Se han utilizado viales de polipropileno de $1 \mathrm{~mL}$, especialmente adaptados para este equipo.

Se emplearon capilares de sílice fundida de $100 \mu \mathrm{m}$ de diámetro interno y 375 um de diámetro externo, de la casa Polymicro Technologies, suministrados por Composite Metal Services. En el caso de las columnas fabricadas mediante radiación uv se emplearon capilares de sílice recubiertos de teflón transparente.

Se usó un termostato de inmersión de la marca SBS para la polimerización de los capilares, así como una bomba de HPLC de la marca Spectra Physics, modelo SP 880o, para lavar las fases estacionarias fabricadas.

Las fases estacionarias empaquetadas fueron ULTIMA C 18 de $5 \mu \mathrm{m}$, Spherisorb oDS1 de $3 \mu \mathrm{m}$ (nombrada como $\mathrm{C}_{18}$ en la memoria) e $\mathrm{YMC}_{30}$ de $3 \mu \mathrm{m}$, amablemente donadas por el Dr. Walton Caldwell, de Princeton Chromatography, el profesor Peter Myers, de Xtec, y por el Dr. Frank Moffat, de Syngenta, respectivamente. 
Las fritas de retención se fabricaron con un dispositivo consistente en un filamento incandescente regulado electricamente, fabricado por Innovatech. Las partículas de fase estacionaria fueron empaquetadas con la ayuda de una bomba neumática de alta presión y una sonda de ultrasonidos acoplada a un reservorio de acero inoxidable capaz de resistir altas presiones.

\subsection{REACTIVOS Y DisOLUCIONES}

Los patrones de vitamina E fueron de Sigma ( $\alpha, \gamma$ y $\delta$-tocoferol) y Merck ( $\beta$-tocoferol). Se prepararon disoluciones madre de todos los patrones en metanol con una concentración de $1000 \mathrm{mg} / \mathrm{L}$, a partir de las cuales se obtuvieron, por dilución, las disoluciones de trabajo (100 mg/L en metanol), a las que se le añadieron pequeñas cantidades de tiourea como marcador del flujo electro-osmótico (EOF). Todas las disoluciones se almacenaron a $4{ }^{\circ} \mathrm{C}$ en ausencia de luz.

Los disolventes acetonitrilo y metanol fueron de Merck con calidad para HPLC. El agua se obtuvo mediante un sistema de purificación de agua Elgastat UHQ.

Para la preparación de los electrolitos de separación se emplearon hidrogeno fosfato sódico, dihidrógeno fosfato sódico, y 2-amino-2-(hidroximetil)-1,3propanodiol (Tris); todos de Panreac. El resto de reactivos empleados para la preparación de tampones y demás disoluciones fueron de calidad «reactivo analítico».

Para la preparación de las fritas de retención en columnas empaquetadas fue necesario el uso de una disolución de silicato sódico (27\% de $\mathrm{SiO}_{2}$, Sigma) y partículas de $\mathrm{SiO}_{2}$ de $3 \mu \mathrm{m}$.

Los monómeros necesarios para la formación de polímeros fueron metacrilato de butilo (BMA, 99\%, de Aldrich), ácido metacrílico (99,5\%, de Acros Organics), dimetacrilato de etileno (98\%, de Aldrich) y ácido 2-acrilamido2-metil-1-propanosulfónico (AMPS).

Se emplearon como disolventes porogénicos 1,4-butanodiol (99\%, de Riedelde Haën), 1-propanol (99,9\%, de Riedel-de Haën) y agua (calidad UHQ). 
Se utilizó metacrilato de 3-(trimetoxisilil)propilo ( $\gamma$-MAPS, de Fluka) como derivatizante de la pared del capilar y 2,2'-Azobis(2-metil-propionitrilo), (AIBN, de Acros Organics) como iniciador.

\subsection{PROCEDIMIENTOS}

\subsubsection{Fabricación de columnas capilares empaquetadas}

Formación de fritas de retención

El proceso consta del sinterizado mediante altas temperaturas de un agregado de partículas de sílice introducidas en la punta de un capilar de unos $35 \mathrm{~cm}$ de longitud. Hay que formar una pasta con partículas microscópicas de $\mathrm{SiO}_{2}$ (3 ó $5 \mu \mathrm{m}$ ) y una disolución comercial de silicato sódico (aproximadamente tres partes de sílice por una de disolución). En un vial se añade una punta de espátula de $\mathrm{SiO}_{2}$ y se le va añadiendo gota a gota la disolución de silicato sódico removiendo con una espátula hasta formar una pasta que se despega de las paredes del vial. Un extremo del capilar se golpea repetidas veces contra la pasta creada para forzar la introducción de una pequeña cantidad (200-500 $\mu \mathrm{m})$ en la punta.

El extremo con la sílice se calienta durante unos segundos con un dispositivo eléctrico compuesto de un filamento metálico incandescente en forma de bobina a través del cual se introduce el extremo del capilar. En este punto es importante el control del tiempo y de la temperatura del filamento; demasiado tiempo o temperatura dan como resultado fritas no permeables.

Con un microscopio se comprueba si la frita es lo suficientemente porosa para permitir un rápido proceso de empaquetado. Mediante el acoplamiento del capilar a una bomba de HPLC se le hace pasar agua a una presión aproximada de 200-250 bar. Se debe obtener un abundante esprái que cesa segundos después de apagar la bomba. Tras retirarlo de la bomba, se comprueba en el microscopio que la frita sigue en su sitio y no ha sido expulsada. Como ya se ha indicado, la fabricación de las fritas es uno de los pasos más importantes en la construcción de columnas capilares empaquetadas y del 
que va a depender en buena medida el éxito del empaquetamiento y la buena eficacia de la columna.

\section{Empaquetamiento}

Para empaquetar satisfactoriamente una columna hay que introducir una suspensión de fase estacionaria lo más rápidamente posible en un capilar vacío. El montaje instrumental se muestra en la Figura 6.1.

Una de las partes más importantes es la cámara de ultrasonidos (Figura 6.2). Esta cámara tiene un volumen aproximado de $4 \mathrm{~mL}$ y se emplea para mantener la suspensión de fase estacionaria durante el proceso de empaquetamiento. El disolvente es impulsado hacia la cámara mediante una bomba

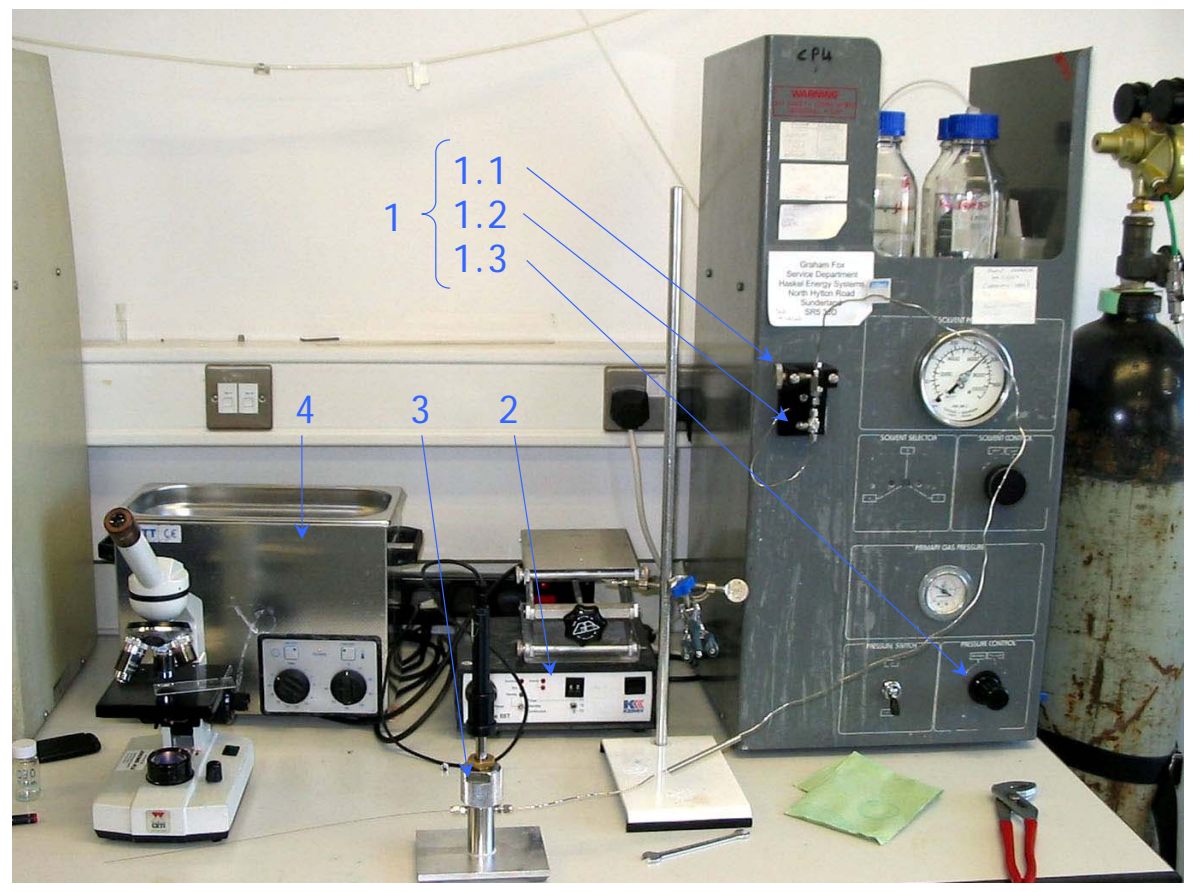

Figura 6.1. Instrumental necesario para empaquetar capilares con fases estacionarias. 1: Bomba. 1.1: Filtro. 1.2: Restrictor. 1.3: Regulador de presión. 2: Generador de ultrasonidos. 3: Sonda de ultrasonidos y depósito de fase estacionaria. 4: Baño de ultrasonidos. 


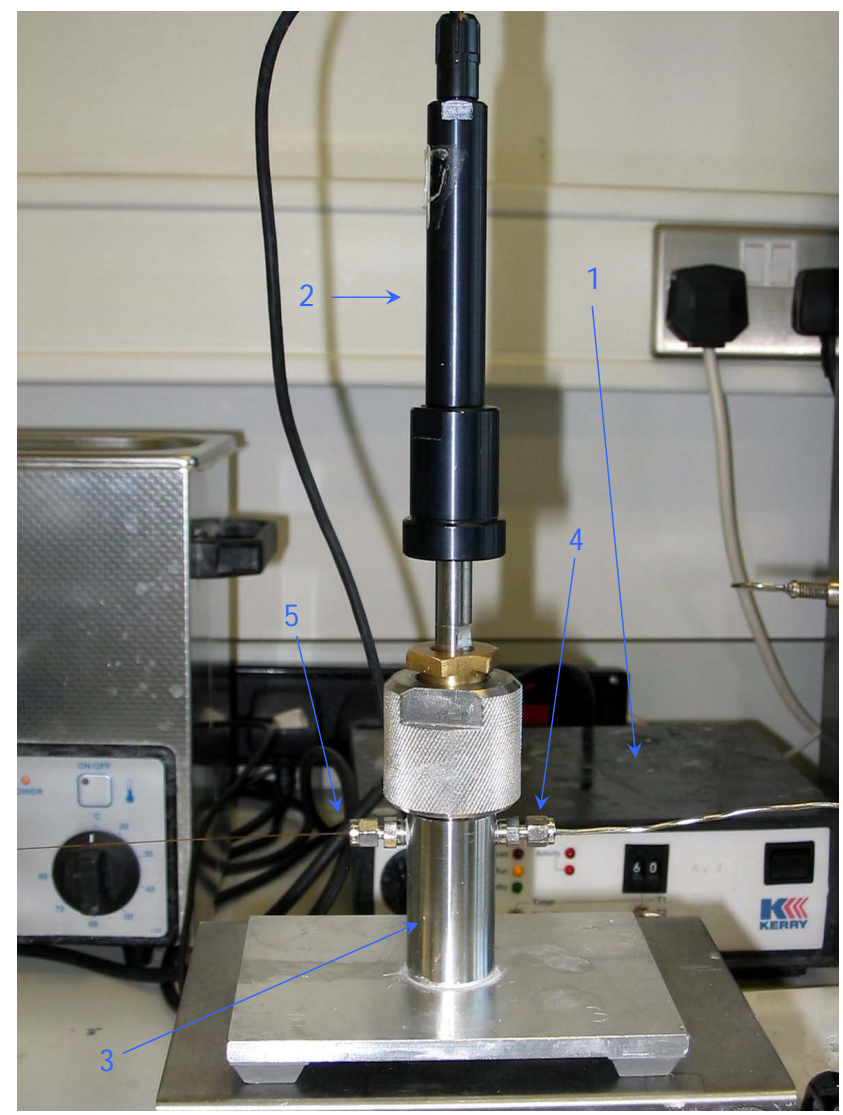

Figura 6.2. Cámara de ultrasonidos. 1: Generador de ultrasonidos. 2: Sonda. 3: depósito de la suspensión. 4: Entrada desde la bomba. 5: Capilar que va a ser empaquetado.

neumática de alta presión y la suspensión es forzada a salir de la cámara para introducirse en el capilar. Existe un filtro de 0,5 $\mu \mathrm{m}$ entre la bomba y la cámara de ultrasonidos para evitar que la fase estacionaria retroceda y dañe la bomba y para evitar que residuos del mecanismo de la bomba contaminen la suspensión de fase estacionaria. Un restrictor permite purgar el sistema y reducir lentamente la presión al final del proceso de empaquetamiento para evitar agitar el lecho empaquetado.

Un capilar de $35 \mathrm{~cm}$ con una frita en un extremo se une directamente al depósito que contiene la suspensión de fase estacionaria, con el extremo del 
capilar colocado en el centro del depósito. En el otro extremo está la frita que permite el paso de disolvente, pero no el de fase estacionaria.

La suspensión de fase estacionaria suele ser de una "concentración» aproximada del $10 \%$ en acetona o isopropanol. La suspensión se almacena en frascos de vidrio y es sonicada por lo menos $15 \mathrm{~min}$ antes de introducirla en la cámara de ultrasonidos, para deshacer los agregados que pudieran haberse formado. Una vez que la cámara de ultrasonidos se ha llenado con la suspensión, ésta se cierra y la sonda se enciende para mantener las partículas suspendidas.

La bomba se conecta y se hace pasar acetona. La presión se hace subir desde cero comprobando que no existen fugas en ningún punto del sistema, para subir la presión hasta 690 bar a continuación. La suspensión es forzada a salir de la cámara y fluir por el capilar a gran velocidad. Un empaquetamiento rápido es esencial para reducir la probabilidad de huecos en el seno del lecho de fase estacionaria y conseguir una columna de gran eficacia. Para lograrlo es importante disponer de una adecuada concentración de fase estacionaria y de una frita lo más permeable posible. Se puede conseguir empaquetar una columna en tan sólo $10 \mathrm{~min}$, aunque en ocasiones este proceso puede durar más de $2 \mathrm{~h}$. Si es posible, el capilar se sumerge en un baño de ultrasonidos durante el proceso para lograr un mayor grado de empaquetamiento.

Una vez que se tiene empaquetada una longitud de $26 \mathrm{~cm}$ aproximadamente, la bomba se apaga, y se deja bajar la presión muy lentamente. Como este proceso puede durar varias horas, bien se deja toda la noche, o la presión se libera con mucho cuidado y muy lentamente con la ayuda del restrictor. Este paso es importante, ya que una variación violenta de la presión tiene como consecuencia un retroceso brusco del flujo y el desordenamiento del empaquetamiento formado.

Cuando la presión ha disminuido a cero, la suspensión restante se recupera con una pipeta para ser usada de nuevo en otra ocasión. La cámara se retira y el capilar se conecta directamente a la bomba tras purgar las conducciones con agua. La columna creada se lava con agua durante varias horas (toda la noche si es posible) a 400-500 bar. 
La segunda frita de retención sólo puede hacerse con agua como disolvente, y con altas presiones (69obar) mientras el agua está fluyendo. Para ello se utiliza el filamento incandescente empleado para fabricar la primera frita, por el cual se introduce el capilar hasta la longitud deseada (unos $24,5 \mathrm{~cm}$ de fase estacionaria). El capilar se calienta en el punto deseado durante unos $4 \mathrm{~s}$. En esta ocasión es la propia fase estacionaria la que se funde para formar la frita. Una vez formada la segundo frita, se libera la presión, la columna se retira y se vuelve a colocar en la dirección opuesta, de modo que el agua fluya desde la primera frita hacia la segunda con una presión aplicada de 690 bar. Este paso tiene como objetivo eliminar el empaquetamiento que queda entre la segunda frita y el extremo abierto del capilar, y comprimir el lecho de fase estacionaria. En este momento, la compresión puede conducir a la existencia de un vacío en el extremo del capilar correspondiente a la primera frita que se puede observar con la ayuda del microscopio, por lo que a veces es necesario quemar una nueva frita a poca distancia del primero y cortar la sección vacía. En la Figura 6.3 se muestra un detalle de la frita del extremo con el capilar empaquetado.

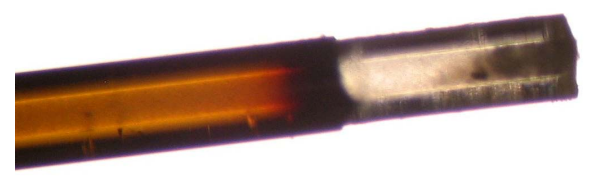

Figura 6.3. Extremo de un capilar empaquetado y frita de retención

\section{Fabricación de la ventana}

Cuando se ha comprobado que el excedente de fase estacionaria ha sido retirado de la zona adyacente a la segunda frita, tiene lugar el quemado de la ventana de detección con la ayuda del filamento incandescente mientras el agua sigue fluyendo.

Las columnas así fabricadas pueden almacenarse durante varias semanas manteniendo los extremos sumergidos en viales con agua sellados para evitar su secado. 


\subsubsection{Fabricación de columnas monolíticas}

Derivatización de la pared del capilar

$3 \mathrm{~m}$ de capilar de sílice fundida se colocan en el equipo de CE. Disponiendo los reactivos adecuados en viales, se hacen pasar a 4 bar por el interior del capilar $\mathrm{NaOH} 1 \mathrm{~m}$ durante $10 \mathrm{~min}$, agua destilada durante $10 \mathrm{~min}, \mathrm{HCl}$ o, $1 \mathrm{M}$ durante $10 \mathrm{~min}$, agua destilada durante $10 \mathrm{~min}$, acetona durante $10 \mathrm{~min}$ y aire durante $5 \mathrm{~min}$ desde un vial vacío. A continuación se le pasa una mezcla $\gamma$-MAPs/acetona (1/4) durante $15 \mathrm{~min}$. El capilar lleno con la mezcla derivatizante se deja toda la noche a temperatura ambiente. Al día siguiente se lava con acetona, agua y aire (10 minutos cada una a 4 bar). El capilar ya seco se conserva con los extremos tapados con dos septos de silicona y se va cortando según se necesite.

\section{Preparación de la mezcla porogénica}

La Tabla 6.1 muestra la composición y las cantidades necesarias de reactivos para la fabricación de las columnas poliméricas. En primer lugar es necesario disolver las cantidades adecuadas del monómero iónico (AMPS) en agua ultrapura. A continuación, en un vial de $10 \mathrm{~mL}$ se pesan con la ayuda de una pipeta pasteur directamente en una balanza las cantidades indicadas de EGDMA, BMA, 1-propanol, 1,4-butanodiol, y la disolución acuosa de AMPs. A este vial se le añade el iniciador (AIBN), se cierra, se homogeneiza y se introduce en un baño de ultrasonidos hasta la completa disolución del AIBN. Esta mezcla puede conservarse refrigerada durante una semana.

\section{Polimerización}

En primer lugar la mezcla se desgasifica en un baño de ultrasonidos o borboteando $\mathrm{N}_{2}$ durante $15 \mathrm{~min}$. Con la ayuda de una jeringa se rellena parcialmente la longitud deseada de $35-40 \mathrm{~cm}$ de capilar tratado con $\gamma$-MAPs dejando el otro extremo vacío, y se sella cada extremo con un trozo de septo de silicona. Se sumerge durante $60 \mathrm{~min}$ en un baño termostatado a $60^{\circ} \mathrm{C}$. Transcurrido este tiempo se sumerge el capilar en agua fría para detener 
Tabla 6.1. Composición y cantidades de reactivos para la fabricación del polímero de butil metacrilato empleado como fase estacionaria en CEC.

\begin{tabular}{|lllll|}
\hline & & Compuesto & $(\%, \mathrm{p} / \mathrm{p})$ & Peso $/ \mathrm{g}$ \\
\hline \multirow{2}{*}{ Monómeros } & $46,0 \%$ & BMA & $40,0 \%$ & 1,791 \\
& & EGDMA & $59,7 \%$ & 1,200 \\
& & AMPs & $0,30 \%$ & $0,3612^{a}$ \\
\hline \multirow{2}{*}{ Disolventes } & $54,0 \%$ & 1-propanol & $62,0 \%$ & 2,184 \\
& & 1,4 -butanodiol & $28,0 \%$ & 0,9861 \\
\hline Iniciador & $1 \%$ de los monómeros & AIBN & $10,0 \%$ & $0,3612^{a}$ \\
\hline
\end{tabular}

${ }^{a}$ Cantidad de una disolución de $0,1278 \mathrm{~g}$ de AMPs en $5 \mathrm{~g}$ de agua ultrapura.

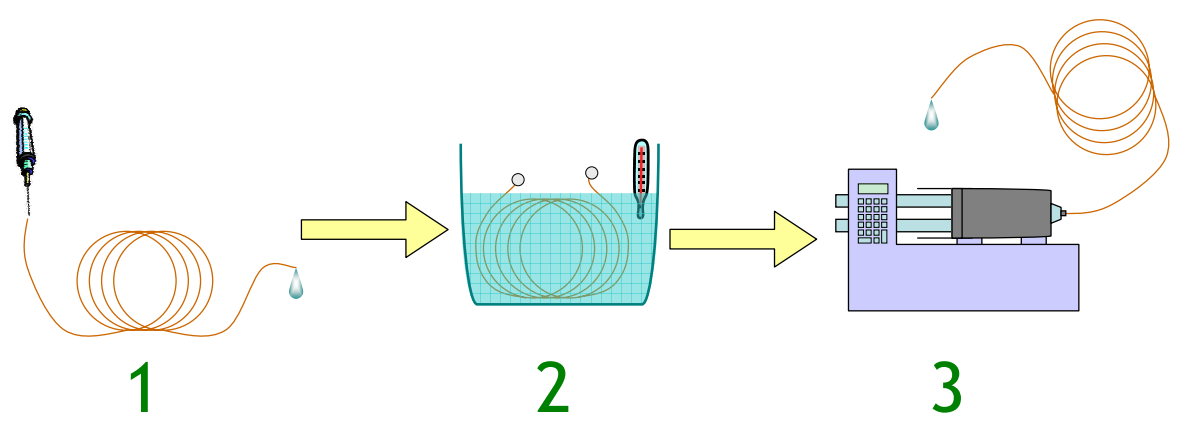

Figura 6.4. Esquema de la fabricación de fases estacionarias poliméricas monolíticas; 1) llenado del capilar con la mezcla porogénica de monómeros, iniciador y disolventes, 2) polimerización iniciada térmicamente, y 3) lavado a presión. 
la polimerización y se le cortan con una pieza de cerámica $0,5 \mathrm{~cm}$ a cada extremo.

Con la ayuda de una férrula de grafito para GC, se acopla la columna creada a una bomba de HPLC y se arrastran los reactivos y disolventes con unos 20 volúmenes de capilar (unos $60 \mu \mathrm{L}$ ) de metanol con una presión de 300400 bar.

Una vez lavado el capilar, y sin permitir que se seque el interior, se corta dejando la longitud deseada de fase estacionaria, y con una cuchilla se retiran $2 \mathrm{~mm}$ del polímero protector en la sección vacía, cortando el capilar por ese extremo dejando $8,5 \mathrm{~cm}$ desde la ventana de detección, de modo que la longitud total sea de $33 \mathrm{~cm}$.

\subsubsection{Separación de vitamina E mediante CEC con columnas empaquetadas}

Las columnas se acondicionan por primera vez, y siempre que se cambie de fase móvil, aplicando una presión de 8 bar en los viales de entrada y salida mientras se aplica la siguiente rampa de voltaje: $5 \mathrm{kV}$ durante los primeros 5 min y de $5 \mathrm{kV}$ hasta $30 \mathrm{kV}$ durante $30 \mathrm{~min}$. Se deja a $30 \mathrm{kV}$ hasta la obtención de una línea base y una corriente estables. La longitud de onda de detección fue de $205 \mathrm{~nm}$.

En todos los análisis se aplicó una presión de 8 bar en los viales de entrada y salida para evitar la formación de burbujas. La inyección fue hidrodinámica (8 bar durante 0,5 min) seguido de un bolo de fase móvil (8bar durante $0,3 \mathrm{~min}$ ). Se añadió tiourea a todas las muestras como marcador del flujo electroosmótico (EOF).

Todas las fases móviles consistieron en Tris $5 \mathrm{~mm}$. Estas disoluciones fueron preparadas diluyendo 20 veces una disolución $200 \mathrm{~mm}$ de Tris en metanol con los disolventes apropiados (metanol, acetonitrilo o agua). Las fases móviles se prepararon diariamente y fueron sonicadas antes de usarse. 


\subsubsection{Separación de vitamina E mediante CEC con columnas monolíticas}

Las columnas se acondicionan siguiendo el procedimiento indicado en la Sección 6.3.3. Durante los análisis también se aplicó presión para evitar la formación de burbujas. Todas las separaciones se llevaron a cabo a $30^{\circ} \mathrm{C}$ con voltajes que oscilaron entre 4 y $30 \mathrm{kV}$.

La inyección es electrocinética ( $30 \mathrm{kV}$ durante $3 \mathrm{~s}$ ). La fase móvil utilizada está formada por acetonitrilo y agua en distintas proporciones (oscila entre el 20 y el $30 \%$ de agua para una separación óptima). La concentración total de sales es de $5 \mathrm{~mm}$ de tampón fosfato a $\mathrm{pH} 7,2$. 



\section{RESULTADOS Y DISCUSIÓN}

\subsection{SEPARACIÓN DE TOCOFEROLES CON COLUMNAS EMPAQUETADAS}

En esta sección se detallan los resultados obtenidos empleando una fase estacionaria con grupos polares incrustados, llamada comercialmente ULTIMA $\mathrm{C}_{1} 8$, para la resolución los 4 tocoferoles $\alpha, \beta, \gamma$ y $\delta$ mediante CEc. Estos resultados se comparan con los obtenidos usando fases enlazadas de $\mathrm{C}_{18}$ y $\mathrm{C}_{30}$. La fase estacionaria ULTIMA $\mathrm{C}_{1} 8$ está formada por un grupo amido situado entre un espaciador y una cadena de 15 átomos de carbono. La estructura se muestra en la Figura 7.1.

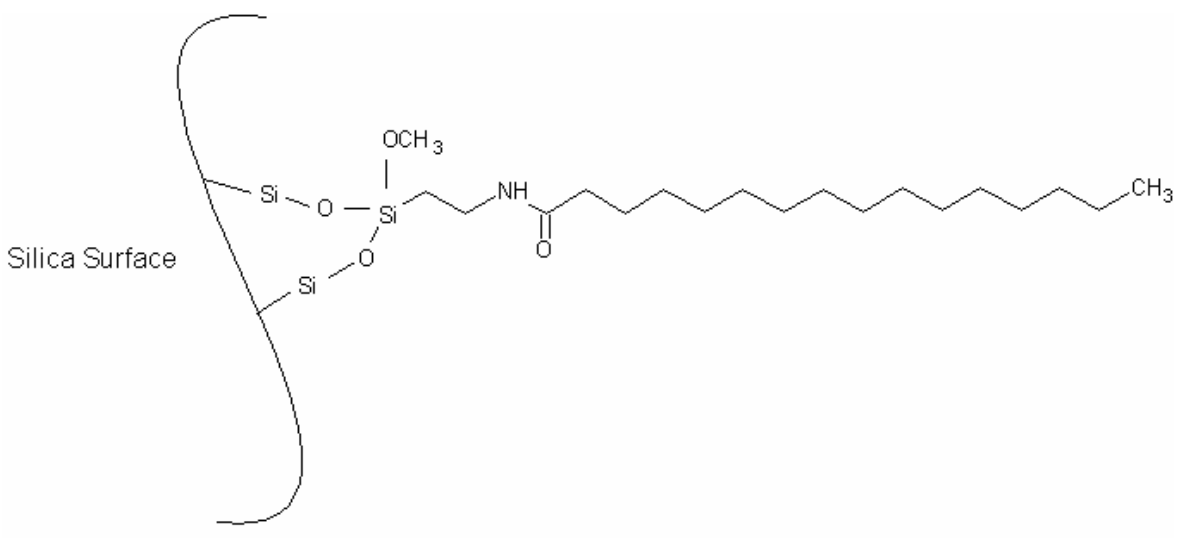

PrincetonSPHER ULTIMA C18

Figura 7.1. Estructura de la fase estacionaria ULTIMA C18, suministrada por el fabricante. 


\subsubsection{Efecto de la composición de la fase móvil en medios no acuosos}

Con las 3 fases estacionarias investigadas (ULTIMA $\mathrm{C}_{1} 8, \mathrm{C}_{18} \mathrm{Y} \mathrm{C}_{30}$ ) se llevó a cabo un estudio de la separación de los tocoferoles $\alpha, \gamma$ y $\delta$ utilizando una fase móvil con diferentes proporciones de acetonitrilo y metanol y manteniendo constante el contenido de sales (Tris $5 \mathrm{~mm}$ ).

Todos los parámetros de este estudio se determinaron a partir de los datos experimentales obtenidos al realizar tres inyecciones en cada una de las condiciones. Los factores de retención $\left(k_{i}\right)$ se determinaron con la ecuación $k_{i}=\left(t_{i}-t_{0}\right) / t_{0}$, donde $t_{i}$ y $t_{0}$ son los tiempos de retención de cada analito y de la tiourea, respectivamente. La resolución entre dos picos consecutivos ( $i$ y $j$ ) viene dada por la expresión $R_{\mathrm{s}(i-j)}=(2.35 / 2)\left[\left(t_{j}-t_{i}\right) /\left(W_{i}-W_{j}\right)\right]$, donde $W_{i}$ y $W_{j}$ son las anchuras de los picos de los analitos $i$ y $j$ en la mitad de su altura.

En la Figura 7.2 se muestran las representaciones de los tiempos de retención, los factores de retención y la resolución en función de la composición de fase móvil.

Se observa que el tiempo de retención de la tiourea (marcador del EOF) disminuye (aumenta el EOF) según aumenta la proporción de acetonitrilo en la fase móvil. En CEC, la fuerza impulsora de la fase móvil es el flujo electroosmótico (EOF). Como éste depende de la relación $\epsilon / \rho$ (constante dieléctrica/viscosidad) de la fase móvil, un incremento de la porción de acetonitrilo en la fase móvil se acompaña de un aumento del Eof debido la mayor relación $\epsilon / \rho$ del acetonitrilo con respecto al metanol. A pesar de que el acetonitrilo parece ser una buena elección como fase móvil para CEC, debido a que proporciona caudales más altos, es peor eluyente que el metanol para los compuestos estudiados en cualquiera de las fases estacionarias investigadas. Los tiempos de retención de los tocoferoles aumentan cuando se trabaja con porcentajes de acetonitrilo superiores al 50-60\%, sin que aumente el tiempo del marcador del EOF. Este efecto es mucho más acusado en la fase con grupos polares incrustados ULTIMA $C_{1} 8$, probablemente debido a que el metanol es mejor eluyente de compuestos que presentan interacciones polares. Resultados similares han sido encontrados por Fanali et al. [126] y Abidi et al. [125]. 


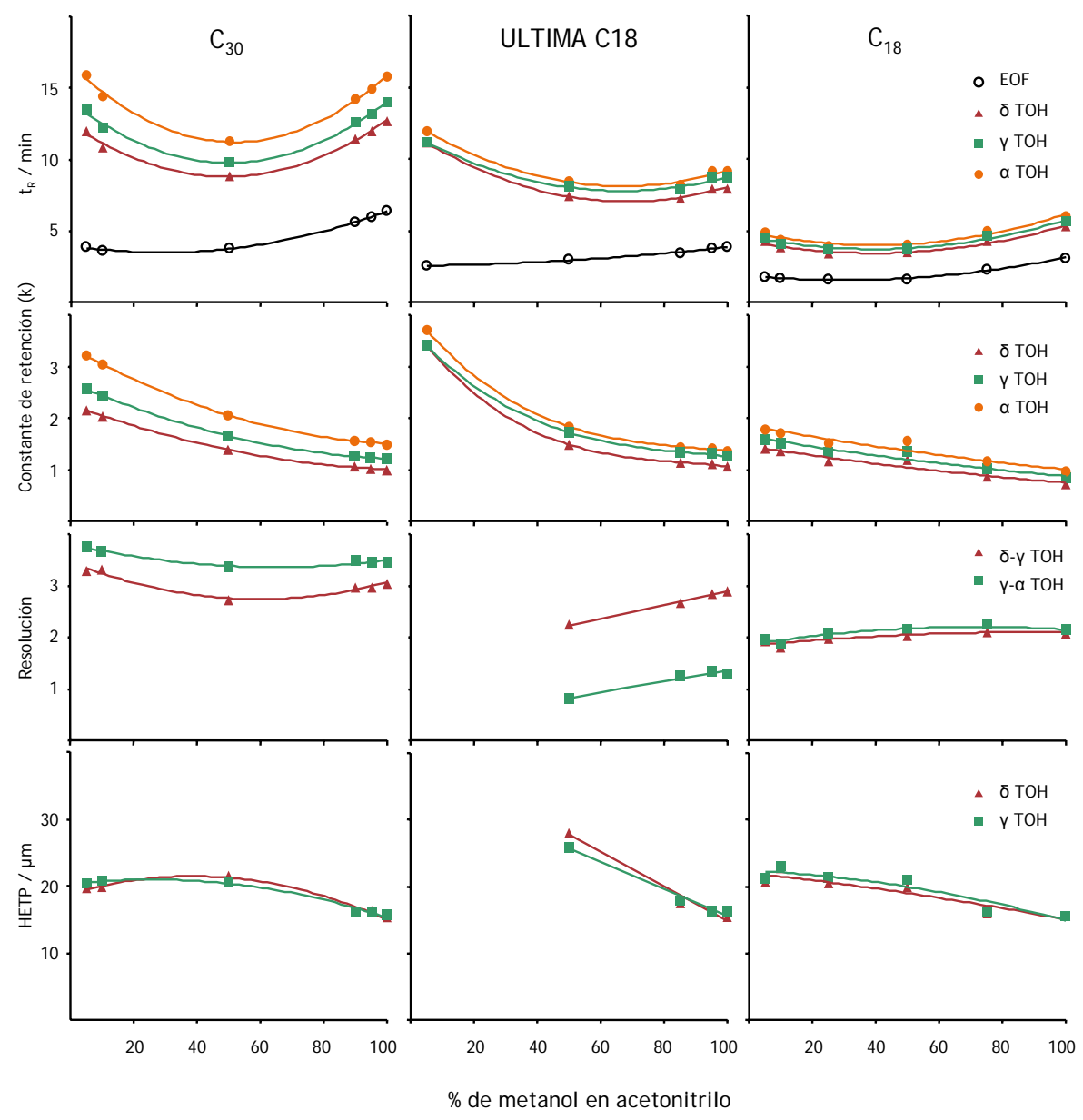

Figura 7.2. Efecto de la composición de la fase móvil (\% de metanol en acetonitrilo) en el tiempo de retención, factores de retención, resolución y eficacia en la separación de los tocoferoles $\alpha, \gamma$ y $\delta$, usando las tres fases estacionarias estudiadas. 
Las tres fases mostraron la máxima eficacia (altura mínima de plato teórico de $15 \mu \mathrm{m}$ ) con el $100 \%$ de metanol. La Figura $7 \cdot 3$ muestra un cromatograma de las tres fases estudiadas cuando se utiliza metanol como fase móvil.

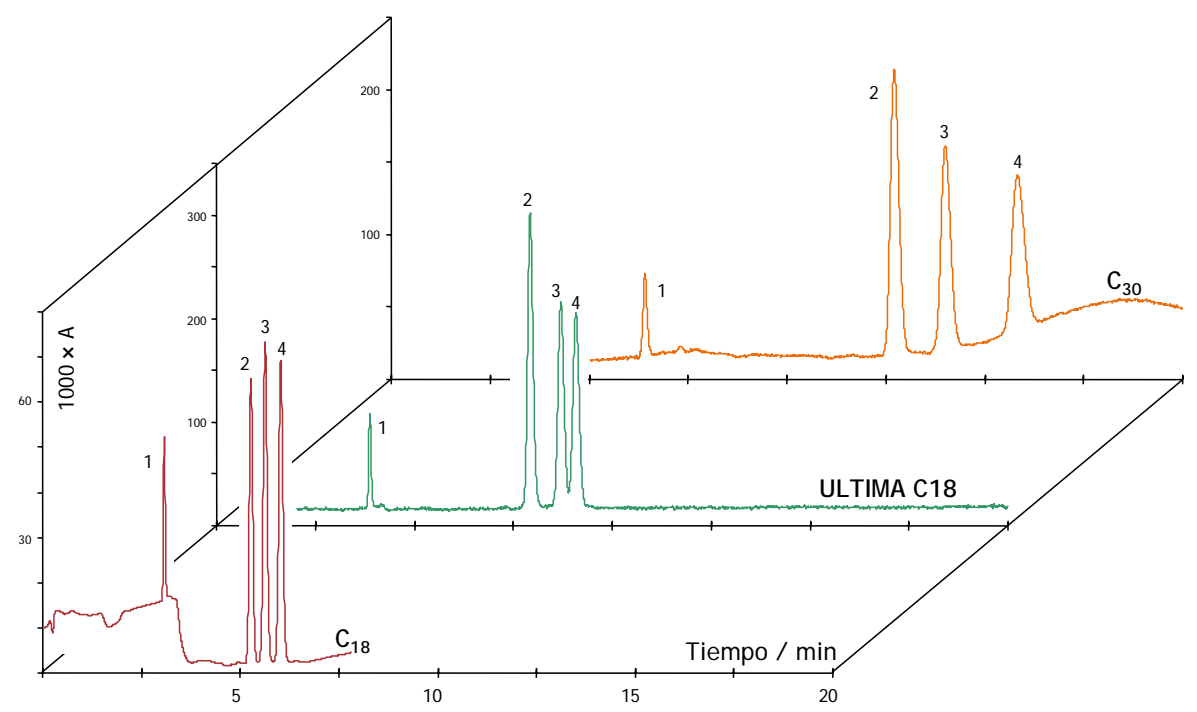

Figura 7.3. Separación de $\alpha, \gamma$ y $\delta$ tocoferoles con las fases estacionarias $C_{18}$, ULTIMA C18 y $\mathrm{C}_{30}$. Fase móvil: Tris $5 \mathrm{~mm}$ en metanol. Separación a $30 \mathrm{kV}$, $30^{\circ} \mathrm{C}$. Picos: 1 , tiourea; $2, \delta$-tocoferol; $3, \gamma$-tocoferol; y $4, \alpha$-tocoferol.

Con las fases estacionarias alquílicas lineales $\left(\mathrm{C}_{18}\right.$ y $\left.\mathrm{C}_{30}\right)$ el cambio de metanol a acetonitrilo no implica una pérdida de resolución; los valores de resolución se mantuvieron más o menos constantes, consiguiéndose una buena separación de los tres compuestos en todo el intervalo estudiado. Como es lógico, los tiempos de retención y la resolución entre los compuestos fueron superiores con la fase estacionaria de $\mathrm{C}_{30}$.

Por el contrario, se observó una diferencia significativa entre los dos disolventes cuando se usa la fase estacionaria con grupos polares incrustados ULTIMA C18. Con acetonitrilo como disolvente principal en lugar de metanol, los picos son menos reproducibles, más anchos y peor definidos, con sólo dos picos superpuestos para los tres compuestos (Figura 7.4-A). La eficacia y la resolución mejoran notablemente según aumenta el contenido de metanol, y se consigue una buena separación de los tres tocoferoles, con buenas 
formas de pico, empleando fases móviles con menos del 50\% de acetonitrilo. Los tiempos de retención con esta fase estacionaria son superiores a los obtenidos en la fase de $C_{18}$ e inferiores a los de la fase de $C_{30}$. Es interesante señalar que con la fase estacionaria con grupos polares, los tocoferoles, que son muy poco polares, son retenidos más fuertemente que en una fase común de $\mathrm{C}_{18}$. Este comportamiento se puede atribuir a interacciones con el grupo amido incrustado en la fase estacionaria, adicionales a las hidrofóbicas correspondientes a la interacción con la parte alquílica lineal. Existen referencias de que estas fases estacionarias con grupos polares incrustados presentan una mayor retención de compuestos fenólicos como resultado de su capacidad de formar puentes de hidrógeno $[71,70]$.

Otra diferencia reseñable en el comportamiento de la fase estacionaria con grupos polares con respecto a la de $C_{18}$ es que la resolución entre los tocoferoles $\gamma$ y $\alpha$ nunca llega a ser hasta la línea base $\left(R_{\mathrm{s}}>1,5\right)$. Sin embargo, con todas las fases móviles estudiadas sí es posible separar estos compuestos en la fase estacionaria de $\mathrm{C}_{18}$.

\subsubsection{Separación de los isómeros $\beta$ y $\gamma$ en una fase estacionaria con grupos polares incrustados}

Normalmente los tocoferoles más difíciles de separar con fases inversas son los isómeros de posición $\beta$ y $\gamma$. Para estos isómeros no existe selectividad alguna en fases de cadenas alquílicas lineales de $C_{8} \circ C_{18}$, y poca en fases más largas. [119, 120].

Para comprobar la utilidad de la fase ULTIMA C18 en la separación los isómeros $\beta$ y $\gamma$, se inyectaron disoluciones de los 4 tocoferoles $(\alpha, \beta, \gamma \mathrm{y}$ $\delta)$. Los mismos experimentos se llevaron a cabo también en la fase de $C_{30}$ con fines comparativos. Se ensayaron fases móviles no acuosas basadas en mezclas de metanol y acetonitrilo. En la Tabla 7.1 se muestra la resolución entre dichos isómeros en función de la composición de la fase móvil.

Cuando se trabaja con la fase ULTIMA C18, la presencia de elevados porcentajes de acetonitrilo en la fase móvil origina un deterioro de la separación de todos los tocoferoles (Figura 7.4), impidiendo el cálculo de los valores de re- 


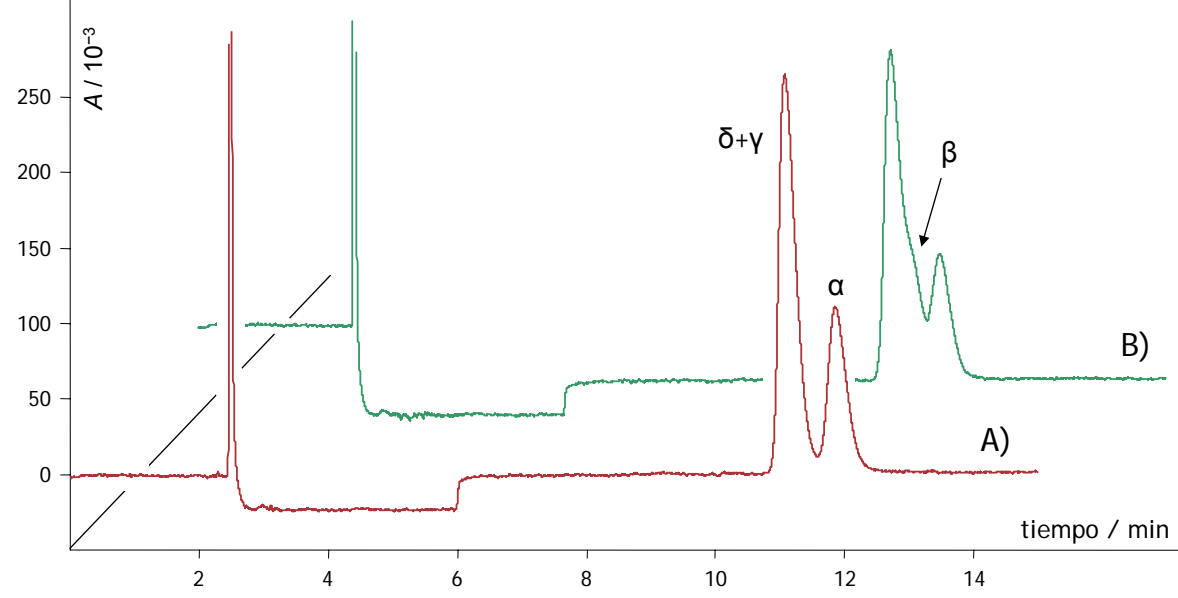

Figura 7.4. Separación en la fase estacionaria ULTIMA C18 de A) $\alpha, \gamma$ y $\delta$ tocoferoles; B) $\alpha, \beta, \gamma$ y $\delta$ tocoferoles. Fase móvil: acetonitrilo/metanol (95/5), Tris $5 \mathrm{~mm}$.

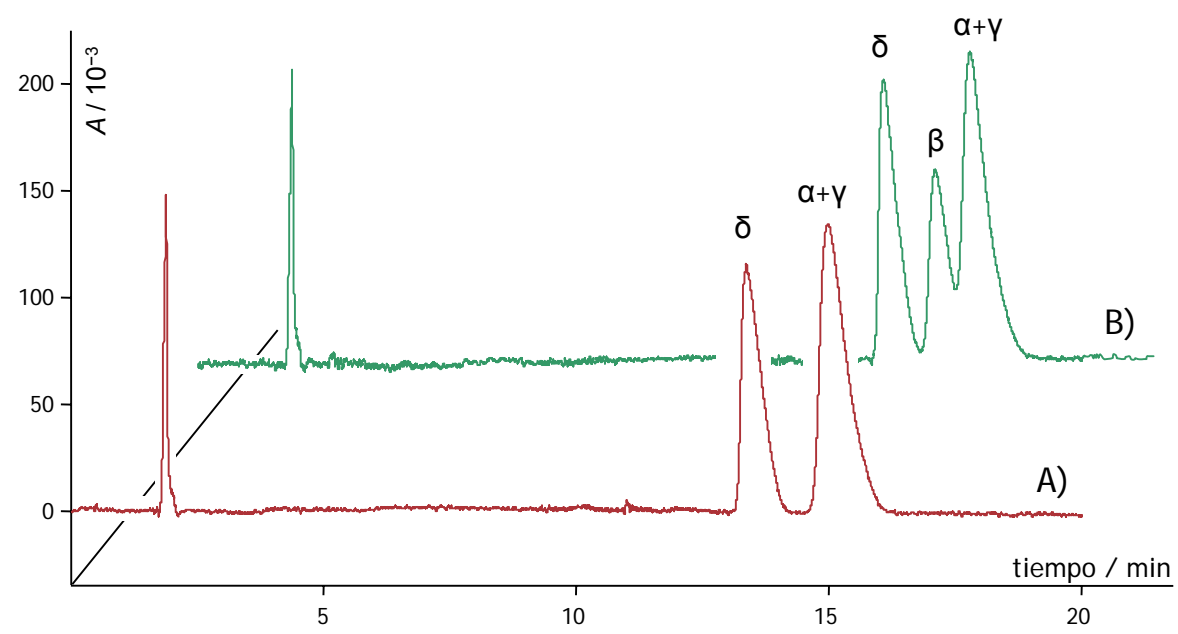

Figura 7.5. Separación en la fase estacionaria ULTIMA C18 de A) $\alpha, \gamma$ y $\delta$ tocoferoles; B) $\alpha, \beta, \gamma$ y $\delta$ tocoferoles. Fase móvil: acetonitrilo/agua $(95 / 5)$, Tris $5 \mathrm{~mm}$. 
Tabla 7.1. Resolución entre los tocoferoles $\beta$ y $\gamma$ en las fases ULTIMA $\mathrm{C}_{1} 8$ y $\mathrm{C}_{30}$. Fase móvil: metanol y acetonitrilo en diferentes proporciones, Tris $5 \mathrm{~mm}$.

\begin{tabular}{|llcccccc|}
\hline & & \multicolumn{8}{c|}{ \% de metanol en acetonitrilo } \\
Fase estacionaria & $R_{\mathrm{S}}$ & 5 & 10 & 50 & 90 & 95 & 100 \\
\hline C $_{30}$ & $\gamma-\beta$ & 0,95 & 0,87 & 0,71 & 0,80 & 0,86 & 0,84 \\
ULTIMA C18 & $\beta-\gamma$ & - & - & - & 0,52 & 0,49 & 0,57 \\
\hline
\end{tabular}

solución cuando el porcentaje de acetonitrilo es superior al $50 \%$. Cuando se trabajó empleando una fase móvil compuesta por acetonitrilo/agua (95/5) no se obtuvieron resultados mejores (Figura 7.5). Los tocoferoles $\alpha, \gamma$ y $\delta$ siguieron saliendo agrupados en dos únicos picos; sin embargo, lo hicieron de manera diferente, con un cambio en sus tiempos relativos de retención (compárense las Figuras 7.4 y 7.5). Este mismo comportamiento, aunque en menor medida y con mayores eficacias, también se observa cuando se aumenta el metanol en la fase móvil; se pasa de no existir separación entre $\delta$ y $\gamma$, hasta su completa resolución, que llega a ser mayor que la existente entre los tocoferoles $\gamma$ y $\alpha$, que nunca llega a ser completa (Figuras 7.3 y 7.6).

Un análisis de los resultados obtenidos indica que, si bien hay cierta selectividad y separación de los isómeros $\beta$ y $\gamma$ en la fase ULTIMA C18, la resolución obtenida con la fase de $C_{30}$ es en todo momento superior. Los tiempos de retención son mayores en la fase $C_{30}$ que en la ULTIMA $C_{1} 8$, como cabe esperar de una mayor retención debida a interacciones hidrofóbicas. Las separaciones obtenidas no llegan a ser totales, dando lugar a picos parcialmente resueltos. La Figura 7.6 muestra la separación en ambas columnas con una fase móvil compuesta por metanol y Tris $5 \mathrm{~mm}$.

Merece la pena destacar que el orden de elución de los isómeros $\beta$ y $\gamma$ es diferente en las dos fases utilizadas: $t_{\mathrm{R}(\beta)}>t_{\mathrm{R}(\gamma)}$ en la fase con grupos polares, mientras que $t_{\mathrm{R}(\gamma)}>t_{\mathrm{R}(\beta)}$ en la fase $\mathrm{C}_{30}$. Este comportamiento confirma la participación de mecanismos de retención adicionales a los puramente hidrofóbicos, que predominan en la fase $\mathrm{C}_{30}$. 


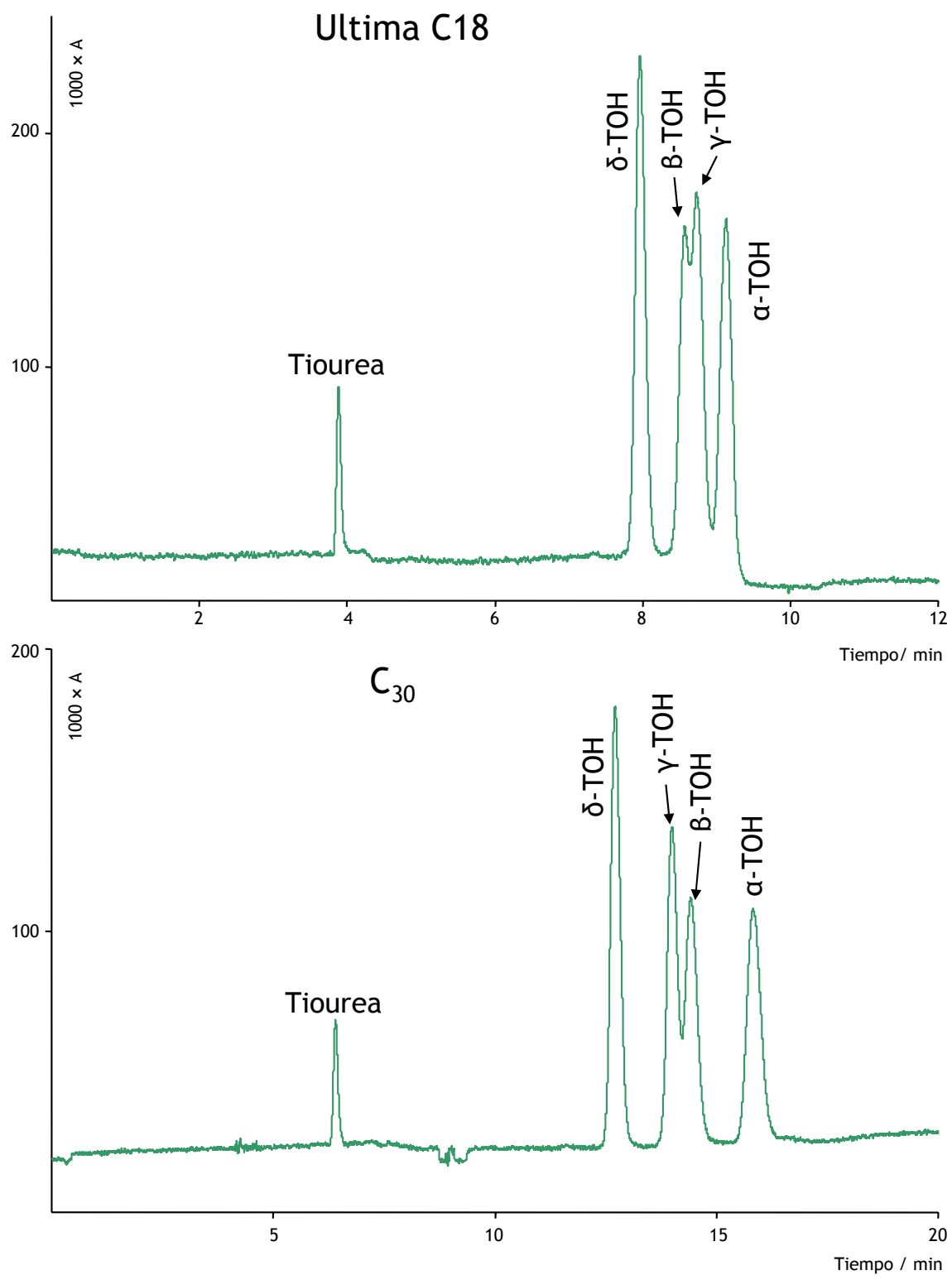

Figura 7.6. Separación de $\alpha, \beta, \gamma$ y $\delta$ tocoferoles con las fases estacionarias, ULTIMA C18 y $\mathrm{C}_{30}$. Fase móvil: Tris $5 \mathrm{~mm}$ en metanol. Separación a $30 \mathrm{kV}$, $30^{\circ} \mathrm{C}$. 
En un intento de conseguir una separación más efectiva de los 4 tocoferoles en la fase ULTIMA $\mathrm{C}_{1} 8$, se aumentó gradualmente el contenido de agua en una fase móvil de metanol. Se consiguió una buena separación de los 4 compuestos $\left(R_{\mathrm{s}(\beta, \gamma)}=1,2\right)$ en un tiempo razonable (menos de $30 \mathrm{~min}$ ) con una fase móvil compuesta por 95/5 (metanol/agua, v/v). Hay que señalar que la adición de un pequeño porcentaje de agua mejora la resolución pero triplica los tiempos de retención. Un ejemplo de la separación se muestra en la Figura $7 \cdot 7$.

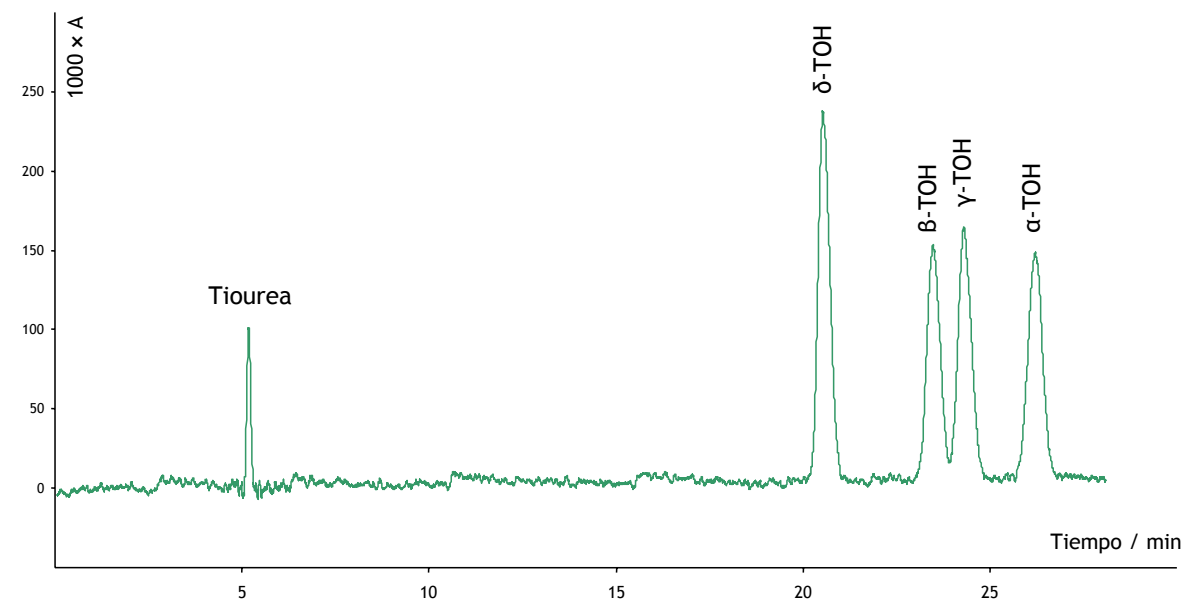

Figura 7.7. Separación de $\alpha, \beta, \gamma$ y $\delta$ tocoferoles en la fase estacionaria ULTIMA C18 empleando una fase móvil compuesta por 95/5 (metanol/agua, v/v) y Tris 5 mm. Resto de condiciones como en la Figura 7.6.

Selectivad de la fase estacionaria ULTIMA C18

El isómero $\gamma$-tocoferol parece ser más polar que el $\beta$-tocoferol, ya que este último es retenido más fuertemente en la fase de $C_{30}$, donde el mecanismo de retención corresponde únicamente a interacciones hidrofóbicas. Estos resultados están de acuerdo con los ya publicados [124]. El orden de retención encontrado en la fase estacionaria con grupos polares incrustados es el inverso para estos dos compuestos. Este mismo orden $\left(t_{R(\beta)}>t_{R(\gamma)}\right)$ ha sido 
encontrado por Richheimer et al. [130] en la separación mediante HPLC con fase inversa en una columna de sílice enlazada a pentafluorofenilo (PFPS). Abidi et al. han publicado el mismo orden de elución en fases estacionarias de octadecilo con alcohol polivinílico (ODPVA) y PFPS en separaciones mediante HPLC y CEC [119, 125].

La característica que tienen en común estas fases estacionarias de fase inversa (PFPS, ODPVA y ULTIMA C18), en las que el orden de elución es $t_{\mathrm{R}(\beta)}>$ $t_{\mathrm{R}(\gamma)}$, es que todas ellas presentan algún tipo de grupo polar. Debe tenerse en cuenta que este orden de elución es el tradicionalmente observado para estos dos isómeros cuando se separan por medio de HPLC en fase normal en columnas de sílice. Según esto, la retención de las formas $\beta$ y $\gamma$ parece estar relacionada con su facilidad de interacción con los grupos polares de estas fases estacionarias.

La posición de los grupos metilo en el anillo aromático es lo que distingue ambos isómeros (Figura 5.2, pág. 69). En el $\beta$-tocoferol están en posición para (en las posiciones 5 y 8 del grupo cromanol), y actúan como un escudo, proteguiendo la zona polar de la molécula (grupo - $\mathrm{OH}$ ), favoreciendo su hidrofobicidad; por ello, posiblemente el $\beta$-tocoferol presenta mayores tiempos de retención en la columna $C_{30}$. Este efecto protector podría dificultar la interación del isómero $\beta$ con el grupo amido de la fase estacionaria ULTIMA $\mathrm{C}_{1} 8$, y por lo tanto su retención en esta columna no estaría favorecida. Por el contrario, el $\gamma$-tocoferol tiene los dos grupos metilo en las posiciones $7 \mathrm{y}$ 8 (posición orto), de tal manera que el efecto protector no tiene lugar, sino que la formación de puentes de hidrógeno con el nitrógeno del grupo amido de la fase estacionaria se ve favorecida, explicando sus mayores tiempos de retención respecto al isómero $\beta$ en este tipo de columnas.

[130] S. L. Richheimer, M. C. Kent, and M. W. Bernart. RP high-performance liquid chromatographic method using a pentafluorophenyl bonded phase for analysis of tocopherols. $J$. Chromatogr. A, 677:75-80, 1994. 


\subsubsection{Conclusiones}

Se ha estudiado la separación de tocoferoles mediante CEC en una fase estacionaria con un grupo polar amido situado en medio de una cadena hidrocarbonada, llamada ULTIMA C18, y se han comparado los resultados obtenidos con los que presentan los tocoferoles empleando fases estacionarias alquílicas lineales de $\mathrm{C}_{18}$ y $\mathrm{C}_{30}$.

Efecto de la composición de la fase móvil en medios no acuosos

El comportamiento de todas las fases estacionarias investigadas fue evaluado con diferentes fases móviles compuestas de acetonitrilo, metanol y mezclas de ambos. Fueron evaluados parámetros tales como los factores de retención, eficacia y resolución en la separación de los tocoferoles $\alpha, \gamma$ y $\delta$.

Se obtuvieron unas buenas separación y resolución de los tres compuestos con las tres fases estacionarias empleando metanol y Tris $5 \mathrm{~mm}$ como fase móvil. Con las fases estacionarias de $\mathrm{C}_{18}$ y $\mathrm{C}_{30}$ la adición de acetonitrilo a la fase móvil implica un aumento de los tiempos de retención de los analitos, sin apenas modificar el resto de las características de la separación. Sin embargo, cuando se emplea la fase estacionaria ULTIMA C18, porcentajes de acetonitrilo superiores al $50 \%$ dan como resultado una pérdida notable de resolución y eficacia.

Separación de los isómeros $\beta$ y $\gamma$ en una fase estacionaria

con grupos polares incrustados

Tanto la fase estacionaria de $C_{30}$ como la ULTIMA $C_{18}$ mostraron selectividad suficiente para la separación de los isómeros de posición $\beta$ y $\gamma$. Sin embargo, el orden de elución de estos dos compuestos se invierte: $t_{R(\beta)}>t_{R(\gamma)}$ en la fase ULTIMA $C_{18}$, y $t_{R(\gamma)}>t_{R(\beta)}$ en la fase $C_{30}$. El orden de separación en la columna de $C_{30}$ se debe a un reparto debido a interacciones hidrofóbicas exclusivamente.

La fase estacionaria ULTIMA C18 consigue para este par de compuestos unos tiempos de retención, resolución y selectividad mayores que los obte- 
nidos en fases de $\mathrm{C}_{18}$ convencionales, debido a la participación de interacciones polares entre el grupo amido de la fase estacionaria y el grupo - $\mathrm{OH}$ de los tocoferoles. El incremento de la selectividad parece estar relacionado con la accesibilidad de la parte polar de los analitos para interaccionar con los grupos polares (grupos amido) de la fase estacionaria.

En este trabajo se ha demostrado que trabajando con la fases estacionaria con grupos polares incrustados ULTIMA C18 y una fase móvil compuesta por metanol/agua (95/5, v/v) y Tris $5 \mathrm{~mm}$ se obtiene una separación adecuada de los cuatro tocoferoles mediante cEc. 


\subsection{SEPARACión DE TOCOFEROLES EN COLUMNAS POLIMÉRICAS MONOLÍTICAS}

\subsubsection{Optimización de la fabricación de las columnas}

Inicialmente se realizaron diversos estudios previos empleando como monómeros el ácido metacríclico y sus ésteres, y utilizando distintos disolventes porogénicos (tolueno, diferentes mezclas de alcoholes, acetonitrilo, agua...). Tras varios ensayos que dieron lugar a monolitos no permeables durante la etapa de lavado, se decidió seguir trabajando con metacrilato de butilo (BMA) como monómero principal, dimetacrilato de etileno (EGDMA) como comonómero entrecruzador y AMPs como monómero cargado capaz de generar flujo electroosmótico (EOF), y una mezcla ternaria de 1,4-butanodiol, 1-propanol y agua, como disolvente porogénico. Ya se ha comentado que variando la composición de esta mezcla se pueden controlar con precisión características de la fase estacionaria como porosidad y superficie específica [131, 83, 94, 95].

\section{Influencia del tipo de polimerización}

En los datos encontrados en bibliografía el tiempo de polimerización térmica oscila entre 16 y 24 horas [83, 94, 95, 132, 133, 134, 131]. En las primeras columnas, tiempos tan prolongados de polimerización dieron como resultado columnas poco permeables e imposibles de lavar con una bomba de HPLC a 400 bar. Debido a ello, se eligió interrumpir la polimerización tras $60 \mathrm{~min}$ de reacción, controlando el tiempo de un modo preciso para no perder reproducibilidad. En este trabajo se han utilizado los monómeros tal cual se

[131] T. Jiang, J. Jiskra, H. A. Claessens, and C. A. Cramers. Preparation and characterization of monolithic polymer columns for CEC. J. Chromatogr. A, 923:215-227, 2001.

[132] J. K. Adu, S. S. Lau, D. G. Watson, M. R. Euerby, G. G. Skellern, and J. N. Tettey. CEc of therapeutic peptides on mixed-mode butylmethacrylate monoliths. Electrophoresis, 26:3445$51,2005$.

[133] G. S. Chirica and V. T. Remcho. Fritless capillary columns for HPLC and CEC prepared by immobilizing the stationary phase in an organic polymer matrix. Anal. Chem., 72:3605-10, 2000 .

[134] B. Buszewski and M. Szumski. Study of bed homogenity of methacrylate-based monolithic columns for $\mu$-HPLC and CEC. Chromatographia, 60:261-267, 2004. 
obtuvieron del distribuidor, sin ninguna etapa de purificación para eliminar los aditivos que normalmente se añaden para prolongar su conservación; posiblemente debido a ello los resultados obtenidos en este trabajo no coincidan exactamente con los descritos en bibliografía.

Con el fin de comparar sus características electrocromatográficas, los polímeros se sintetizaron tanto térmicamente como con radiación uv. Las condiciones de polimerización fueron las siguientes:

- Polimerización térmica: baño termostatado a $60^{\circ} \mathrm{C}$ durante $60 \mathrm{~min}$.

- Polimerización Uv: cámara de $10 \mathrm{~L}$ recubierta internamente con papel de aluminio y cerrada completamente salvo una abertura que coincide en tamaño con la ventana de la lámpara uv (8 W, 254 nm). Polimerización a temperatura ambiente durante $16 \mathrm{~h}$.

Las columnas poliméricas obtenidas con radiación uv resultaron poco homogéneas, con fragmentos muy porosos, acompañados de otros muy compactos y de partes sin polimerizar. Esto es debido, posiblemente, a que la polimerización no ha tenido lugar en un fotoreactor adecuado, y a que la lámpara empleada tiene poca potencia.

Además, se pudo apreciar en los primeros cromatogramas una mayor retención y eficacia en las columnas polimerizadas térmicamente. Un ejemplo de las dos separaciones obtenidas con polímeros generados mediante radiación uv y mediante iniciación térmica se muestran en la Figura 7.8.

\section{Derivatización de la pared del capilar}

En las primeras columnas fabricadas se pudo comprobar que si el polímero era poco permeable, el monolito se desplazaba en la etapa de lavado e incluso podía llegar a ser expulsado del capilar. Por ello, antes de la etapa de polimerización fue necesario tratar el interior del capilar con un reactivo bifuncional ( $\gamma$-MAPs) que en primer lugar se une a los grupos silanol de la pared, para más tarde participar en la reacción de polimerización y fijar el polímero al capilar. En la Sección 6.3.2 (pág. 80) y en la Figura 7.9 se describe el procedimiento de derivatización de la pared usando este reactivo. 


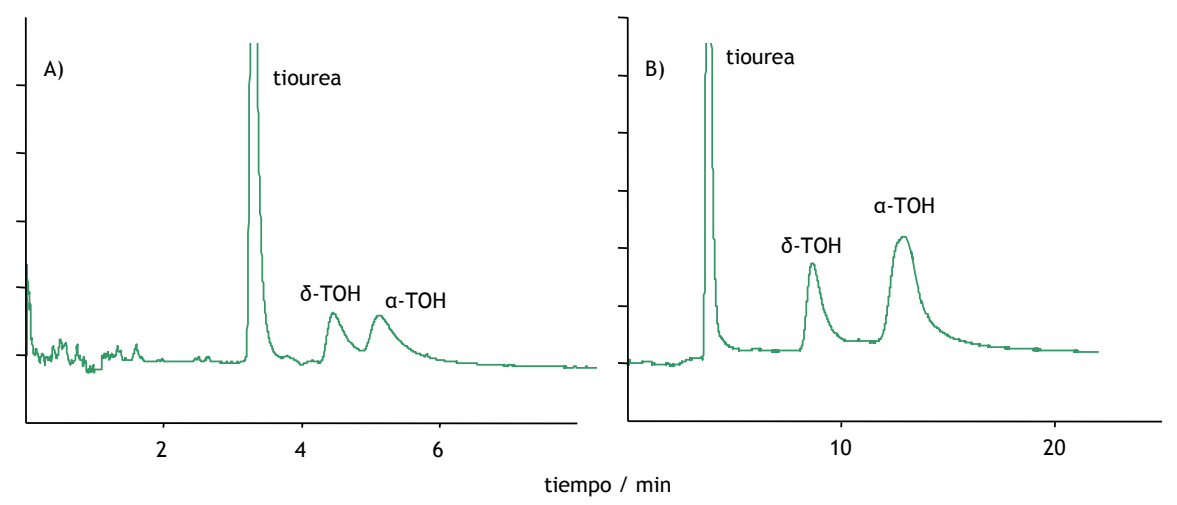

Figura 7.8. Comparación de los cromatogramas obtenidos con inicio de la polimerización mediante A) una lámpara uv, y B) térmicamente. Fase móvil: acetonitrilo/Tris $10 \mathrm{~mm}, 8 \mathrm{o} / 20$. Voltaje de separación: $30 \mathrm{kV}$, longitud efectiva: $10 \mathrm{~cm}$.
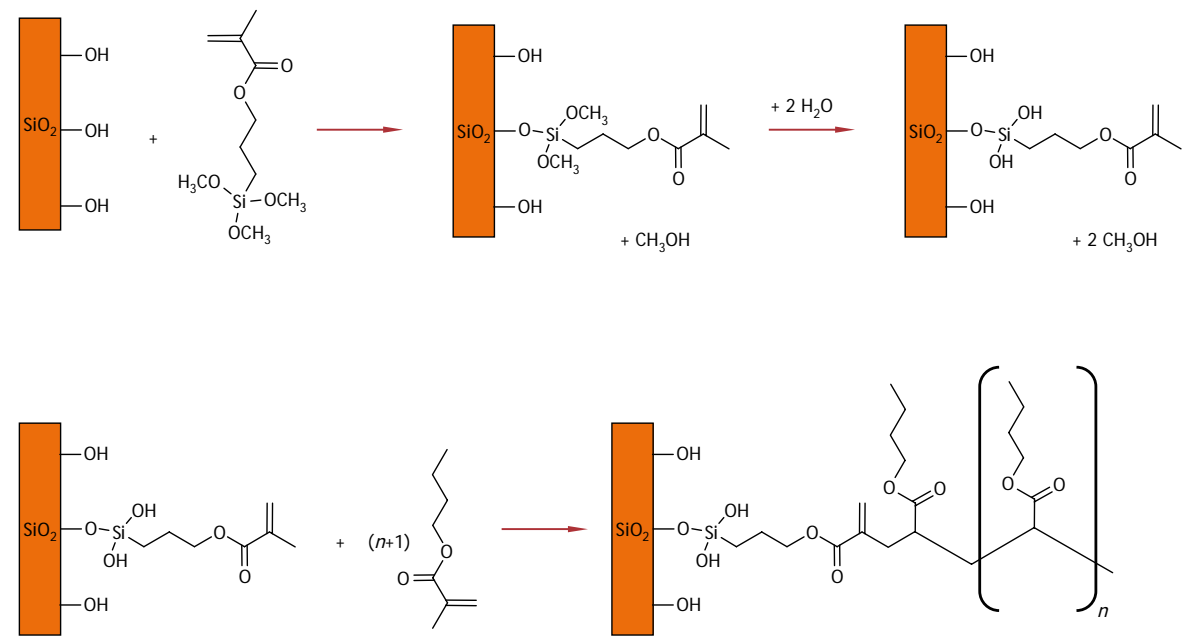

Figura 7.9. Proceso de derivatización de la pared interna del capilar de sílice con $\gamma$-MAPs. 
En la Figura 7.10 se muestran las microfotografías realizadas mediante microscopía electrónica de barrido (SEM) a capilares derivatizados y sin derivatizar. Se puede observar cómo en la columna sin ningún tipo de tratamiento el monolito está separado de la pared del capilar debido a la contracción que sufre durante la polimerización, mientras que en las paredes tratadas, el polímero queda perfectamente alineado con el corte debido a la adhesión de la fase estacionaria, además de observarse el recubrimiento de la pared interna.

\section{Estudio de porosidad}

Se ha comprobado que una de las variables que más influyen en la eficacia de las columnas es la fracción de disolvente porogénico presente en la mezcla total. Se mantuvieron constantes tanto la composición de disolventes como la de monómeros, pero variando la relación entre ellas. Los resultados obtenidos indican que, en general, cuando el porcentaje de disolvente es mayor se obtienen polímeros con poros de mayor tamaño, y por tanto con menor eficacia en las separaciones (Tabla 7.2).

Tabla 7.2. Relación entre la cantidad de disolvente porogénico y eficacia.

\begin{tabular}{|cc|}
\hline Disolvente (\%) & Eficacia $/ 10^{3}$ platos $/ \mathrm{m}$ \\
\hline 77 & $3-5$ \\
60 & $10-30$ \\
54 & $50-90$ \\
\hline
\end{tabular}

Cuando se observan las microfotografías obtenidas mediante SEM (Figura 7.11) se puede ver que una variación entre el 60\% y el 50\% de disolvente porogénico tiene una gran influencia en la morfología del polímero. Se advierte cómo los huecos son mayores y menos homogéneos en las columnas obtenidas con mayor porcentaje de disolvente porogénico mientras que los poros son menores y la superficie específica es mucho mayor cuando se tra- 

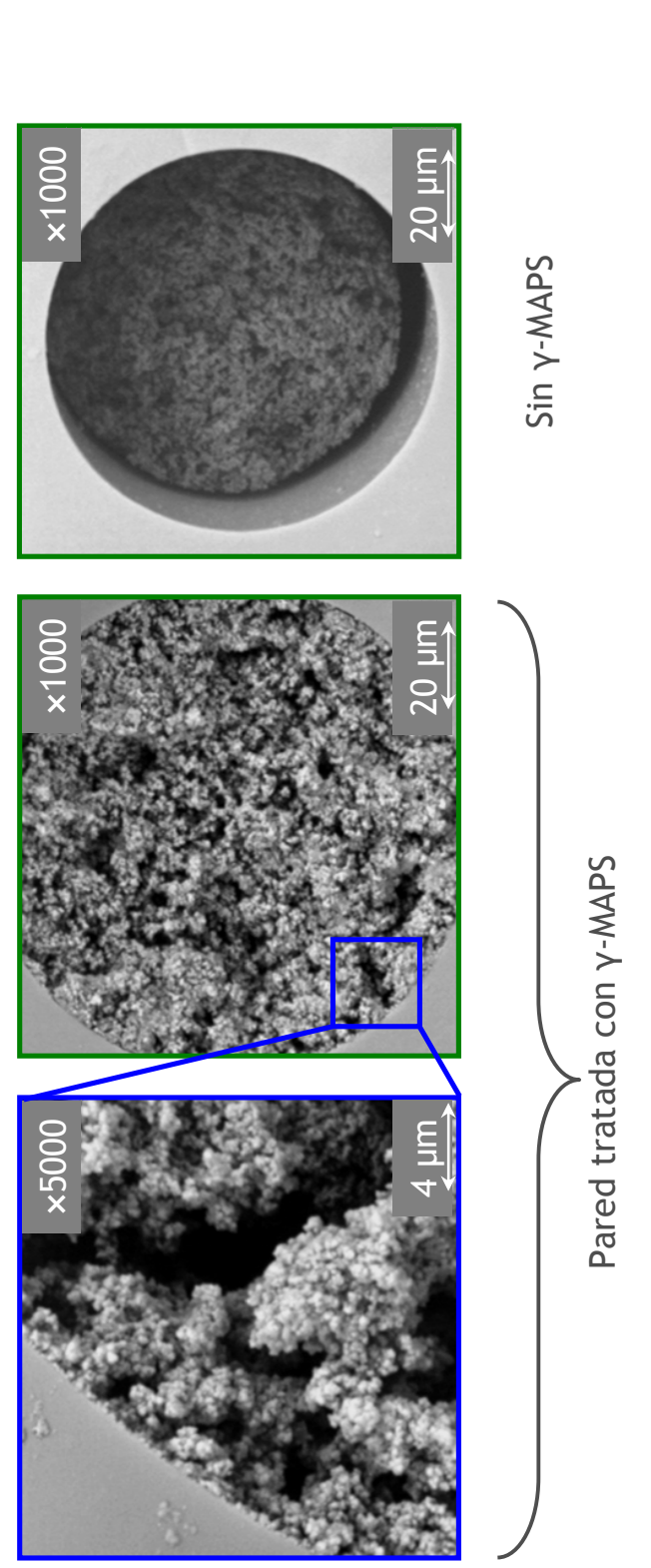

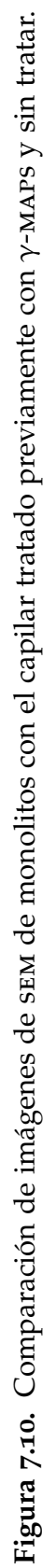




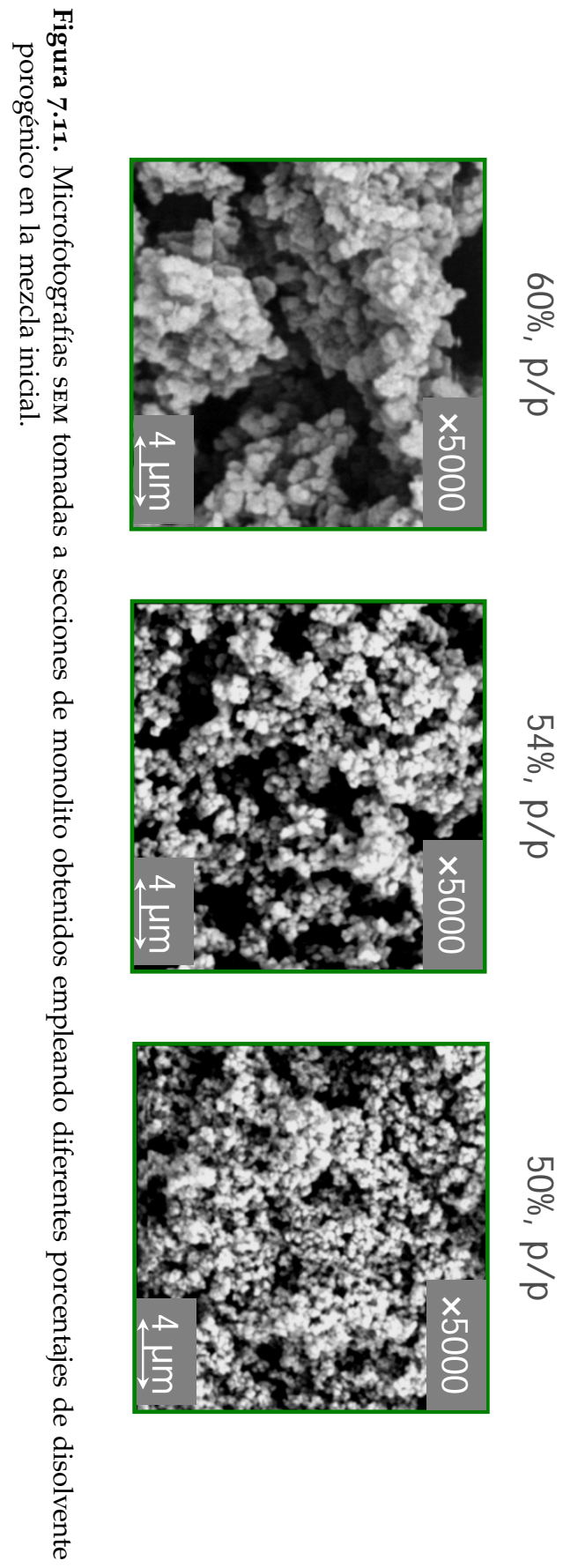


baja con menor porcentaje de disolvente. Por estas razones, en los siguientes estudios se utilizó la menor fracción de disolvente porogénico posible que permitió un fácil lavado del polímero y un paso adecuado de la corriente eléctrica.

\section{Influencia de la longitud de fase estacionaria}

Se ensayaron longitudes efectivas de columna de entre 5 y $24,5 \mathrm{~cm}$. Se comprobó que con la longitud estándar para columnas de CEC de $24,5 \mathrm{~cm}$ los tiempos de retención fueron excesivamente largos (en ocasiones de hasta 90 min para el $\alpha$-tocoferol) y no reproducibles. Además hay que indicar que estas columnas son muy difíciles de lavar y proporcionan un EOF y una corriente inestables. Los tiempos de retención, forma de los picos y la reproducibilidad se mejoraron cuando se trabajó con longitudes menores. La Figura 7.12 muestra un ejemplo de las separaciones obtenidas con una longitud de fase estacionaria de $30 \mathrm{~cm}$ y de $5 \mathrm{~cm}$. Con estas columnas fue necesario modificar la composición de fase móvil necesaria para conseguir una buena separación de los tres tocoferoles principales. A la vista de estos resultados se continuó trabajando con capilares rellenos con $5 \mathrm{~cm}$ de fase estacionaria.

\section{Condiciones óptimas}

En la Figura 7.13 se muestran las proporciones óptimas utilizadas para la fabricación de los monolitos. El porcentaje de disolvente porogénico fue del $54 \%$, y la mezcla de monómeros del $46 \%$, con un $1 \%$ de iniciador (AIBN) respecto al peso total de los monómeros.

Los otros parámetros fijados han sido $5 \mathrm{~cm}$ de longitud efectiva con capilares de $100 \mu \mathrm{m}$ de diámetro interno, pared del capilar derivatizada y con un tiempo de polimerización de 1 hora a $60^{\circ} \mathrm{C}$ en un baño termostatado. 

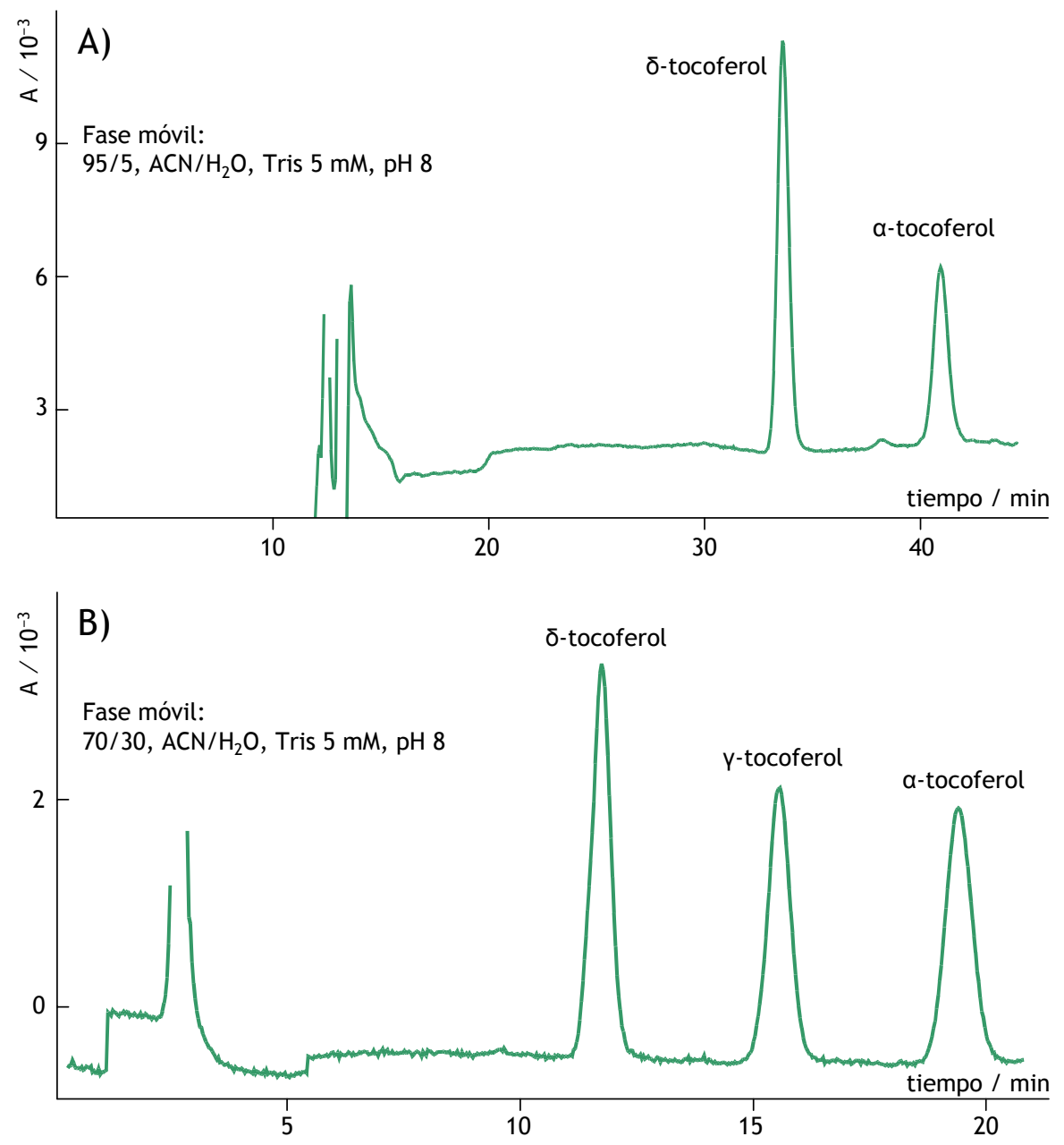

Figura 7.12. Efecto de la longitud de fase estacionaria en la separación de tocoferoles: A) $30 \mathrm{~cm}$, B) $5 \mathrm{~cm}$. Inyección electrocinética: $30 \mathrm{kV}$ durante $3 \mathrm{~s}$. 


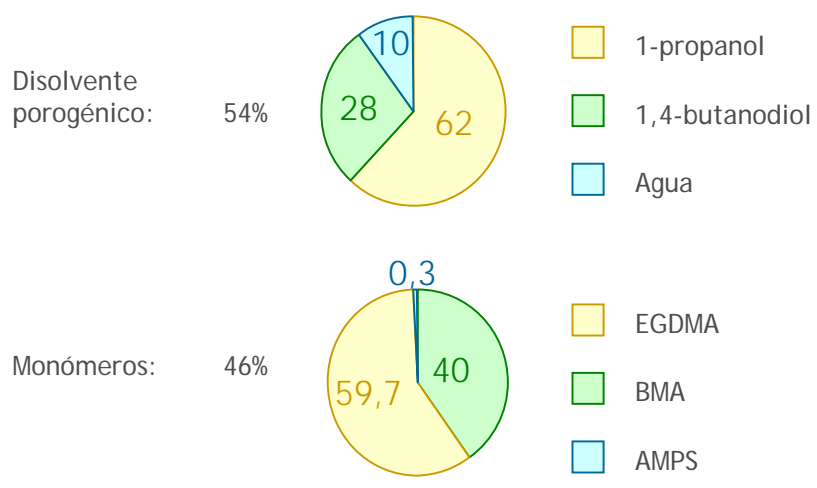

Figura 7.13. Composición ( $\%, p / p)$ de la mezcla de monómeros y disolventes empleada en la fabricación de columnas monolíticas para CEC. Cantidad de iniciador (AIBN), 1 \% del peso total de monómeros.

\subsubsection{Características cromatográficas}

Flujo electroosmótico

Se comprobó experimentalmente la relación existente entre la concentración de sales y la velocidad de flujo, calculada a partir del tiempo de retención de la tiourea. Como corresponde a las técnicas de separación electrocinéticas, la magnitud del flujo electroosmótico está relacionada con la viscosidad de la disolución, el campo aplicado, el potencial zeta, el radio iónico, y otros parámetros mediante las siguientes ecuaciones:

$$
\begin{gathered}
u_{\mathrm{eo}}=E \frac{\epsilon \zeta}{\eta} \\
\zeta=\frac{4 \pi \eta \delta}{\epsilon} \\
\delta=\frac{1}{3 \times 10^{7}|z|} \frac{1}{\sqrt{C}}
\end{gathered}
$$

donde $u_{\text {eo }}$ es la velocidad del flujo electroosmótico, $E$ es el potencial aplicado, $\epsilon$ es la constante dieléctrica, $\zeta$ es el potencial zeta, $\eta$ es la viscosidad de la disolución, $\delta$ es el espesor de la doble película o radio iónico de Debye, $|z|$ es la carga eléctrica de la sal que forma el electrolito, y $C$ es la concentración de sales en el medio de separación. 
Agrupando y simplificando términos se concluye que con unas condiciones experimentales fijas, y tan sólo variando la concentración de electrolito, la relación de $u_{\mathrm{eo}}$ es lineal con $\frac{1}{\sqrt{C}}$.

En la Figura 7.14 se muestra la relación entre $u_{\mathrm{eo}} \mathrm{y} \frac{1}{\sqrt{C}}$ empleando una fase móvil compuesta de acetonitrilo/agua (90/10) con diferentes concentraciones de Tris. Se puede observar la buena linealidad y el ajuste a las ecuaciones propuestas.

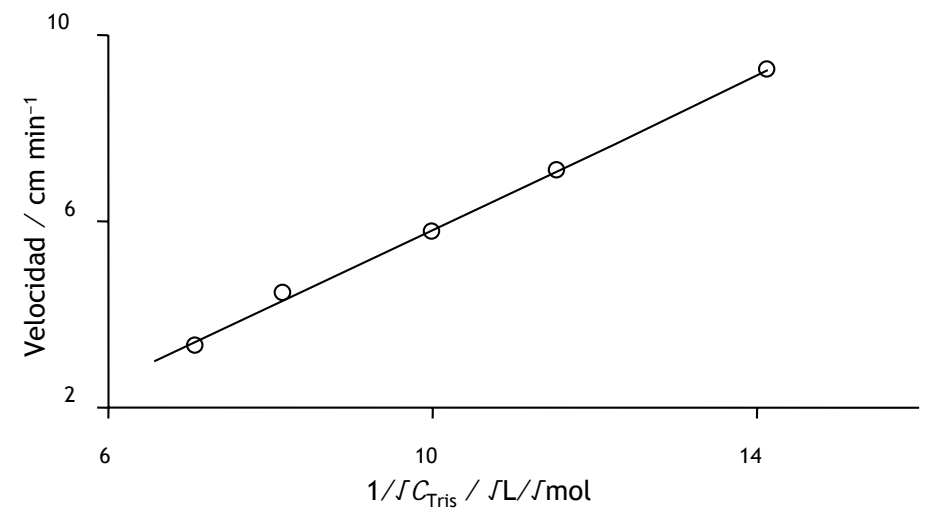

Figura 7.14. Variación de la velocidad del Eof con la fuerza iónica (inversa de la raíz de la concentración de electrolito)

En estudios realizados para comprobar la precisión de la magnitud del EOF se comprobó que éste es más reproducible empleando como electrolito tampón fosfato. Por ello, en estudios y separaciones posteriores se reemplazó el Tris por tampón fosfato a $\mathrm{pH} 7,2$.

\section{Resolución}

Para estudiar el efecto de la composición de la fase móvil en la separación de los tocoferoles $\alpha, \gamma$ y $\delta$, se varió el porcentaje de agua en la fase móvil entre 15 y $30 \%$, empleando acetonitrilo como parte orgánica y manteniendo constante la concentración de sales ( 5 mM de tampón fosfato a $\mathrm{pH} 7,2$ ). 
Los cromatogramas resultantes se muestran en la Figura 7.15. Se puede observar cómo la resolución de los tres compuestos es casi completa con una composición de fase móvil de 80/20, y se encuentran perfectamente resueltos con 75/25, con un tiempo de retención de la forma $\alpha$ de menos de 10 min. Representando los valores de las resoluciones entre las dos parejas consecutivas de picos frente al porcentaje de componente orgánico (Figura 7.16) se puede apreciar gráficamente la composición necesaria para una resolución total entre los compuestos $(>1,5)$.

Aunque resulta difícil comparar las resoluciones obtenidas en las columnas poliméricas, con las obtenidas en las columnas empaquetadas (Sección 7.1), se podría concluir que las fases estacionarias monolíticas fabricadas en esta sección son menos polares, pues se necesita como mínimo un $20 \%$ de agua en la fase móvil para conseguir una separación hasta la línea base de los tres tocoferoles, mientras que la resolución es prácticamente total con una columna de $C_{18}$ y una fase móvil no acuosa. Sin embargo, hay que tener en cuenta que la longitud de fase estacionaria es de sólo $5 \mathrm{~cm}$, frente a los $25 \mathrm{~cm}$ de las columnas empaquetadas.

\section{Eficacia}

Como ya se ha mencionado, en la estructura de la fase estacionaria y en la eficacia de las separaciones, la composición de la mezcla porogénica de disolventes y monómeros es crítica. Siguiendo las indicaciones de otros autores $[83,94,95,131,135]$ en este trabajo se utilizó como disolvente una mezcla ternaria de agua, 1,4-butanodiol y 1-propanol, y su porcentaje se modificó hasta obtener la máxima eficacia.

La altura de plato teórica en función de los voltajes aplicados se determinó realizando un estudio en el que se inyectó una disolución de $\alpha, \gamma$ y $\delta$ tocoferol con una fase móvil compuesta por un $30 \%$ de agua en acetonitrilo y $5 \mathrm{~mm}$ de tampón fosfato a $\mathrm{pH}$ 7,2, empleando diferentes voltajes de separación. Las representaciones de altura de plato de los tres compuestos en

[135] J. Grafnetter, P. Coufal, E. Tesařová, J. Suchánková, Z. Bosáková, and J. Ševčík. Optimization of binary porogen solvent composition for preparation of butyl methacrylate monoliths in capillary LC. J. Chromatogr. A, 1049:43-49, 2004. 


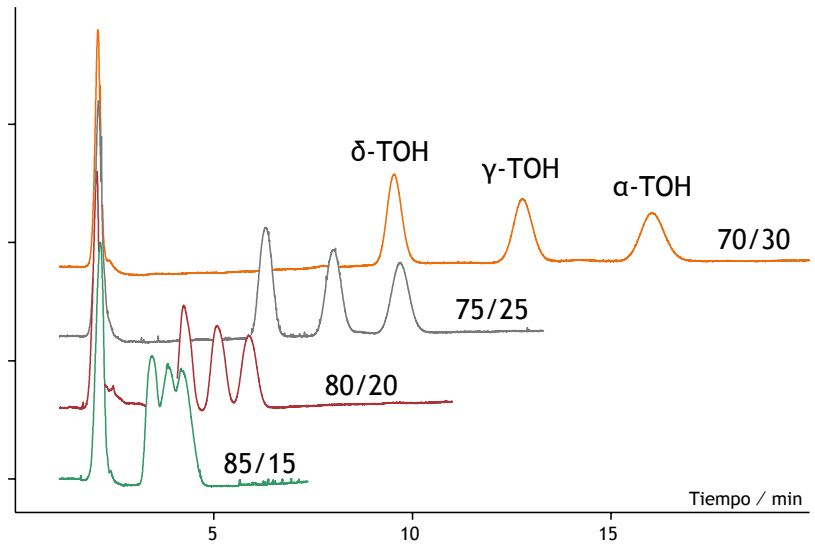

Figura 7.15. Efecto de la composición de la fase móvil en la separación de $\alpha$, $\gamma$ y $\delta$ tocoferoles. Fase móvil: diferentes relaciones de acetonitrilo/agua con 5 mM de tampón fosfato $(\mathrm{pH} 7,2)$.

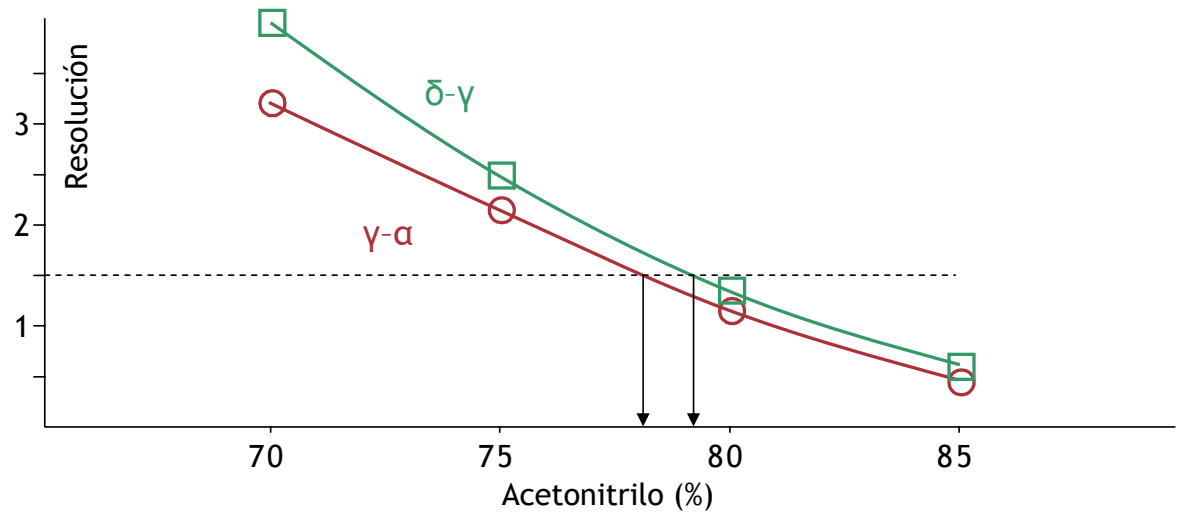

Figura 7.16. Resolución de los diferentes tocoferoles en función de la cantidad de acetonitrilo en la fase móvil. 
función del caudal (gráficas de Van Deemter) se muestran en la Figura 7.17. El caudal se ha calculado a partir del tiempo de retención de la tiourea. En el estudio se obtienen unos resultados semejantes para los 3 compuestos, con eficacias del orden de 65.000 platos $/ \mathrm{m}$ para las separaciones más rápidas $(30 \mathrm{kV})$.

Una menor altura de plato $(H)$ equivale a un mayor número de platos por metro de fase estacionaria y a una mayor eficacia. En el intervalo de velocidades investigado se observa para $H$ una tendencia lineal positiva, lo que concuerda con el hecho de que estamos trabajando con caudales por encima de la velocidad óptima de flujo. En la Figura 7.18 se representan las resoluciones obtenidas en este estudio. Se puede observar que, aun estando lejos del caudal óptimo, se consiguen unas buenas separación y resoluciones con un tiempo de análisis razonable (1o min) utilizando el máximo voltaje permitido por el equipo.

\section{Selectividad en la separación de isómeros $\beta$ y $\gamma$}

Ya se ha mencionado que las fases estacionarias de $C_{18}$ no presentan selectividad alguna para la separación de los tocoferoles $\gamma$ y $\beta$. Se analizó una mezcla de patrones de los 4 tocoferoles para comprobar si en las fases monolíticas de BмA existe algún tipo de separación entre los isómeros $\beta$ y $\gamma$. Se trabajó utilizando un voltaje de separación de $4 \mathrm{kV}$ para reducir el flujo y conseguir mayor eficacia. En la Figura 7.19 se muestra un cromatograma de los cuatro tocoferoles y de vitamina A, empleando una fase móvil compuesta por acetonitrilo/tampón fosfato $5 \mathrm{~mm} \mathrm{pH} \mathrm{7,2} \mathrm{(70/30} \mathrm{v/v).} \mathrm{Se} \mathrm{observa} \mathrm{sepa-}$ ración entre los isómeros $\gamma$ y $\beta$, aunque no su completa resolución. El orden de retención es $t_{\mathrm{R}(\gamma)}<t_{\mathrm{R}(\beta)}$, como corresponde a separaciones debidas a interacciones únicamente hidrofóbicas [136].

[136] R. Carabias-Martínez, E. Rodríguez-Gonzalo, N. W. Smith, and L. Ruano-Miguel. Use of a polar-embedded stationary phase for the separation of tocopherols by CEC. Electrophoresis, 27:4423-4430, 2006. 


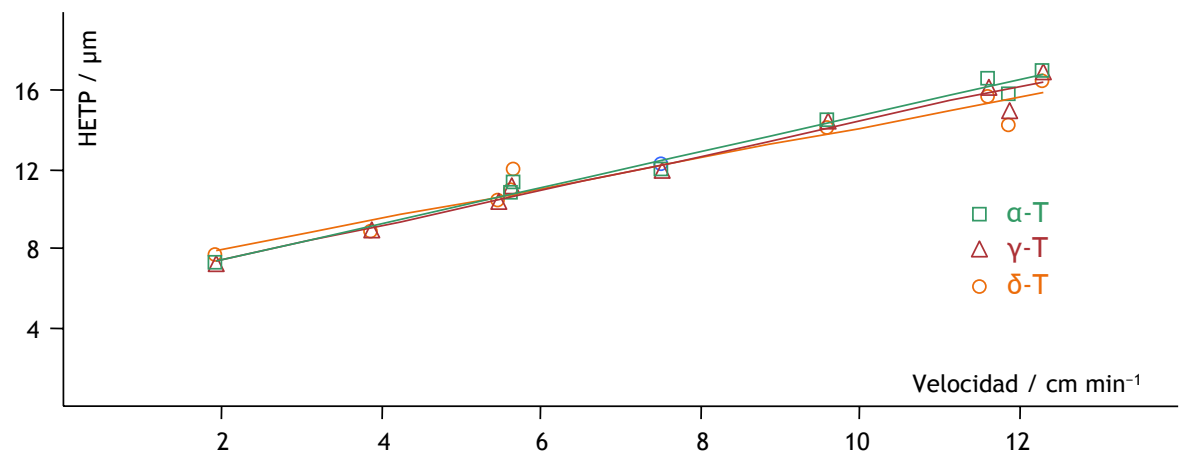

Figura 7.17. Altura de plato teórico frente a caudal de fase móvil. Condiciones: Fase móvil, acetonitrilo/tampón fosfato $5 \mathrm{~mm} \mathrm{pH} \mathrm{7,2.} \mathrm{(70/30).}$

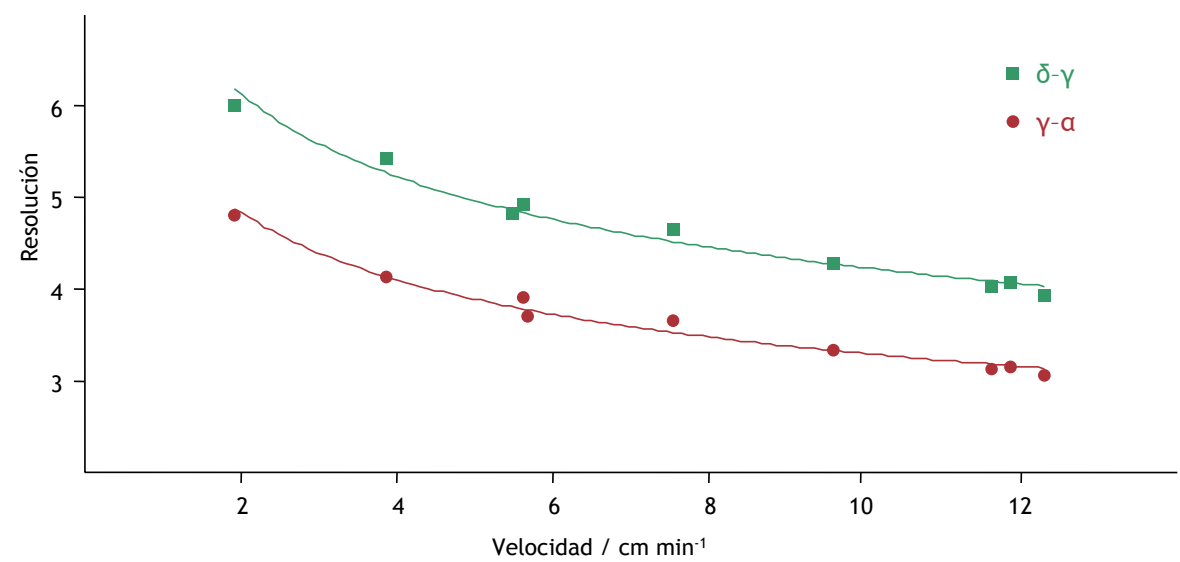

Figura 7.18. Resolución en función de caudal a diferentes voltajes aplicados; condiciones como en Fig. 7.17. 


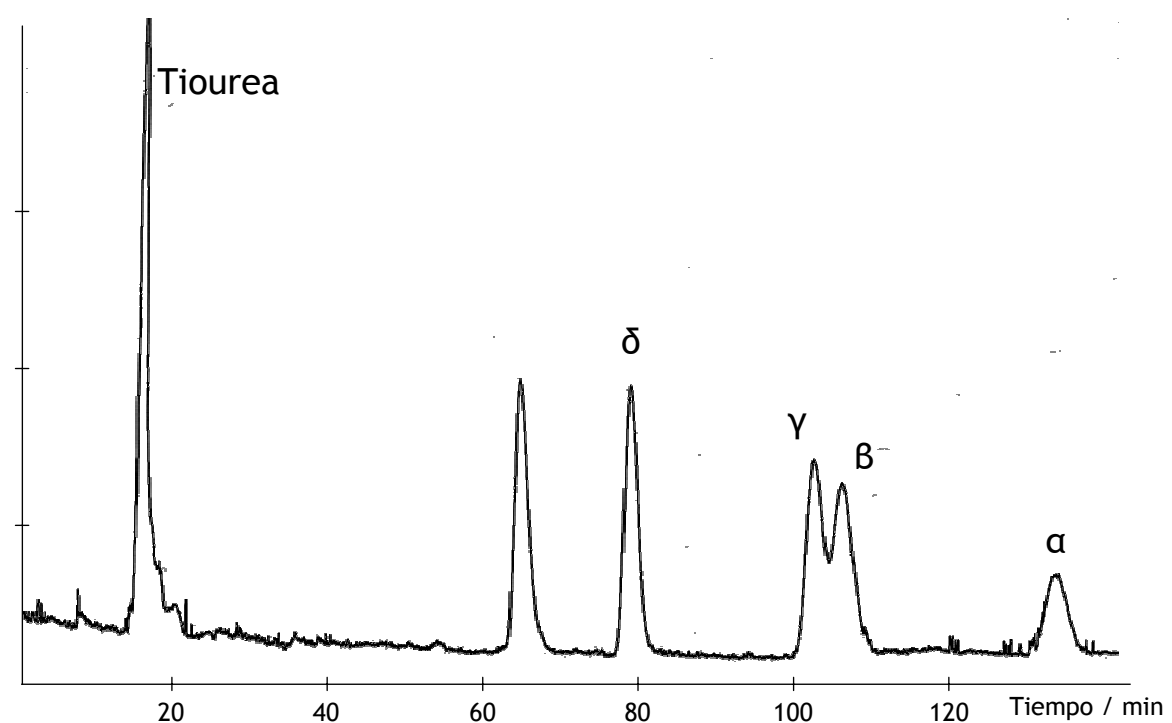

Figura 7.19. Separación de $\alpha, \beta, \gamma$ y $\delta$-tocoferoles a $4 \mathrm{kV}$. Pico sin etiquetar: Vitamina A. Resto de condiciones como en Fig. 7.17.

\subsubsection{Conclusiones}

Se han estudiado las variables que influyen en la fabricación de columnas monolíticas poliméricas para su uso en CEC con polímeros basados en BMA y EGDMA. Se han estudiado las características cromatográficas de las columnas fabricadas y se ha estudiado su capacidad de separación de isómeros de vitamina E.

\section{Fabricación de las columnas}

Para anclar el monolito polimérico a la pared del capilar resultó indispensable el tratamiento del interior del capilar con el reactivo bifuncional $\gamma$-MAPs. De este modo se evita su movimiento o expulsión durante la etapa de lavado, o incluso durante las separaciones. El tipo de polimerización fue térmica. Se escogió como longitud de fase estacionaria $5 \mathrm{~cm}$. Longitudes mayores aumentan notablemente los tiempos de retención y dan lugar a separaciones no reproducibles y columnas difíciles de lavar. 
La polimerizacióin debe realizarse con una mezcla compuesta por un $54 \%$ de disolventes (agua, 1,4-butanodiol y 1-propanol) y $46 \%$ de monómeros (BMA y EGDMA). Cantidades menores de disolvente dan lugar a columnas poco permeables, sin capacidad de generar EOF e imposibles de lavar. Cantidades mayores de disolvente empeoran las características de la separación debido a la formación de poros más grandes durante la polimerización.

\section{Separación de tocoferoles}

Se ha conseguido una buena separación de las tres formas principales de vitamina $\mathrm{E}(\alpha, \gamma$ y $\delta$ tocoferoles) con tiempos y eficacias similares a las obtenidas habitualmente en HPLC con fases estacionarias de $C_{18}$. La composición óptima de fase móvil para la separación de estos tres compuestos ha sido acetonitrilo/tampón fosfato $5 \mathrm{~mm}, \mathrm{pH} 7,2$, (75/25, v/v). En estas condiciones se han conseguido unas resoluciones superiores a 2, y unos tiempos de retención para el último analito ( $\alpha$-tocoferol) de menos de $10 \mathrm{~min}$.

Se ha encontrado cierta selectividad entre los isómeros $\gamma$ y $\beta$-tocoferol que no existe en las fases estacionarias de $C_{18}$. Se puede conseguir la resolución parcial de estos dos compuestos a costa de emplear elevados tiempos de retención (140 $\mathrm{min})$.

Como conclusión general se puede decir que en este trabajo se ha demostrado la utilidad del uso de columnas monolíticas poliméricas en la separación de tocoferoles. Sin embargo, es necesario señalar que a pesar de los buenos resultados, las columnas fabricadas han adolecido de falta de reproducibilidad. Sólo una parte de todas las columnas polimerizadas sirvió para la separación de tocoferoles, bien por la dificultad de su lavado o por no generar flujo electroosmótico. Otro campo en el que no resulta tan crítica la composición y fabricación de capilares monolíticos poliméricos, es su uso como sorbentes de extracción en fase sólida, tema del que trata la Parte III de esta tesis. 


\section{Parte III}

SEPARACIÓN MEDIANTE ELECTROFORESIS CAPILAR DE PLAGUICIDAS CARBÁMICOS Y

PRECONCENTRACIÓN EN POLÍMEROS

MONOLÍTICOS 



\section{8}

\section{INTRODUCCIÓN}

Como se ha comentado en la introducción de la Parte I, los plaguicidas carbámicos son muy usados actualmente debido a su elevada efectividad y por el hecho de presentar múltiples aplicaciones (insecticidas, fungicidas, herbicidas, etc.). Sustituyeron progresivamente a los plaguicidas organoclorados y organofosforados por sus menores persistencia y toxicidad. Sus principales características son su elevada polaridad, su solubilidad en agua, su baja persistencia en el ambiente y su inestabilidad térmica.

A pesar de que la técnica analítica más empleada para la separación y detección de plaguicidas es la cromatografía de gases (GC), la inestabilidad térmica de esta familia de compuestos limita el uso de esta técnica. Este inconveniente puede evitarse mediante una etapa previa de derivatización, que implica un incremento del tiempo de análisis y puede introducir interferencias. Algunos investigadores han propuesto métodos y dispositivos especiales para analizarlos mediante GC: SPME [10, 137], PTV [12, 13], etc. (véase la introducción de la Parte I).

Debido a su inestabilidad térmica, los métodos más empleados para el análisis de plaguicidas carbámicos utilizan HPLC como técnica de separación, con detección fluorimétrica [4], de absorción uv [1] (ambas con una etapa de derivatización post-columna) o de espectrometría de masas [7].

Desde hace algunos años, la electroforesis capilar (CE) se está consolidándo como una técnica analítica de enorme versatilidad por ser adecuada para el

[137] R. Carabias-Martínez, C. García-Hermida, E. Rodríguez-Gonzalo, and L. Ruano-Miguel. Behaviour of carbamate pesticides in GC and their determination with SPE and SPME as preconcentration steps. J. Sep. Sci., 28:2130-8, 2005. 
análisis de una amplia variedad de contaminantes orgánicos, por lo que se considera una alternativa adecuada y complementaria a las técnicas cromatográficas más tradicionales.

\subsection{ELECTROFORESIS CAPILAR PARA EL ANÁLISIS DE PLAGUICIDAS CARBÁMICOS}

Existe una amplia variedad de modalidades de CE, siendo la electroforesis capilar zonal (CZE) y la cromatografía electrocinética micelar (MEKC) las más empleadas para el análisis de contaminantes ambientales. Cuando se emplea CZE, la separación se basa en las diferentes movilidades electroforéticas (directamente relacionadas con la relación carga/tamaño) que adquieren los analitos cargados bajo la acción de un campo eléctrico. Sin embargo, la mayoría de los compuestos estudiados en este trabajo tienen un caracter neutro y no pueden ser separados por CzE.

La МЕкC, desarrollada en 1984 por Terabe [138], surgió en un esfuerzo por ampliar el uso de la CE a la separación de compuestos neutros. Esta técnica, aunque se basa en el fenómeno electrocinético propio de la CZE, aprovecha los principios básicos de la cromatografía (interacción entre analitos y una fase estacionaria) para llevar a cabo la separación. Al electrolito se le adiciona uno o varios tensioactivos formadores de micelas. El flujo electroosmótico es el encargado de transportar los analitos a traves del capilar desde la entrada hasta la ventana de detección, mientras que los agregados micelares tienen un movimiento relativo a éstos en sentido opuesto. La separación de los solutos no iónicos en МЕKс se basa en el reparto de los analitos entre las micelas y el seno de la disolución. Este reparto origina diferencias en la movilidades netas de los analitos y permite la separación de éstos.

Uno de los principales inconvenientes con los que cuentan las técnicas electroforéticas es la pequeña sensibilidad derivada del pequeño paso óptico, en caso de la detección uv-visible, y de la pequeña cantidad de muestra inyectada, del orden de nanolitros. Este hecho hace casi obligada la aplicación de

[138] S. Terabe, K. Otsuka, K. Ichikawa, A. Tsuchiya, and T. Ando. Electrokinetic separations with micellar solutions and open-tubular capillaries. Anal. Chem., 56:111-113, 1984. 
técnicas de preconcentración de muestra previas al análisis electroforético. Numerosos autores han tratado de concentrar la muestra inyectada en el interior del capilar mediante modificaciones en la velocidad electroforética de los analitos (stacking mediante inyección de grandes volúmenes de muestra, stacking mediante campo amplificado, isotacoforesis o sweeping). Sin embargo, el modo más habitual de conseguir un aumento de sensibilidad es realizar una etapa previa de preconcentración de modo independiente a la separación (off-line).

En la Tabla 8.1 se muestran los trabajos realizados en los últimos años que emplean CE para la determinación de pesticidas. Aparecen recogidos aquellos trabajos que determinan alguno de los pesticidas estudiados en esta memoria haciendo referencia la modalidad de CE empleada, las etapas de preconcentración, la matriz, la detección y los límites de detección alcanzados. Los trabajos recogidos ponen de manifiesto cómo actualmente la extracción en fase sólida (SPE) se ha convertido en el método de preparación de muestra más empleado. 


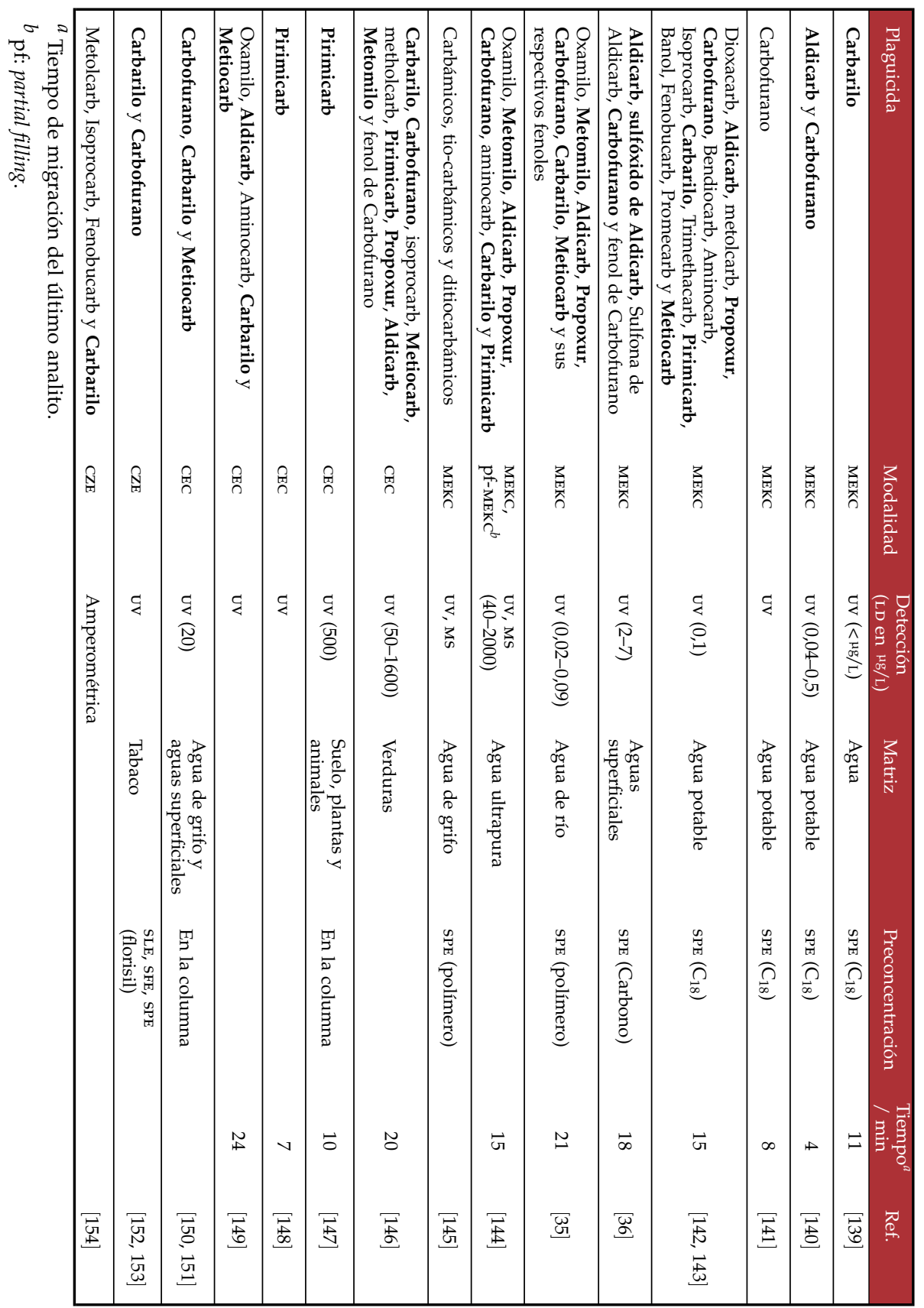

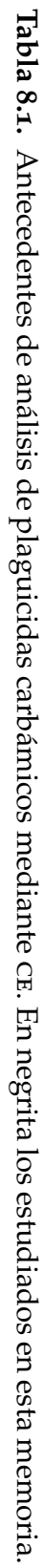


[139] A. Farran, S. Ruiz, C. Serra, and M. Aguilar. Comparative study of HPLC and MEKC applied to the analysis of different mixtures of pesticides. J. Chromatogr. A, 737:109-116, 1996.

[140] Y. S. Fung and J. L. L. Mak. Determination of pesticides in drinking water by MEKC. Electrophoresis, 22:2260-2269, 2001.

[141] H. Susse and H. Muller. Pesticide analysis by мEкC. J. Chromatogr. A, 730:337-343, 1996.

[142] Y. S. Wu, H. K. Lee, and S. F. Y. Li. Separation and determination of pesticides by CE. I. Rapid separation of fifteen $\mathrm{N}$-methylcarbamate insecticides via мекс. J. Microcolumn Sep., 10:239-247, 1998.

[143] Y. S. Wu, HK Lee, and S. F. Y. Li. Separation and determination of pesticides by CE. II. Determination of $N$-methylcarbamates in drinking water by МЕKC with SPE and oncolumn enrichment. J. Microcolumn Sep., 10:529-535, 1998.

[144] M. Molina, S. K. Wiedmer, M. Jussila, M. Silva, and M. L. Riekkola. Use of a partial filling technique and reverse migrating micelles in the study of $\mathrm{N}$-methylcarbamate pesticides by MEKC-ESI-MS. J. Chromatogr. A, 927:191-202, 2001.

[145] M. Rossi and D. Rotilio. Analysis of carbamate pesticides by мекс. J. High Res. Chromatogr., 20:265-268, 1997.

[146] X. Wu, L. Wang, Z. Xie, J. Lu, C. Yan, P. Yang, and G. Chen. Rapid separation and determination of carbamate insecticides using isocratic elution pressurized CEC. Electrophoresis, 27:768-77, 2006.

[147] P. A. Cooper, K. M. Jessop, and F. Moffatt. CEC for pesticide analysis: effects of environmental matrices. Electrophoresis, 21:1574-9, 2000.

[148] F. Moffatt, P. A. Cooper, and K. M. Jessop. Comparison of CEC with HPLC for the analysis of pirimicarb and related compounds. J. Chromatogr. A, 855:215-26, 1999.

[149] M. Zhang and Z. El Rassi. CEC with polyacrylamide monolithic stationary phases having bonded dodecyl ligands and sulfonic acid groups: evaluation of column performance with alkyl phenyl ketones and neutral moderately polar pesticides. Electrophoresis, 22:2593-9, 2001.

[150] T. Tegeler and Z. El Rassi. On-column trace enrichment by sequential frontal and elution electrochromatography. 1. Application to carbamate insecticides. Anal. Chem., 73:33653372, 2001.

[151] T. Tegeler and Z. El Rassi. On-column trace enrichment by sequential frontal and elution CEC:II. Enhancement of sensitivity by segmented capillaries with z-cell configurationapplication to the detection of dilute samples of moderately polar and nonpolar pesticides. J. Chromatogr. A, 945:267-279, 2002.

[152] F. M. Lanças, S. R. Rissato, and M. S. Galhiane. Off-line SFE-CZE analysis of carbamates residues in tobacco samples. Chromatographia, 42:323-328, 1996.

[153] F. M. Lanças, S. R. Rissato, and M. S. Galhiane. Analysis of carbaryl and carbofuran in tobacco samples by HRGC, HPLC, and CZE. J. High Res. Chromatogr., 19:200-206, 1996.

[154] X. Cheng, Q. Wang, S. Zhang, W. Zhang, P. He, and Y. Fang. Determination of four kinds of carbamate pesticides by CZE with amperometric detection at a polyamide-modified carbon paste electrode. Talanta, 71:1083-1087, 2007. 


\subsection{EXTRACCIÓN EN FASE SÓLIDA Y ELECTROFORESIS CAPILAR}

La SPE es una de las técnicas más empleadas para aumentar la sensibilidad en CE y efectuar la limpieza de las muestras. La SPE seguida de una separación mediante CE puede llevarse a cabo utilizando diversas estrategias:

1. Preconcentración off-line: en esta modalidad no existe integración entre la etapa de preconcentración y la de separación. La muestra eluida del sorbente, o parte de ella, es inyectada manualmente en el sistema electroforético.

2. Preconcentración at-line: en este caso la preconcentración puede realizarse de una forma automática, pero no existe una conexión directa entre el eluato y el capilar electroforético. En esta modalidad la preconcentración se suele realizar con sistemas en continuo y en algunos casos se usa un robot para tomar el volumen de elución e introducirlo en el sistema de separación.

3. Preconcentración on-line: Para efectuar este acoplamiento se utilizan válvulas u otros dispositivos para realizar la transferencia del eluato de la SPE al capilar electroforético. Se necesita una interfase para realizar la transferencia y además, se debe resolver el problema de la diferencia existente entre el volumen de elución y el de inyección.

4. Preconcentración in-line: En ella existe una integración total entre la preconcentración y la separación ya que el sorbente se introduce en el mismo capilar de la separación. El sorbente puede estar formado por fases empaquetadas, membranas, o polímeros monolíticos.

Las denominaciones de estas cuatro estrategias son las más aceptadas en la actualidad [155, 156]. Sin embargo, es necesario señalar que existe una cierta confusión con estos términos de modo que muchas determinaciones in-line y at-line son denominadas por sus autores como on-line.

[155] F. W. A. Tempels, J. Teeuwsen, I. K. Kyriakou, G. Theodoridis, W. J. M. Underberg, G. W. Somsen, and G. J. de Jong. Chromatographic preconcentration coupled on-line to CE via a Tee-split interface. J. Chromatogr. A, 1053:263-268, 2004.

[156] P. Puig, F. Borrull, M. Calull, and C. Aguilar. Recent advances in coupling SPE and CE. Trends Anal. Chem., 26:664-678, 2007. 
En la preconcentración in-line tiene lugar la retención de los analitos en una fase estacionaria colocada en el extremo de entrada del capilar de separación. La elución suele realizarse mediante la inyección de un porcentaje adecuado de componente orgánico. Las primeras publicaciones datan de mediados de la década de 1990, cuyos primeros montajes experimentales consistían en el acoplamiento de una pequeña columna empaquetada con una fase estacionaria hidrofóbica, retenida mediante fritas, acoplada directamente al capilar de separación [157, 158]. Esta técnica presenta la ventaja no sólo de preconcentrar, sino también de limpiar la muestra, y ha sido usada principalmente en la preconcentración y análisis de muestras biológicas [159, 160] (sangre, orina), para analitos tales como péptidos [161, 162], proteínas [163, 164], medicamentos [165], etc.

Dependiendo del tipo y configuración de la fase estacionaria las preconcentraciones in-line pueden realizarse en capilares abiertos, columnas empaquetadas, columnas monolíticas o columnas de electrocromatografía.

[157] A. M. Hoyt, S. C. Beale, J. P. Larmann, and J. W. Jorgenson. Preparation and evaluation of an on-line preconcentrator for CE. J. Microcolumn Sep., 5:325-325, 1993.

[158] A. J. Tomlinson, W. D. Braddock, L. M. Benson, R. P. Oda, and S. Naylor. Preliminary investigations of preconcentration-CE-Ms. J. Chromatogr. B, 669:67-73, 1995.

[159] S. Sentellas, L. Puignou, and M. T. Galceran. CE with on-line enrichment for the analysis of biological samples. J. Sep. Sci., 25:975-987, 2002.

[160] N. Johannesson, E. Pearce, M. Dulay, R. N. Zare, J. Bergquist, and K. E. Markides. On-line biological sample cleanup for ES-MS using sol-gel columns. J. Chromatogr. B, 842:70-74, 2006.

[161] G. M. Janini, M. Zhou, L. R. Yu, J. Blonder, M. Gignac, T. P. Conrads, H. J. Issaq, and T. D. Veenstra. On-column sample enrichment for CE sheathless ESI-Ms: evaluation for peptide analysis and protein identification. Anal. Chem., 75:5984-5993, 2003.

[162] N. M. Vizioli, M. L. Rusell, and C. N. Carducci. On-line preconcentration CE for purity profiling of synthetic peptides. Anal. Chim. Acta, 514:167-177, 2004.

[163] D. Figeys, A. Ducret, and R. Aebersold. Identification of proteins by CE-tandem Ms. Evaluation of an on-line sPE device. J. Chromatogr. A, 763:295-306, 1997.

[164] E. Rohde, A. J. Tomlinson, D. H. Johnson, and S. Naylor. Protein analysis by membrane preconcentration-CE: systematic evaluation of parameters affecting preconcentration and separation. J. Chromatogr. B, 713:301-11, 1998.

[165] K. Jinno, M. Kawazoe, Y. Saito, T. Takeichi, and M. Hayashida. Sample preparation with fiber-in-tube SPME for capillary electrophoretic separation of tricyclic antidepressant drugs in human urine. Electrophoresis, 22:3785-90, 2001. 


\subsubsection{Preconcentración en capilares abiertos}

En esta modalidad una parte del capilar se recubre con la fase estacionaria y en otra parte del capilar tiene lugar la separación. Esta variante permite que en la etapa de preconcentración se puedan utilizar caudales altos; sin embargo, presenta el inconveniente de tener una baja capacidad de retención.

Breadmore et al. [166, 167, 168] fueron los primeros que emplearon este tipo de configuración para preconcentrar analitos iónicos mediante en interacciones de intercambio iónico. Li et al. [169, 170] han preconcentrado aminoácidos mediante interacciones iónicas con un sol-gel cargado positivamente. Otros autores han empleado capilares con la pared funcionalizada con cadenas de $C_{18}$ para la retención de herbicidas triazínicos [171] o con quelatos metálicos para la preconcentración de proteínas $[172,173]$. También se pueden preconcentrar iones en paredes recubiertas de látex polimerizado junto con fases intercambiadoras de iones [174].

[166] M. C. Breadmore, M. Macka, P. R. Haddad, and N. Avdalovic. Open-tubular ion-exchange CEC of inorganic anions. Analyst, 125:1235-1241, 2000.

[167] M. C. Breadmore, A. S. Palmer, M. Curran, M. Macka, N. Avdalovic, and P. R. Haddad. On-column ion-exchange preconcentration of inorganic anions in open tubular CEC with elution using transient-isotachophoretic gradients. 3. Implementation and method development. Anal. Chem., 74:2112-2118, 2002.

[168] M. C. Breadmore, M. Macka, N. Avdalovic, and P. R. Haddad. On-column ion-exchange preconcentration of inorganic anions in open tubular CEC with elution using transientisotachophoretic gradients. 2. Characterization of the isotachophoretic gradient. Anal. Chem., 73:820-828, 2001.

[169] W. Li, D. Fries, A. Alli, and A. Malik. Positively charged sol-gel coatings for on-line preconcentration of amino acids in CE. Anal. Chem., 76:218-27, 2004.

[170] W. Li, D. Fries, and A. Malik. Negatively charged sol-gel column with stable electroosmotic flow for online preconcentration of zwitterionic biomolecules in capillary electromigration separations. J. Sep. Sci., 28:2153, 2005.

[171] J. Cai and Z. El Rassi. On-line preconcentration of triazine herbicides with tandem octadecyl capillaries-CZE. J. Liq. Chromatogr., 15:1179-1192, 1992.

[172] J. Cai and Z. El Rassi. Selective on-line preconcentration of proteins by tandem metal chelate capillaries-CZE. J. Liq. Chromatogr., 16:2007-2024, 1993.

[173] L. Zhang, L. Zhang, W. Zhang, and Y. Zhang. On-line concentration of peptides and proteins with the hyphenation of polymer monolithic immobilized metal affinity chromatography and CE. Electrophoresis, 26:2172-2178, 2005. 
Una modificación de los capilares abiertos puede considerarse el uso de dos capilares con diferente diámetro interno [175, 176, 177]. En estos sistemas la preconcentración tiene lugar en el primer capilar, que contiene la fase estacionaria, y en el segundo ocurre la separación electroforética. La ventaja de esta configuración es que el capilar de separación no necesita estar recubierto y la separación por CE y la preconcentración se pueden optimizar por separado. Se han propuesto distintos métodos para acoplar ambos capilares tales como conexiones usando tubo de politetrafluoroetileno (PTFE) y conexiones tipo $T$. Hutchinson et al. [175] utilizan para preconcentrar un capilar de $10 \mathrm{~cm} \times 25-50 \mu \mathrm{m}$ conectado a un capilar de separación de $75 \mu \mathrm{m}$ de diámetro interno. Esta configuración se ha utilizado para la determinación de aniones inorgánicos en aguas de río. Una ventaja de esta configuración es la de poder realizar inicialmente la preconcentración y posteriormente acoplar el capilar al de separación electroforética para realizar la elución y la separación. Este método ha sido aplicado al análisis de nitrito, nitrato y yoduro en aguas, con LD de 28,11 y $74 \mu \mathrm{g} / \mathrm{L}$, respectivamente. Los acoplamientos que utilizan conexiones en forma de $T$ permiten efectuar la preconcentración sin que la muestra pase por el capilar de separación [177].

[174] J. P. Hutchinson, P. Zakaria, A. R. Bowie, M. Macka, N. Avdalovic, and P. R. Haddad. Latex-coated polymeric monolithic ion-exchange stationary phases. 1. Anion-exchange CEC and in-line sample preconcentration in CE. Anal. Chem., 77:407-16, 2005.

[175] J. P. Hutchinson, M. Macka, N. Avdalovic, and P. R. Haddad. Use of coupled open-tubular capillaries for in-line ion-exchange preconcentration of anions by CEC with elution by a transient isotachophoretic gradient. J. Chromatogr. A, 1039:187-192, 2004.

[176] Z. X. Zhang and Y. Z. He. On-line cation-exchange preconcentration and CE coupled by tee joint interface. J. Chromatogr. A, 1066:211-218, 2005.

[177] S. Zhang, M. Macka, and P. R. Haddad. Preparation and characterisation of dual-layer latex-coated columns for open-tubular capillary electrochromatographic preconcentration of cations combined in-line with their separation by CE. Electrophoresis, 27:1069-1077, 2006. 


\subsubsection{Preconcentración en columnas empaquetadas}

En 1995 Strausbauch et al. [178] consiguen la preconcentración y separación de siete hipoglucémicos mediante czE usando un relleno de partículas de $\mathrm{C}_{18}$ en una punta del capilar retenidas entre lana de vidrio. Beattie et al. [179] utilizan un método semejante para conseguir incrementos de sensibilidad de 700 veces en la determinación de dos metalotioneínas. Kundsen et al. [18o] también separan metalotioneínas con el mismo método, pero esta vez emplean una resina polimérica de estireno-divinilbenceno atrapada en la punta del capilar entre dos membranas. En 1996 He et al. [181] preconcentran Veramapil en $2 \mathrm{~mm}$ de relleno de HPLC en la punta de un capilar y separan posteriormente sus enantiómeros con ciclodextrinas, consiguiendo límites de detección 200 veces mejores que sin preconcentración. Li et al. [182] comparan el comportamiento de rellenos de $\mathrm{C}_{18}$ con el de una membrana de poli(estireno-divinilbenceno) para la extracción de lipopolisacáridos previa a su separación y detección mediante CZE-MS. Otras aplicaciones de esta técnica incluyen el uso de fases de inmunoafinidad [183], análisis de fármacos en orina [184] y el análisis directo de muestras biológicas [185].

Las técnicas propuestas anteriormente son válidas siempre y cuando el medio de separación sea compatible con la presencia del medio de elución (normalmente orgánico), y tienen como inconvenientes la pérdida de eficacia (el bolo de muestra no puede ser demasiado grande), aparición de picos con

[178] M. A. Strausbauch, S. J. Xu, J. E. Ferguson, M. E. Nunez, D. Machacek, G. M. Lawson, P. J. Wettstein, and J. P. Landers. Concentration and separation of hypoglycemic drugs using SPE-CE. J. Chromatogr. A, 717:279-91, 1995.

[179] J. H. Beattie, R. Self, and M. P. Richards. The use of solid phase concentrators for on-line preconcentration of metallothionein prior to isoform separation by CZE. Electrophoresis, 16:322-328, 1995 .

[180] C. B. Knudsen and J. H. Beattie. On-line SPE-CE for enhanced detection sensitivity and selectivity: application to the analysis of metallothionein isoforms in sheep fetal liver. J. Chromatogr. A, 792:463-473, 1997.

[181] J. Y. He, A. Shibukawa, M. Zeng, S. Amane, T. Sawada, and T. Nakagawa. On-capillary sample preconcentration incorporated in chiral CE. Anal. Sci., 12:177-181, 1996.

[182] J. Li, P. Thibault, A. Martin, J. C. Richards, W. W. Wakarchuk, and W. van der Wilp. Development of an on-line preconcentration method for the analysis of pathogenic lipopolysaccharides using CE-ES-MS. Application to small colony isolates. J. Chromatogr. A, 817:325-36, 1998. 
colas (volúmenes muertos en las uniones), e interferencias en el campo eléctrico debidas a la presencia en el capilar de diferentes medios. Para solucionar esto, Petersson et al. [186] utilizan un relleno empaquetado de 1-3 mm, controlando cuidadosamente las etapas de carga de muestra y de lavado con el medio de separación, que lo hacen desde el extremo de salida del capilar, para posteriormente inyectar una pequeña cantidad de disolvente orgánico en el extremo de entrada. Por otra parte, Tomlinson et al. emplean delgadas membranas poliméricas en lugar de lechos empaquetados para mejorar la eficacia de la separación y reducir los grandes volúmenes que con frecuencia son necesarios para extraer los compuestos [187, 188, 189, 190].

Más recientemente, Benavente et al. [191] han preconcentrado péptidos en partículas de $\mathrm{C}_{18}$ procedentes de un cartucho de extracción empaquetadas en un pequeño capilar de $250 \mu \mathrm{m}$. Por otra parte, Saavedra et al. [192] han

[183] N. A. Guzman, M. A. Trebilcock, and J. P. Advis. The use of a concentration step to collect urinary components separated by $\mathrm{CE}$ and further characterization of collected analytes by Ms. J. Liq. Chromatogr., 14:997-1015, 1991.

[184] M. E. Swartz and M. Merion. On-line sample preconcentration on a packed-inlet capillary for improving the sensitivity of capillary electrophoretic analysis of pharmaceuticals. $J$. Chromatogr., 632:209-213, 1993.

[185] I. Morita and J. I. Sawada. CE with on-line sample pretreatment for the analysis of biological samples with direct injection. J. Chromatogr., 641:375-381, 1993.

[186] M. Petersson, K. G. Wahlund, and S. Nilsson. Miniaturised on-line sPE for enhancement of concentration sensitivity in CE. J. Chromatogr. A, 841:249-261, 1999.

[187] A. J. Tomlinson and S. Naylor. Membrane preconcentration-CE-Ms in the analysis of biologically derived metabolites and biopolymers. Biomed. Chromatogr., 10:325-330, 1996.

[188] A. J. Tomlinson and S. Naylor. A strategy for sequencing peptides from dilute mixtures at the low femtomole level using membrane preconcentration-CE-MS/Ms). J. Liq. Chromatogr., 18:3591-3615, 1995 .

[189] A. J. Tomlinson, L. Benson, S. Jameson, D. H. Johnson, and S. Naylor. Utility of membrane preconcentration-CE-Ms in overcoming limited sample loading for analysis of biologically derived drug. J. Am. Soc. Mass Spectrom., 8:15-24, 1997.

[190] Q. Yang, A. J. Tomlinson, and S. Naylor. Membrane preconcentration CE. Anal. Chem., 71:183A-189A, 1999.

[191] F. Benavente, M. C. Vescina, E. Hernandez, V. Sanz-Nebot, J. Barbosa, and N. A. Guzman. Lowering the concentration limits of detection by on-line SPE-CE-ES-MS. J. Chromatogr. A, 1140:205-212, 2007.

[192] L. Saavedra, N. Maeso, A. Cifuentes, and C. Barbas. Development of a frit-free spe-based in-column preconcentration system for CE. J. Pharm. Biomed. Anal., 44:471-476, 2007. 
empleado un relleno polimérico procedente de un cartucho de SPE de intercambio catiónico, para retener 3-nitrotirosina en medio ácido y extraer el analito posteriormente con el medio de separación a $\mathrm{pH}$ 7,2. En el campo medioambiental, Zhang et al. [193, 194] han preconcentrado y separado clorofenoles en muestras acuosas con incrementos de sensibilidad de 4.000 veces.

\subsubsection{Preconcentración en columnas monolíticas}

Como ya se ha visto en la Parte II, un relleno monolítico está formado por la polimerización in situ de una mezcla de monómeros en el interior de un tubo capilar. Además de su aplicación más frecuente, como fase estacionaria en CEC o $\mu$ HPLC, la conexión in-line de una etapa de preconcentración antes de una separación por HPLC, CEC O CE es otro de sus posibles usos. Ya se ha comentado que este tipo de fases presentan las ventajas de su fácil fabricación, bajo coste y la posibilidad de diseñar fases con una polaridad y selectividad a medida, ya que es posible variar la composición de los monómeros y los disolventes porogénicos. La posibilidad de diseñar fases con distinta polaridad facilita la preconcentración de una gran varidad de analitos. Como principales inconvenientes se pueden destacar su falta de robustez y reproducibilidad como fases estacionarias para cromatografía. Sin embargo, hay que señalar que cuando se usan como medios de preconcentración, las características de eficacia o selectividad no son tan importantes como cuando se realiza una separación cromatográfica. Debido a que su fabricación resulta menos crítica cuando se usan en etapas de preconcentración, se puede considerar que son una buena alternativa a los sorbentes tradicionales y posiblemente su uso abrirá nuevas posibilidades analíticas.

El uso de polímeros monolíticos como fases de SPE no es muy antiguo. La primera publicación apareció en 1998 [195]. En ella, Xie et al., utilizando divinilbenceno comercial ( $80 \%$ con $20 \%$ de etilestireno) y dodecanol como

[193] L. H. Zhang, C. J. Zhang, X. Chen, Y. Q. Feng, and X. Z. Wu. In-capillary sPE-CE for the determination of chlorophenols in water. Electrophoresis, 27:3224-3232, 2006.

[194] L. H. Zhang and X. Z. Wu. CE with in-capillary spe sample cleanup. Anal. Chem., 79:25622569,2007 . 
disolvente porogénico, consiguen un monolito con una superficie específica de $400 \mathrm{~m}^{2} / \mathrm{g}$; la polimerización se efectuó térmicamente en el interior de un tubo de PEEK de $20 \times 1 \mathrm{~mm}$ y se usó en la retención de compuestos fenólicos. Debido a su gran hidrofobicidad, las fases monolíticas preparadas con monómeros aromáticos son especialmente adecuadas para retener compuestos no polares. Por el contrario, compuestos más polares presentan recuperaciones bajas. Este inconveniente puede subsanarse añadiendo a la mezcla porogénica pequeñas cantidades de monómeros polares, como el 2-hidroxietil metacrilato [19]; en estas condiciones se obtienen aumentos de la recuperación de fenol de un 58 a un $92 \%$.

La aplicación de una fase monolítica a la preconcentración in-line en CE fue publicada por primera vez en 2003 por Baryla y Toltl [196]. Estos autores prepararon $1 \mathrm{~cm}$ de polímero obtenido a partir de ácido metacrílico para la preconcentración y la separación por CE de propanolol. En primer lugar, la muestra se bombea a través del capilar y el exceso se lava con agua. Posteriormente el capilar se llena con el tampón de separación-elución desde el extremo de salida usando el EOF como bomba; el tampón de separación desorbe la muestra y la concentra en una pequeña banda. Se mide la corriente que pasa por el circuito como parámetro indicativo de cuándo el capilar está lleno y la muestra extraída. Al principio la corriente es muy pequeña porque el capilar está relleno con agua, pero crece rápidamente hasta alcanzar una corriente constante, que indica que el capilar está lleno de tampón de separación. En este momento se invierte el voltaje y comienza la separación. Con este procedimiento estos autores obtuvieron buenos factores de preconcentración; sin embargo, hay que señalar que solamente analizan un compuesto. Shaller et al. [197] siguen el mismo método que los anteriores y consiguen una buena separación de tres antidepresivos. En este caso el polímero empleado se obtiene a partir de metacrilato de butilo con pequeñas

[195] S. Xie, F. Svec, and J. M. J. Fréchet. Porous polymer monoliths: Preparation of sorbent materials with high-surface areas and controlled surface chemistry for high-throughput, online, SPE of polar organic compounds. Chem. Mater., 10:4072-4078, 1998.

[196] N. E. Baryla and N. P. Toltl. On-line preconcentration in CE using monolithic methacrylate polymers. Analyst, 128:1009-1012, 2003.

[197] D. Schaller, E. F. Hilder, and P. R. Haddad. Separation of antidepressants by CE with in-line sPE using a novel monolithic adsorbent. Anal. Chim. Acta, 556:104-111, 2006. 
cantidades de metacrilato de 3-sulfopropilo. En 1996 Breadmoore [198] polimeriza mediante luz uv los mismos monómeros que los anteriores para la retención y posterior separación de aminoácidos.

Otras aplicaciones de polímeros monolíticos como medios de extracción también incluyen mecanismos de retención tales como inmunoextración [199] o polímeros impresos [200, 201].

\subsubsection{Preconcentración en columnas de electrocromatografía capilar}

En CEC también se pueden aprovechar las fases estacionarias como medio de preconcentración antes de la separación. Ping et al. [202] comprueban que los analitos no se distribuyen uniformemente durante la inyección en una columna de CEC como lo hacen en CZE, sino que el bolo de la muestra es más corto debido al reparto con la fase estacionaria. Con un monolito de basado en metacrilato de butilo mejoran la sensibilidad de un solo analito hasta 20.000 veces sin separación. Starkey et al. [203] polimerizan una mezcla basada en acrilamida y consiguen detectar isoflavonas en suero sin pérdida de resolución inyectando disoluciones acuosas durante 90 s. Con este procedimiento los límites de detección son de $100 \mu \mathrm{g} / \mathrm{L}, 7$ veces inferiores a los obtenidos con inyección directa. El mismo grupo ha diseñado un método

[198] M. C. Breadmoore. Preconcentration and frontal electroelution of amino acids for in-line SPE-CE. Anal. Chim. Acta, 556:121-126, 2006.

[199] J. M. Armenta, B. Gu, P. H. Humble, C. D. Thulin, and M. L. Lee. Design and evaluation of a coupled monolithic preconcentrator-CZE system for the extraction of immunoglobulin G from human serum. J. Chromatogr. A, 1097:171-178, 2005.

[200] F. J. Lara, F. Lynen, P. Sandra, A. M. García-Campaña, and F. Alés-Barrero. Evaluation of a molecularly imprinted polymer as in-line concentrator in CE. Electrophoresis, 29:3834, 2008.

[201] M. Zhang, J. Xie, Q. Zhou, G. Chen, and Z. Liu. On-line sPE of ceramides from yeast with ceramide III imprinted monolith. J. Chromatogr. A, 984:173-183, 2003.

[202] G. Ping, Y. Zhang, W. Zhang, L. Zhang, P. Schmitt-Kopplin, and A. Kettrup. On-line concentration of neutral and charged species in CEC with a methacrylate-based monolithic stationary phase. Electrophoresis, 25:421-7, 2004.

[203] J. A. Starkey, Y. Mechref, C. K. Byun, R. Steinmetz, J. S. Fuqua, O. H. Pescovitz, and M. V. Novotny. Determination of trace isoflavone phytoestrogens in biological materials by CE. Anal. Chem., 74:5998-6005, 2002. 
diferente evitando cambiar el medio de separación y el de inyección, introduciendo un bolo de agua que precede a los analitos. Este bolo de agua modifica las características de la fase estacionaria y la hace más afín por los componentes de la muestra [203].

En la actualidad los procesos de preconcentarción in-line acoplados a CE están siendo objeto de múltiples investigaciones. Tres recopilaciones actualizadas en la fecha de escritura de esta memoria son las de Puig et al. [156, 204] y la de Saavedra y Barbas [205].

\section{3. ОВJеTIVO}

El objetivo de esta parte de la tesis es el desarrollo de un método electroforético para la separación de 13 compuestos (plaguicidas carbámicos y metabolitos) mediante мекс. Debido a la naturaleza débilmente básica de dos de los compuestos estudiados (Carbendazima y Pirimicarb), se ha optimizado la separación de estos dos compuestos mediante CZE en medio ácido.

Debido a la falta de sensibilidad de la CE, uno de los objetivos de este trabajo es el desarrollo de métodos que incluyan la preconcentración en un capilar usando polímeros monolíticos de divinilbenceno. Según que la técnica de separación posterior sea MEKC o CZE, se ha trabajado con configuraciones diferentes. En el caso de una separación mediante MEKC, la preconcentración y extracción tiene lugar en un capilar diferente al de la posterior separación. En el caso de utilizar cze la preconcentración se realiza in-line.

[204] P. Puig, F. Borrull, M. Calull, and C. Aguilar. Sorbent preconcentration procedures coupled to CEC for environmental and biological applications. Anal. Chim. Acta, 616:1$18,2008$.

[205] L. Saavedra and C. Barbas. Chromatography-based on- and in-line preconcentration methods in CE. J. Biochem. Biophys. Methods, 70:289-297, 2007. 



\section{PARTE EXPERIMENTAL}

\subsection{INSTRUMENTAL}

La separación electroforética se ha llevado a cabo empleando el equipo descrito en la página 73. Además de los viales habituales de polipropileno de $1 \mathrm{~mL}$, se utilizaron viales para pequeños volúmenes de muestra (microviales de $100 \mu \mathrm{L})$.

Los capilares de sílice fueron de la casa Polymicro Technologies; se empleó tubería de teflón de $350 \mu \mathrm{m}$ de diámetro interno para unir capilares.

Se empleó un termostato de inmersión SBS para la polimerización de los capilares, así como material usual de laboratorio: micropipetas, baño de ultrasonidos, balanza analítica, material de vidrio, etc.

\subsection{REACTIVOS Y DISOLUCIONES}

Los patrones de plaguicidas y metabolitos fueron de una pureza superior al 98,5\%. Se obtuvieron en su mayor parte de Dr. Ehrenstorfer: Carbofurano, Propoxur, Metiocarb, Carbarilo, Carbetamida, Aldicarb, sulfóxido de Aldicarb, Isopropoxifenol, 1-Naftol y Carbendazima. Pirimicarb, Metomilo y Asulam fueron de Fluka.

Se prepararon disoluciones madre de todos los plaguicidas y sus metabolitos en metanol con una concentración de $200 \mathrm{mg} / \mathrm{L}$, a partir de las cuales se obtuvieron, por dilución, las disoluciones de trabajo. Todas las disoluciones se almacenaron a $4{ }^{\circ} \mathrm{C}$ en ausencia de luz. 
El tensioactivo SDS y el ácido acético (calidad de HPLC) fueron suministrados por Scharlau y Fluka, respectivamente. Los disolventes orgánicos empleados (acetonitrilo y metanol) fueron de Merck con calidad de HPLC. El agua se obtuvo mediante un sistema de purificación de agua Elgastat UHQ. El resto de reactivos empleados para la preparación de tampones y demás disoluciones fueron de calidad «reactivo analítico».

Los monómeros utilizados en la formación de los polímeros fueron: metacrilato de butilo (BMA, 99\%, de Aldrich), divinilbenceno (DVB, 80\%, con impurezas de 3- y 4-etilbenceno, de Fluka), dimetacrilato de etileno (98\%, de Aldrich). Los disolventes porogénicos empleados fueron: 1,4-butanodiol (99\%, de Riedel-de Haën), 1-propanol (99,9\%, de Riedel-de Haën) y octanol (>99\%, de Aldrich). Se empleó metacrilato de 3-(trimetoxisilil)propilo ( $\gamma$ MAPS, de Fluka) como agente derivatizante de la pared interna del capilar, y 2,2'-Azobis(2-metil-propionitrilo) (AIBN, de Acros Organics), como iniciador de la polimerización.

\subsection{PROCEDIMIENTOS}

\subsubsection{Separación de plaguicidas carbámicos mediante МЕKC}

Los capilares nuevos deben ser acondicionados antes de su uso mediante los siguientes pasos:

- Lavado a presión (1 bar) durante 20 min con $\mathrm{NaOH}$ o,1 M.

- Lavado a presión (1 bar) durante 10 min con el electrolito en el que se lleva a cabo la separación.

- Aplicación de una diferencia de potencial de $30 \mathrm{kV}$ durante $2 \mathrm{~min}$ para asegurar que la intensidad de corriente es estable.

Diariamente, antes de comenzar la sesión de trabajo, el capilar se trata de igual manera reduciendo a la mitad los tiempos de cada uno de estos pasos.

Las condiciones de separación elegidas como óptimas son: 
- Capilar de $75 \mu \mathrm{m}$, con 58,5 cm de longitud total y $50 \mathrm{~cm}$ de longitud efectiva.

- Electrolito de separación compuesto por 6o mM de SDS y 20 mM de tampón bórico-borato $(\mathrm{pH}=9,2)^{*}$ en agua ultrapura. Esta disolución se mantiene refrigerada durante dos semanas.

- Las muestras son acuosas, y contienen el metanol residual de las disoluciones patrón $(<10 \%)$.

- La inyección es hidrodinámica: 25 mbar durante 4 s.

- El voltaje de separación es de $30 \mathrm{kV}$ durante $7 \mathrm{~min}$.

- Entre análisis consecutivos se realiza un lavado a presión de 2 min con el electrolito de separación.

La detección se lleva a cabo espectrofotométricamente. La identificación de los plaguicidas se realiza a partir de sus diferentes tiempos de migración y mediante la comparación de sus espectros de absorción de uv con los de la base de datos.

Las variables cuantitativas son la altura y el área de pico corregida (relación entre el área y tiempo de migración). Las longitudes de onda empleadas para la cuantificación de cada analito son las siguientes: sulfóxido de Aldicarb, Aldicarb, Isopropoxifenol, Carbetamida, Propoxur, Carbofurano y Metiocarb, 200 nm; Metomilo, 234 nm; Carbarilo, 222 nm; Pirimicarb, 246 nm; Asulam, $255 \mathrm{~nm}$; y Carbendazima, $284 \mathrm{~nm}$. La cuantificación se realiza mediante patrón externo.

\subsubsection{Separación de Pirimicarb y Carbendazima mediante CZE}

El acondicionado de capilares nuevos se lleva a cabo igual que en el caso de la separación mediante МЕKc.

Las condiciones de separación son:

*El tampón se añade diluyendo la cantidad adecuada de una disolución de tetraborato sódico $200 \mathrm{~mm}$, sin ajustar el $\mathrm{pH}$. 
- Capilar de $75 \mu \mathrm{m}$, con 58,5 cm de longitud total y $50 \mathrm{~cm}$ de longitud efectiva.

- Electrolito de separación compuesto por $15 \mathrm{mM}$ de SDS, $1 \mathrm{M}$ de ácido acético $(5,7 \%, \mathrm{v} / \mathrm{v})$ y $2 \%(\mathrm{v} / \mathrm{v})$ de agua en acetonitrilo. Esta disolución se prepara diariamente.

- Inyección hidrodinámica de 25 mbar durante $4 \mathrm{~s}$.

- El voltaje de separación es de $30 \mathrm{kV}$ durante $8 \mathrm{~min}$, o hasta la aparición del EOF.

- Entre análisis consecutivos se realiza un lavado a presión de 2 min con el electrolito de separación.

La detección y cuantificación se lleva a cabo del mismo modo que en la separación mediante MEKC, con la única diferencia de las longitudes de onda empleadas para la detección: $\mathbf{2 4 1} \mathbf{~ n m}$ para Pirimicarb y $220 \mathbf{n m}$ para Carbendazima.

\subsubsection{Fabricación de polimeros monolíticos}

En un vial de $10 \mathrm{~mL}$ se pesan el iniciador (AIBN), el divinilbenceno y el 1octanol en la proporción 1/100/300. La disolución se introduce en un baño de ultrasonidos durante 15 min para disolver el AIBN y desgasificarla. Con la ayuda de una jeringa se rellena la longitud deseada de un capilar y se tapan los extremos pinchándolos con dos trozos de septo de silicona. El capilar se introduce en un baño de $60^{\circ} \mathrm{C}$ durante $16 \mathrm{~h}$. Tras sacar el capilar del baño ya polimerizado, se le fabrica una ventana de detección a $8,5 \mathrm{~cm}$ del extremo vacío y se lava con metanol aplicando 1 bar de presión en el equipo de CE hasta la obtención de una línea base estable. Tras el lavado, el capilar se corta para obtener la longitud de polímero deseada.

Los capilares utilizados fueron derivatizados previamente con $\gamma$-MAPs mediante el procedimiento indicado en la página 80. 


\subsubsection{Separación de plaguicidas carbámicos mediante МЕКС tras una etapa de preconcentración en un polímero monolítico}

Este método comprende dos partes. En primer lugar la preconcentración de una muestra acuosa en un capilar relleno de un polímero monolítico, y después el intercambio del cartucho que contiene el capilar de preconcentracion por el cartucho que contiene el capilar de separación. La Tabla 10.2 y la Figura 10.3 en las páginas 148 y 149, respectivamente, recogen esquemáticamente el proceso.

\section{Preconcentración y elución en el polímero creado}

Las dimensiones del capilar fueron de $100 \mu \mathrm{m} \times 40 \mathrm{~cm}$, con $16 \mathrm{~cm}$ de polímero en el extremo de entrada. Todas las muestras son pasadas por un filtro de nailon de 0,22 $\mu \mathrm{m}$ para evitar la obstrucción de los polímeros empleados. El proceso de preconcentración y extración queda descrito mediante las siguientes etapas:

- Lavado y paso de muestra aplicando 12 bar en el vial de entrada. En este paso todo lo que se pasa a través del capilar cae en un vial de desecho.

* Lavado del monolito con metanol durante 1 minuto para arrastar sustancias retenidas de análisis anteriores.

* Acondicionado del polímero con agua durante 1 min.

* Paso de la muestra acuosa durante 15-30 min.

* Lavado con agua para reemplazar la matriz de la muestra antes de la elución con metanol.

- Elución de la muestra con metanol ( 1 bar) hasta la aparición en la ventana de detección del pico del extracto y caída hasta el 10\% de la altura máxima del pico. En esta etapa el vial de salida es un microvial de $100 \mu \mathrm{L}$. 


\section{Separación electroforética}

Tras la elución de los analitos en el microvial, el cartucho del capilar donde ha tenido lugar la preconcentración se sustituye por el de la separación. La separación mediante MEKC, identificación y cuantificación se llevan a cabo siguiendo los procedimientos descritos en la Sección 9.3.1, inyectando directamente desde el microvial donde se han recogido los analitos eluidos.

\subsubsection{Separación de Pirimicarb y Carbendazima mediante CZE tras una etapa de preconcentración in-line}

En este método la preconcentración tiene lugar en el mismo capilar en el que posteriormente tendrá lugar la separación (preconcentración in line). Tras lavar el capilar con agua, éste se llena con el medio de separación desde el extremo de salida aplicando una diferencia de potencial negativa. El medio de separación utilizado es el descrito en la Sección 9.3.2 (15 mM de sDs, $1 \mathrm{M}$ de ácido acético $(5,7 \%, \mathrm{v} / \mathrm{v})$ y $2 \%(\mathrm{v} / \mathrm{v})$ de agua en acetonitrilo). En la Figura 10.21 de la página 187 se describe esquemáticamente el proceso.

\section{Preconcentración y separación}

Se emplea un capilar de $75 \mu \mathrm{m} \times 50 \mathrm{~cm}$, con $5 \mathrm{~cm}$ de polímero en el extremo de entrada. Este extremo se une a un capilar vacío de $7,5 \mathrm{~cm}$ con la ayuda de un tubo de teflón de 1,5 cm de longitud y $350 \mu \mathrm{m}$ de diámetro interno.

Todas las muestras son filtradas con ayuda de una jeringa (filtros de nailon de $0,22 \mu \mathrm{m}$ ) para evitar la obstrucción de la fase estacionaria. El proceso de preconcentración, elución y separación queda descrito mediante las siguientes etapas:

- Lavado y paso de muestra. En esta etapa todo lo que se pasa a través del capilar cae en un vial de desecho.

* Lavado del monolito con el medio de separación durante 1 minuto para arrastar sustancias retenidas y posibles restos de plaguicidas de análisis anteriores ( 2 bar durante 1 min). 
* Acondicionado del polímero con agua (2 bar durante 1 min).

* Paso de la muestra acuosa durante 15-30 minutos en función de la concentración (12 bar).

* Lavado con agua para reemplazar la matriz de la muestra antes del relleno con el medio de separación y eliminar todas las especies iónicas presentes ( 2 bar durante $1 \mathrm{~min}$ ).

- Elución de la muestra con el BGE aplicando voltaje negativo $(-15 \mathrm{kV})$ hasta alcanzar un valor de corriente del $70 \%$ de la intensidad máxima (en valor absoluto, ya que tiene valor negativo). En este punto, tanto los viales de entrada como de salida contienen el medio de separación.

- Separación electroforética. Aplicación de $30 \mathrm{kV}$. La detección y cuantificación se efectúa como en 9.3.2. 



\section{RESULTADOS Y DISCUSIÓN}

\subsection{PRECONCENTRACIÓN Y SEPARACIÓN DE PLAGUICIDAS CARBÁMI- COS MEdiANTE CROMATOGRAFía ELECTROCINÉTICA MICELAR}

\subsubsection{Separación mediante cromatografía electrocinética micelar}

Debido al carácter neutro de la mayoría de los compuestos estudiados, la modalidad de cromatografía electrocinética micelar (МЕKC) es una de las opciones válidas para su separación. Como ya se ha dicho anteriormente, la adición de un tensioactivo en una concentración superior a su CMc al electrolito de separación posibilita la separación de compuestos neutros debido a las diferencias en sus constantes de reparto entre el interior de la micela y el seno de la disolución.

Para encontrar las condiciones óptimas de la separación de los 12 compuestos (entre plaguicidas y metabolitos) se comenzó realizando unos ensayos previos empleando condiciones similares a las utilizadas por Wu et al. [142, 143], con $10 \mathrm{~mm}$ de tampón fosfato a $\mathrm{pH} 7$ y $60 \mathrm{~mm}$ de dodecil sulfato sódico (SDS) como agente formador de micelas. Se inyectaron disoluciones de patrones de todos los analitos por separado para comprobar sus tiempos de migración y guardar sus espectros de absorción uv-visible en la base de datos para posteriores identificaciones. Los resultados obtenidos distan bastante de los obtenidos por Wu et al.; los compuestos comigran, los picos son anchos, y el último, el Metiocarb, migra después de 20 minutos. Modificando las concentraciones de tampón entre 5 y $30 \mathrm{~mm}$ y tensioactivo entre 20 y 8o mm tampoco se obtuvieron resultados satisfactorios. 
Tras cambiar el electrolito por un tampón de bórico-borato ( $\mathrm{pH} 9,2)$ los electroferogramas mejoraron notablemente; se obtuvieron picos más estrechos y un tiempo de análisis considerablemente menor (5-10 min). Sin embargo, hay que indicar que en estas condiciones no todos los analitos se encontraban resueltos.

\section{Optimización de la separación}

A la vista de los resultados obtenidos, se procedió a la optimización de la separación trabajando con bórico-borato como tampón. La separación electroforética se optimizó variando la concentración de tampón, la de SDS, el voltaje aplicado, la temperatura y la adición de un componente orgánico (metanol).

Se llevó a cabo un diseño factorial fraccionado con dos niveles por cada factor. Los niveles los factores se muestran en la Tabla 10.1. Se incluyó un experimento repetido con valores intermedios de cada factor para estimar el fallo de ajuste y para comprobar si existen componentes no lineales en el modelo ajustado. El orden de experimentación fue aleatorio.

Los electroferogramas de los 16 experimentos del estudio se muestran en la Figura 10.1. Se puede observar que existen tres zonas críticas para la obtención de una buena separación de todos los compuestos:

1. La separación entre Carbofurano y Aldicarb (marcada en amarillo en la figura).

2. El conjunto de señales que forman el Isopropoxifenol, la Carbetamida y el Propoxur, que en función de la composición del tampón de separación cambian su orden de migración (marcada en verde).

3. Carbarilo y Pirimicarb, cuyo orden de migración se ve afectado por la presencia de metanol (marcada en naranja).

El resto de componentes de la muestra se encuentran resueltos en todo momento, excepto Carbofurano y 1-Naftol en un experimento. 

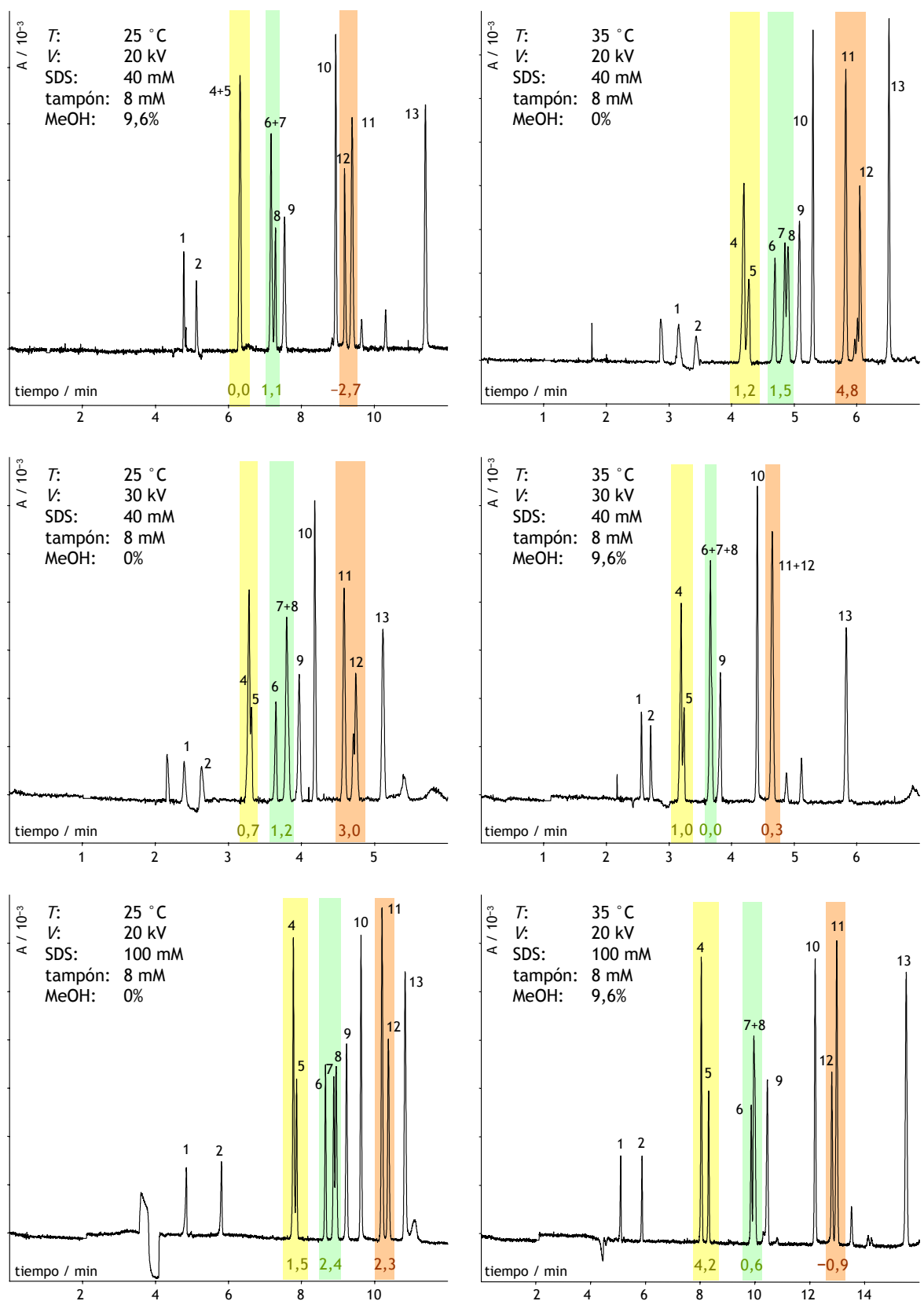

Figura 10.1. Optimización de la separación mediante MEKc. Electroferogramas de $\operatorname{los} 2^{4}$ experimentos. Aparecen en texto coloreado los valores de las 3 respuestas evaluadas.

Leyenda: 1, sulfóxido de Aldicarb; 2, Metomilo; 3, Asulam; 4, Carbendazima; 5, Aldicarb; 6, Isopropoxifenol; 7, Carbetamida; 8, Propoxur; 9, Carbofurano; 10, 1-Naftol; 11, Carbarilo; 12, Pirimicarb; y 13, Metiocarb. 

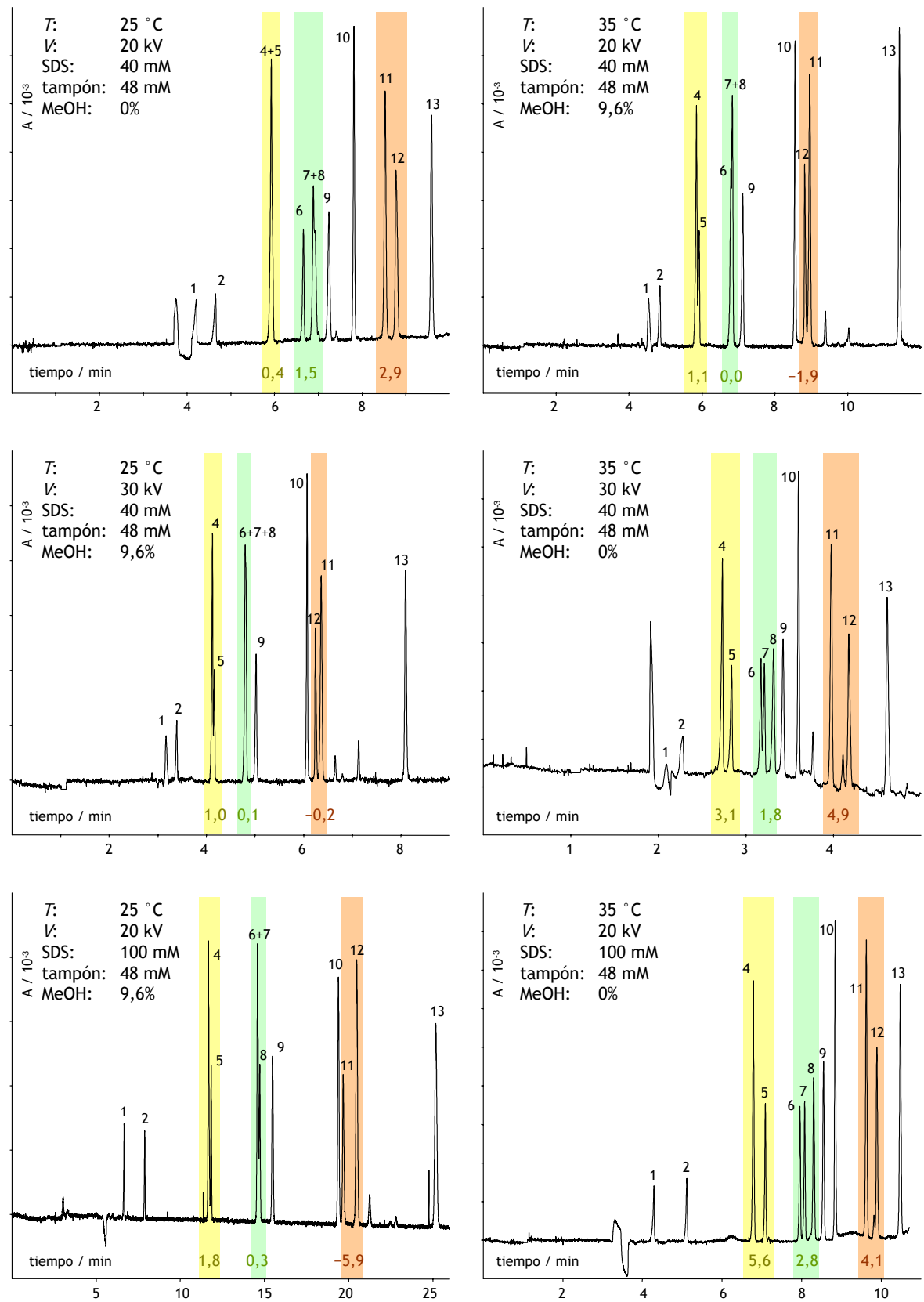

Figura 10.1. Continuación. 

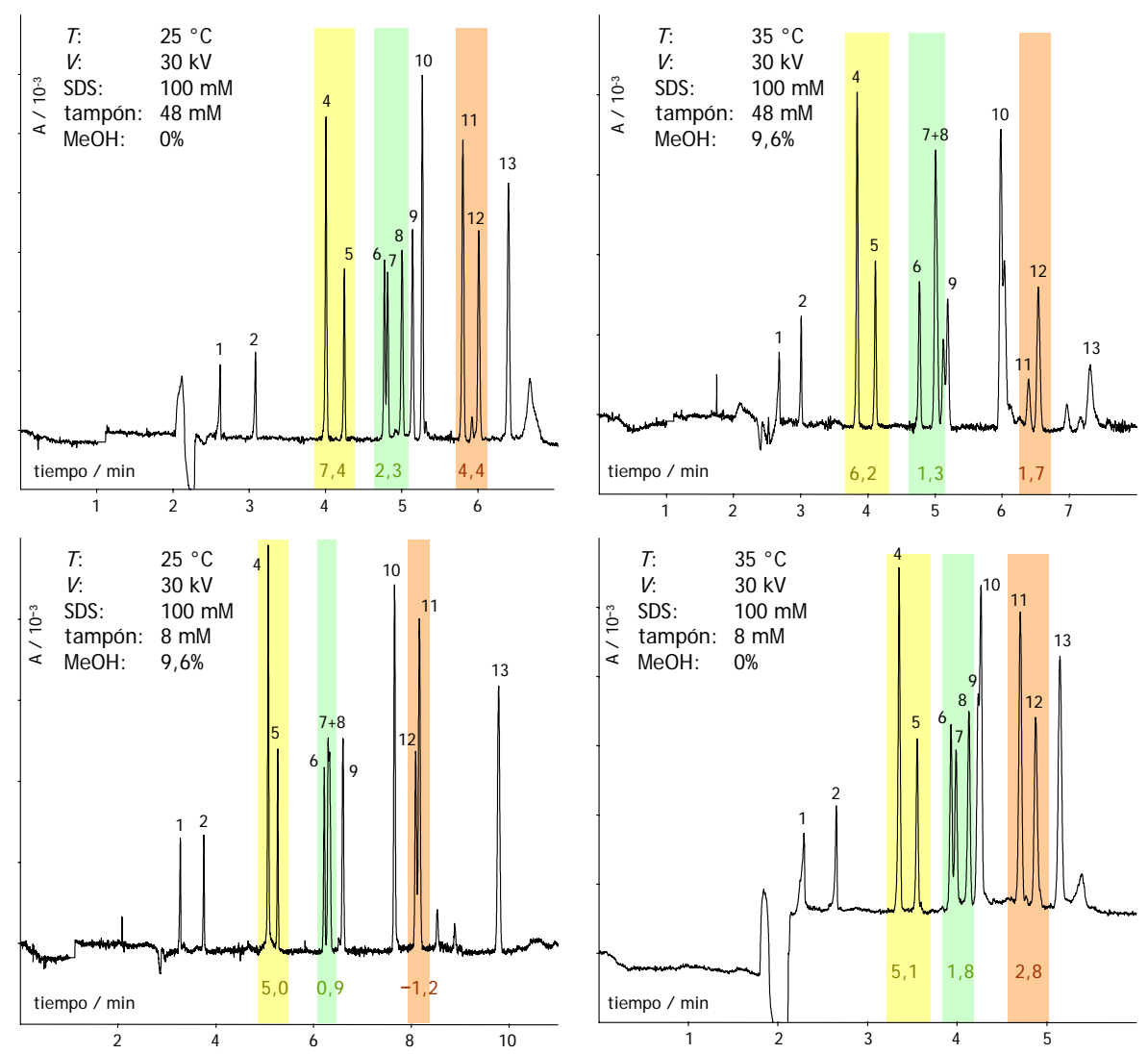

Figura 10.1. Continuación. 
Tras un estudio de los electroferogramas, las variables escogidas como respuestas han sido:

- $R_{1}$ : la resolución entre Carbendazima y Aldicarb.

- $R_{2}$ : la media geométrica de la resolución entre los tres picos consecutivos de Isopropoxifenol, Carbetamida y Propoxur.

- $R_{3}$ : la resolución entre Carbarilo y Pirimicarb.

En la Tabla 10.1 también aparecen los valores de los efectos de todos los factores en las tres respuestas.

Los datos experimentales se ajustaron mediante mínimos cuadrados al modelo más sencillo que no dio fallo de ajuste. En la Tabla 10.1 se muestran, para cada respuesta, los valores de cada efecto, su intervalo de confianza para una probabilidad del $95 \%$, el fallo de ajuste calculado para el modelo propuesto y el coeficiente de correlación. Se puede comprobar cómo el fallo de ajuste es en todo momento superior a 0,05, por lo que no fue necesario incluir en el modelo los efectos debidos a las interacciones de dos factores.

Se observa que para la separación entre Carbendazima y Aldicarb $\left(R_{1}\right)$ es especialmente significativa la concentración de SDS y en menor medida el voltaje aplicado y la temperatura de separación; los tres factores afectan de un modo positivo a la separación. A la separación de Isopropoxifenol, Carbetamida y Propoxur $\left(R_{2}\right)$ le afecta positivamente la concentración de SDS y negativamente la de metanol. La resolución entre Carbarilo y Pirimicarb $\left(R_{3}\right)$ se ve afectada principalmente por la presencia de metanol en el medio de separación hasta el punto de alterar el orden de migración de estos dos analitos y conseguirse una buena separación en los dos niveles extremos del diseño.

Para seguir trabajando en unas condiones adecuadas para la separación de todos los analitos al mismo tiempo se maximizó una función de deseabilidad en la que se asignaron valores 1 a resoluciones mayores de 2 y valores de o a las menores de 1,5. Las condiciones óptimas encontradas por el programa informático incluían varias opciones entre las que se probaron las más ade- 


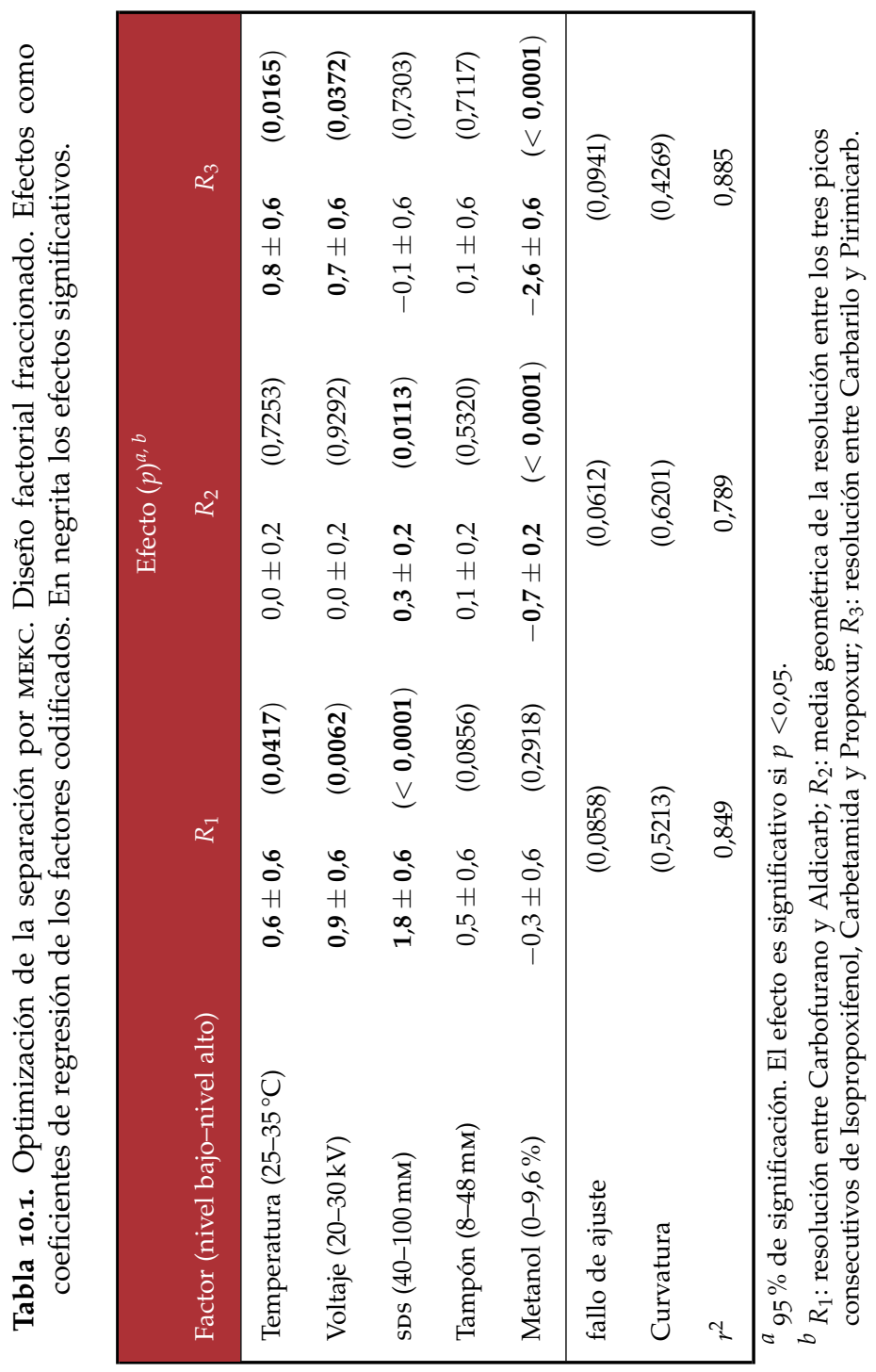


cuadas; aquellas que ofrecieron menores tiempos de análisis, intensidades menores de $100 \mu \mathrm{A}$, etc.

Se decidió continuar trabajando con las siguientes condiciones: $30^{\circ} \mathrm{C}$ de temperatura, $30 \mathrm{kV}$ de voltaje de separación, 6o mM de SDS, $20 \mathrm{~mm}$ de tampón bórico-borato y en ausencia de metanol en el medio de separación. No se llevaron a cabo etapas posteriores de optimización al haber alcanzado ya una buena separación de todos los analitos en un tiempo razonable. La Figura 10.2 muestra la separación de $\operatorname{los} 13^{*}$ analitos en las condiciones elegidas.

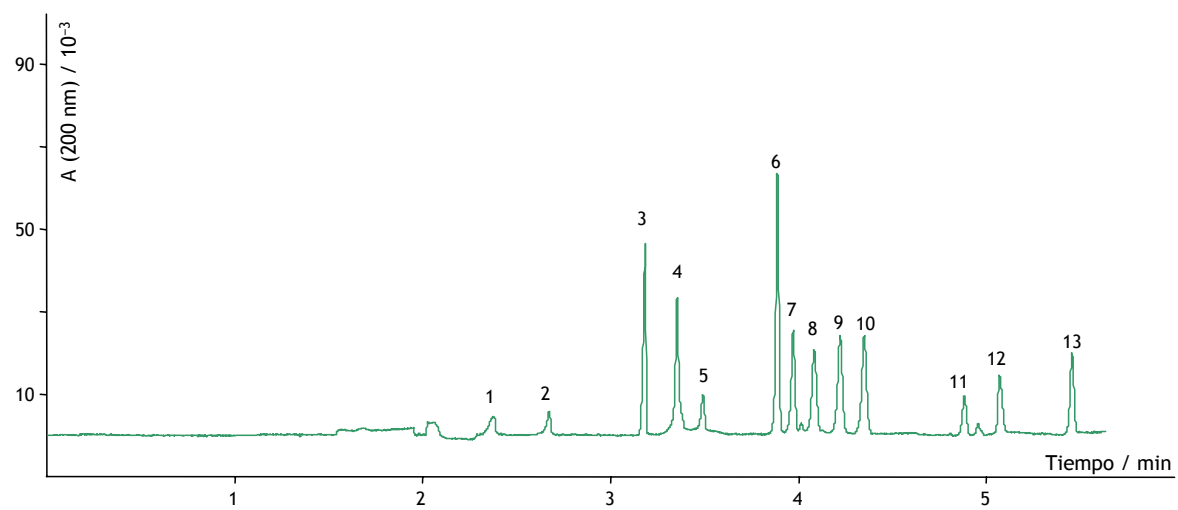

Figura 10.2. Separación optimizada de $35 \mathrm{mg} / \mathrm{L}$ de los 13 plaguicidas carbámicos mediante MEKC. Medio de separación: $60 \mathrm{~mm}$ de SDS y $20 \mathrm{~mm}$ de tampón bórico-borato. Otras condiciones: $30^{\circ} \mathrm{C}, 30 \mathrm{kV}$. Identificación de picos como en la Figura 10.1.

\subsubsection{Preconcentración y separación mediante cromatografía electrocinética micelar}

Según se ha visto en la introducción de esta tercera parte, el acoplamiento ideal entre una preconcentración mediante SPE y una separación electroforética se consigue cuando el sorbente se coloca dentro del capilar de separa-

*Después de optimizada la separación se incluyó un nuevo analito, el Asulam (pico 3). Su tiempo de migración se encuentra entre el del Metomilo y el del Carbendazima, y está perfectamente resuelto. Su migración neta no se debe a su interacción con el medio micelar sino a su movilidad electroforética, por ser un compuesto cargado negativamente al $\mathrm{pH}$ en el que tiene lugar la separación. 
ción, y una vez que la preconcentración ha tenido lugar, la muestra eluida se separa electroforéticamente (preconcentración in-line) sin ningún tipo de dilución. A pesar de que en los últimos años varios autores han trabajado con in-line-SPE-CE, hasta la fecha ninguno de ellos ha utilizado MEKC como medio de separación debido a la destrucción del medio micelar por los disolventes orgánicos empleados para eluir los analitos. En nuestro caso, en todos los intentos de hacer la retención, el lavado, el llenado con el medio de separación y la elución con un pequeño volumen de disolvente orgánico, la separación resultó en un solo pico de todos los compuestos sin resolver debido a la ausencia de micelas en el bolo en el que son arrastrados los analitos.

Para conseguir la preconcentración en un capilar monolítico y la posterior separación mediante MEKC se propone un sistema en que la retención de los compuestos se efectúa en un capilar diferente a aquél en el que tiene lugar la separación. La preconcentración tiene lugar aplicando presión en el equipo de CE en un sorbente polimérico monolítico sintetizado en el interior de un capilar de sílice. Una vez que la muestra ha pasado por el sorbente, ésta se eluye con metanol sobre un vial vacío. El cartucho con el capilar de preconcentración se sustituye por el que contiene el capilar de separación, y la separación tiene lugar inyectando el extracto recogido en la elución. Este modo de preconcentración permite la retención y elución de pequeños volúmenes de muestra (hasta $1 \mathrm{~mL}$ ) de modo consecutivo, que después se analizan mediante MEKC.

De forma general, los pasos se muestran en la Tabla 10.2 y la Figura 10.3, y de modo más detallado en la Sección 9.3.1 (pág. 132).

\section{Polímeros de metacrilato de butilo}

Los primeros estudios se realizaron utilizando los polímeros monolíticos empleados en la construcción de columnas para CEC, es decir, polímeros basados en metacrilato de butilo (BMA), con dimetacrilato de etilén glicol (EGDMA) como entrecruzador, y 1,4-butanodiol, 1-propanol y agua como disolventes porogénicos. 
Tabla 10.2. Etapas generales de la preconcentración de plaguicidas en un capilar monolítico para su separación mediante MEKC

\begin{tabular}{|lllllll|}
\hline & & Etapa & Entrada & Salida & & \\
\hline & 1 & Lavado & Metanol & Desecho & $2-12$ bar & $1 \mathrm{~min}$ \\
Capilar de & 2 & Lavado & Agua & Desecho & $2-12$ bar & $1 \mathrm{~min}$ \\
preconcentración & 3 & Preconcentración & Muestra & Desecho & $2-12$ bar & $5-30 \mathrm{~min}$ \\
& 4 & Lavado & Agua & Desecho & $2-12$ bar & $1 \mathrm{~min}$ \\
& 5 & Elución & Metanol & Microvial & 1 bar & \\
\hline Capilar de & 6 & Inyección & Muestra recogida & BGE & $25 \mathrm{mbar}$ & $4 \mathrm{~s}$ \\
separación & 7 & Separación & BGE & BGE & $30 \mathrm{kV}$ & \\
\hline
\end{tabular}

Para conseguir unas características aptas para su uso como sorbentes es preciso que sean capaces de permitir fácilmente el paso de muestra. Debido a ello se necesita una composición diferente a la utilizada en CEC, que empleaba presiones de 200-400 bar para lavar las columnas. Estas presiones no pueden ser aplicadas por el equipo de CE cuya máxima presión es de 12 bar. La proporción de disolventes empleada en este caso fue del $75 \% \mathrm{p} / \mathrm{p}$, frente al $54 \%$ empleado para columnas de CEC. La composición exacta se muestra en la Tabla 10.3.

Tabla 10.3. Composición ( $\%, \mathrm{p} / \mathrm{p})$ del polímero de butil metacrilato usado para la preconcentración previa separación mediante MEKC

\begin{tabular}{|l|lll|}
\hline Monómeros & $25 \%$ & BMA & $40 \%$ \\
& & EGDMA & $60 \%$ \\
\hline Disolventes & $75 \%$ & 1-propanol & $62 \%$ \\
& & 1,4-butanodiol & $28 \%$ \\
& & Agua & $10 \%$ \\
\hline Iniciador & $1 \%$ de los monómeros & AIBN & \\
\hline
\end{tabular}



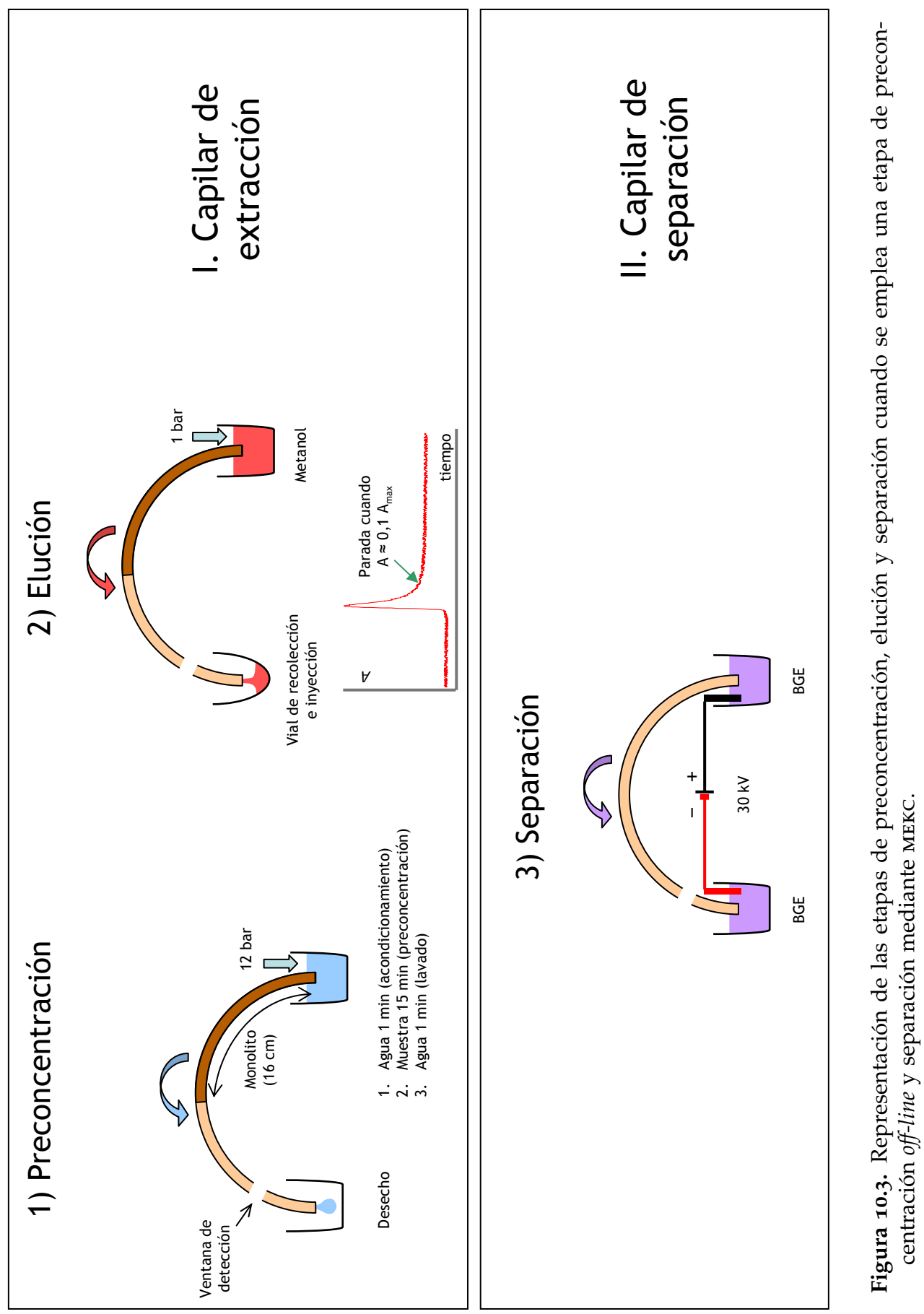
En las primeras pruebas efectuadas se rellenaron $25 \mathrm{~cm}$ de un capilar de $100 \mu \mathrm{m}$ con la pared interna tratada con $\gamma$-MAPs (procedimiento en pág. 80) con la mezcla de monómeros y disolventes, dejando $8,5 \mathrm{~cm}$ vacíos en un extremo. El capilar con la mezcla polimerizante se mantuvo en un baño a $60^{\circ} \mathrm{C}$ durante $60 \mathrm{~min}$. El polímero resultante permite su lavado con metanol en el equipo de CE.

Para comprobar la retención, lavado y elución de los analitos, se monitorizó la absorbancia de una disolución de $35 \mathrm{mg} / \mathrm{L}$ tras su paso por el polímero de BMA (Figura 10.4). También se muestra la presión aplicada en el vial de entrada durante las diferentes etapas. Durante la preconcentración de la muestra, la señal crece rápidamente, debido a la llegada del frente de la muestra a la ventana de detección, momento a partir del cual la señal se mantiene constante hasta la etapa de lavado con agua, cuando la línea base vuelve a su origen. Este hecho indica que los analitos no se retienen completamente en el polímero de BMA, y debido a ello se produce una señal cuando los analitos pasan por el detector. Estos polímeros presentan una baja superficie específica y por ello el mecanismo de retención predominante es la absorción. Este mecanismo sigue una cinética lenta y sólo se alcanza el equilibrio tras un largo tiempo de contacto entre polímero y disolución. Durante la elución con metanol, los analitos retenidos originan una señal elevada y transitoria. La cantidad óptima de metanol para la elución de la muestra se estableció cuando la señal decreció hasta el 10\% del máximo observado.

Para comprobar la efectividad real de la preconcentración en este tipo de material, se procedió a la recolección de los analitos eluidos con metanol sobre $10 \mu \mathrm{L}$ de agua dispuestos en un microvial*, interrumpiendo la recolección cuando los analitos hubieron pasado por la ventana de detección, es decir, cuando la absorbancia máxima fue un 10\% de la máxima señal registrada. Tras ello, se intercambió el cartucho por aquél con el capilar de la separación, y se inyectó el extracto recogido. Las Figuras 10.5-A y 10.5-B muestran los electroferogramas de la muestra inyectada directamente y del extracto recogido, respectivamente. Se observa que empleando los políme-

\footnotetext{
${ }^{*}$ Los $10 \mu \mathrm{L}$ de agua fueron añadidos por dos motivos: para asegurar la recolección de lo extraído por contacto de la punta del capilar con el agua del vial debido a que el pequeño volumen es posible que no cayera sobre el vial, y para disminuir la fracción de componente orgánico, que podría ser elevada e incompatible con la separación mediante MEKC.
} 


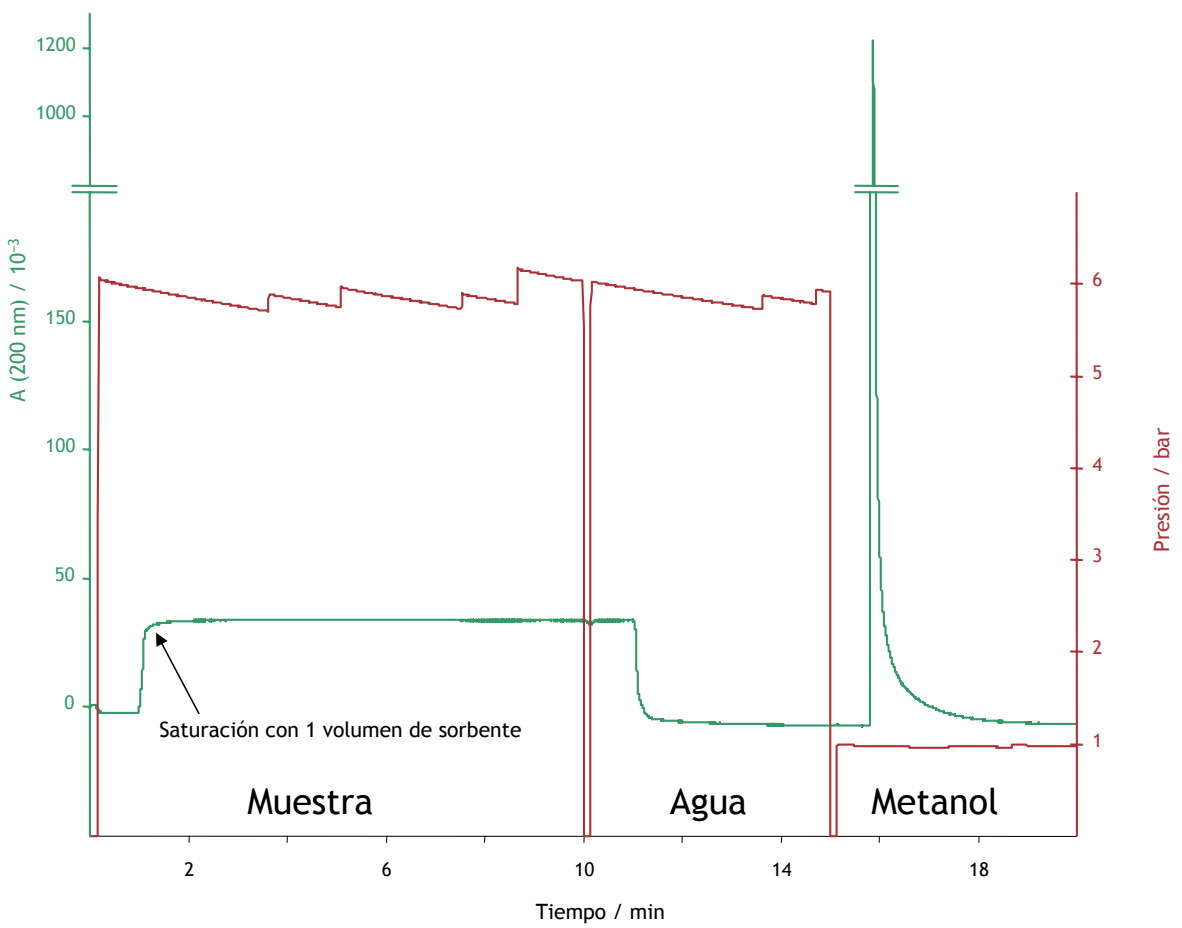

Figura 10.4. Señales obtenidas durante el paso sucesivo de una mezcla de $35 \mathrm{mg} / \mathrm{L}$ de todos los plaguicidas ( 6 bar), agua (6 bar) y metanol (1 bar) a través de $25 \mathrm{~cm}$ un polímero de BмA. 
ros de BMA, si bien existe cierta retención de los compuestos estudiados, no hay un aumento en la sensibilidad. Todo parece indicar que en el material empleado se saturan enseguida los sitios activos en los que los compuestos pueden quedar retenidos. Además, esta retención es especialmente negativa para los compuestos más polares (Sulfóxido de Aldicarb y Metomilo), y para el Asulam, que se encuentra cargado negativamente con valores de $\mathrm{pH}$ mayores de 4,1 .

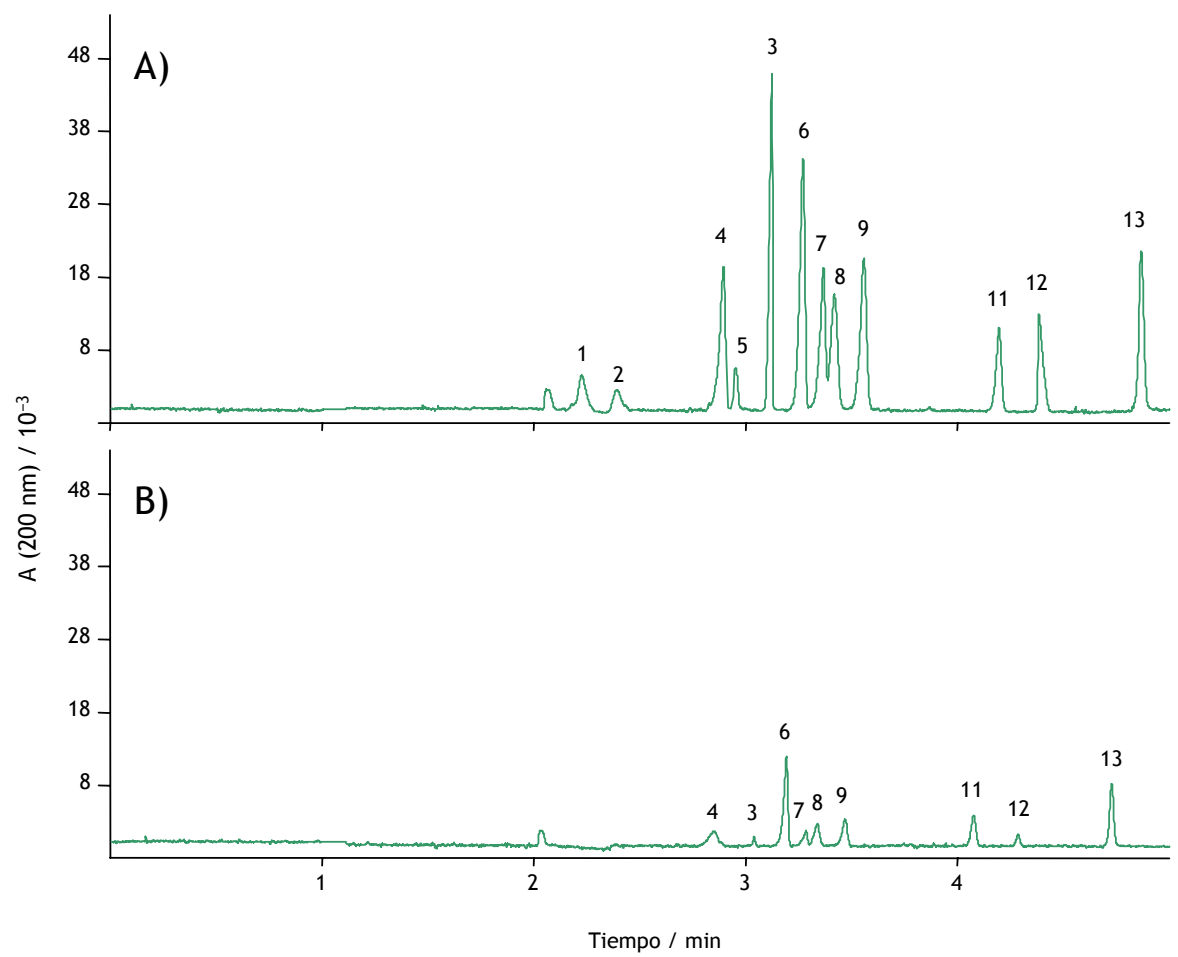

Figura 10.5. Separación mediante мекс de una disolución de todos los plaguicidas con una concentración media de $35 \mathrm{mg} / \mathrm{L}$.

A) Inyectada directamente.

B) Preconcentrada en $25 \mathrm{~cm} \times 100 \mu \mathrm{m}$ de un polímero de BмA durante $10 \mathrm{~min}$ a 6 bar y depositado el extracto sobre $10 \mu \mathrm{L}$ de agua.

Leyenda: 1, sulfóxido de Aldicarb; 2, Metomilo; 3, Asulam; 4, Carbendazima; 5, Aldicarb; 6, Isopropoxifenol; 7, Carbetamida; 8, Propoxur; 9, Carbofurano; 10, 1-Naftol; 11, Carbarilo; 12, Pirimicarb; y 13, Metiocarb. 


\section{Polimeros de divinilbenceno}

Tras comprobar que los polímeros derivados del ácido acrílico poseen una capacidad de retención limitada, se sintetizaron polímeros basados en divinilbenceno (DVB), que según todas las referencias son mucho más porosos y ofrecen mayor superficie específica para retener compuestos por adsorción $[195,206]$.

El monómero comercial empleado fue divinilbenceno del 80\% (monómero bifuncional o entrecruzador) con impurezas de 3 y 4-etilvinilbenceno (monómeros). Se mantuvo la composición del $75 \%$ de disolventes y $25 \%$ de monómeros, con el 1 \% respecto a los monómeros de AIBN como iniciador. La reacción de polimerización se inició térmicamente y se mantuvo durante 16 horas a $60^{\circ} \mathrm{C}$. Con tiempos menores, la polimerización de este tipo de monómeros fue incompleta; además, se obtuvieron trozos de polímero y restos de monómeros sin reaccionar que fueron expulsados durante la etapa de lavado.

Se polimerizaron $25 \mathrm{~cm}$ en un capilar de $100 \mu \mathrm{m}$ y se estudió su comportamiento como sorbente en las mismas condiciones que los capilares anteriores. Los resultados obtenidos con polímeros de DVB fueron diferentes a los obtenidos con polímeros de BMA. El caudal de muestra que se obtiene con este tipo de sorbente es relativamente elevado (entre 1 y $5 \mathrm{~mL} / \mathrm{h}$, mientras que en los polímeros de BMA el caudal máximo fue de $0,3 \mathrm{~mL} / \mathrm{h}$ ), hecho que permite preconcentrar más cantidad de muestra en menos tiempo. Además, no se observó crecimiento en la señal durante la etapa de preconcentración, lo que indica que con estas condiciones los analitos son retenidos completamente en el sorbente de PDVB.

Las Figuras 10.6-A y 10.6-B comparan los electroferogramas de una disolución con una concentración media de $35 \mathrm{mg} / \mathrm{L}$ inyectada directamente, y tras su preconcentración durante $5 \mathrm{~min}$ a 6 bar. Se puede observar cómo existe un ligero aumento de la señal para casi todos los analitos con tan solo $5 \mathrm{~min}$ de preconcentración, mientras que con el polímero de BMA con 1o min la preconcentración era muy pobre (Figura 10.4-B). Con 15 min de preconcen-

[206] F. Svec. Less common applications of monoliths: Preconcentration and sPE. J. Chromatogr. B, 841:52-64, 2006. 
tración (Figura 10.6-C), la magnitud de las señales se triplica y deja de ser visible el Asulam.

Con el fin de comprobar la eficacia de la preconcentración de disoluciones más diluidas de los plaguicidas, se pasó durante media hora 1,05 g de una disolución con una concentración media de 0,35 mg/L a 12 bar. En la Figura 10.7 se muestran los electroferogramas de la muestra inyectada directamente y con preconcentración. En el electroferograma de la muestra preconcentrada (Figura 10.7-B) se pueden observar las señales de todos los analitos con la excepción del sulfóxido de Aldicarb (1) y Asulam (3). La ausencia de Metomilo (2) es debido a que este analito debe medirse a $234 \mathrm{~nm}$.

\section{Influencia de la sección del capilar}

Con el fin de aumentar la capacidad de retención se polimerizaron capilares más anchos ( 250 y $400 \mu \mathrm{m}$ de diámetro interno) y se compararon los resultados con los obtenidos en capilares de $100 \mu \mathrm{m}$.

Trabajando con capilares de $250 \mu \mathrm{m}$ la cantidad de sorbente aumenta y permite el paso de mayor cantidad de muestra por unidad de tiempo. Sin embargo, si bien la altura y el área son ligeramente mayores, la resolución de los picos y la eficacia de la separación empeoran notablemente debido a la mayor proporción de metanol en la muestra extraída y posteriormente inyectada en el capilar electroforético (Figura 10.8)

Trabajando con polímeros formados en capilares más anchos (400 $\mu \mathrm{m})$, no se observa un aumento en la sensibilidad, debido posiblemente a que en estas condiciones el agua de lavado presente en el capilar ejerce un efecto de dilución que no es compensado con la mayor preconcentración obtenida en la etapa de microextracción. Estos resultados revelan que un aumento en el diámetro del sorbente monolítico no tiene siempre un efecto positivo en la sensibilidad ya que es necesario tener en cuenta el volumen de agua presente en el capilar.

Otra variable estudiada ha sido la influencia del contenido residual de agua en el capilar antes de que tenga lugar la elución. Los estudios realizados con capilares que, después de la etapa de lavado, fueron secados mediante 


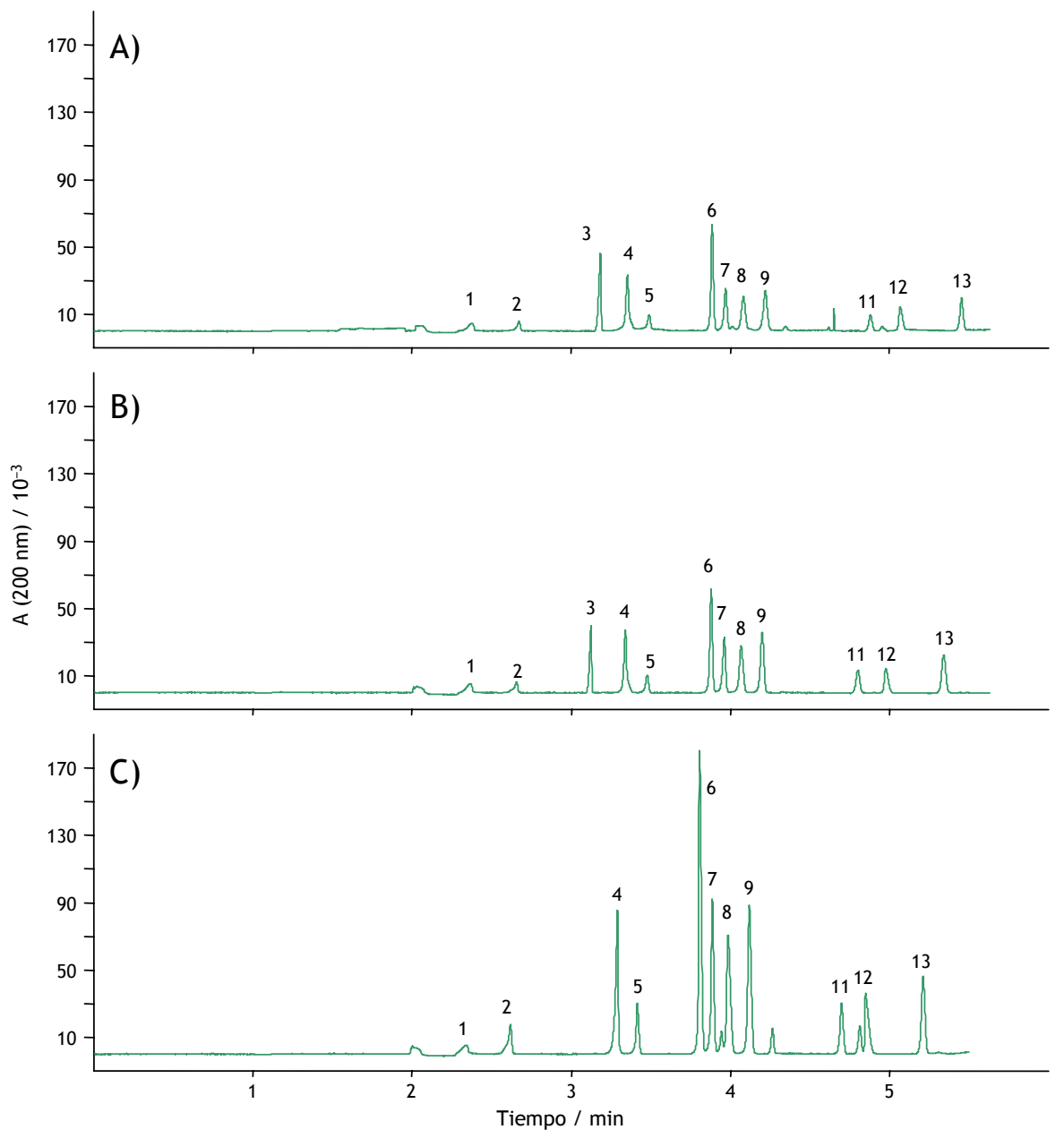

Figura 10.6. Separación mediante MEкC de una disolución de todos los plaguicidas con una concentración media de $35 \mathrm{mg} / \mathrm{L}$.

A) Inyectada directamente.

B) Preconcentrada durante $5 \mathrm{~min}$ a 6 bar en $25 \mathrm{~cm} \times 100 \mu \mathrm{m}$ de PDVB y depositado el extracto sobre $10 \mu \mathrm{L}$ de agua.

C) Igual que B) pero con 15 min de preconcentración.

Leyenda como en Fig. 10.5. 


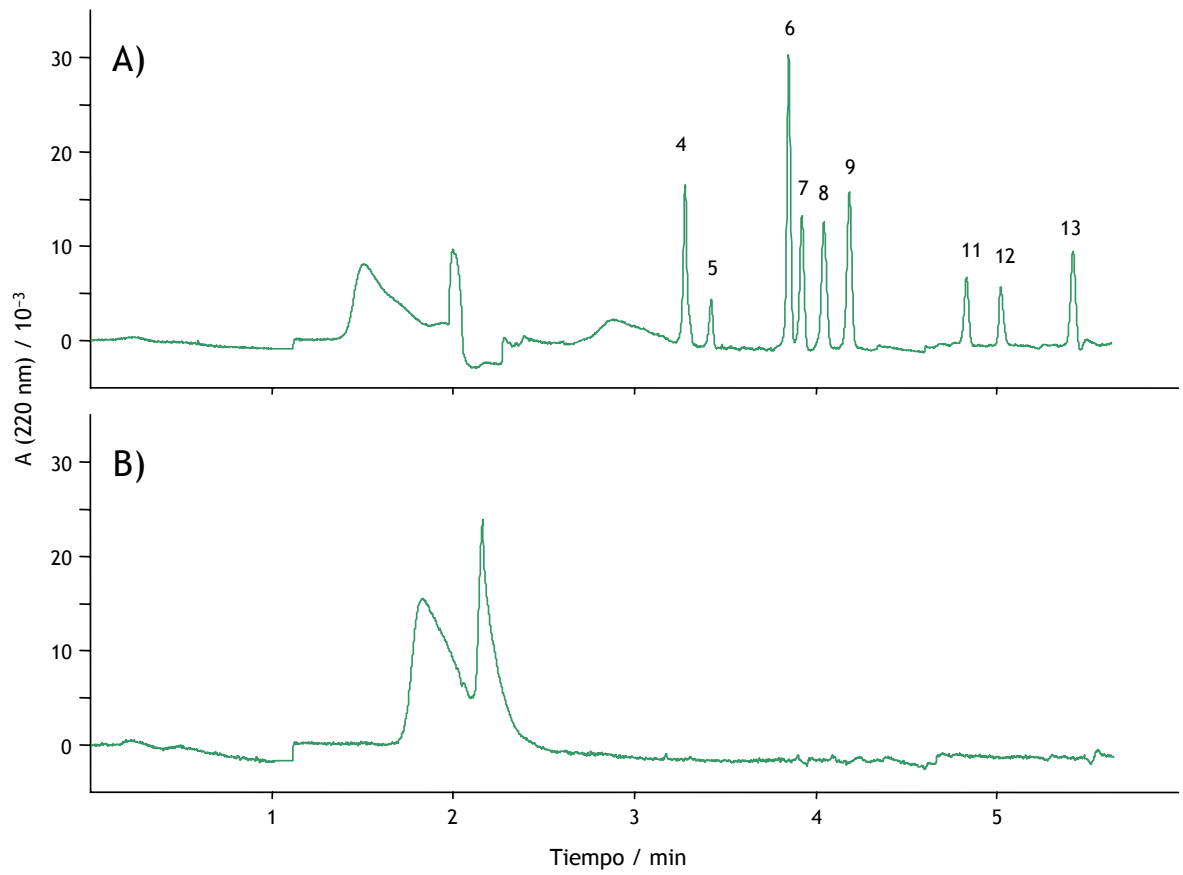

Figura 10.7. Separación mediante мEKC de una disolución de todos los plaguicidas con una concentración media de $0,35 \mathrm{mg} / \mathrm{L}$.

A) Preconcentrada durante $30 \mathrm{~min}$ a 12 bar en $25 \mathrm{~cm} \times 100 \mu \mathrm{m}$ de PDVB y depositado el extracto sobre $10 \mu \mathrm{L}$ de agua.

B) Inyectada directamente.

Leyenda como en Fig. 10.5. 


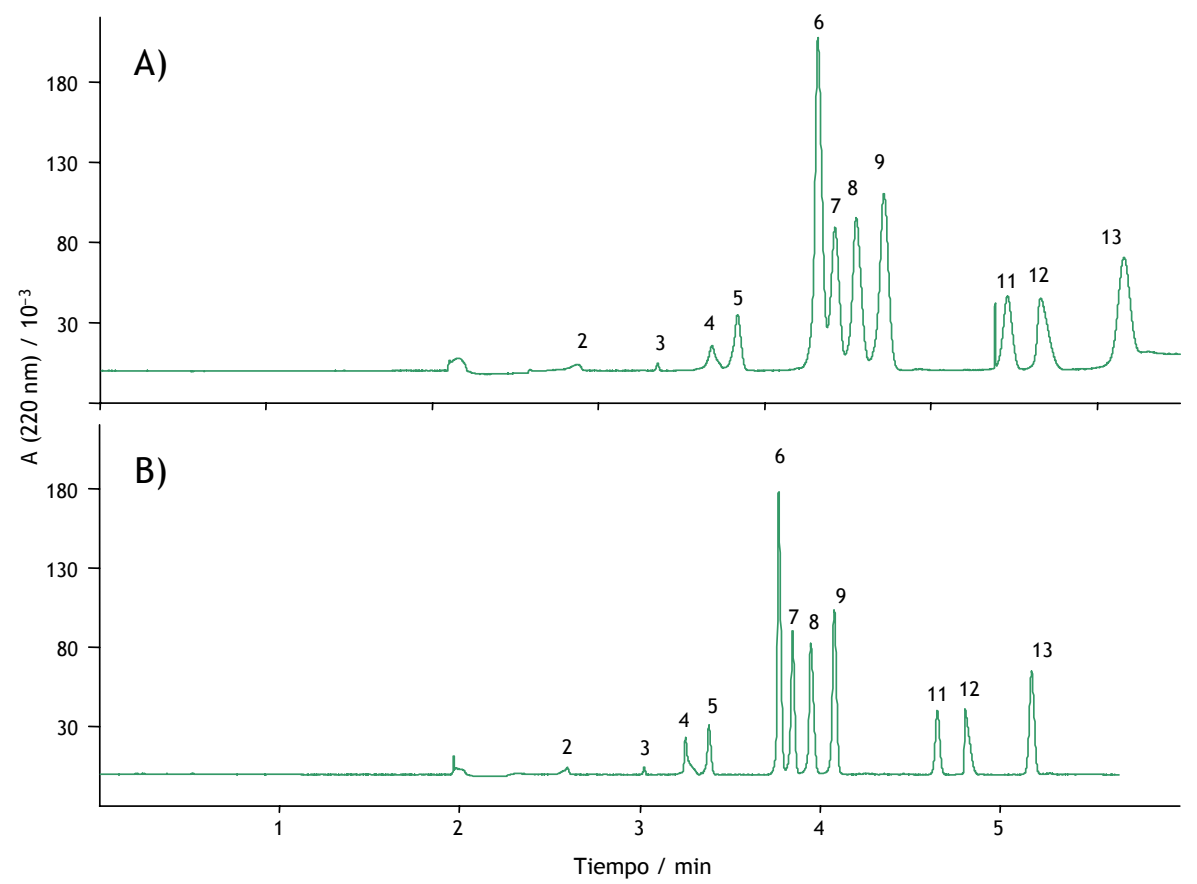

Figura 10.8. Separación mediante MEKC de una disolución de todos los plaguicidas con una concentración media de $4,4 \mathrm{mg} / \mathrm{L}$ preconcentrada $30 \mathrm{~min}$ a 12 bar en un sorbente de PDVB y depositado el extracto sobre $10 \mu \mathrm{L}$ de agua.

A) $14 \mathrm{~cm} \times 250 \mu \mathrm{m}$ de polímero.

B) $25 \mathrm{~cm} \times 100 \mu \mathrm{m}$.

Leyenda como en Fig. 10.5. 
el paso a presión de una corriente de aire durante diez minutos, revelan que en estas condiciones los extractos metanólicos tienen que ser diluidos adecuadamente con agua antes de su inyección, ya que la inyección de los extractos directamente no permite la separación.

A la vista de estos resultados los capilares no fueron secados entre la etapa de lavado y la de elución. En estas condiciones los capilares que presentaron la máxima sensibilidad y resolución fueron los de PDVB de $100 \mu \mathrm{m}$.

\section{Estudio del volumen de agua en el vial de recolección}

Para que el extremo de salida del capilar de extracción estuviera en contacto con un líquido y asegurar la recolección de la gota eluida, y para que la fracción de metanol no fuera demadiado elevada, los primeros estudios se realizaron recogiendo el metanol empleado en la elución sobre $10 \mu \mathrm{L}$ de agua. Con objeto de comprobar si, efectivamente es adecuado recoger el extracto sobre un pequeño volumen de agua, se realizó un estudio en el que se modificó el volumen de agua presente en el vial de recolección entre o y $10 \mu \mathrm{L}$. Se pudo comprobar que la señal aumenta al disminuir el volumen de agua añadido sin que la ausencia de agua en el vial de recolección genere problemas en la recogida del metanol empleado en la elución. En la Figura 10.9 se muestran los electroferogramas obtenidos recogiendo el metanol sobre $10 \mu \mathrm{L}$ añadidos al microvial (como se hicieron todas las pruebas descritas hasta ahora) y recogiendo el extracto sobre un vial seco.

Cuando el disolvente de elución se recogió sobre un vial seco se observó una ligera pérdida de eficacia debido a la mayor fracción de disolvente orgánico pero que no llegó a afectar a la resolución entre los picos. De acuerdo con estos resultados, en estudios posteriores el metanol se recogió sobre viales secos. En dichas condiciones es posible la detección de 10 gg/L de la mayoría de los analitos preconcentrando durante $30 \mathrm{~min}$ (Figura 10.10). 


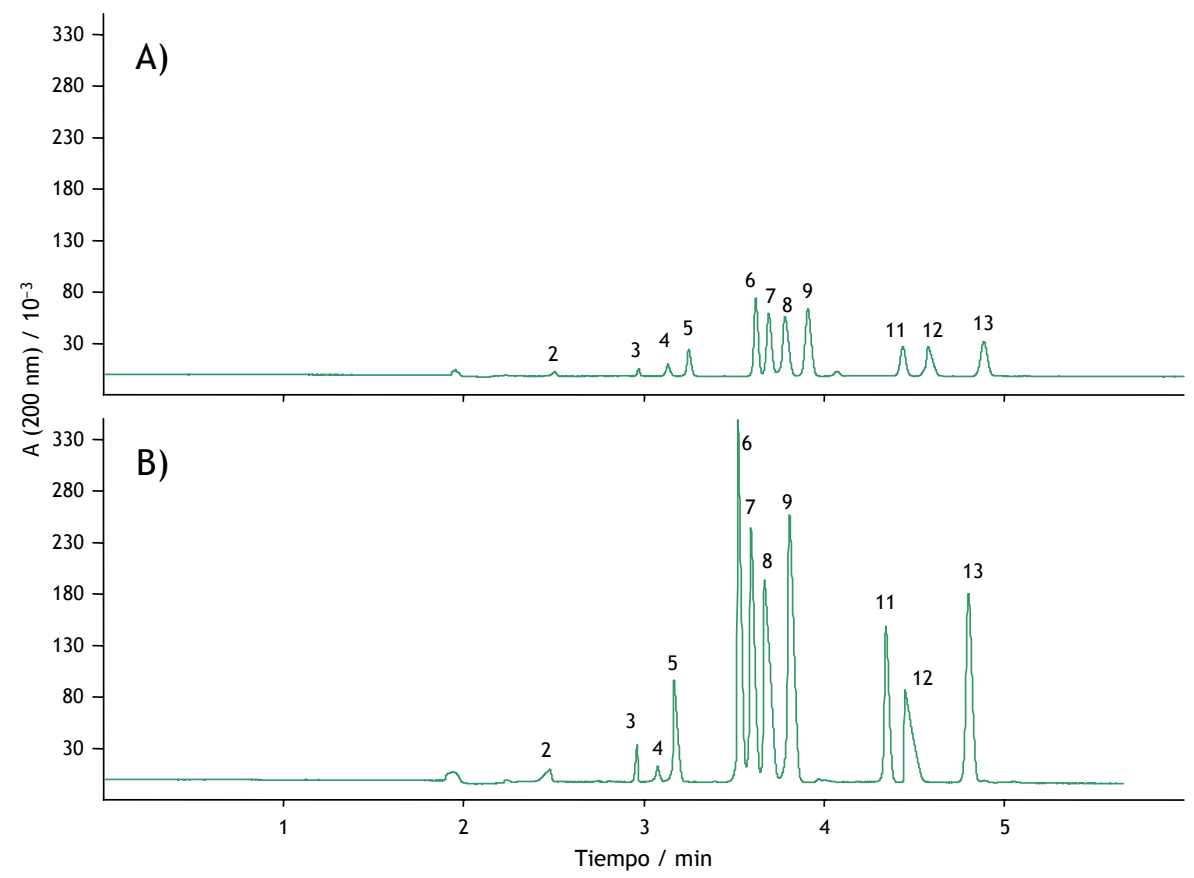

Figura 10.9. Separación mediante MEKC de una disolución de todos los plaguicidas con una concentración media de $0,35 \mathrm{mg} / \mathrm{L}$ preconcentrada $15 \mathrm{~min}$ a $12 \mathrm{bar}$ en $16,5 \mathrm{~cm} \times 100 \mu \mathrm{m}$ de PDVB y depositado el extracto sobre:

A) $10 \mu \mathrm{L}$ de agua.

B) Sobre un vial seco.

Leyenda como en Fig. 10.5. 


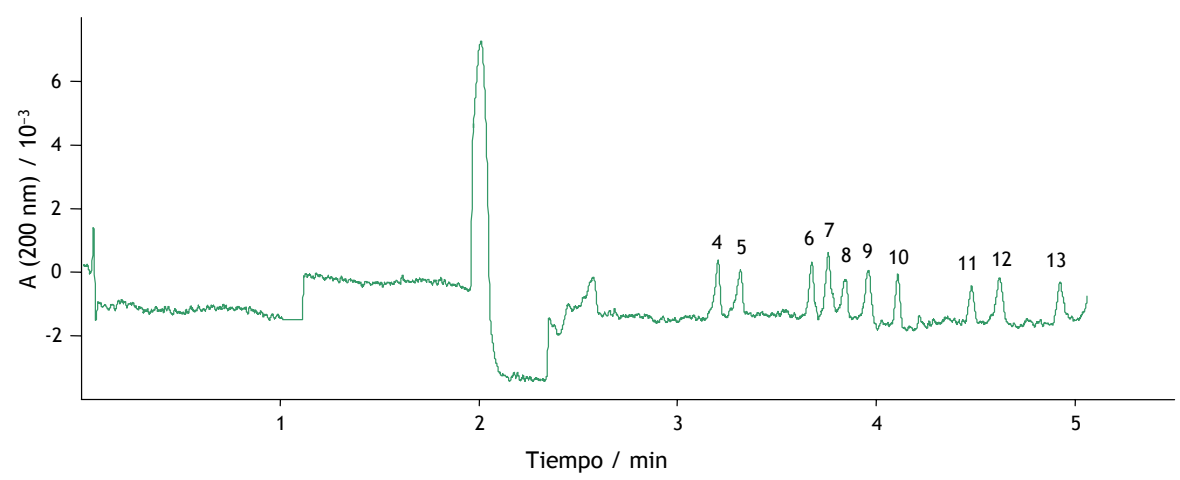

Figura 10.10. Separación mediante MEKc de una disolución de los 13 plaguicidas (concentración: $10 \mathrm{\mu g} / \mathrm{L}$, excepto sulfóxido de Aldicarb, Metomilo, Aldicarb y Pirimicarb, $20 \mu \mathrm{g} / \mathrm{L}$ ), preconcentrada $30 \mathrm{~min}$ a 12 bar en $25 \mathrm{~cm} \times 100 \mu \mathrm{m}$ de PDVB.

Leyenda como en Fig. 10.5.

\section{Caracterización mediante microscopía electrónica de barrido}

Con el fin de relacionar el comportamiento observado de los monolitos fabricados con su morfología, se realizaron microfotografías con un microscopio electrónico de barrido (SEM).

En la Figura 10.11 se muestran las microfotografías de los polímeros de BMA y de DVB en capilares de $100 \mu \mathrm{m}$ con diferentes niveles de ampliación. Lo primero que se pudo observar en todas las microfotografías de los monolitos de PDVB fue que en todos los casos la posición del polímero ocupaba preferentemente una parte de la sección del capilar, dejando un hueco en el otro extremo. Este comportamiento es el responsable del elevado flujo conseguido con este polímero, ya que se comporta de modo parecido a un capilar abierto de menor diámetro con las paredes recubiertas de fase estacionaria. Esta morfología puede ser debida a las diferentes características de los disolventes y monómeros empleados en su fabricación. Durante la polimerización se forman muy pronto partículas poliméricas con una densidad muy diferente a la de la disolución, que van precipitando y depositándose en uno de los lados del capilar. Por el contrario, en las microfotografías realizadas a capilares rellenos con el polímero derivado del BмA, el monolito se reparte uniformemente por toda la sección del capilar. Los polímeros de BMA están 
1O.1. PRECONCENTRACIÓN Y SEPARACIÓN DE PLAGUICIDAS

CARBÁMICOS MEDIANTE MEKC

161
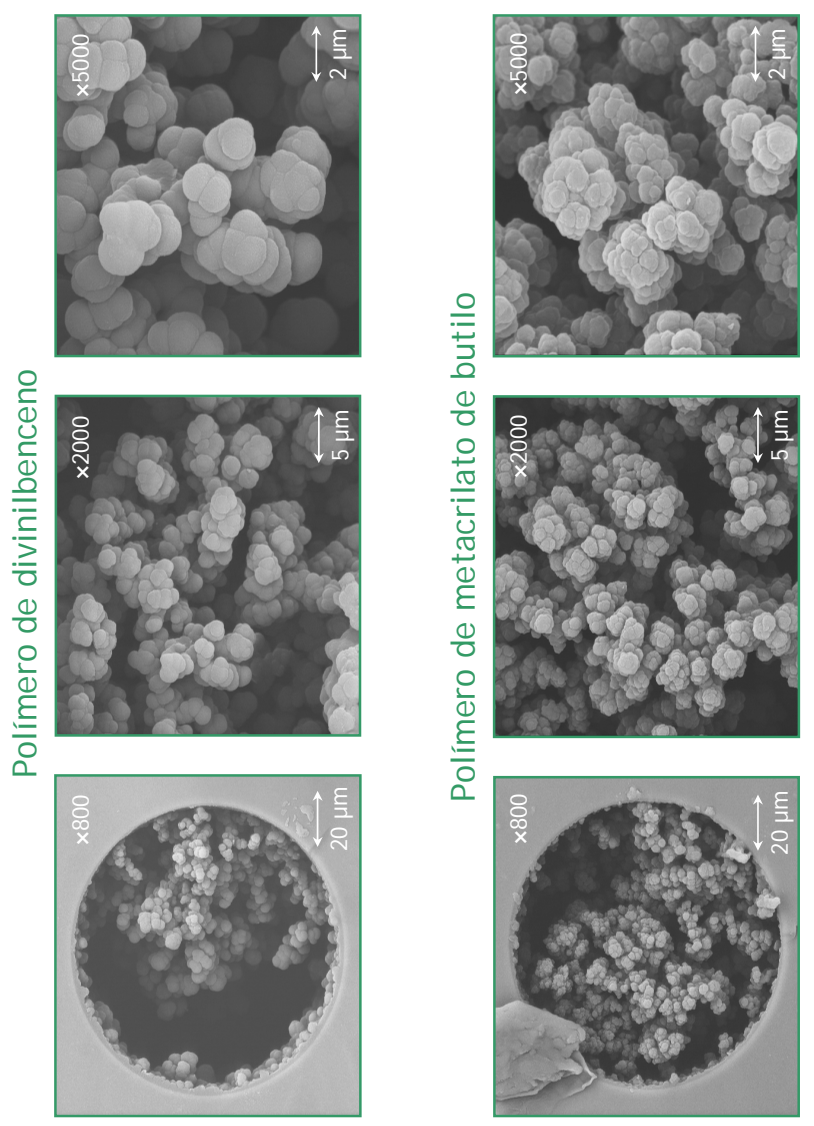

$\stackrel{D}{ \pm}^{2}$
$\frac{1}{0}$
$\frac{D}{0}$

$\stackrel{\ddot{d}}{\mathscr{0}}$

脶

द्वे

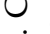

ㄷํㅇ

氜

정

음

o $>$

导

욤

ชิ

욜

정

드

क

음

胥

क

क 0

ह

舁

을워

으노․

늠

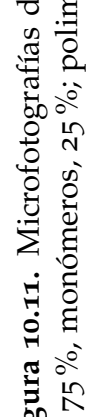

运 
formados por nódulos de forma irregular menores en tamaño (unos 0,5 $\mu \mathrm{m}$ ), mientras que los de PDVB, son esféricos y más grandes ( $1 \mu \mathrm{m})$.

Estas características de los polímeros de DVB y la presencia de una mayor superficie específica son las responsables de su mayor capacidad de retención.

\section{Estudio de la longitud del polimero y del tiempo de preconcentración}

Un aumento de la longitud del sorbente incrementa su capacidad de retención, sin embargo la mayor resistencia que ofrece al paso de fluidos permite un caudal menor. Por el contrario, un acortamiento de la columna puede aumentar el caudal y la cantidad de muestra tratada por unidad de tiempo. Sin embargo, caudales demasiado elevados pueden no permitir una interacción suficiente entre polímero y analitos, dando como resultado menores capacidades de retención.

Para analizar todos estos factores se realizó un estudio variando la longitud del polímero y el tiempo de preconcentración aplicando una presión de 12 bar a una muestra con una concentración variable de los plaguicidas estudiados (sulfóxido de Aldicarb, o,5, Metomilo, o,6, Asulam, o,6, Carbendazima, 0,3, Aldicarb, 0,3, Isopropoxifenol, 0,4, Carbetamida, 0,3, Carbofurano, 0,3, Propoxur, o,3, Carbarilo, o,2, Pirimicarb, o,4 y Metiocarb, o,2 mg/L).

Las longitudes de polímero fueron de 25, 16 y $8 \mathrm{~cm}$. Todo el estudio se llevó a cabo en la misma columna, primero de $25 \mathrm{~cm}$, y cortando después sucesivamente hasta la longitud deseada. Los diferentes tiempos de preconcentración fueron de 7, 15 y $30 \mathrm{~min}$ (9 experiencias en total). Se podría haber variado también el caudal modificando la presión aplicada, pero se estudia indirectamente puesto que las diferentes longitudes permiten un caudal máximo distinto.

En la Figura 10.12 aparecen representadas las variaciones de las señales obtenidas frente a la cantidad de muestra preconcentrada para cada una de las tres longitudes estudiadas.

Los resultados obtenidos dependieron de la naturaleza de los diferentes analitos. El analito más polar (sulfóxido de Aldicarb) y el Asulam (cargado) no 


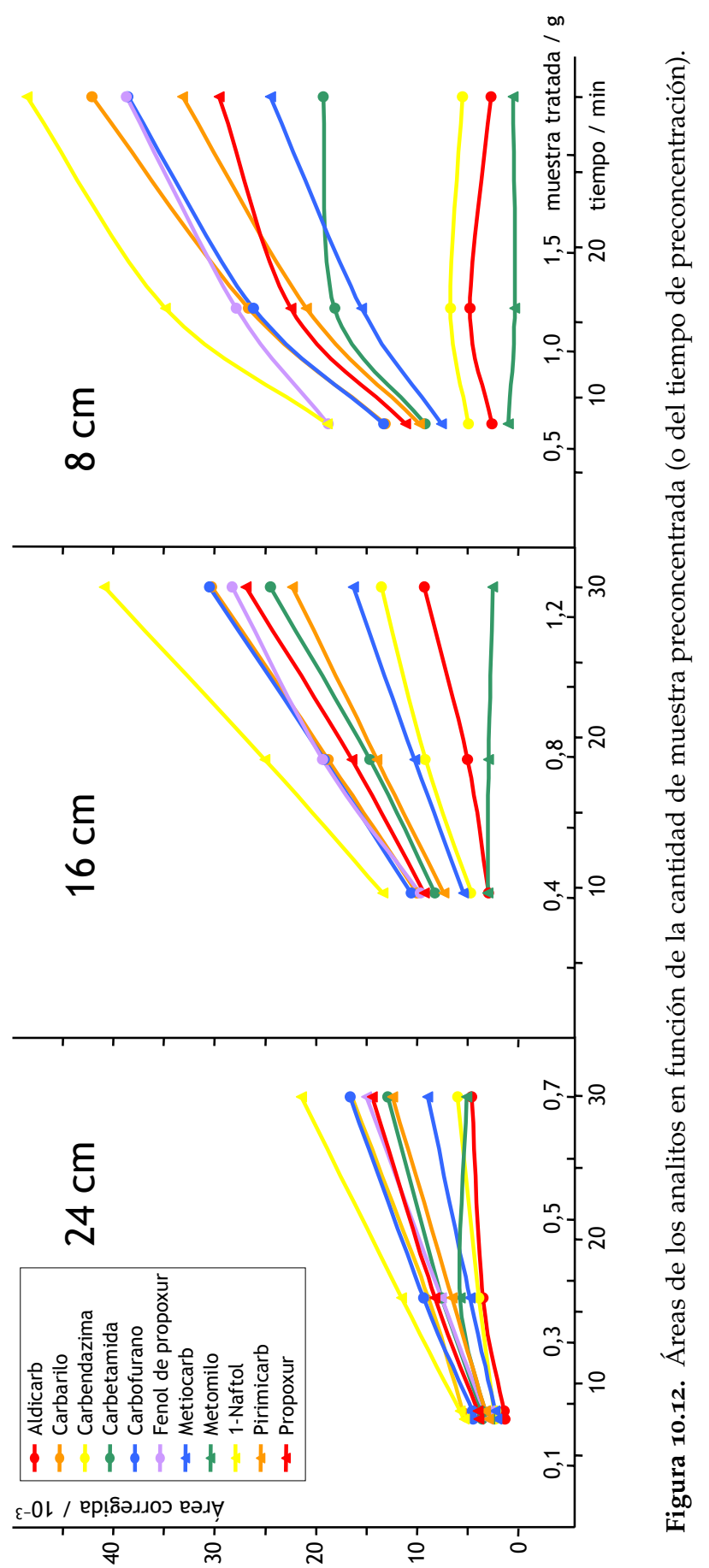




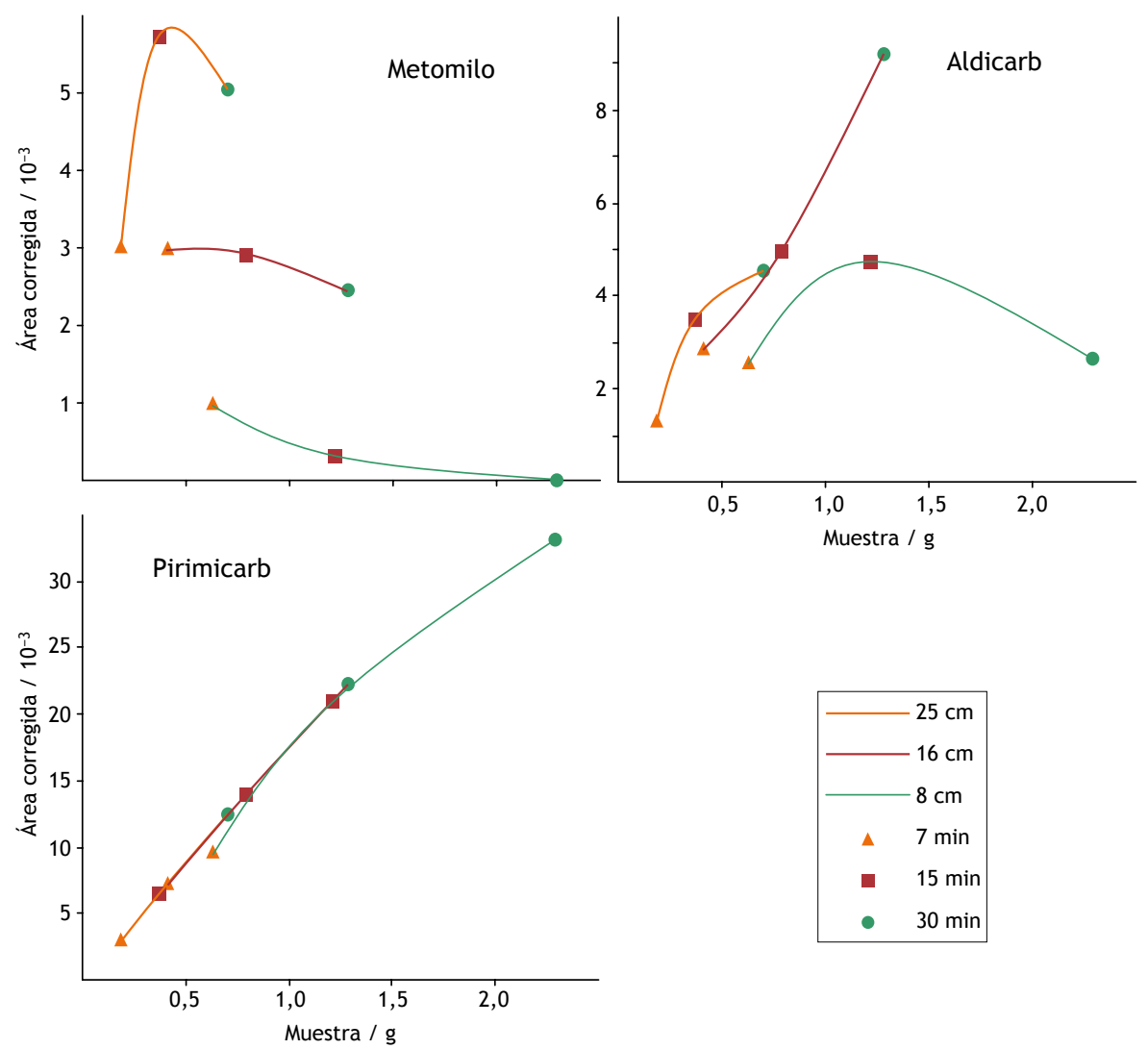

Figura 10.13. Variación de las áreas de algunos analitos en función de la cantidad de muestra tratada, empleando diferentes tiempos de preconcentración y longitudes de polímero. 
fueron detectados en ninguno de los ensayos, por lo que se puede concluir que el polímero de DVB no es adecuado para su preconcentración.

El Metomilo, con un valor de $\log P_{\mathrm{OW}}$ de 0,093, presentó una retención muy baja. Su señal desciende al aumentar el tiempo de preconcentración y es inversamente proporcional a la longitud de la fase estacionaria. Tan sólo existe incremento en la señal cuando se usa una longitud de $25 \mathrm{~cm}$ y se pasa de 7 a 15 min de preconcentración, para descender después con 30 min (Figura 10.13).

Los analitos con una polaridad intermedia (Aldicarb, Carbendazima, y Carbetamida, $\log P_{\mathrm{OW}}$ de 0,053, 1,5 y 1,7, respectivamente) presentaron un descenso de la señal en el sorbente más corto $(8 \mathrm{~cm})$ cuando se incrementó el tiempo de preconcentración. Sin embargo su señal es lineal con la cantidad de muestra tratada en sorbentes más largos. La Figura 10.13 muestra el comportamiento del Aldicarb.

Para el resto de analitos $-N$-metil carbamatos, productos fenólicos de descomposición (Isopropoxifenol y 1-Naftol) y Pirimicarb- el descenso de señal con sorbentes de $8 \mathrm{~cm}$ fue mucho menos acusado, observándose para casi todos estos analitos una relación lineal entre la cantidad preconcentrada y la señal obtenida; este hecho está de acuerdo con su menor polaridad y su orden de migración en MEKC. En la Figura 10.13 se muestra las señales obtenidas para el Pirimicarb en función de la muestra preconcentrada.

La Figura 10.14 muestra la cantidad de muestra preconcentrada para cada uno de los 9 experimentos y el caudal medio de cada longitud. Durante este estudio, el caudal medio para la longitud de $25 \mathrm{~cm}$ fue de $1,5 \mathrm{~mL} / \mathrm{h}$ aplicando una presión de 12 bares. A lo largo de todos los estudios anteriores el caudal máximo para cada columna osciló entre 1,5 y 2,4 $\mathrm{mL} / \mathrm{h}$ con la misma longitud.

A pesar de que todas las muestras fueron filtradas, a medida que el sorbente se utiliza, el paso de muestra va siendo cada vez menor hasta que éste queda totalmente obstruido. Observando la punta en un microscopio se aprecia un ennegrecimiento de aproximadamente $0,5 \mathrm{~mm}$ de longitud. Cuando esto ocurre, el corte de un par de milímetros soluciona el problema. La variación de longitud es prácticamente despreciable frente al total y el polímero 


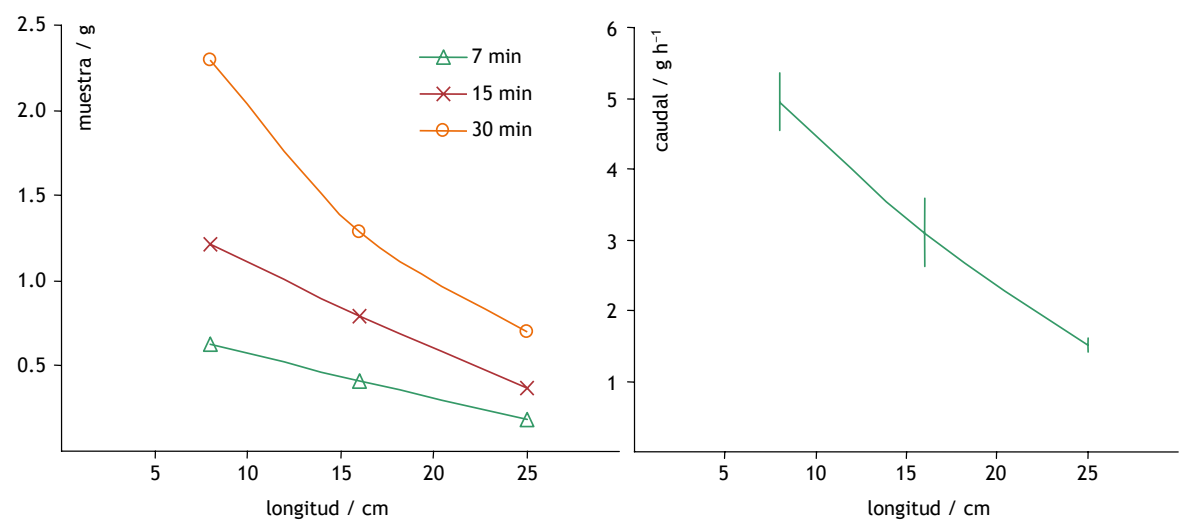

Figura 10.14. A) Cantidad de muestra preconcentrada en función del tiempo de preconcentración y de la longitud del polímero, y B) Caudal en función de la longitud aplicando 12 bar.

mantiene sus características. Esta caída de caudal ocurre mucho más rápidamente en columnas cortas en las que el paso de muestra es mucho más rápido. Las barras de error de la Figura 10.14 correspondientes a la desviación estándar del caudal en cada una de las pruebas sirven para visualizar la mayor durabilidad de polímeros más largos. La imprecisión del caudal afecta a la cantidad de muestra tratada y a la cuantificación de los analitos, si bien esta variación se puede corregir usando un patrón interno o normalizando las señales al dividir por la cantidad de muestra tratada.

De acuerdo con los resultados obtenidos en este estudio se decidió seguir utilizando polímeros de longitud intermedia $(16 \mathrm{~cm})$ utilizando tiempos de preconcentración de 15 ó 30 min.

\subsubsection{Características analíticas}

Separación mediante MEKC sin preconcentración

Se analizaron directamente sin preconcentrar disoluciones en agua desionizada de todos los analitos en diferentes intervalos de concentración de acuerdo con su sensibilidad, para comprobar la linealidad de la respuesta y poder hallar unas ecuaciones de calibrado y límites de detección con los 
que poder calcular los factores de preconcentración cuando se emplea una etapa previa de preconcentración. Los parámetros de regresión de las rectas de calibrado obtenidas se muestran en la Tabla 10.4 .

Los límites de detección han sido calculados considerando la concentración de soluto que produce una señal analítica equivalente a tres veces el ruido de fondo. Esta concentración se calcula a partir de la expresión LD $=3 \times$ $s_{\mathrm{B}} / b$, donde $s_{\mathrm{B}}$ representa la desviación estándar de la señal en la zona del compuesto de una inyección en blanco, considerando todas las etapas de tratamiento de muestra, y $b$, la pendiente de su recta de calibrado calculada en alturas. Los resultados obtenidos se encuentran comprendidos entre $68 \mathrm{y}$ $6,7 \times 10^{3} \mu \mathrm{g} / \mathrm{L}$ para el Carbarilo y el sulfóxido de Aldicarb, respectivamente.

\section{Separación mediante MEKC con una etapa de preconcentración}

Para evaluar las características analíticas de la separación de plaguicidas carbámicos mediante MEKC con una etapa de preconcentración en un capilar monolítico se analizaron disoluciones de todos los analitos disueltos en agua desionizada, utilizando 1-Naftol como patrón interno. La preconcentración tuvo lugar en un polímero de $16 \mathrm{~cm}$ durante 15 min a 12 bar. Los resultados se encuentran recogidos en la Tabla 10.5.

Se puede comprobar la buena linealidad existente entre señal y concentración con una etapa de preconcentración en un capilar diferente al de la separación. La sensibilidad varía bastante entre todos los analitos; además de los factores debidos a su diferente absorción de radiación, también influye su diferente comportamiento frente al sorbente. El sulfóxido de Aldicarb no se detecta y la pendiente del Metomilo es claramente inferior a la del resto de analitos; ya se ha comprobado que el Metomilo presenta una clara tendencia a la saturación del sorbente (Sección 10.1.2 y Figura 10.13).

La precisión del método se determinó a partir de la desviación estándar de 8 medidas consecutivas de una disolución en agua de todos los plaguicidas (excepto Metomilo, sulfóxido de Aldicarb y Asulam) con una concentración de 50 rg/L y 1-Naftol como patrón interno a $100 \mu \mathrm{g} / \mathrm{L}$. La cantidad de muestra preconcentrada osciló entre 0,82 y 1,11 g. Esta variación pone de manifiesto 


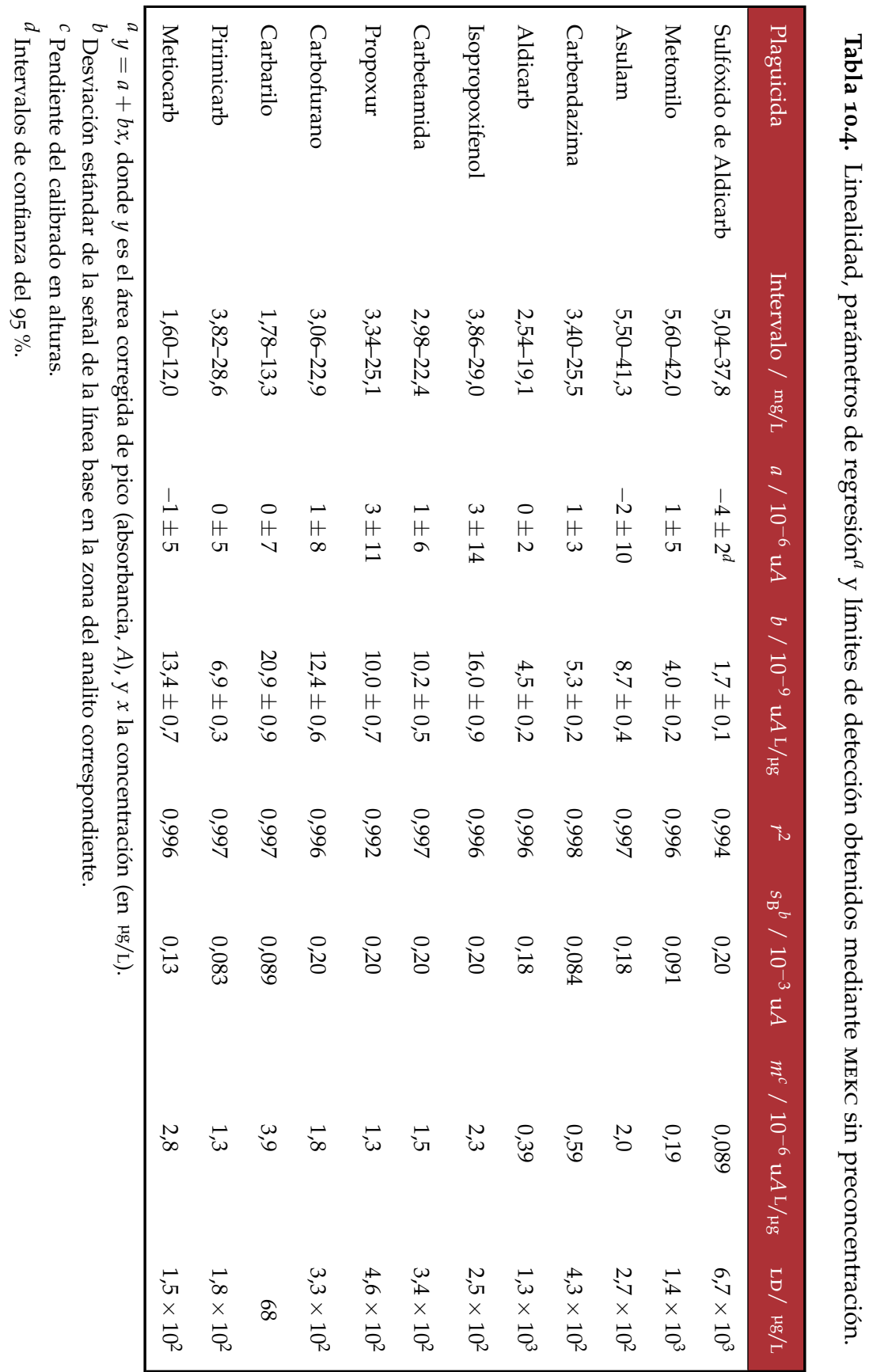


la necesidad de usar un patrón interno para cuantificar. Se puede observar que, excepto para el Aldicarb, los valores de precisión no superan en ningún caso el $15 \%$. Esta magnitud es aceptable teniendo en cuenta los niveles de concentración de los analitos y los procesos de extracción y elución que se llevan a cabo.

Los límites de detección han sido calculados de la misma manera que para el método sin preconcentración, es decir, a partir de la desviación estándar de la señal del blanco en la zona del pico electroforético. Los resultados obtenidos oscilan entre 1 y $8 \mathrm{\mu g} / \mathrm{L}$ excepto para los plaguicidas más polares (Aldicarb, $16 \mu \mathrm{g} / \mathrm{L}$ y Metomilo, 93 $\mathrm{g} / \mathrm{L}$ ). Estos límites de detección indican que con el método propuesto se obtiene un incremento considerable de la sensiblidad en un tiempo de análisis total de 20 min. Sería posible rebajar los límites de detección incrementando el tiempo de preconcentración.

Los factores de preconcentración se determinaron mediante la relación entre las pendientes de los calibrados en alturas con y sin preconcentración. Se obtuvieron valores entre 44 y 72, excepto para el Metomilo, que es más polar y el menos retenido en el sorbente polimérico empleado.

La principal ventaja de este método semiautomatizado es que se puede llevar a cabo una preconcentración de pequeños volúmenes de muestra en un sorbente monolítico sin la necesidad de utilizar microválvulas, conexiones externas o uniones en $T$. Además, la síntesis de los polímeros monolíticos es fácil y la metodología se puede realizar únicamente el equipo de CE. La Tabla 10.6 muestra las características analíticas de diferentes métodos con acoplamientos on-line y at-line de SPE a CE descritos en bibliografía. 


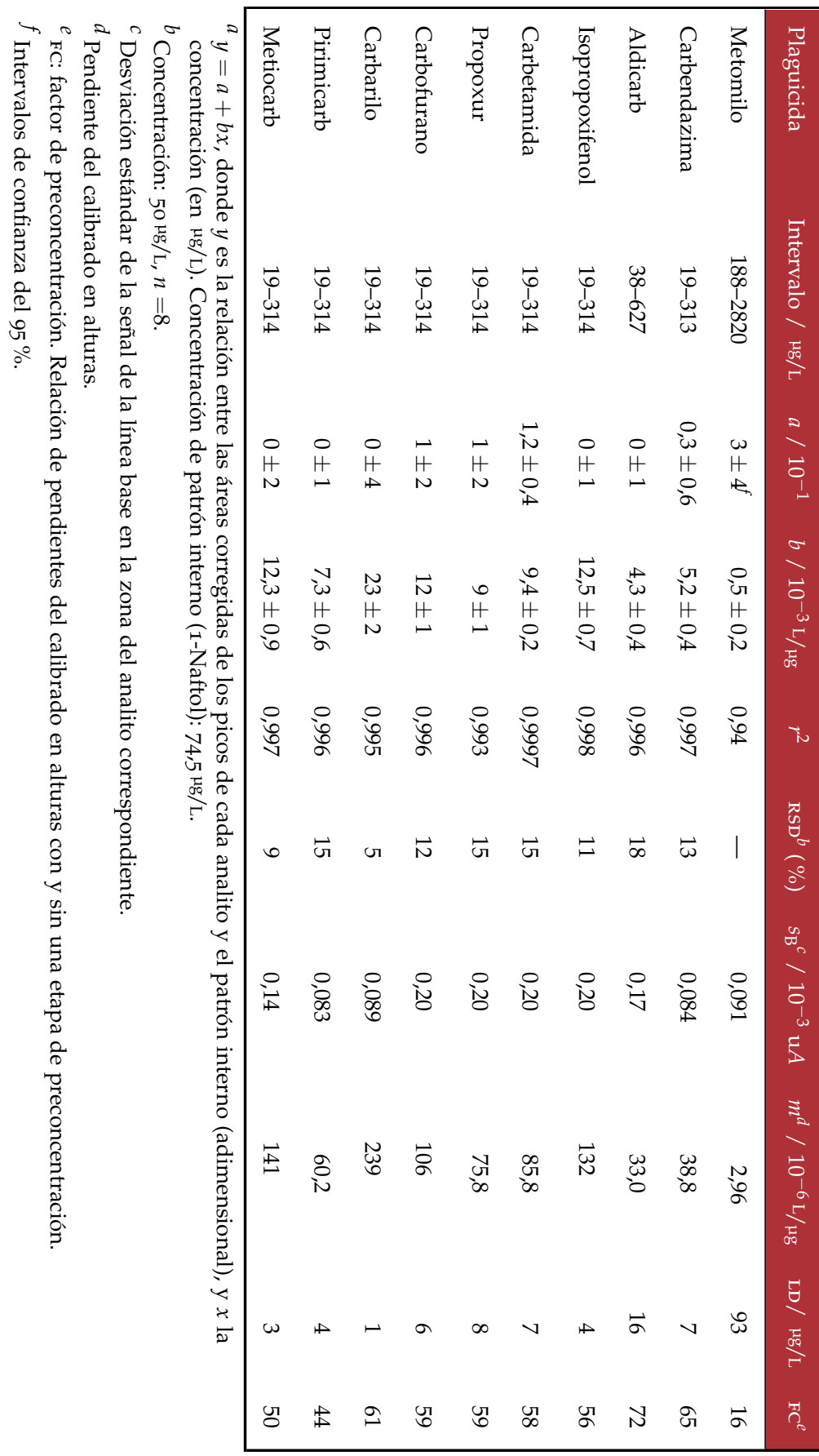

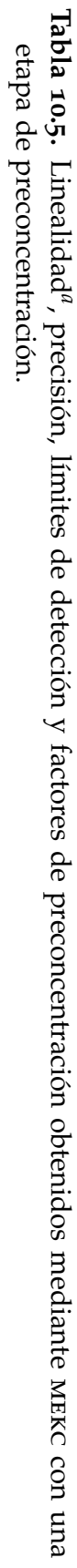


1O.1. PRECONCENTRACIÓN Y SEPARACIÓN DE PLAGUICIDAS

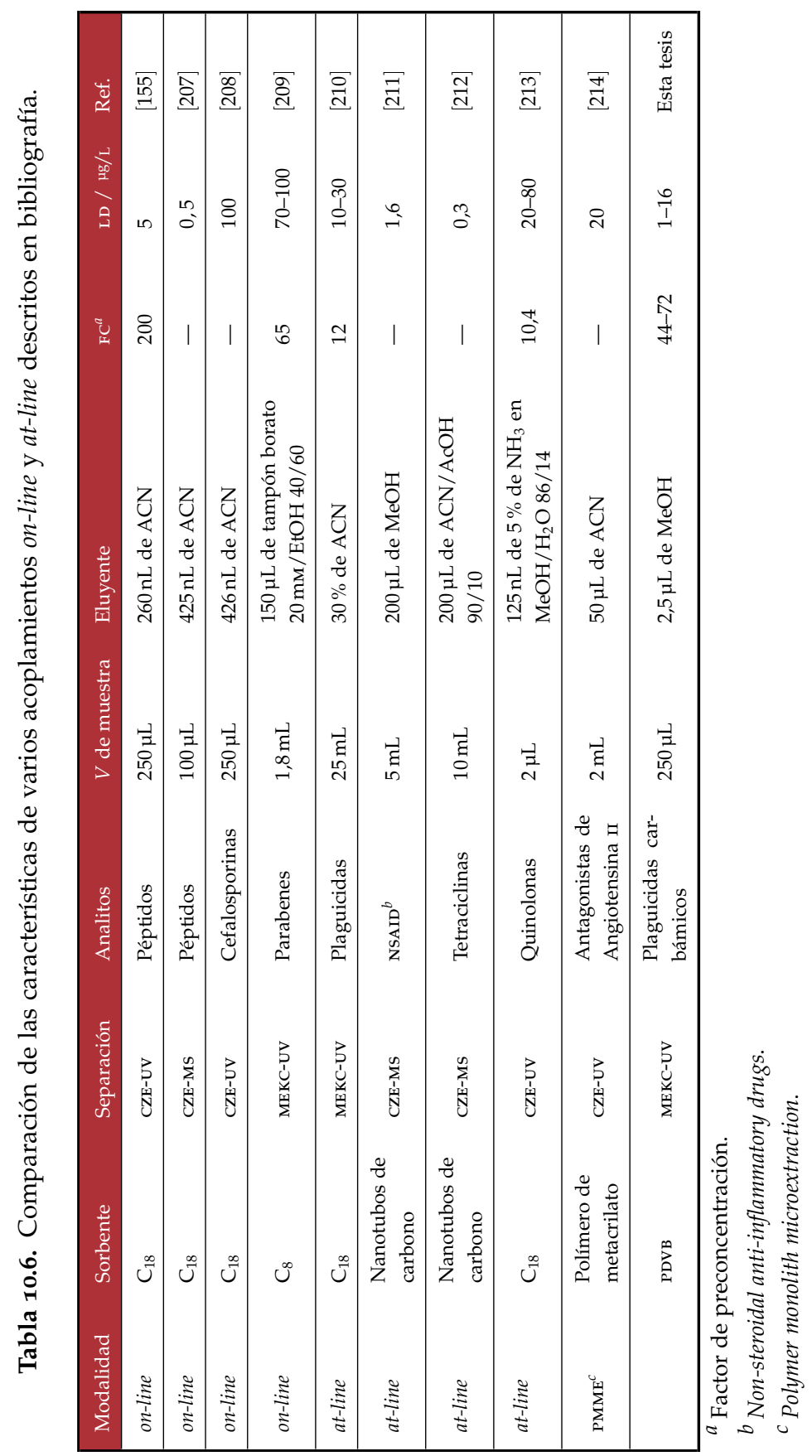


[207] F. W. A. Tempels, W. J. M. Underberg, G. W. Somsen, and G. J. de Jong. On-line coupling of SPE and CE-MS for peptide analysis. Electrophoresis, 28:1319-1326, 2007.

[208] P. Puig, F. W. A. Tempels, F. Borrull, M. Calull, C. Aguilar, G. W. Somsen, and G. J. de Jong. On-line coupling of SPE and CE for the determination of cefoperazone and ceftiofur in plasma. J. Chromatogr. B, 856:365-370, 2007.

[209] F. Han, Y. Z. He, and C. Z. Yu. On-line pretreatment and determination of parabens in cosmetic products by combination of flow injection analysis, SPE and мекс. Talanta, 74:1371, 2008.

[210] P. Hinsmann, L. Arce, A. R1'os, and M. Valcárcel. Determination of pesticides in waters by automatic on-line SPE-CE. J. Chromatogr. A, 866:137-146, 2000.

[211] B. Suárez, BM Simonet, S. Cárdenas, and M. Valcárcel. Determination of non-steroidal anti-inflammatory drugs in urine by combining an immobilized carboxylated carbon nanotubes minicolumn for SPE with CE-MS. J. Chromatogr. A, 1159:203-207, 2007.

[212] B. Suárez, B. Santos, B. M. Simonet, S. Cárdenas, and M. Valcárcel. SPE-CE-Ms for the determination of tetracyclines residues in surface water by using carbon nanotubes as sorbent material. J. Chromatogr. A, 1175:127-132, 2007.

[213] F. Priego Capote and M. D. Luque de Castro. On-line preparation of microsamples prior to CE. Electrophoresis, 28:1214-1220, 2007.

[214] M. Zhang, F. Wei, Y. F. Zhang, J. Nie, and Y. Q. Feng. Novel polymer monolith microextraction using a poly (methacrylic acid-ethylene glycol dimethacrylate) monolith and its application to simultaneous analysis of several angiotensin II receptor antagonists in human urine by CZE. J. Chromatogr. A, 1102:294-301, 2006. 
10.2. PRECONCENTRACIÓN Y SEPARACIÓN DE PLAGUICIDAS CARBÁMICOS MEDIANTE ELECTROFORESIS CAPILAR ZONAL

\subsubsection{Separación mediante electroforesis capilar zonal}

Algunos de los compuestos estudiados presentan la particularidad de comportarse como bases débiles. En concreto, Pirimicarb, Carbendazima y Asulam, con unos $\mathrm{p} k_{\mathrm{a}}$ de las especies protonadas de 4,54, 4,2 y 1,3, respectivamente. Por lo tanto, si se desean separar mediante CZE es necesario trabajar con valores de $\mathrm{pH}$ inferiores a 1,3 para conseguir la protonación de los tres analitos.

Se ensayó la separación de estos tres analitos mediante CE en un medio ácido no acuoso (acetonitrilo), con $15 \mathrm{~mm}$ de $\mathrm{HClO}_{4}$. Tras inyectar patrones de los tres compuestos disueltos en el medio de separación, se obtuvo un solo pico electroforético para Pirimicarb y Carbendazima. La inyección individual de estos dos analitos confirmó que comigran debido a que poseen movilidades electroforéticas de magnitud similar.

El sDs, además de estabilizar la corriente en medios no acuosos, se ha usado satisfactoriamente como formador de pares de iones en separaciones mediante NACE de compuestos cargados cuyas movilidades electroforéticas difieren sólo ligeramente [215, 216], como es el caso de Pirimicarb y Carbendazima. Se obtuvo una buena separación de los tres compuestos en menos de $5 \mathrm{~min}$ con la presencia de $15 \mathrm{~mm}$ de sDs en el medio de separación (Figura 10.15).

El principal inconveniente de utilizar $\mathrm{HClO}_{4}$ en NACE es su inestabilidad. Pequeñas cantidades de agua, tanto en el medio de separación como en la muestra, dan como resultado caídas de corriente frecuentes y malas separaciones. Debido a ello se estudiaron otros ácidos: acético, tricloroacético y trifluoroacético. Sin embargo, la naturaleza tan débilmente básica del Asulam

[215] R. Carabias-Martínez, E. Rodríguez-Gonzalo, J. Domínguez-Álvarez, and J. HernándezMéndez. CZE in nonaqueous solvents in the presence of ionic additives. Anal. Chem., 69:4437-4444, 1997.

[216] R. Carabias-Martínez, E. Rodríguez-Gonzalo, J. Domínguez-Álvarez, and J. HernándezMéndez. Comparative study of separation and determination of triazines by MEKC and NACE application to residue analysis in natural waters. Electrophoresis, 23:494-501, 2002. 


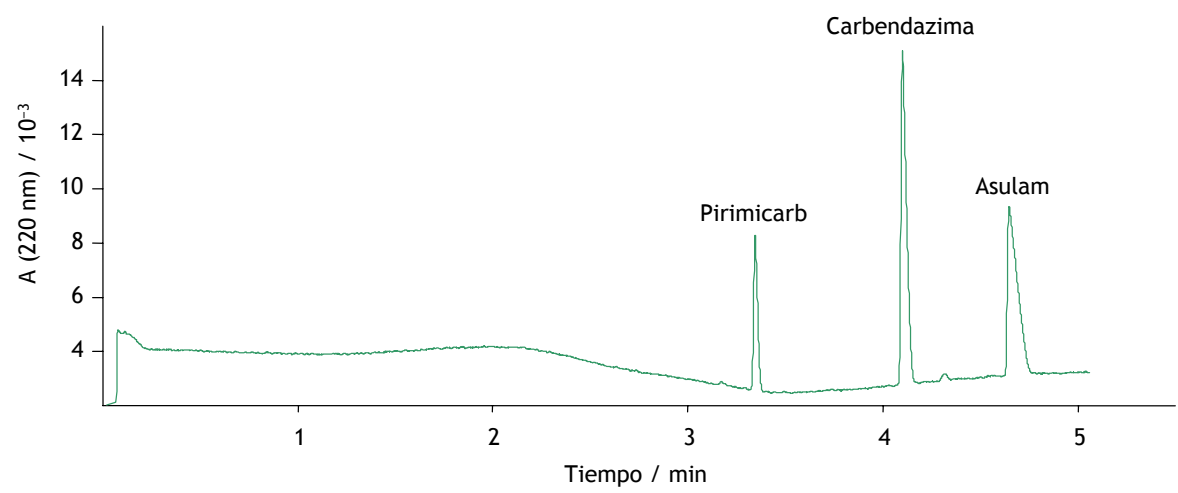

Figura 10.15. Separación mediante CzE de Asulam, Pirimicarb y Carbendazima (10 mg/L cada uno). Medio de separación: $\mathrm{HClO}_{4} 15 \mathrm{~mm}$, SDS $15 \mathrm{~mm}$ en acetonitrilo. $30 \mathrm{kV}$.

no permitió su protonación con ninguno de ellos, obteniéndose únicamente los picos correspondientes a Pirimicarb y Carbendazima. Por esta razón, en lo sucesivo se estudió únicamente el comportamiento de Pirimicarb y Carbendazima en acetonitrilo en presencia de ácido acético 1,O M.

En un medio compuesto por SDS $5 \mathrm{mM}$ y ácido acético $1 \mathrm{M}$ en acetonitrilo la inyección de una mezcla patrón de Pirimicarb y Carbendazima origina una buena separación de los dos analitos, aunque los picos son anchos y poco simétricos. La mejora en la separación conseguida con la adición de SDS se ve limitada por su baja solubilidad en acetonitrilo; $5 \mathrm{~mm}$ fue la máxima cantidad que se pudo disolver en dicho medio no acuoso. La adición de una pequeña cantidad de agua al medio de separación permite aumentar la concentración de SDS disuelta. Así, se ensayó un medio de separación compuesto por $1 \mathrm{M}(5,7 \%, \mathrm{v} / \mathrm{v})$ de ácido acético, $5 \%(\mathrm{v} / \mathrm{v})$ de agua y $15 \mathrm{~mm}$ de sDs en acetonitrilo. Las señales obtenidas con este BGE crecieron en altura y eficacia, y aumentó su resolución (Figura 10.16-A).

\section{Compresión de Pirimicarb}

Con objeto de comprobar la posibilidad de analizar directamente muestras acuosas, se inyectaron disoluciones de los plaguicidas diluyendo las disoluciones madre con agua. En estas condiciones se observó un fuerte efecto 

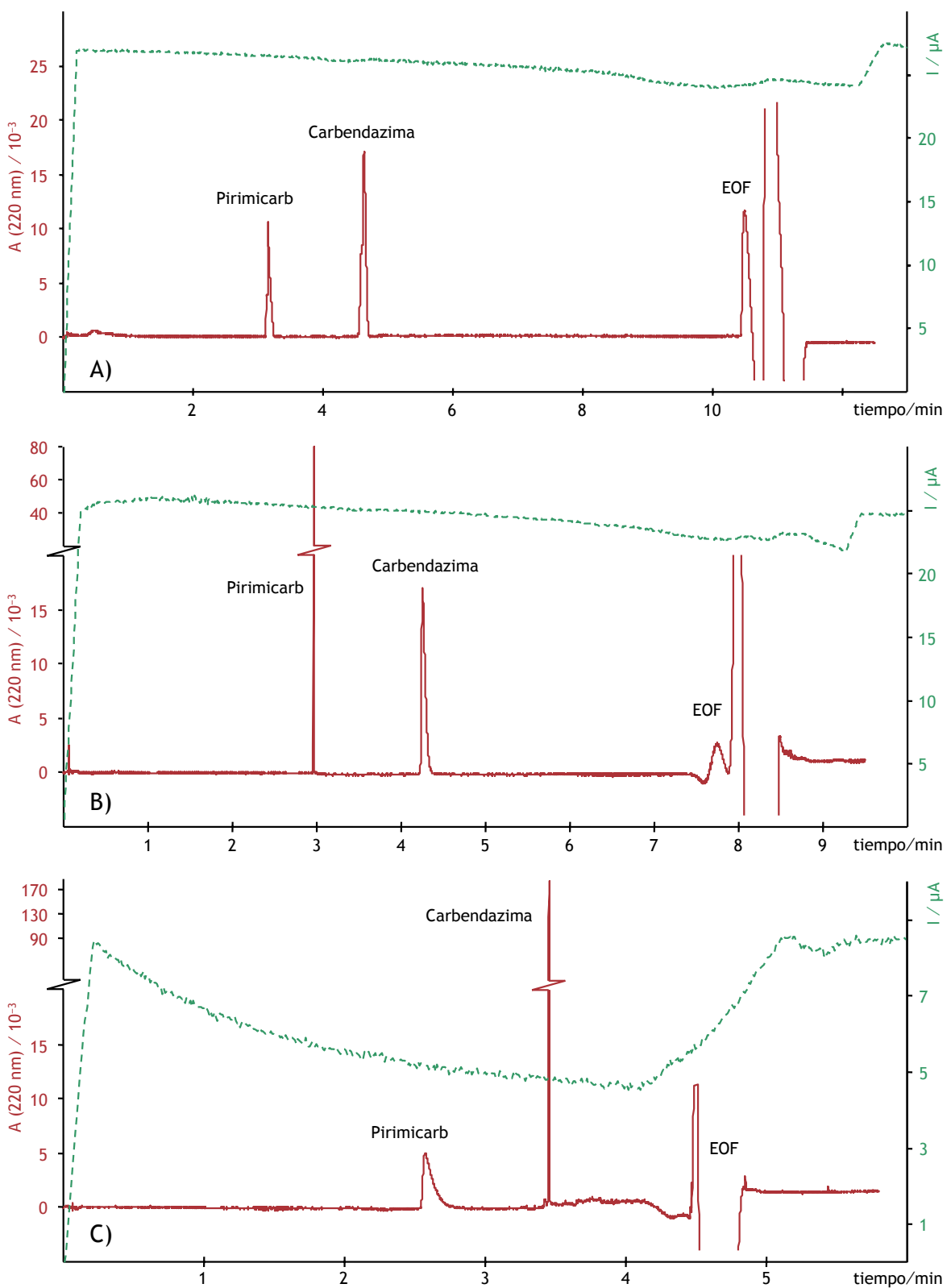

Figura 10.16. Separación mediante CZE $(30 \mathrm{kV})$ de Pirimicarb y Carbendazima (10 $\mathrm{mg} / \mathrm{L}$ cada uno).

A) Analitos disueltos en acetonitrilo;

B) y C) muestra acuosa.

Medio de separación de A) y B): ácido acético 1 M, SDS 15 mM, 5\% (v/v) de agua en acetonitrilo.

Medio de separación de C): ácido acético 1 M, SDS 5 mM en acetonitrilo. 
de compresión de la señal del Pirimicarb (Figura 10.16-B) mientras la Carbendazima migraba normalmente. La compresión del pico del Pirimicarb se produce siempre que la muestra es acuosa, y desaparece cuando el medio de inyección es semejante al medio de separación (acetonitrilo). El registro de la corriente que circula por el circuito cuando la muestra inyectada es acuosa, presenta una disminución de la inensidad que vuelve a recupaerar su valor inicial después de aparecer la señal correspondiente al EOF.

\section{Compresión de Carbendazima}

Con miras a conseguir la misma compresión para la Carbendazima se estudiaron diferentes medios de separación variando las cantidades de agua y sDsen el medio de separación. Se encontró el mismo comportamiento para la Carbendazima con un medio compuesto por $1 \mathrm{M}$ de ácido acético y $5 \mathrm{~mm}$ de sDs en acetonitrilo, sin presencia de agua (Figura 10.16-C). Con este BGE, el EOF fue ligeramente mayor $\left(t_{\mathrm{EOF}}=4,6 \mathrm{~min}\right)$ y la corriente registrada menor $(I \approx 8 \mu \mathrm{A})$. La corriente registrada mostró un descenso más pronunciado durante la separación, aunque ésta recuperó su valor inicial tras la expulsión del capilar del bolo de agua de la muestra. Como en el caso anterior, el efecto de compresión de la Carbendazima ocurrió únicamente cuando se inyectan muestras acuosas. En ningún caso es posible obtener la compresión de los dos analitos simultáneamente.

La presencia de estos picos estrechos (picos de sistema) parece estar relacionada con las llamadas «zonas de sistema» (términos usados por primera vez por Poppe en 1992 [217]). La compresión se produce cuando existe una coincidencia entre las zonas de sistema y el tiempo de migración de cada analito en los diferentes BGE. Se decidió hacer un estudio más detallado de las variables que pudieran afectar al fenómeno suceso de compresión de picos, tanto las relacionadas con la composición de la muestra como con el medio de separación.

[217] H. Poppe. Overloading and interaction phenomena in electrophoretic separations. Anal. Chem., 64:1908-1919, 1992. 
Efecto de la composición de la muestra en el pico de sistema

La variable más influyente en la composición de la muestra sobre la posición de la zona de sistema fue con diferencia la relación acetonitrilo/agua. La zona de sistema afectó a los picos de Pirimicarb y Carbendazima con diferentes medios de separación cada uno, pero en cualquier caso, siempre que la muestra inyectada fuera acuosa. En un estudio más detallado con ambos BGE en el que se variaron gradualmente las proporciones de acetonitrilo y agua en la muestra, se pudo observar que la zona de sistema se desplaza hacia menores tiempos de migración con porcentajes crecientes de agua en la muestra inyectada. Para cada BGE la zona de sistema afecta a la señal del analito correspondiente con porcentajes de agua en acetonitrilo superiores al $60 \%$, apareciendo como una sola señal muy estrecha.

También se investigó la presencia de ácido acético en la muestra. La adición de ácido acético en el intervalo o-1 M no modificó la existencia de la zona de sistema en un BGE compuesto por $5 \%$ de agua y $15 \mathrm{mM}$ de SDS en acetonitrilo (condiciones de compresión del Pirimicarb). Sin embargo, su presencia empeoró notablemente la eficacia de la separación, llegando a ensanchar lo suficiente el pico del Pirimicarb como para que parte de éste escape de la zona de sistema (Figura 10.17).

$\mathrm{Ni}$ la adición de un ácido fuerte a la muestra $\left(\mathrm{HClO}_{4}\right.$ en el intervalo o$100 \mathrm{~mm}$ ), ni la de otros electrolitos ( $\mathrm{NaCl}$ y sDs, ambos entre o y $44 \mathrm{~mm}$ ) afectaron a la compresión del Pirimicarb. Sin embargo, sí se observó un descenso acusado de la sensibilidad de los dos analitos con concentraciones crecientes de electrolito ( $>10 \mathrm{~mm})$. Resultados similares fueron observados empleando las condiciones de compresión de la Carbendazima (BGE compuesto por ácido acético 1 M y SDS $5 \mathrm{~mm}$ en acetonitrilo).

\section{Efecto de la composición del medio de separación en el pico de sistema}

Se estudió la concentración de sDs entre o y $25 \mathrm{~mm}$ en un medio compuesto por un $5 \%$ de agua en acetonitrilo. Como se ha mencionado en la página 173 no existe separación sin SDS en el BGE y se observa un solo pico para los dos analitos con un tiempo de retención ligeramente menor que el del Eor. 


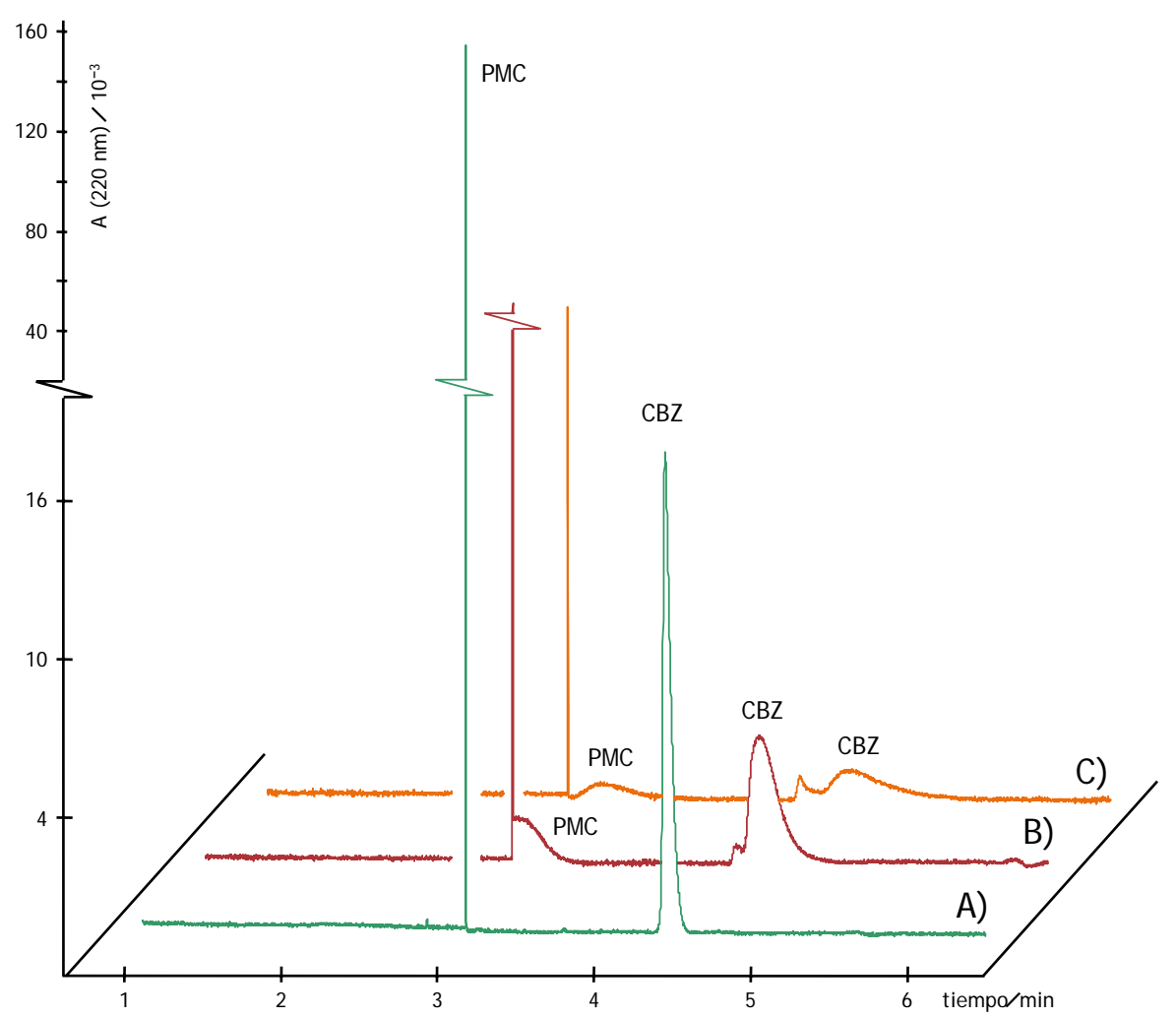

Figura 10.17. Influencia de la concentración de ácido acético en muestras acuosas. Medio de separación: Ácido acético $1 \mathrm{M}$, agua $5 \%$ (v/v) y SDS $15 \mathrm{~mm}$ en acetonitrilo. A) $\mathrm{AcOH} 1 \mathrm{M}, \mathrm{B}) \mathrm{AcOH}$ o,116 м y C) $\mathrm{AcOH}$ o,o10 M.

Con una concentración de $5 \mathrm{~mm}$ ya hay separación entre los dos compuestos. Con $8 \mathrm{~mm}$ la zona de sistema afecta parcialmente al pico del Pirimicarb, del cual se comprime la parte izquierda. Con concentraciones de sDs de entre 15 y $25 \mathrm{~mm}$ la señal de Pirimicarb aparece íntegramente comprimida. Con $25 \mathrm{~mm}$ el Pirimicarb comienza a salir del área de influencia de la zona de sistema, que lo deja a su izquierda (electroferogramas y condiciones en la Figura 10.18).

La cantidad de ácido acético en el BGE tuvo un efecto menor. Se varió su cantidad en el intervalo o,25-3 M, en un medio compuesto por $5 \%$ de agua y SDS $15 \mathrm{~mm}$ (condiciones de compresión del Pirimicarb). Se encontró que una concentración creciente de ácido disminuye el $t_{\mathrm{R}}$ de la zona de sistema res- 

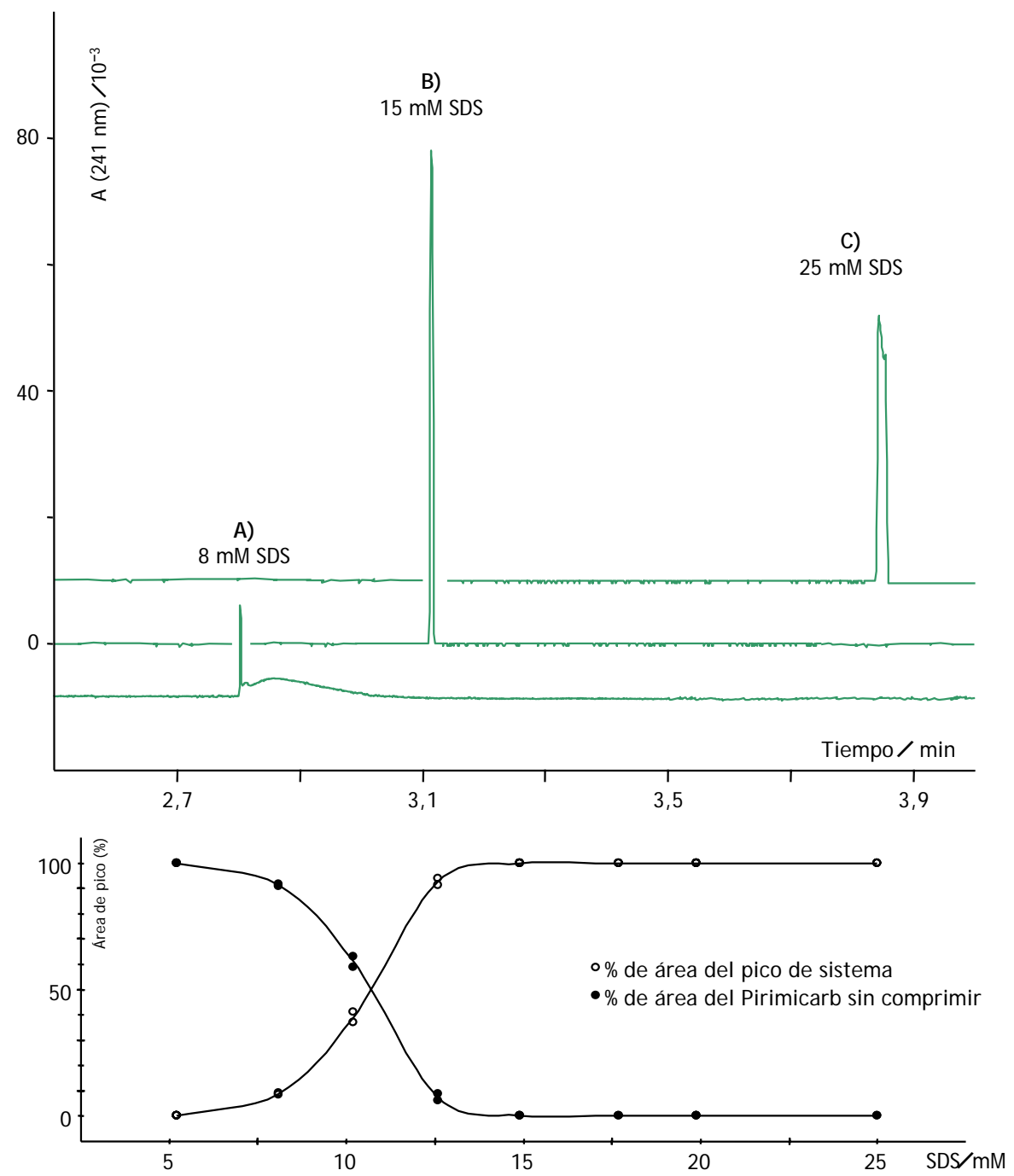

Figura 10.18. Influencia de la concentración de SDS en el BGE. Medio de separación: $5 \%(\mathrm{v} / \mathrm{v})$ de agua y acido acético $1 \mathrm{M}$ en acetonitrilo. Concentración de SDS indicada en el electroferograma.

Abajo: Porcentajes del área del Pirimicarb como pico de sistema y como pico sin comprimir en función de la concentración de SDS en el BGE. 
pecto al pico del Pirimicarb, apareciendo éste íntegramente comprimido con concentraciones de ácido acético de 1-2 M. Con $3 \mathrm{M}$ el efecto de compresión desaparece.

Se probaron otros aditivos diferentes al SDs: acetato amónico (en el intervalo o-22 $\mathrm{mM}$ ) y perclorato de litio (o-43 $\mathrm{mm}$ ). El uso de acetato amónico no permitió la separación de los dos analitos, observándose un solo pico cerca de la señal del EOF. Con la adición de perclorato de litio sí se consiguió la separación de los dos analitos, pero con picos muy anchos y menor resolución que la conseguida con SDS. No se observó ninguna zona de sistema con ninguno de los dos electrolitos ensayados.

Sin embargo, el factor más influyente en la composición del BGE sobre la posición de la zona de sistema fue el porcentaje de agua presente en el medio de separación. Se estudió la inyección de muestras de agua en BGE compuestos por acetonitrilo y SDS con diferentes cantidades de agua (o-8\%, v/v) (Figura 10.19). En todos los experimentos apareció una estrecha alteración de la señal acompañada de un pequeño escalón en la línea base. Con fines comparativos, en la parte derecha de la Figura 10.19 se muestran las inyecciones de patrones acuosos de los analitos en las mismas condiciones. Se puede comprobar cómo la compresión de los picos ocurre cuando el tiempo de migración de los analitos coincide con el de la perturbación de la línea base. Con un BGE compuesto por un $100 \%$ de acetonitrilo la zona de sistema coincide con el tiempo de migración de la Carbendazima. Con porcentajes de agua entre o y $5 \%$ la perturbación migra entre los dos analitos y no afecta a ninguno de ellos. Como ya se ha comprobado, se obtiene un pico comprimido del Pirimicarb con un $5 \%$ de agua. Y con porcentajes superiores al $6 \%$ el tiempo de migración de la zona de sistema es inferior al del Pirimicarb, sin afectar a éste. Destaca el hecho de que la magnitud de esta perturbación se hace menor a medida que aumenta el contenido de agua en el BGE.

\section{Comportamiento de otros analitos}

Con el objeto de comprobar si las zonas de sistema afectan a otros analitos que pueden separarse en el mismo $\mathbf{B G E}$, se incluyeron varios compuestos de naturaleza diferente al Pirimicarb y Carbendazima. Los compuestos elegidos 
Muestra blanco
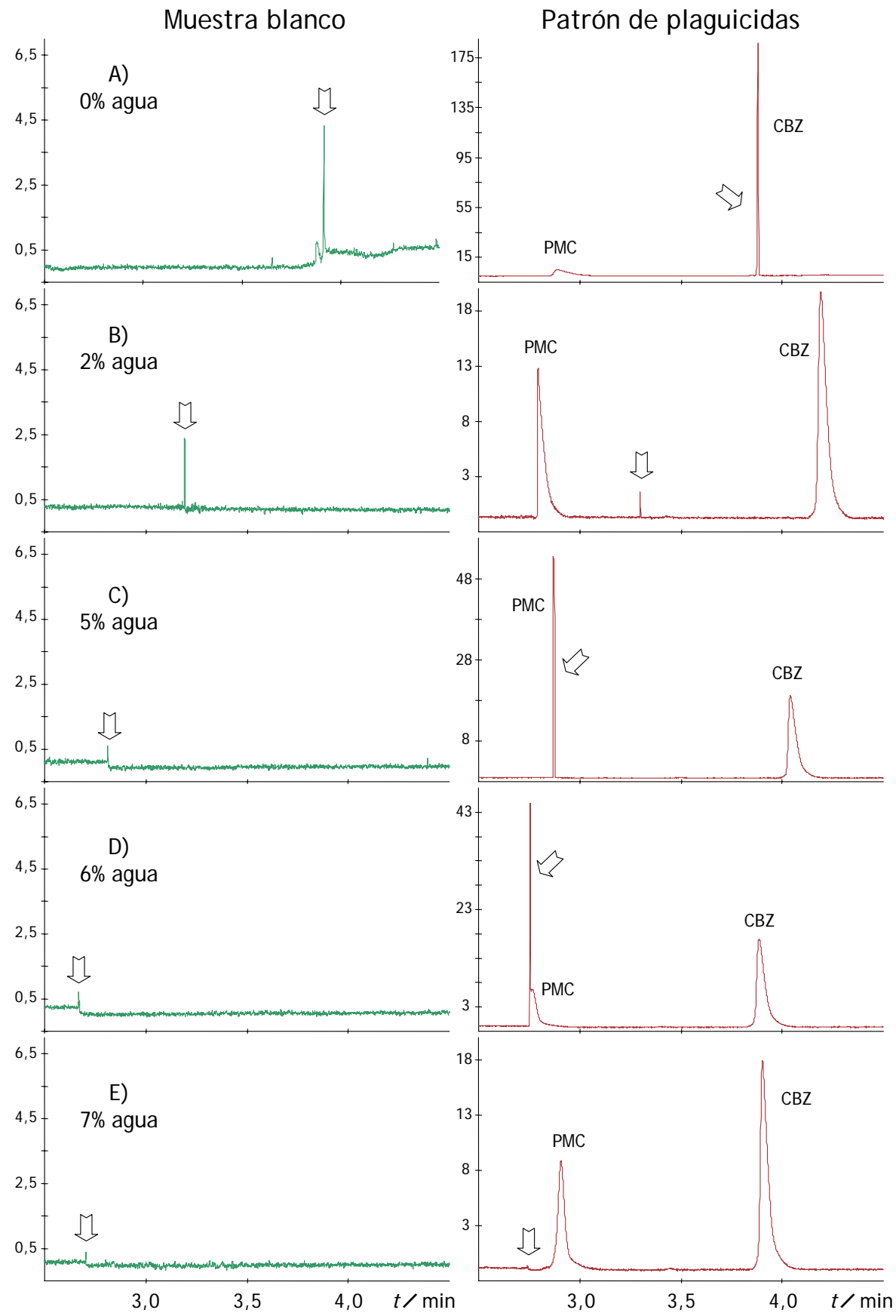

Figura 10.19. Influencia del contenido de agua (\%,v/v) en el BGE. La flecha señala la perturbación de la zona de sistema. Izquierda: inyección de agua (blanco). Derecha: inyección de plaguicidas disueltos en agua $(10 \mathrm{mg} / \mathrm{L})$. Medio de separación: Ácido acético $1 \mathrm{M}$ en acetonitrilo. SDs: A) $5 \mathrm{mM}, \mathrm{B})-\mathrm{D})$ $15 \mathrm{~mm}$. Detección a $220 \mathrm{~nm}$. 
fueron dos sales de amonio cuaternarias (los herbicidas Dicuat y Paracuat) y tres metiltiotriazinas (los herbicidas Ametrina, Prometrina y Terbutrina). Dicuat y Paracuat son cationes con doble carga, de tal manera que se espera que muestren una elevada movilidad electroforética.

En las Figuras 10.20-A y 10.20-B se muestran las separaciones de dichos compuestos en los medios de separación que originan la compresión de Pirimicarb y Carbendazima, respectivamente.

En las condiciones de compresión del Pirimicarb todos los analitos inyectados migran por separado con buena forma de pico. Los tiempos de migración de Paracuat y Dicuat son inferiores a los del Pirimicarb, mientras que las metiltiotriazinas poseen un tiempo de migración ligeramente superior al de la Carbendazima.

Cuando no se añade agua al medio de separación (condiciones de compresión de la Carbendazima), las 3 metiltiotriazinas presentaron el mismo comportamiento que la Carbendazima, con una única señal comprimida en un solo pico para los 4 compuestos. (Figura 10.20-B). Este comportamiento es parecido al publicado por Kenndler et al. [218, 219], quienes separan proteínas con SDS en la zona del bolo de muestra, no en el BGE. Estos autores sugieren que el sistema se comporta como una separación isotacoforética no intencionada.

\section{Discusión}

A pesar de que el origen de esta compresión no está claro, su presencia fue reproducible e independiente del tipo de capilar, dimensiones, y equipo de CE empleado.

Estas zonas de sistema son debidas a alteraciones en la composición inicialmente uniforme del BGE ocasionadas por la introducción de un bolo de

[218] E. Kenndler and K. Schmidt-Beiwl. Effect of SDS in protein samples on separation with free CZE. J. Chromatogr., 545:397-402, 1991.

[219] L. Kremser, G. Bilek, and E. Kenndler. Effect of detergent on electromigration of proteins: CE of very low density lipoprotein receptor modules and viral proteins. Electrophoresis, 28:3684-90, 2007 . 


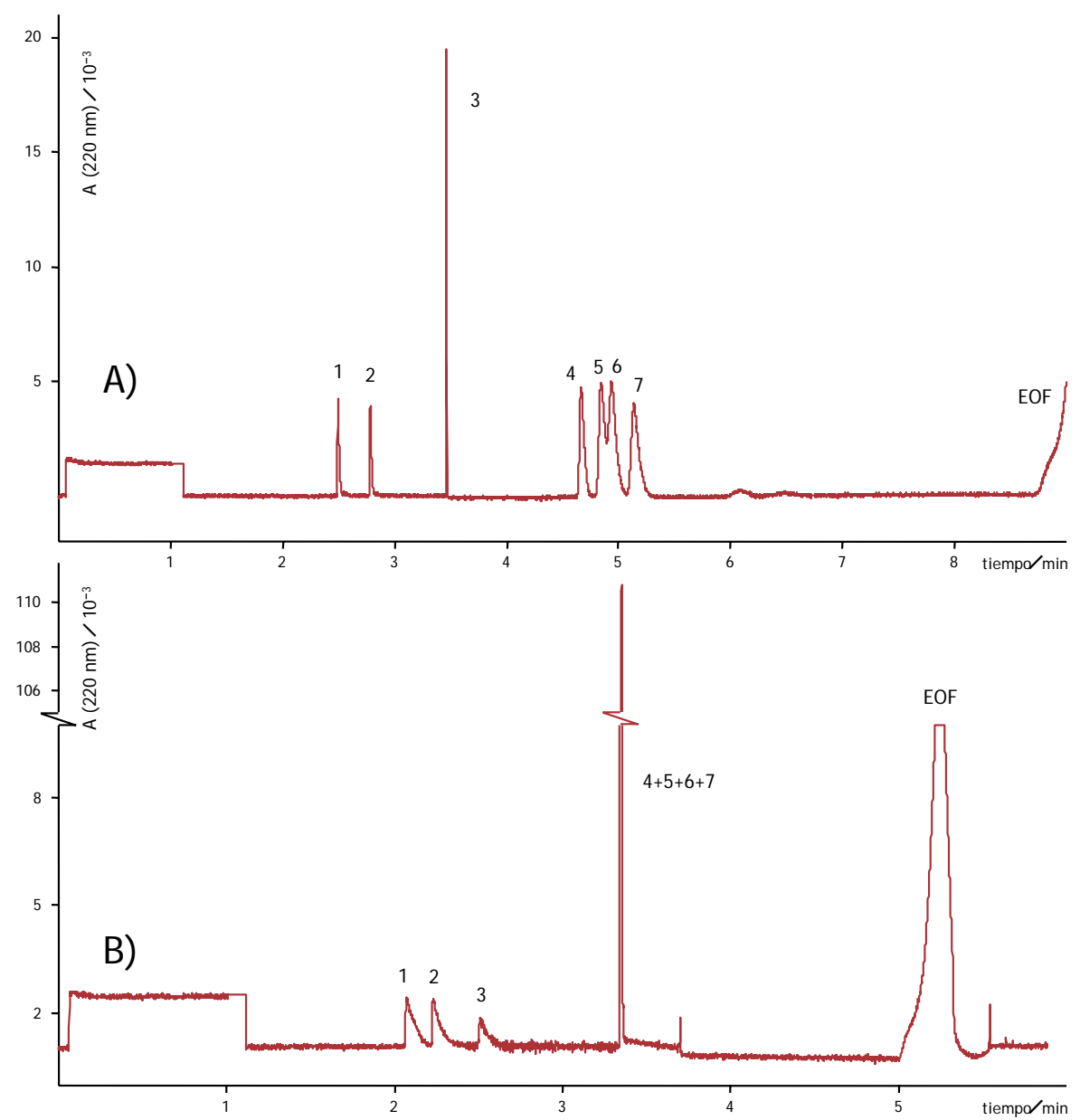

Figura 10.20. Separación mediante cze de varios plaguicidas iónicos en A) ácido acético $1 \mathrm{M}$, SDS $15 \mathrm{mM}, 5 \%(\mathrm{v} / \mathrm{v})$ de agua en acetonitrilo, y B) ácido acético $1 \mathrm{M}$, SDS $5 \mathrm{~mm}$ en acetonitrilo.

Picos: 1, Paracuat (10 mg/L); 2, Dicuat (10 mg/L); 3, Pirimicarb (10 mg/L); 4, Carbendazima (10 mg/L); 5, Ametrina (20 mg/L); 6, Prometrina (20 mg/L); 7, Terbutrina $(20 \mathrm{mg} / \mathrm{L})$. 
muestra con una composición diferente. Estas alteraciones tienen su propia movilidad electroforética, y pueden ocasionar picos de sistema a su paso por el detector.

Una de las primeras y más comprensivas explicaciones hasta la fecha de estas «zonas de sistema» ha sido la de Hans Poppe [217, 220], quien ha descrito el comportamiento de un sistema electroforético de varios componentes mediante un modelo matemático de valores propios. En cualquier caso, se ha demostrado que en separaciones reales, con más componentes iónicos, y presencia de ácidos y bases, el problema puede ser más complejo [221, 222]. La explicación de la presencia de zonas de sistema no resulta fácil y existen diferentes modelos teóricos y matemáticos que tratan de justificar y predecir su existencia y posición. El asunto ha sido ampliamente tratado por Beckers [223, 224, 225, 226, 227] y también Boček et al. [228, 229, 230, 231].

[220] H. Poppe. System peaks and non-linearity in CE and HPLC. J. Chromatogr. A, 831:105-121, 1999.

[221] J. L. Beckers. Uvdetection in CzE. Peaks or dips: that is the question. J. Chromatogr. A, 679:153-165, 1994 .

[222] J. L. Beckers. System peaks and disturbances to the baseline uv signal in CZE. J. Chromatogr., 662:153-166, 1994

[223] J. L. Beckers. Calculation of the composition of sample zones in CZE I. Mathematical model. J. Chromatogr. A, 693:347-357, 1995.

[224] J. L. Beckers. Calculation of the composition of sample zones in CZE II. Simulated electropherograms. J. Chromatogr. A, 696:285-294, 1995.

[225] J. L. Beckers. Calculation of the composition of sample zones in CZE III. Weak bases and the application of background electrolytes with two co-ions. J. Chromatogr. A, 741:265-277, 1996.

[226] J. L. Beckers. Calculation of the composition of sample zones in CZE IV. Weak acids and system characteristics. J. Chromatogr. A, 764:111-126, 1997.

[227] J. L. Beckers. Peak deformation in cationic analysis caused by system zones. Electrophoresis, 22:2684, 2001.

[228] P. Gebauer and P. Boček. System peaks in CZE I. Simple model of vacancy electrophoresis. J. Chromatogr. A, 772:73-79, 1997.

[229] C. Desiderio, S. Fanali, P. Gebauer, and P. Boček. System peaks in CZE II. Experimental study of vacancy peaks. J. Chromatogr. A, 772:81-89, 1997.

[230] J. L. Beckers, P. Gebauer, and P. Boček. System zones in CzE. Electrophoresis, 22:3648-3658, 2001.

[231] P. Boček, P. Gebauer, and J. L. Beckers. Success and failure with phthalate buffers in CzE. Electrophoresis, 22:1106-11, 2001. 


\section{Utilidad analítica de los picos de sistema}

A pesar del notable incremento de señal que se produce cuando se comprime la señal de un analito, y tras comprobar la linealidad de su área (la altura se mostró más irreproducible y no lineal) con la concentración, la inyección de muestras en blanco dio lugar a picos de sistema y escalones en la línea base totalmente irreproducibles. Este hecho incrementa muchísimo el límite de detección de los analitos que salen como picos de sistema, ya que la desviación estándar de las señales producidas por muestras en blanco hace imposible distinguir entre picos debidos al ruido de fondo y verdaderos positivos.

Podría por lo tanto pensarse que la aparición de picos de sistema no interferiría en la cuantificación de concentraciones elevadas de analitos. Sin embargo se ha comprobado que la zona de sistema abarca un margen más amplio que el pico de sistema correspondiente y ocasiona que aparezca un solo pico comprimido con todos los analitos que migran en la zona de sistema.

Se puede concluir por lo tanto que la compresión de analitos como picos de sistema es del todo indeseable y que hay que evitar en todo lo posible este suceso.

En separaciones sucesivas de Carbendazima y Pirimicarb mediante czE se utilizará un electrolito compuesto por ácido acético $1 \mathrm{M}$, SDS $15 \mathrm{mM}$, y $2 \%$ $(\mathrm{v} / \mathrm{v})$ de agua en acetonitrilo.

\subsubsection{Preconcentración in-line y separación mediante electroforesis capilar zonal}

Cuando se lleva a cabo una separación mediante czE, el medio orgánico de separación es capaz de eluir los analitos de un sorbente situado en el mismo capilar de separación (acoplamiento in-line). Se estudió el acoplamiento inline para el análisis de los plaguicidas cargados en medio ácido, Pirimicarb y Carbendazima (separación optimizada en la Sección 10.2.1). 
El polímero empleado (basado en divinilbenceno) ha sido el caracterizado y optimizado para su uso como sorbente antes de una separación mediante MEKC en la Sección 10.1.2 (composición en la página 134). La metodología de preconcentración propuesta en este trabajo se ha basado en las publicaciones de Baryla y Toltl [196] y Schaller et al. [197]: la muestra acuosa se pasa por el polímero monolítico aplicando presión. Posteriormente se lava el capilar y el sorbente con agua y se expulsa el agua del capilar y se llena con el medio orgánico de separación aplicando un voltaje negativo, hasta el cambio de corriente. El proceso se muestra de forma esquemática en la Tabla 10.7 y la Figura 10.21.

La principal ventaja de esta metodología radica en que, al realizarse la preconcentración y la separación en el mismo capilar, es posible la automatización del proceso, con las mejoras en rapidez y reproducibilidad que esto conlleva. En este caso no hay dilución de la muestra eluida, sino que se detecta la totalidad de los analitos retenidos y los límites de detección alcanzados son mucho menores que con otro tipo de acoplamientos.

Tabla 10.7. Etapas generales de la preconcentración in-line de plaguicidas en un capilar monolítico para su separación mediante CZE

\begin{tabular}{|llllll|}
\hline \multicolumn{2}{|c|}{ Etapa } & Entrada & Salida & & \\
\hline 1 & Lavado & Metanol & Desecho & $2-12$ bar & $1 \mathrm{~min}$ \\
2 & Acondicionado & Agua & Desecho & $2-12 \mathrm{bar}$ & $1 \mathrm{~min}$ \\
3 & Preconcentración & Muestra & Desecho & $2-12 \mathrm{bar}$ & $5-30 \mathrm{~min}$ \\
4 & Lavado & Agua & Desecho & $2-12$ bar & $1 \mathrm{~min}$ \\
5 & Elución & BGE & BGE & $-15 \mathrm{kV}$ & Hasta cambio brusco de corriente \\
7 & Separación & BGE & BGE & $30 \mathrm{kV}$ & \\
\hline
\end{tabular}

\section{Longitud del polímero}

En los estudios realizados trabajando en МЕКC se comprobó que la longitud más adecuada de polímero era de $16 \mathrm{~cm}$. Por ello en este estudio se comenzó 


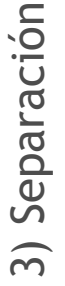

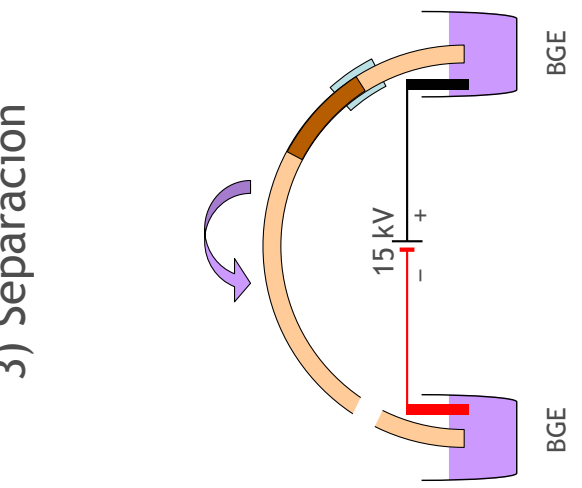

岁

ठี

5

ํํํ

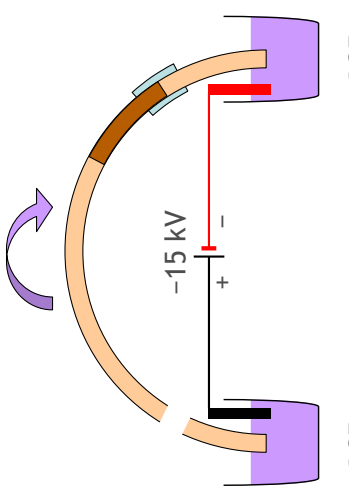

岕

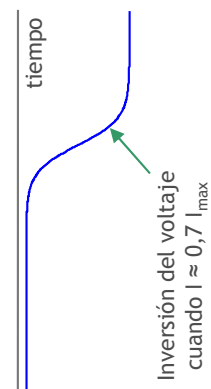

$\frac{0}{0}$

음

$\stackrel{\frac{c}{\varrho}}{=}$

을

岗 рер!suәтu

ก

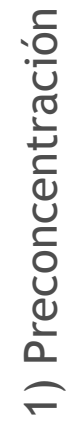

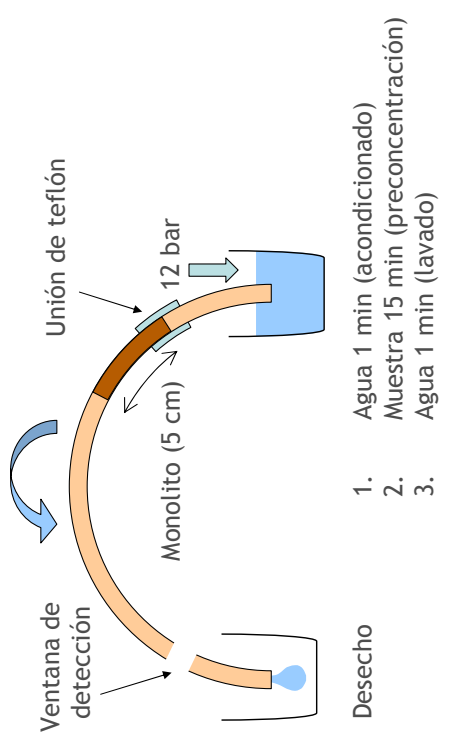

, iㅗ

o

䒕

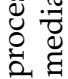

웜

ริ

尊

入

ฉั.

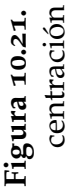


trabajando con polímeros monolíticos de $16 \mathrm{~cm}$ colocados en el extremo de entrada del capilar con una longitud total de $58,5 \mathrm{~cm}$ y efectiva de $50 \mathrm{~cm}$. Se intentó la preconcentración y separación de una muestra que contenía $0,1 \mathrm{mg} / \mathrm{L}$ de cada uno de los analitos aplicando 6 bar durante $1 \mathrm{~min}$.

Las separaciones obtenidas en estas condiciones dieron lugar a corrientes inestables, picos anchos, y en muchas ocasiones los compuestos estaban repartidos en diferentes señales electroforéticas.

Este comportamiento está de acuerdo con el descrito en bibliografía, y ocurre cuando el medio de retención es demasiado largo. Esto ocasiona que el volumen necesario para la elución sea muy elevado dando lugar a señales anchas y con colas. Además, cuando con esta técnica se usa un monolito demasiado largo es muy probable que comience la separación antes de que se hayan eluido los analitos retenidos en el extremo del polímero, que se eluirían con el BGE de cola. Esto explicaría la existencia de diferentes picos para cada compuesto.

De acuerdo con estos resultados se modificó la longitud del polímero encontrándose que con $5 \mathrm{~cm}$ de sorbente se obtienen señales bien definidas y corrientes estables.

\section{Tiempo de preconcentración}

En los estudios realizados anteriormente (Sección 10.1.2) se comprobó que para el Pirimicarb se obtiene una señal que aumenta con el tiempo de preconcentración en polímeros de $8 \mathrm{~cm}$. Sin embargo para la Carbendazima se obtiene una señal que disminuye al superar el tiempo de concentración los 15 min con sorbentes cortos $(8 \mathrm{~cm})$. De acuerdo con estos resultados, se decidió emplear un tiempo de 15 min como adecuado para la preconcentración de los dos analitos.

La cantidad de muestra preconcentrada con este método depende del caudal con el que se pasa la muestra, y éste está relacionado con la porosidad obtenida en el proceso de polimerización. El control adecuado de la polimerización garantiza una reproducibilidad aceptable del comportamiento del 
monolito. Con $15 \mathrm{~min}$ de preconcentración aplicando 12 bar, la cantidad de muestra tratada fue $0,97 \pm 0,09 \mathrm{~g}(n=7$, con dos capilares diferentes).

\section{Inversión del voltaje}

La etapa más crítica de la metodología propuesta es la elección del momento en el que los analitos se consideran completamente eluidos, se produce la inversión de la polaridad y comienza la separación electoforética. Si la inversión del voltaje sucede demasiado pronto, la fase orgánica no alcanza el polímero y no se eluyen los analitos; y si el volumen de llenado excede el volumen del capilar se corre el riesgo de arrastrar completamente los analitos y expulsarlos fuera del capilar.

En este trabajo se propone no colocar el medio de retención en el extremo del capilar, sino a unos centímetros de la entrada. De este modo es posible asegurar que la totalidad de los analitos retenidos son eluidos antes de que el capilar se encuentre completamente lleno de BGE. Trabajando en estas condiciones se consigue una mayor reproducibilidad y además el tiempo necesario durante la etapa de la elución es menos crítico. Para asegurar la existencia de un trozo de capilar hueco en el extremo del capilar, a un capilar con $5 \mathrm{~cm}$ de polímero en un extremo, y cortado de forma lo más perpendicular posible se le acopló un pedazo de capilar hueco de $7,5 \mathrm{~cm}$ mediante un tubo de teflón de $350 \mu \mathrm{m}$ de diámetro interno. Este acoplamiento permite la posibilidad del corte de unos milímetros de sorbente en caso de obstrucción, sin que afecte ni a la estabilidad de la corriente ni a la forma de los picos.

La monitorización de la corriente que pasa por el circuito durante la etapa de elución permite decidir en qué momento ha terminado el llenado del capilar y la elución de los analitos, y por tanto puede comenzar la separación. La corriente registrada es muy pequeña al principio debido a que el capilar está lleno de agua sin ningún electrolito. Llegado un momento el valor de la corriente crece rápidamente hasta un valor constante que indica que el capilar está lleno de вGE y los analitos han sido eluidos.

Para estudiar el momento apropiado para invertir el voltaje se estudió la variación del área de los picos de Pirimicarb y Carbendazima en función de la 
corriente alcanzada durante la etapa de elución. Antes de cada experimento se aplicaron $15 \mathrm{kV}$ con el capilar lleno de BGE para determinar el valor máximo de corriente que puede alcanzarse. La Figura 10.22 representa la variación del área de pico frente al \% de corriente en el que se invirtió el voltaje y comenzó la separación. Se puede observar cómo con valores de corriente inferiores al $20 \%$, el BGE aún no ha llegado al sorbente y por lo tanto no eluye los analitos. Se aprecia cómo las áreas caen bruscamente por encima del $90 \%$, momento en el que los analitos son expulsados del capilar por el extremo de entrada. En la Figura 10.22 también se puede comprobar cómo el tiempo de migración de cada compuesto aumenta al hacerlo la relación $I / I_{\text {máx }}$. Este desplazamiento de los tiempos de migración se justifica porque la distancia que tienen que recorrer los analitos hasta la ventana de detección es algo mayor a medida que la migración comienza en puntos cada vez más cercanos al extremo de entrada.

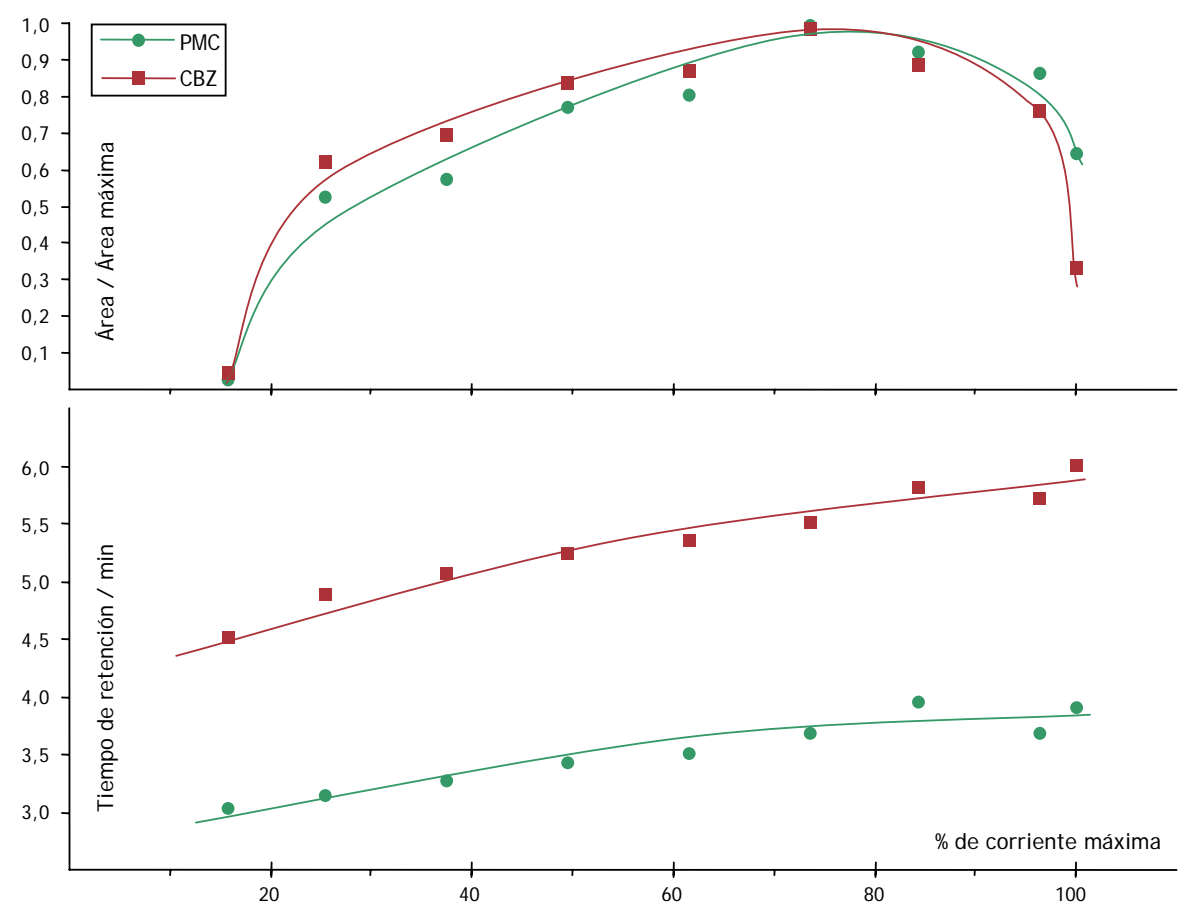

Figura 10.22. Variación de la señal y tiempos de migración en función del \% de corriente máxima alcanzado en la extracción. 
La Figura 10.23 muestra la absorbancia y la intensidad registradas durante la elución. Se observa en el registro de la absorbancia un escalón en la señal debido al cambio del agua por el BGE en la ventana de detección. Unos minutos más tarde ocurre el incremento en la corriente (en valor absoluto). También se puede apreciar una pequeña oscilación en la corriente a $4,3-4,4 \mathrm{~min}$, debida probablemente al momento en el que el eluyente está pasando por el sorbente.

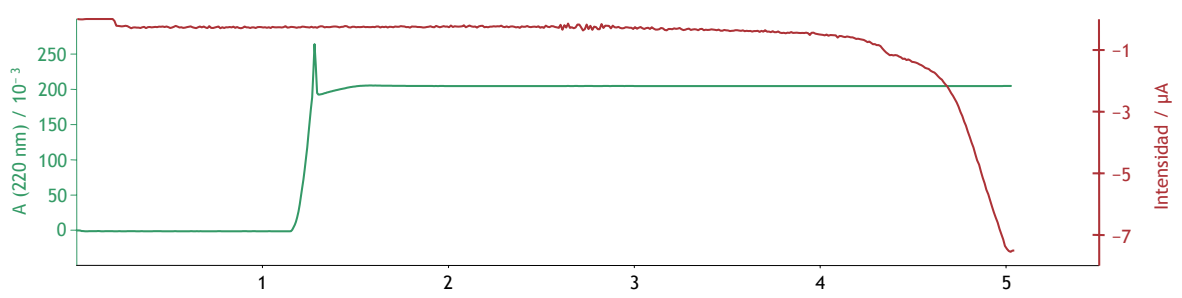

Figura 10.23. Señal espectrofotométrica y corriente registradas durante la etapa de elución.

De acuerdo con los resultados obtenidos se eligió como momento óptimo de interrupción de la elución, cuando el valor de la corriente es del 70\% respecto al conseguido con el capilar lleno de вGE.

La Figura 10.24 compara dos electroferogramas correspondientes a una muestra de $1 \mathrm{mg} / \mathrm{L}$ inyectada directamente y una muestra de $1 \mathrm{\mu g} / \mathrm{L}$ preconcentrada durante 15 min a 12 bar. Se evaluó la eficacia en la separación mediante el número de platos. Los valores obtenidos sin preconcentración (Figura 10.24-B) fueron de $13,2 \times 10^{4}$ y $6,7 \times 10^{4}$ para Pirimicarb y Carbendazima, respectivamente. Cuando se llevó a cabo el proceso de preconcentración in-line (Figura 10.24-A), el número de platos fue de $12,7 \times 10^{4}$ y $4,7 \times 10^{4}$ para Pirimicarb y Carbendazima. Estos resultados indican que la eficacia en la separación no es modificada significativamente por la etapa de preconcentración ni por la presencia del sorbente monolítico en el interior del capilar. 


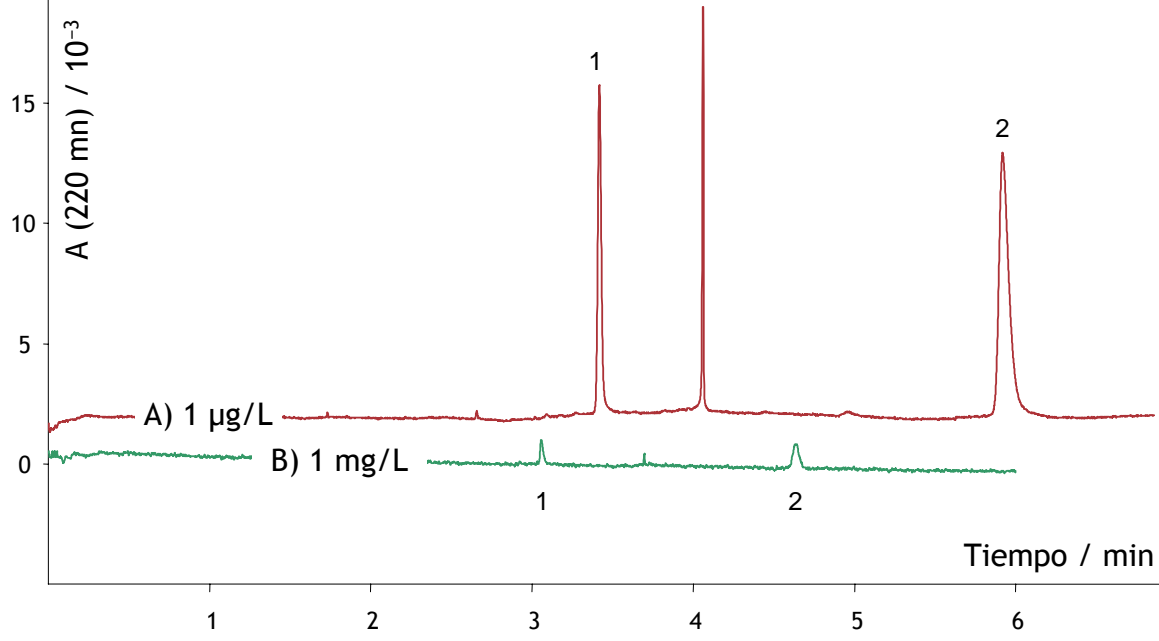

Figura 10.24. Electroferogramas correspondientes a

A) in-line-SPE-CZE; concentración: 1 $\mu \mathrm{g} / \mathrm{L}$; preconcentración durante $15 \mathrm{~min}$.

B) Inyección directa, hidrodinámica, 25 mbar durante $4 \mathrm{~s}$; concentración: $1 \mathrm{mg} / \mathrm{L}$.

\section{Zona de sistema}

Se ha comprobado que utilizando una etapa de preconcentración in-line también aparecen los picos de sistema descritos en la Sección 10.2.1. La presencia de estos picos se debe a la presencia de agua en el extremo de entrada del capilar después de que ha tenido lugar el llenado del capilar con el medio orgánico con el que tiene lugar la elución de los analitos del polímero.

Cuando se produce la etapa de preconcentración in-line, las zonas de sistema pueden coincidir con las señales de los analitos, originando la aparición de picos comprimidos. Como ya se ha indicado, se debe evitar la coincidencia de la migración de la zona de sistema y de los analitos. En las Figuras 10.24 y 10.25 se puede observar que con el BGE empleado (ácido acético 1 M, SDS $15 \mathrm{~mm}$ y $2 \%$ (v/v) de agua en acetonitrilo) el pico del sistema aparece entre las señales de los dos analitos. 


\subsubsection{Características analíticas}

\section{Separación mediante czE sin preconcentración}

Las características analíticas del método sin etapa de preconcentración se han determinado analizando directamente disoluciones acuosas de Pirimicarb y Carbendazima. Las ecuaciones de los calibrados, precisión y límites de detección se muestran en la Tabla 10.8. La linealidad se estudió en un intervalo de concentración de entre 1 y $20 \mathrm{mg} / \mathrm{L}$. La precisión se determinó a partir del análisis de 8 réplicas consecutivas con una concentración de 10,9 y 11,6 mg/L para el Pirimicarb y el Carbendazima, respectivamente. Los límites de detección han sido calculados de la misma manera que para el caso de la separación con MEKC, es decir, a partir de la desviación estándar de la señal del fondo en la zona del pico electroforético.

\section{Separación mediante czE con etapa de preconcentración in-line}

Las características analíticas del método utilizando preconcentración in-line y separación mediante czE de disoluciones de Pirimicarb y Carbendazima también se muestran el la Tabla 10.8. La preconcentración se realizó haciendo pasar por un sorbente polimérico de $5 \mathrm{~cm}$ una disolución de los analitos aplicando 12 bar durante $15 \mathrm{~min}$.

Con el fin de aumentar la precisión de las medidas cuantitativas, y ante la ausencia de un patrón interno adecuado que corrija las pequeñas variaciones de la cantidad de muestra preconcentrada, las señales originadas por cada analito se normalizan dividiéndose entre la cantidad de muestra pasada a través del polímero. Esta cantidad se determinó pesando la muestra antes y después de la etapa de preconcentración.

La precisión del análisis se calculó a partir de 7 medidas realizadas 2 días diferentes usando dos capilares distintos. Los valores obtenidos (12,5 y $6 \%$ para Pirimicarb y Carbendazima, respectivamente) son adecuados e inferiores a las desviaciones estándar relativas admitidas por el documento SAN- 
Tabla 10.8. Características analíticas de CZE sin preconcentración e in-line-SPE-CZE.

\begin{tabular}{|c|c|c|c|}
\hline & & Pirimicarb & Carbendazima \\
\hline \multirow{5}{*}{ CZE } & $a^{a} / \mathrm{u} A$ & $\left(-1,8 \pm 0,6^{b}\right) \times 10^{-6}$ & $(-2,3 \pm 0,1) \times 10^{-6}$ \\
\hline & $b / \mathrm{L} / \mu \mathrm{g} \mathrm{u} A$ & $(7,11 \pm 0,08) \times 10^{-9}$ & $(11,0 \pm 0,2) \times 10^{-9}$ \\
\hline & $r^{2 c}$ & 0,9997 & 0,9995 \\
\hline & $\operatorname{RSD}(\%)^{d}$ & 6,0 & 5,1 \\
\hline & $\mathrm{LD} / \mu \mathrm{g} / \mathrm{L}$ & 0,1 & 0,19 \\
\hline \multirow{5}{*}{ SPE-CZE ${ }^{e}$} & $a^{a} / \mathrm{u} A$ & $(-1 \pm 14) \times 10^{-6}$ & $(-7 \pm 18) \times 10^{-6}$ \\
\hline & $b / \mathrm{L} / \mu \mathrm{g} \mathrm{u} A$ & $(77 \pm 6) \times 10^{-6}$ & $(124 \pm 7) \times 10^{-6}$ \\
\hline & $r^{2 f}$ & 0,998 & 0,9993 \\
\hline & $\operatorname{RSD}(\%)^{g}$ & 12,5 & 6,3 \\
\hline & $\mathrm{LD} / \mu \mathrm{g} / \mathrm{L}$ & 0,01 & 0,01 \\
\hline \multicolumn{2}{|c|}{ Incremento de sensibilidad ${ }^{h}$} & $13,6 \times 10^{3}$ & $7,8 \times 10^{3}$ \\
\hline \multicolumn{4}{|c|}{$\begin{array}{l}a y=a+b x, \text { donde } y \text { es el área corregida de pico (absorbancia), y } x \text { la } \\
\text { concentración }(\text { en } \mu \mathrm{g} / \mathrm{L}) .\end{array}$} \\
\hline \multicolumn{4}{|c|}{${ }^{b}$ Intervalos de confianza del $95 \%$} \\
\hline \multicolumn{4}{|c|}{${ }^{c}$ Intervalo estudiado: $1-20 \mathrm{mg} / \mathrm{L}$} \\
\hline \multicolumn{4}{|c|}{$\begin{array}{l}{ }^{d} \text { Desviación estándar relativa para un nivel de concentración de } 10,9 \text { y } \\
11,6 \mathrm{mg} / \mathrm{L} \text {, para Pirimicarb y Carbendazima, respectivamente }(n=8) \text {. }\end{array}$} \\
\hline \multicolumn{4}{|c|}{${ }^{e}$ Parámetros normalizados para $1 \mathrm{~g}$ de muestra preconcentrada. } \\
\hline \multicolumn{4}{|c|}{$f_{\text {Intervalo estudiado: } 0,1-5^{\mu g} / \mathrm{L} .}$} \\
\hline \multicolumn{4}{|c|}{$\begin{array}{l}g \text { Desviación estándar relativa para un nivel de concentración de o, } 5^{\mathrm{\mu g} / \mathrm{L}} \text { en } \\
\text { dos capilares diferentes durante dos días consecutivos }(n=7) \text {. }\end{array}$} \\
\hline \multicolumn{4}{|c|}{$\begin{array}{l}h \text { Relación de pendientes del calibrado en alturas con y sin etapa de } \\
\text { preconcentración. }\end{array}$} \\
\hline
\end{tabular}


$\mathrm{CO} / 2007 / 3131$ [232]. De acuerdo con este documento (párrafo 56) en la validación de un método la desviación estándar relativa debe ser inferior al $20 \%$ para un nivel próximo al límite de cuantificación. Se puede observar que también son inferiores a los obtenidos empleando una etapa de preconcentración en el capilar y separación por МЕкс.

Los límites de detección han sido calculados a partir de la concentración de analito que produce una señal 3 veces superior a la desviación estándar de la señal del blanco en la zona del pico electroforético. Se han obtenido unos valores de $0,01 \mu \mathrm{g} / \mathrm{L}$ para los dos analitos. Estos valores son menores que los obtenidos por Molina et al. [35] con una preconcentración off-line en un cartucho polimérico antes de su separación por мекс.

Con el método de preconcentración in-line aquí descrito, se consiguen incrementos de sensibilidad del orden de $10^{4}$, en términos de relación entre las pendientes de los calibrados en alturas de los dos métodos. Este incremento de sensibilidad es muy superior al alcanzado en caso de utilizar como tratamiento de muestra la extración en un capilar diferente al de la separación por MEKC (Sección 10.1.2). Este grado de preconcentración alcanzado con el método propuesto indica que éste es muy sensible y rápido, ya que el proceso completo se puede realizar de una forma automática empleando unos $30 \mathrm{~min}$.

\section{Aplicación a muestras reales}

El método in-line-sPe-CZE se aplicó al análisis de agua de grifo y agua de río. Ambas matrices fueron dopadas con diferentes cantidades de los analitos. La Figura 10.25-A muestra el electroferograma obtenido al analizar un agua de grifo con una concentración de analitos de o,1 $\mathrm{\mu g} / \mathrm{L}$, nivel establecido por la legislación europea como el máximo permitido para plaguicidas individuales en aguas potables.

La Figura 10.25-B muestra el electroferograma obtenido en el análisis de un agua de río dopada con una cantidad 5 veces mayor: 0,5 pg/L. En dicho elec-

[232] Comisión Europea. Method validation and quality control procedures for pesticide residues analysis in food and feed. Documento núm. SANCO/2007/3131, 31-10-2007. 


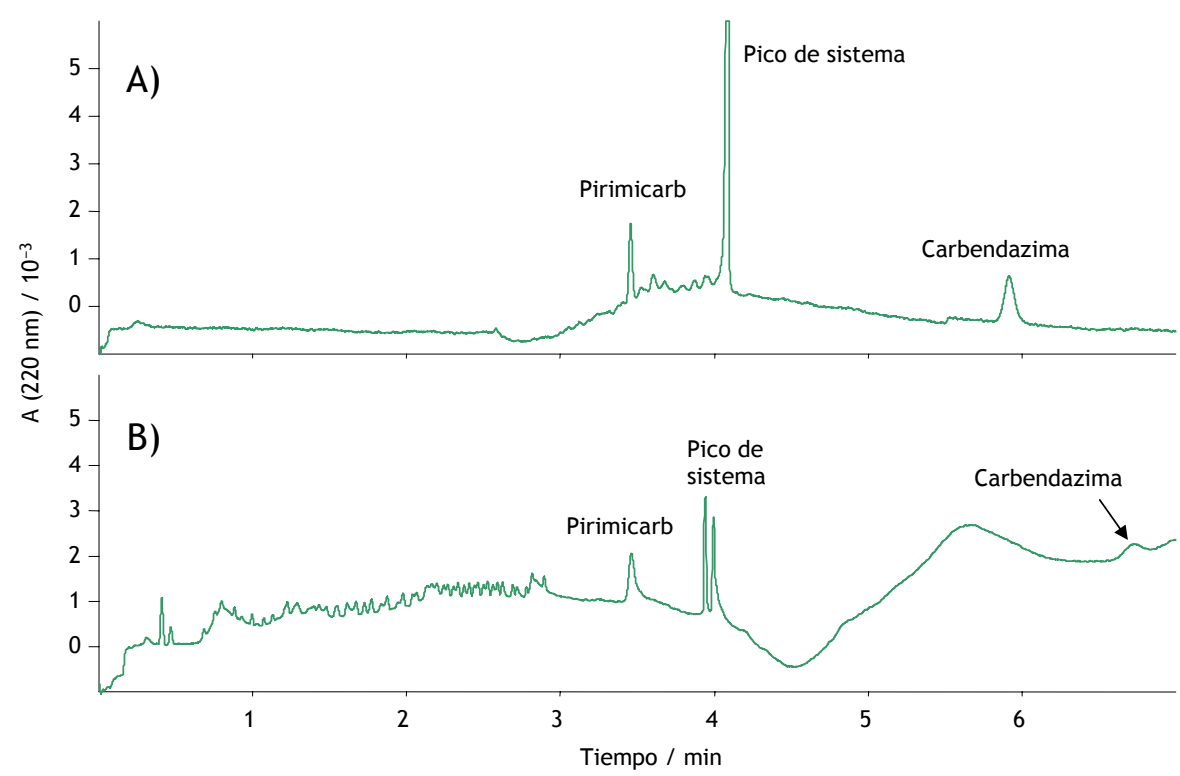

Figura 10.25. Electroferogramas correspondientes a la determinación de Pirimicarb y Carbendazima mediante in-line-SPE-CZE.
A) Agua de grifo. Concentración: $0,1 \mu g / L$.

B) Agua de río. Concentración: o, $5^{\mu \mathrm{g}} / \mathrm{L}$.

troferograma se observa que al analizar muestras de agua de río existe un claro efecto de matriz. Este efecto es el responsable de que los factores de preconcentración para Pirimicarb y Carbendazima sean de $2,1 \times 10^{3}$ y $3,8 \times 10^{2}$, respectivamente. Estos valores son 7 y 20 veces menores que los obtenidos en análisis de agua ultrapura dopada.

Al analizar aguas de grifo, se comprobó que los capilares pueden usarse 1012 veces sin pérdida de precisión en la señal analítica. Sin embargo, cuando se analizan aguas de río, se observó un ennegrecimiento de la entrada del sorbente tras 4-5 muestras analizadas. Este hecho produce una disminución del caudal de muestra preconcentrada y por lo tanto también de la sensibilidad. Cortando aproximadamente $1 \mathrm{~mm}$ de sorbente, éste puede volver a usarse de nuevo. 
En la Tabla 10.9 se muestran los factores de preconcentración obtenidos por otros autores empleando preconcentraciones in-line y los obtenidos en esta investigación.

[233] R. Xie and R. Oleschuk. Capillary-based sPE with columns prepared using different bead trapping methods. Electrophoresis, 26:4225-4234, 2005.

[234] E. Hernandez, F. Benavente, V. Sanz-Nebot, and J. Barbosa. Analysis of opioid peptides by on-line SPE-CE-ESI-MS. Electrophoresis, 28:3957-3965, 2007.

[235] J. R. E. Thabano, M. C. Breadmore, J. P. Hutchinson, C. Johns, and P. R. Haddad. CE of neurotransmitters using in-line SPE and preconcentration using a methacrylate-based weak cation-exchange monolithic stationary phase and a $\mathrm{pH}$ step gradient. J. Chromatogr. A, 1175:117-126, 2007. 


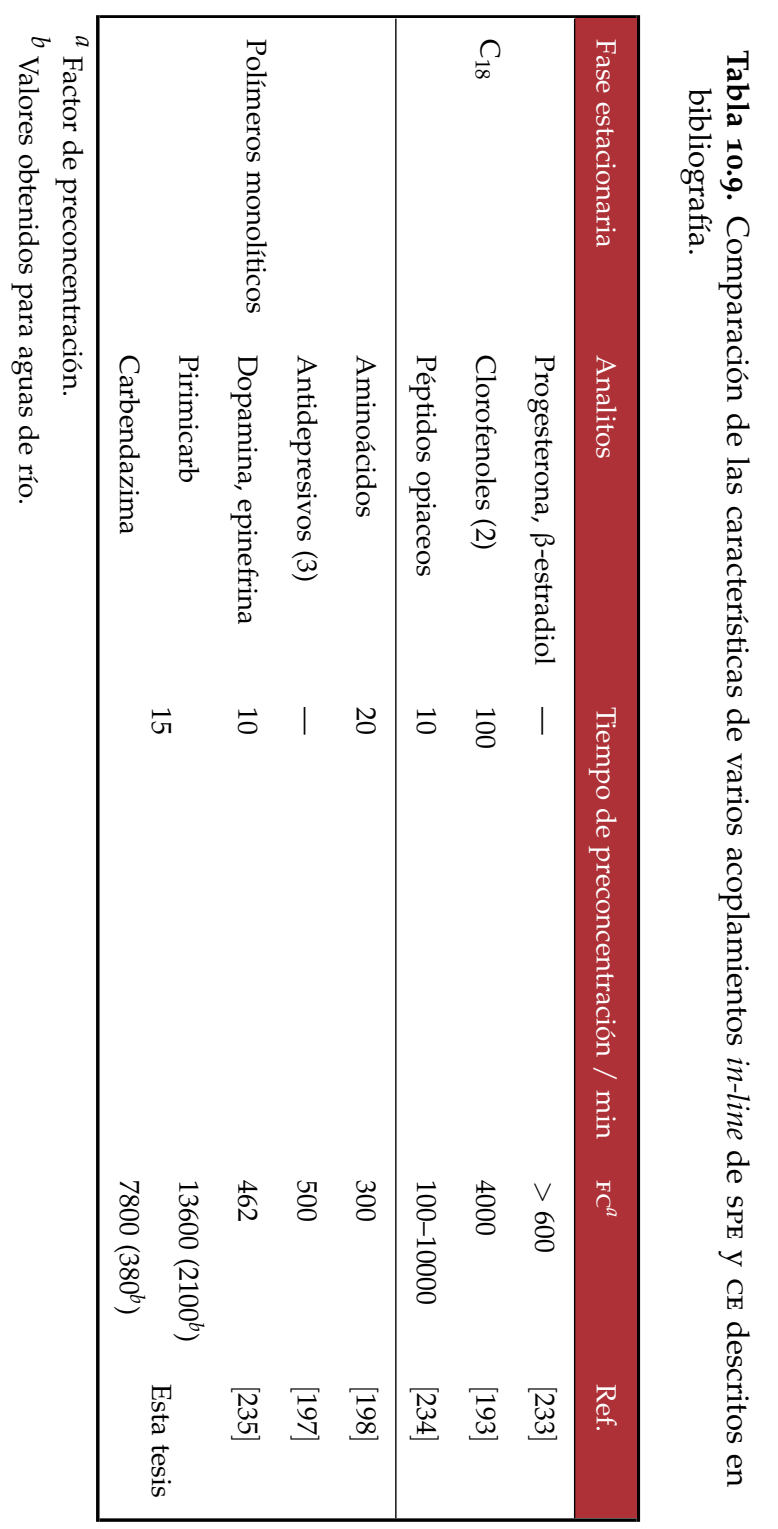




\section{CONCLUSIONES}

\section{Separación electroforética de plaguicidas carbámicos}

En esta parte de la memoria se ha optimizado la separación mediante MEKC de trece plaguicidas carbámicos. En las mejores condiciones encontradas se consigue la resolución de los trece compuestos en menos de 6 min de análisis, empleando una disolución de SDS (6o mM) tamponada con ácido bóricoborato (20 mM, $\mathrm{pH} 9,2)$ COMO BGE.

También se ha optimizado la separación mediante cze de Pirimicarb y Carbendazima, que se encuentran cargados en medio ácido. Para su separación se han empleado diferentes medios de separación compuestos por acetonitrilo, ácido acético, SDS, y pequeñas cantidades de agua. Durante el estudio de la separación se ha puesto de manifiesto la existencia de zonas de sistema, que perturban la señal de cualquier analito cuyo tiempo de migración coincida con el suyo. Se ha estudiado la posición y comportamiento de estas zonas de sistema buscando unas condiciones experimentales en las que éstas no coincidan con los tiempos de migración de los analitos: $2 \%$ de agua en acetonitrilo con ácido acético 1 M y SDS 15 mM.

\section{Preconcentración en capilares monolíticos}

y separación mediante MEKC

Cuando se trabaja en un medio de separación acuoso como el empleado en la separación por MEKC, no es posible el acoplamiento in-line de una etapa de preconcentración. Se ha propuesto un método de preconcentración en 
dos etapas. Primero tiene lugar la retención de los compuestos en un polímero monolítico situado en el interior de un capilar de sílice dispuesto en un cartucho de $\mathrm{CE}$, mediante la aplicación de presión en el propio equipo de CE. Tras la preconcentración, los analitos retenidos se eluyen metanol y se recogen en un vial. En un segundo cartucho se encuentra el capilar de separación, en el que se inyecta el extracto eluido.

Se han estudiado polímeros basados en metacrilato de butilo y en divinilbenceno, siendo estos últimos los más apropiados para la preconcentración de plaguicidas carbámicos. Con una longitud de sorbente de $16 \mathrm{~cm}$ y $15 \mathrm{~min}$ de preconcentración se consigue un incremento medio de sensibilidad de 60 . Esta etapa de preconcentración soluciona en parte la poca sensibilidad de las técnicas electroforéticas, y ofrece un método alternativo a separaciones basadas en cromatografía líquida para este tipo de plaguicidas.

\section{Preconcentración in-line en capilares monolíticos y separación mediante CZE}

Con el mismo tipo de polímero empleado en la preconcentración para MEKC, se ha propuesto un método de preconcentración in-line para la determinación de Pirimicarb y Carbendazima. En el método propuesto, la retención de los analitos tiene lugar al pasar la muestra acuosa por un sorbente de $5 \mathrm{~cm}$. El llenado del capilar con el BGE y la elución de los analitos tiene lugar aplicando voltaje negativo hasta observar un cambio brusco de corriente; en ese momento se invierte el voltaje y tiene lugar la separación. La ventaja de esta modalidad de preconcentración es que no existe dilución de la muestra preconcentrada y que el $100 \%$ de los analitos eluidos es detectado a su paso por el detector.

La incorporación del lecho polimérico dentro del capilar de separación no afecta de un modo significativo a la eficacia de la separación ni a la forma de los picos, y la resolución entre los analitos fue similar a la obtenida sin etapa de preconcentración. La principial ventaja de el método desarrollado es que permite una rápida y fácil determinación de estos plaguicidas en aguas potables de acuerdo con la legislación actual. 
APÉNDICES 



\section{PLAGUICIDAS ESTUDIADOS}

La información de este apéndice ha sido extraída de The Pesticide Manual (British Crop Protection Council, $11^{\mathrm{a}}$ edición, 1997).<smiles>CNC(=O)O/N=C/C(C)(C)SC</smiles>

Aldicarb CAS RN 116-06-3<smiles>CCNC(=O)C(C)OC(=O)Nc1ccccc1</smiles>
Carbetamida CAS RN 16118-49-3<smiles>COC(=O)NS(=O)(=O)c1ccc(N)cc1</smiles>

$$
\text { Asulam }
$$

CAS RN 3337-71-1<smiles>CNC(=O)Oc1cccc2c1OC(C)(C)C2</smiles>

Carbofurano
CAS RN 1563-66-2<smiles>CNC(=O)Oc1cccc2ccccc12</smiles>

Carbarilo CAS RN 63-25-2<smiles>COC(=O)Nc1nc2ccccc2[nH]1</smiles>

Carbendazima CAS RN 10605-21-7<smiles>CNC(=O)O/N=C(\C)SC</smiles>

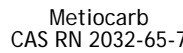

Metomilo CAS RN 16752-77-5<smiles>Cc1nc(N(C)C)nc(OC(=O)N(C)C)c1C</smiles>

Pirimicarb CAS RN 23103-98-2<smiles>CC(C)Oc1ccccc1O</smiles>

O-Isopropoxifenol CAS RN 4812-20-8<smiles>Oc1cccc2ccccc12</smiles>

1-Naftol
CAS RN 90-15-3<smiles>CNC(=O)Oc1ccccc1OC(C)C</smiles>

Propoxu CAS RN 114-26-1

$$
\begin{gathered}
\text { Sulfóxido de Aldicarb } \\
\text { CAS RN 1646-87-3 }
\end{gathered}
$$

Figura A.1. Plaguicidas carbámicos estudiados. 


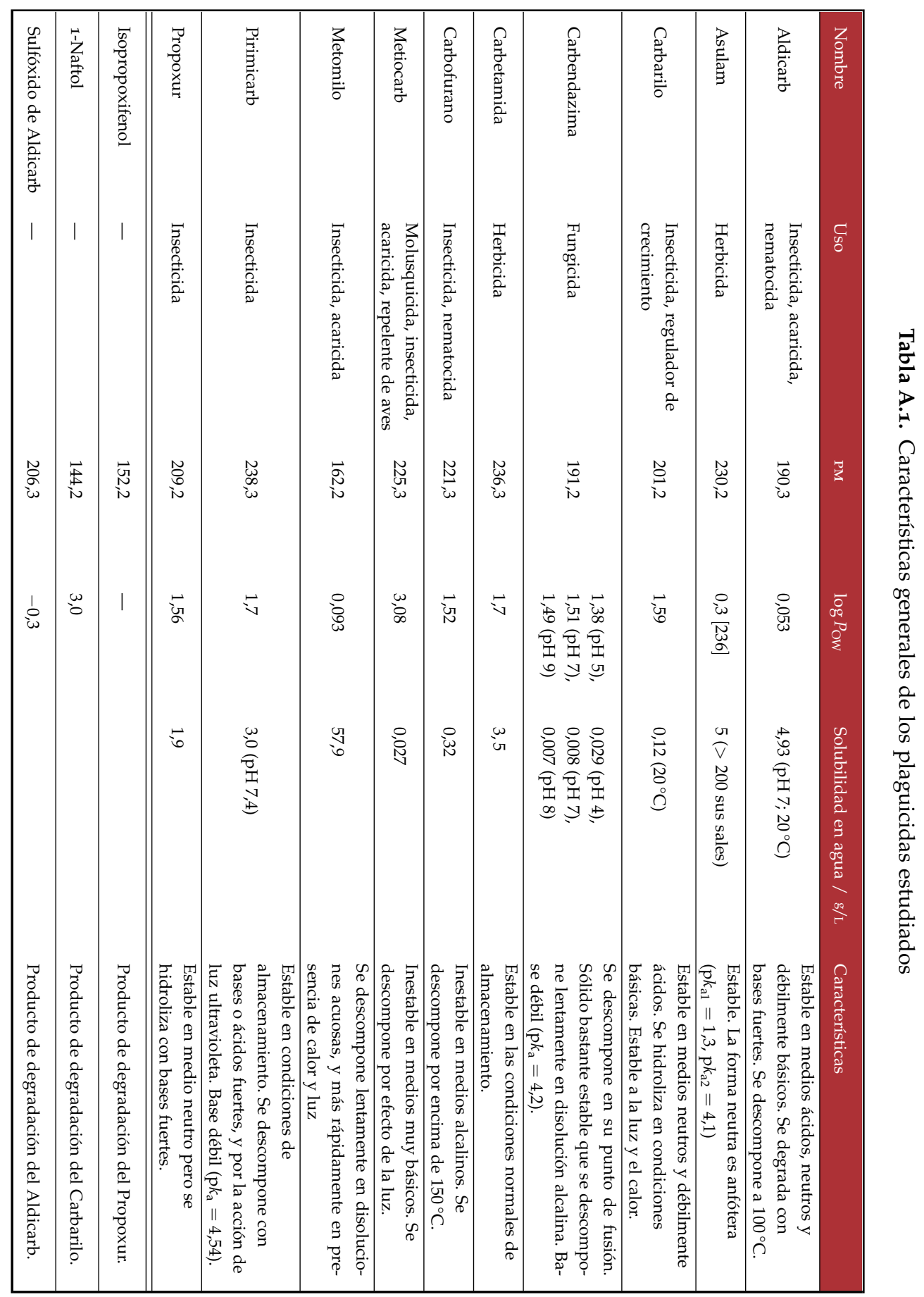




\section{MONÓMEROS EMPLEADOS}

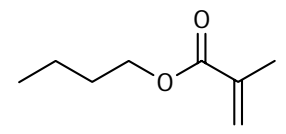

Metacrilato de butilo

$$
\text { (BMA) }
$$

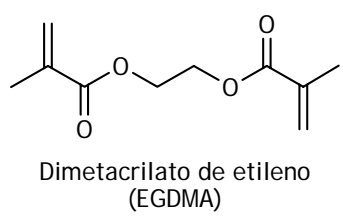<smiles>C=Cc1cccc(C=C)c1</smiles>

Divinilbenceno<smiles>C=Cc1cccc(CC)c1</smiles><smiles>C=Cc1ccc(CC)cc1</smiles>

3- y 4-etilestireno
Iniciador<smiles>CC(C)(C#N)N=NC(C)(C)C#N</smiles>

2,2'-azo-bis-isobutironitrilo (AIBN)

Figura B.1. Monómeros e iniciador utilizados.

\begin{tabular}{|lllll|}
\hline & Nombre & CAS RN & PM & Densidad / g/L \\
\hline \multirow{3}{*}{ Monómeros } & BMA & $97-88-1$ & 142,2 & 0,895 \\
\cline { 2 - 5 } & EGDMA & $97-90-5$ & 198,2 & 1,051 \\
\cline { 2 - 5 } & Divinilbenceno & $108-57-6$ & 130,2 & \multirow{2}{*}{0,919} \\
\cline { 2 - 5 } & 3- y 4-etilestireno & $3454-07-7,7525-62-4$ & 132,2 & \\
\hline \multirow{2}{*}{$\begin{array}{l}\text { Disolventes } \\
\text { porogénicos }\end{array}$} & 1,4-butanodiol & $110-63-4$ & 90,1 & 1,02 \\
\cline { 2 - 5 } & 1-propanol & $71-23-8$ & 60,1 & 0,804 \\
\cline { 2 - 5 } & Agua & $7732-18-5$ & 18,0 & 1,00 \\
\cline { 2 - 5 } & 1-octanol & $111-87-5$ & 130,2 & 0,824 \\
\hline
\end{tabular}





\section{C \\ PROVEEDORES Y MARCAS}

Acros Organics (Geel, Bélgica). http://www.acros.com

Elga http://www.elgalabwater.com

Dr. Ehrenstorfer GmbH (Augsburgo, Alemania).

http:/ / www.analytical-standards.com

Gilson (Middleton, Winsconsin, EEUU). http://www.gilson.com

Hewlett Packard Actualmente Agilent Techlologies (Waldbronn, Alemania). Suministrado por Agilent Technologies España, sL (Las Rozas, Madrid, España). http:/ / www.agilent.es

Jenway (Dunmow, Essex CM6 3LB, Reino Unido) http://www.jenway.com

Merck KGaA (Darmstadt, Alemania). http://www.merck.de

Panreac Química SAU (Castellar del Vallès,Barcelona, España) http:/ / www.panreac.com

Polymicro Technologies, LLC (Phoenix, Arizona, EEUU), http:/ /www.cmsukltd.com, suministrado por Composite Metal Services Ltd (Shipley BD17 7AD, Reino Unido), http:/ / www.polymicro.com

SBS (Rubí, Barcelona, España) http:/ /es.websbs.com

Scharlau (Sentmenat Barcelona, España). http://www.scharlau.com

Shimadzu (Kyoto, Japón). http://www.shimadzu.com 
Sigma, Aldrich, Sigma-Aldrich, Riedel-de Haën, Supelco y Fluka se comercializan actualmente a través de Sigma-Aldrich Química, sA (Tres Cantos, Madrid, España). http:/ / www.sigma-aldrich.com

Spectra-Physics (Irvine, California, EEUU). http://www.newport.com

Varian inc. (Palo Alto, California, EEUU). http://www.varianinc.com

Waters Corporation (Milford, Massachusetts, EEUU). http://www.waters.com 


\section{$\mathrm{D}$ \\ LEGISLACIÓN}

En el Real Decreto 140/2003 [61] se establecen los criterios sanitarios que deben cumplir las aguas de consumo humano y las instalaciones que permiten su suministro desde la captación hasta el grifo del consumidor y el control de éstas.

En el Real Decreto se entiende por pesticida o plaguicida:

Los insecticidas, herbicidas, fungicidas, nematocidas, acaricidas, alguicidas, rodenticidas, molusquicidas orgánicos, metabolitos, productos de degradación o reacción y los productos relacionados como los reguladores de crecimiento.

En el mencionado Real Decreto no se especifican las características de calidad de cada grupo de plaguicidas, sino que están englobados dentro de los parámetros «Total de plaguicidas»y «Plaguicida individual», para los cuales establece que los valores de concentración máxima admisible sean $0,5 \mu \mathrm{g} / \mathrm{L}$ como valor total, y $0,1 \mu \mathrm{g} / \mathrm{L}$ por sustancia individual.

Debido a que existen entre 600 y 700 principios activos utilizados como plaguicidas en todo el mundo, distribuidos en más de 2.500 formulaciones, el número de pesticidas susceptibles de ser analizados es muy elevado. En consecuencia, se establece que el parámetro «Total de plaguicidas» sea la:

Suma de todos los plaguicidas definidos [...] que se sospeche puedan estar presentes en el agua.

Las comunidades autónomas velarán para que se adopten las medidas necesarias para poner a disposición de la autoridad sanitaria y de los 
gestores del abastecimiento el listado de plaguicidas fitosanitarios utilizados mayoritariamente en cada una de las campañas contra plagas del campo y que puedan estar presentes en los recursos hídricos susceptibles de ser utilizados para la producción de agua de consumo humano.

Las características básicas de calidad en las corrientes de aguas superficiales, cuando sean destinadas a la producción de agua potable, se recogen en una normativa legal diferente [237]:

Las aguas superficiales susceptibles de ser destinadas al consumo humano quedan clasificadas en los tres grupos siguientes, segun el grado de tratamiento que deben recibir para su potabilizacion:

Tipo A1 Tratamiento físico simple y desinfección.

Tipo A2 Tratamiento físico normal, tratamiento químico y desinfección.

Tipo A3 Tratamientos físico y químico intensivos, afino y desinfección.

Concretamente, establece que el contenido total máximo de plaguicidas sea de 1, 2,5 y $5^{\mu \mathrm{g} / \mathrm{L}}$ para aguas del tipo A1, A2 y A3, respectivamente.

[237] Orden de 11 de mayo de 1988 sobre caracteristicas basicas de calidad que deben ser mantenidas en las corrientes de agua superficiales cuando sean destinadas a la produccion de agua potable. воЕ, 124:15823-15824, 24-05-1988. 
PUBLICACIONES 



\section{Rita Carabias-Martínez \\ César García-Hermida \\ Encarnación Rodríguez- \\ Gonzalo \\ Luis Ruano-Miguel}

Departamento de Química

Analítica, Nutrición y

Bromatología, Facultad de

Ciencias Químicas, Universidad

de Salamanca, Salamanca, Spain

\section{Behaviour of carbamate pesticides in gas chromatography and their determination with solid- phase extraction and solid-phase microextraction as preconcentration steps}

\begin{abstract}
This work reports a study of the chromatographic behaviour of seven carbamate pesticides (aldicarb, carbetamide, propoxur, carbofuran, carbaryl, methiocarb, and pirimicarb) by gas chromatography-mass spectrometry (GC-MS). Variables such as injector temperature, solvent, injection mode, and the degree of ageing of the chromatographic column were studied. One of the aims of this work was to achieve a controlled decomposition of carbamates by a solid-phase microextraction (SPME) preconcentration step with a polyacrylate fibre in order to obtain reproducible chromatographic signals of the degradation products. Optimisation of the SPME process was accomplished by means of experimental design. Several methods using ultrapure water were developed with different preconcentration configurations: SPME-GC-MS, SPE followed by SPME-GC-MS, and SPE plus GC-MS. For all the pesticides studied, method detection limit (MDL) values below $0.1 \mu \mathrm{g} \mathrm{L}^{-1}$ were reached in at least one of the proposed configurations.
\end{abstract}

Key Words: Gas chromatography; Solid phase microextraction; Carbamates; Pesticides; Experimental design

Received: November 19, 2004; revised: March 9, 2005; accepted: March 29, 2005

DOI 10.1002/jssc.200400047

\section{Introduction}

The persistence of organochlorine pesticides and the toxicity of organophophorus pesticides have led to their replacement by other, more readily degradable, polar, and less persistent pesticides, such as the carbamates. The general structures of these are derived from carbamic acid through the introduction of different substituents $\left(R^{1} O^{2} O_{N}{ }^{2} R^{3}\right)$, where $R^{1}$ usually includes a phenyl or a heterocyclic aromatic ring, and $\mathrm{R}^{2}$ and $\mathrm{R}^{3}$ are often methyl or H groups.

Carbamate pesticides have been available commercially since the 1950s, and are currently widely used in pest control since they have high effectiveness and many different uses (insecticides, fungicides, herbicides, nematocides, acaricides, molluscicides, and growth regulators). The characteristics of carbamate pesticides are their polarity, their solubility in water, and their thermal instability.

GC and HPLC are the methods most widely used for the detection of pesticides in environmental samples. How-

Correspondence: Dr. Rita Carabias-Martínez, Departamento de Química Analítica, Nutrición y Bromatología, Plaza de la Merced s. n., 37008 Salamanca, Spain.

Phone/Fax: +34 923294483. E-mail: rcm@usal.es.

Abbreviations: MDL, method detection limit; PA, polyacrylate; POW, octanol-water partition coefficient

J. Sep. Sci. 2005, 28, 2130-2138 www.jss-journal.de ever, most carbamate pesticides are thermally labile. Due to this thermal instability and their high polarity, HPLC methods are preferred over GC methods, MS and fluorescence detection being the systems usually employed [1, 2]. Despite this, GC approaches are also used, with a derivatisation step prior to chromatographic separation, although this entails additional complexity and cost. More modern methods such as biosensors are also applied to the determination of carbamates [3].

Several special devices have been designed to minimise the decomposition of thermally labile compounds in GC (short columns [4, 5]; programmed temperature vaporizer devices [4, 6]; low pressure GC [7], and supersonic GC [8]). Several reports have studied the photodegradation of such pesticides $[9,10]$. Nevertheless, few studies have addressed the thermal degradation of carbamate pesticides. Trehy et al. [5] have shown that aldicarb decomposes to its corresponding nitrile both thermally and in the presence of anaerobic microorganism, while Santos et al. [11] studied the thermal decomposition of carbamates in $\mathrm{GC}$ as a function of several variables, such as concentration, needle length, and injector temperature.

Owing to the low concentration levels at which these compounds are present in environmental samples, one or several preconcentration steps are required to isolate the analytes, bring them to a suitable concentration level, and

(C) 2005 WILEY-VCH Verlag GmbH \& Co. KGaA, Weinheim 
remove matrix interference components. Solid-phase extraction (SPE) is a well-known approach and is the most common technique for the preconcentration of pesticides [12]. Different sorbents are available for carbamate preconcentration but octadecyl silica is the sorbent most widely employed [13-20].

Currently, solid-phase microextraction (SPME) has also become one of the methods of choice for the isolation and preconcentration of analytes in different matrices. The basic concepts of SPME were reported by Belardi and Pawliszyn [21], and are based on the distribution of analytes between the extracting phase immobilised on the fibre and the matrix (water, air, soils, foodstuffs, etc.). Although SPME has been extensively used for the preconcentration of different pesticides in several matrices, there are few references to carbamate preconcentration by SPME [22-24].

Owing to the broad use of carbamate pesticides in agriculture, it would be interesting to be able to evaluate them when multi-residue analyse by GC are being carried out. Accordingly, it is necessary to know their behaviour when working with this separation technique.

The present work addresses the chromatographic behaviour of carbamate pesticides in GC, both in direct injection mode and with a SPME preconcentration step. The compounds generated both in direct injection as a function of the solvent used (ethyl acetate or methanol) and on using SPME were determined. One of the aims of the work was to achieve a controlled decomposition that would yield reproducible signals using a preconcentration step by SPME prior to separation and detection in GC-MS. Finally, several analytical methods were developed using doped ultrapure water to determine these compounds in water samples, using different preconcentration steps (SPE and SPME).

\section{Experimental}

\subsection{Materials}

The SPME holder and polyacrylate (PA) fibre ( $85 \mu \mathrm{m}$ thickness) were supplied by Supelco (Bellefonte, CA, USA). The fibre was conditioned prior to use by placing it in the injector of the gas chromatograph for $3 \mathrm{~h}$ at $300^{\circ} \mathrm{C}$. Following this, a series of blank assays was performed until no chromatographic signals were obtained. SPME was carried out in $12 \mathrm{~mL}$ vials specially designed for the purpose.

An SBS immersion thermostat from Selecta (Barcelona, Spain) was used to maintain a constant temperature during SPME extraction. The magnetic stirrer used was a Jenway 1000 model from Selecta.

SPE cartridges, Sep-Pack tC18, were purchased from Waters (Milford, Massachusetts, USA). A Gilson Minipuls

J. Sep. Sci. 2005, 28, 2130-2138 www.jss-journal.de
2 HP 4 peristaltic pump was used to propel the sample through the cartridge.

Sodium chloride at a purity of $99.8 \%$, RA quality, was obtained from Scharlau (Barcelona, Spain). Methanol, acetonitrile, and ethyl acetate of HPLC grade were supplied by Merck (Darmstadt, Germany). Ultra-high quality water was obtained with an Elgastat UHQ water purification system.

\subsection{Standards}

The carbamate pesticides (aldicarb CAS RN [116-06-03], carbetamide CAS RN [16118-49-3], propoxur CAS RN [114-26-1], carbofuran CAS RN [1563-66-2], carbaryl CAS RN [63-25-2], and methiocarb CAS RN [2032-65-7]) and the metabolites (1-naphthalenol CAS RN [90-15-3] and 2-isopropoxyphenol CAS RN [4812-20-8]) were obtained from Dr. Ehrenstorfer (Augsburg, Germany). Pirimicarb CAS RN [23103-98-2] was purchased from Riedel-de Haën (Seelze-Hannover, Germany). All compounds were used without further purification (minimum percent purity greater than $98 \%$ ).

Standard stock solutions of the carbamates and their metabolites ( $100 \mathrm{mg} \mathrm{L}^{-1}$ ) were prepared by weighing and dissolving the compounds in methanol. These stock solutions were stored at $4{ }^{\circ} \mathrm{C}$ and were suitably diluted when needed to obtain working standard solutions.

\subsection{GC-MS conditions}

The GC-MS system consisted of a GC-17A gas chromatograph (Shimadzu, Kyoto, Japan) coupled to a QP5000 quadrupole mass spectrometer (Shimadzu). A capillary column (DB5, poly-5\% diphenyl-95\% dimethylsiloxane), $30 \mathrm{~m} \times 0.25 \mathrm{~mm}$ ID and $0.25 \mu \mathrm{m}$ film thickness (J\&W Scientific, Folsom, CA, USA) was used. The chromatographic conditions were as follows: injector temperature, $300^{\circ} \mathrm{C}$; oven temperature program, $40^{\circ} \mathrm{C}(7 \mathrm{~min})$ to $140^{\circ} \mathrm{C}$ ( $1 \mathrm{~min}$ ) at a rate of $30^{\circ} \mathrm{C} \mathrm{min}^{-1}$ and then to $270^{\circ} \mathrm{C}(5 \mathrm{~min})$ at $40^{\circ} \mathrm{C} \mathrm{min}-1$. The carrier gas was helium at a column flow rate of $1.7 \mathrm{~mL} \mathrm{~min}^{-1}$. The temperature of the interface was $270^{\circ} \mathrm{C}$. $\mathrm{m} / \mathrm{z}$ ranged from 50 to 250 . A sampling frequency of $2 \mathrm{~s}^{-1}$ was applied in scan mode and a $5 \mathrm{~s}^{-1}$ sampling frequency was applied in SIM mode. Spectra were obtained at $70 \mathrm{eV}$ and sample injection was accomplished in splitless mode. Desorption time was $6.5 \mathrm{~min}$. The ions selected for identification and quantification in SIM mode are shown in Table 1.

\subsection{Procedures}

\subsubsection{Carbamate determination by GC-MS with SPME as the preconcentration step}

A $0.1-\mathrm{mL}$ volume of a multicomponent solution of pesticides prepared from stock solutions was diluted with $6 \mathrm{~mL}$ of brine and ultrapure water up to a volume of $10 \mathrm{~mL}$. This

(C) 2005 WILEY-VCH Verlag GmbH \& Co. KGaA, Weinheim 
Table 1. Compounds and $m / z$ ratios employed in identification and quantification (bold).

\begin{tabular}{|l|l|c|}
\hline Pesticide & Compound detected & $\mathrm{m} / \mathbf{z}$ \\
\hline Aldicarb & Aldicarb nitrile & $\mathbf{1 0 0 , 1 1 5 , 6 8}$ \\
\hline Carbetamide & Phenyl isocyanate & $\mathbf{6 4 , 9 1 , 1 1 9}$ \\
\hline Propoxur & Propoxur phenol & $\mathbf{1 1 0 , 1 5 2 , 8 1}$ \\
\hline Carbofuran & Carbofuran phenol & $\mathbf{1 6 4 , 1 4 9 , 1 0 3}$ \\
\hline Carbaryl & Carbaryl phenol & $\mathbf{1 4 4 , 1 1 5 , 8 9}$ \\
\hline Methiocarb & Methiocarb phenol & $\mathbf{1 6 8 , 1 5 3 , 1 0 9}$ \\
\hline Pirimicarb & Pirimicarb & $\mathbf{1 6 6 , 2 3 8 , 7 2}$ \\
\hline
\end{tabular}

$10 \mathrm{~mL}$ was placed in a vial containing a magnetic bar. The vial was placed in a thermostatted bath over a magnetic stirrer support. The septum of the vial was pierced with an SPME needle, the stirrer was started, and the fibre was exposed to the solution. After 120 min of preconcentration at $25^{\circ} \mathrm{C}$, the fibre was withdrawn and the vial was removed and exposed for $6.5 \mathrm{~min}$ to a temperature of $300^{\circ} \mathrm{C}$ in the injector of the gas chromatograph. Identification of the analytes was accomplished using the corresponding retention times and the signal of three ions of each analyte (Table 1).

\subsubsection{Carbamate determination by GC-MS with SPE and SPME as preconcentration steps}

A 250-mL volume of sample was passed at a flow rate of

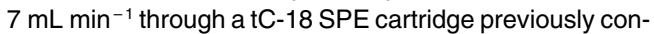
ditioned with $10 \mathrm{~mL}$ of acetonitrile and $10 \mathrm{~mL}$ of water. Once the cartridge had been dried out, the analytes were eluted with $2 \mathrm{~mL}$ of acetonitrile. Solvent $(2 \mathrm{~mL}$ ) was evaporated off under a stream of $\mathrm{N}_{2}$ and the residue was redissolved in $8 \mathrm{~mL}$ of an aqueous solution of $60 \% \mathrm{v} / \mathrm{v}$ of brine.

The SPME step was carried out under the above-indicated conditions.

\subsubsection{Carbamate determination by GC-MS with SPE as the preconcentration step}

A 250-mL volume of sample was passed through an SPE cartridge conditioned as indicated above. The analytes retained were eluted with $2 \mathrm{~mL}$ of acetonitrile. The eluate collected was evaporated to dryness under a stream of $\mathrm{N}_{2}$ and the residue was redissolved in $500 \mu \mathrm{L}$ of acetonitrile; $1 \mu \mathrm{L}$ was injected directly into the chromatograph.

\section{Results and discussion}

\subsection{Chromatographic behaviour of the carbamates} studied

\subsubsection{Identification of the chromatographic signals obtained by direct injection into the gas chromatograph}

Figure 1.A shows the chromatogram obtained upon injecting $1 \mu \mathrm{L}$ of a sample containing the seven carbamates in

J. Sep. Sci. 2005, 28, 2130-2138 www.jss-journal.de

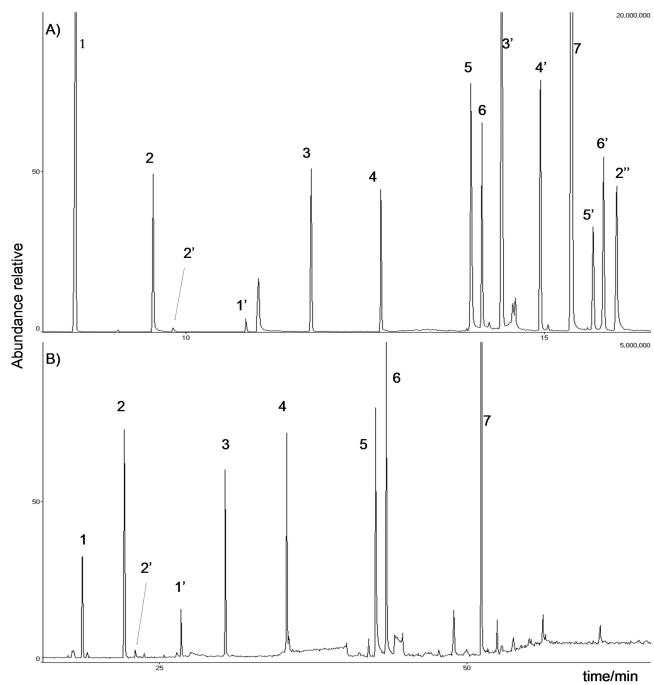

Figure 1. GC-MS chromatograms (scan mode) obtained upon performing direct injection of the seven carbamates in a new column (A), and in an old one (B). Analyte concentration, $10 \mathrm{mg} \mathrm{L}^{-1}$ each, in ethyl acetate. Labels on peaks in elution order: $1=$ aldicarb nitrile, $2=$ phenyl isocyanate, $2^{\prime}=$ aniline, $1^{\prime}=$ not identified, $3=$ propoxur phenol, $4=$ carbofuran phenol, $5=$ carbaryl phenol, $6=$ methiocarb phenol, $3^{\prime}=$ propoxur, $4^{\prime}=$ carbofuran, $7=$ pirimicarb, $5^{\prime}=$ carbaryl, $6^{\prime}=$ methiocarb , and $2^{\prime \prime}=$ carbetamide.

ethyl acetate. Table 2 shows the compounds separated by $\mathrm{GC}$, indicating the pesticides they derive from together with the number with which the signal of each compound is labelled.

Table 2. Parent carbamate pesticides and compounds identified.

\begin{tabular}{|l|l|c|}
\hline Pesticide & Compounds detected & Signal label \\
\hline Aldicarb & Aldicarb nitrile & 1 \\
\cline { 2 - 3 } & Not identified & $1^{\prime}$ \\
\hline Carbetamide & Phenyl isocyanate & 2 \\
\cline { 2 - 3 } & Aniline & $2^{\prime}$ \\
\cline { 2 - 3 } & Carbetamide & $2^{\prime \prime}$ \\
\hline \multirow{3}{*}{ Cropoxur } & Propoxur phenol & 3 \\
\cline { 2 - 3 } & Propoxur & $3^{\prime}$ \\
\hline \multirow{3}{*}{ Carbaryl } & Carbofuran phenol & 4 \\
\cline { 2 - 3 } & Carbofuran & $4^{\prime}$ \\
\hline Methiocarb & Carbaryl phenol & 5 \\
\cline { 2 - 3 } & Carbaryl & $5^{\prime}$ \\
\hline Pirimicarb & Methiocarb phenol & 6 \\
\cline { 2 - 3 } & Methiocarb & $6^{\prime}$ \\
\hline
\end{tabular}

(C) 2005 WILEY-VCH Verlag GmbH \& Co. KGaA, Weinheim 


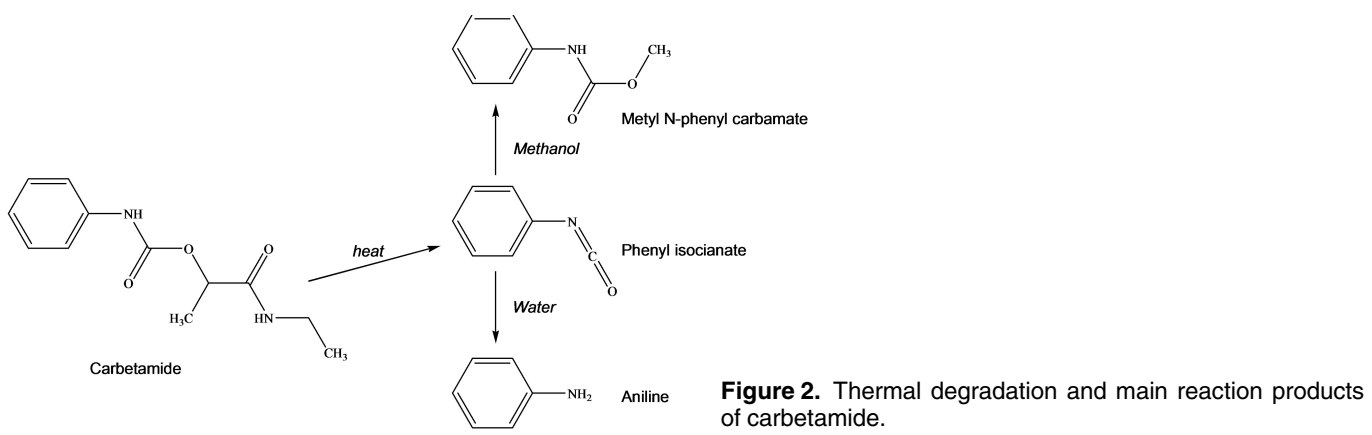

Pirimicarb (labelled as 7) was the only pesticide that did not decompose thermally and it generated a unique signal corresponding to its undegraded molecule. Aldicarb gave rise to two chromatographic signals, one of them due to aldicarb nitrile (signal 1) and another minor signal (signal $1^{\prime}$ ) due to an unidentified compound. For the rest of the analytes, signals corresponding to the non-decomposed compounds were observed, together with different signals generated by the thermal degradation products. As a result of the thermal decomposition of carbetamide, phenyl isocyanate (2) and aniline ( $\left.2^{\prime}\right)$ were observed, as well as the signal corresponding to carbetamide $\left(2^{\prime \prime}\right)$. The phenyl $\mathrm{N}$-methyl carbamates, propoxur, carbofuran, carbaryl, and methiocarb $\left(3^{\prime}-6^{\prime}\right)$ were degraded thermally to afford their phenolic forms (labelled 3-6).

Apart from the signals mentioned above, other compounds were obtained when carbamates were injected dissolved in methanol. Owing to the high temperatures employed, the methyl esters generated by reaction of the pesticides with methanol were found. These compounds detected were: methyl $N$-methyl carbamate, a possible reaction product of all the compounds with the structure of $\mathrm{N}$-methyl carbamates (aldicarb, propoxur, carbofuran, carbaryl, and methiocarb), N,N-dimethyl carbamate from pirimicarb, and methyl $\mathrm{N}$-phenyl carbamate from carbetamide.

\subsubsection{Influence of the age of the chromatographic column}

Preliminary studies were carried out with a chromatographic column that had been extensively used (employed for over one year for daily analysis of environmental samples and synthesis product purity tests). In that column pirimicarb (7) was the only pesticide for which a signal corresponding to the undegraded compound was observed. In the case of the other analytes, no signals of the parent compounds were observed (Fig. 1.B). These findings show that the carbamates are not completely degraded in the injector; instead, their decomposition occurs both during the injection step and during elution along the chromatographic column. Moreover, degradation along the column is a function of the lifetime (ageing) of the column. Santos et al. [11] have also observed that the use of columns with a long lifetime favours the degradation of thermally unstable compounds.

\subsubsection{Carbamate reactivity in GC}

The reactivity was studied by direct injection into the GC system of the analytes dissolved in methanol or ethyl acetate. According to their chemical structures, the carbamates studied in the present work can be divided into four groups, each of them showing a different type of behaviour.

Aldicarb has the structure of an oxime carbamate and the major product of its thermal degradation is the corresponding nitrile [5].

Carbetamide has the structure of an $\mathrm{N}$-phenyl carbamate and during its decomposition it gives rise to different products (Fig. 2). The main product of its thermal degradation is phenyl isocyanate (signal 2). The remaining products generated may be due to parallel reactions, depending on the solvent employed and the ageing of the column. The major product is methyl $N$-phenyl carbamate when the solvent used is methanol and phenyl isocyanate if a nonreactive solvent is used. Aniline ( $\left.2^{\prime}\right)$ is also formed if traces of water are present in the medium, especially if an old column is used. This may be because aniline is produced by a reaction in the column between the isocyanate and traces of water. The behaviour shown by carbetamide is similar to that of the phenylurea herbicides [25].

Propoxur, carbofuran, carbaryl, and methiocarb are $\mathrm{N}$ methyl carbamic esters of aromatic rings, and decompose via a McLafferty rearrangement to give the corresponding phenol and isocyanate [11]. The presence of methyl $N$ methyl carbamate when methanol is present can be explained in terms of methanolysis of the isocyanate produced in the reaction (Fig. 3).

(C) 2005 WILEY-VCH Verlag GmbH \& Co. KGaA, Weinheim 


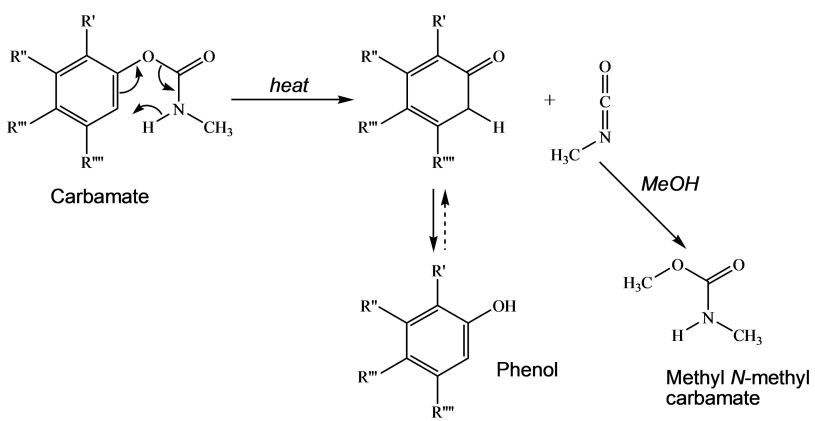

Figure 3. Thermal degradation of phenyl $N$ methyl carbamates. McLafferty rearrangement.

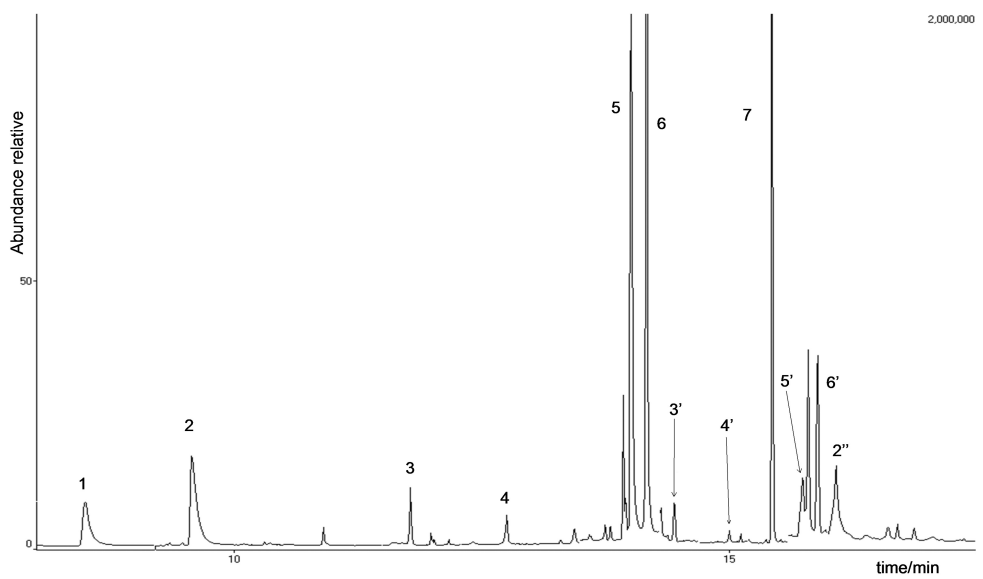

Figure 4. GC-MS chromatogram (SIM mode), after SPME. Concentration: $400 \mu \mathrm{g} \mathrm{L}^{-1}$ (aldicarb, carbetamide, and pirimicarb) and $20 \mu \mathrm{g} \mathrm{L}^{-1}$ (propoxur, carbofuran, carbaryl, and methiocarb). (See labelling in Fig. 1 or Table 2.)

The two $\mathrm{N}$-methyl groups of pirimicarb prevent the McLafferty rearrangement, even though the substituent is aromatic. The presence of methyl $\mathrm{N}, \mathrm{N}$-dimethyl carbamate when the solvent used was methanol suggests an alternative degradation route, which plays a minor role in the pesticides in which a McLafferty rearrangement is able to take place.

\subsection{Solid-phase microextraction (SPME) process}

\subsubsection{Injection into the chromatograph by SPME}

Direct injection into the GC column of a relatively concentrated solution of the seven carbamates dissolved in ethyl acetate revealed that the degradation of propoxur, carbofuran, carbaryl, and methiocarb was not reproducible (RSD $=14-25 \%, n=7$ ). However, in the case of aldicarb, carbetamide, and pirimicarb, values ranging between 4 and $8 \%$ were obtained. This better precision may be due to the fact that pirimicarb is not degraded and that the mechanisms of decomposition of aldicarb and of carbeta- mide are different from those shown by phenyl $\mathrm{N}$-methyl carbamates.

In view of the above results, a study was undertaken with the aim of achieving controlled decomposition by introducing an SPME preconcentration step. Our group [25] has already reported that one of the advantages of SPME is the controlled decomposition of certain thermally unstable compounds. The type of polymeric covering chosen was PA of $85 \mu \mathrm{m}$ thickness, based on the polarity of the analytes.

Figure 4 shows a chromatogram of a solution of the seven carbamate pesticides introduced into the GC chromatograph after SPME. Aldicarb (1) and pirimicarb (7) gave rise to a single chromatographic signal, and carbetamide afforded the signal of the isocyanate (2) and carbetamide $\left(2^{\prime \prime}\right)$. The phenyl $N$-methyl carbamates $\left(3^{\prime}-6^{\prime}\right)$ afforded their phenolic forms $(3-6)$, together with the parent compound signals $\left(3^{\prime}-6^{\prime}\right)$, the decomposition products being the major ones found for each compound. When precon-

(C) 2005 WILEY-VCH Verlag GmbH \& Co. KGaA, Weinheim 
Table 3. Analytical characteristics for the SPME-GC-MS method.

\begin{tabular}{|l|c|c|c|c|c|}
\hline Pesticide & $\begin{array}{c}\text { Intercept } \\
10^{4} \text { counts s }\end{array}$ & $\begin{array}{c}\text { Slope } \\
\text { counts s L } \mu g^{-1}\end{array}$ & $r^{2}$ & $\begin{array}{c}\text { RSD }(\%)[c o n c e n- \\
\left.\text { tration/ } \mu \mathrm{L} \mathrm{L}^{-1}\right]\end{array}$ & $\begin{array}{c}\mathrm{MDL}^{\mathrm{b}} \text { ) } \\
\mu \mathrm{L} \mathrm{L}^{-1}\end{array}$ \\
\hline Aldicarb & $1 \pm 1$ & $(5.4 \pm 0.6) \times 10^{2}$ & 0.999 & $11[47.5]$ & 15 \\
\hline Carbetamide & $2 \pm 2$ & $(7.7 \pm 0.8) \times 10^{2}$ & 0.999 & $10[43.6]$ & 19 \\
\hline Propoxur & $2 \pm 3$ & $(13 \pm 3) \times 10^{3}$ & 0.995 & $10[3.3]$ & 1.4 \\
\hline Carbofuran & $0.4 \pm 1$ & $(4 \pm 1) \times 10^{3}$ & 0.994 & $13[4.2]$ & 2 \\
\hline Carbaryl & $3.5 \pm 2$ & $(6 \pm 1) \times 10^{4}$ & 0.996 & $17[2.6]$ & 1.2 \\
\hline Methiocarb & $0.8 \pm 12$ & $(14 \pm 2) \times 10^{4}$ & 0.998 & $13[1.2]$ & 0.6 \\
\hline Pirimicarb & $25 \pm 52$ & $(6 \pm 2) \times 10^{3}$ & 0.984 & $14[12.1]$ & 4.6 \\
\hline
\end{tabular}

a) RSD, relative standard deviation $(n=4)$ determined for the concentration level indicated in brackets.

b) $\mathrm{MDL}=t \cdot s$ (method detection limit; $t$ is Student's $t$ value for $4-1$ degrees of freedom and a significance level of $\alpha=0.05 ; s$ is the standard deviation calculated with the same measurements employed for RSD).

centration was carried out using SMPE, the chromatographic signals of the degradation products of the carbamates showed good precision (Table 3). This detail, together with the fact that these signals were always observed, regardless of the age of the column and of the concentration of pesticide, indicates that these signals are appropriate for the quantification of carbamates. Injection by SPME permits a controlled decomposition of carbamates to be achieved, since under these conditions degradation largely occurs in the injector, and reproducibly so, decomposition along the chromatographic column not being significant.

\subsubsection{Optimisation of the SPME process}

The SPME process was optimised by experimental design. Experimental design is needed for comprehensive investigation of effects such as interactions and, furthermore, to keep the number of experiments performed to a minimum. Many studies have optimised the parameters affecting the extraction and desorption of analytes from SPME fibres by means of experimental design [26-29]. Moreover, experimental design has been applied to the extraction of pesticides [30-32] in environmental samples.

In this work, two- and three-level designs were applied, extraction temperature, ionic strength, extraction time, and desorption temperature being the variables under study. The response was evaluated in terms of peak area for each analyte.

First, a $2^{4-1}$ screening design was applied. No interactions were found and the desorption temperature did not seem to have any significant effect on the signal area, while the remaining factors did seem to have a positive and significant effect. The desorption temperature was fixed as $300^{\circ} \mathrm{C}$ in later studies, while the extraction time, extraction temperature, and ionic strength were selected as the main

J. Sep. Sci. 2005, 28, 2130-2138 www.jss-journal.de factors affecting the SPME process for the subsequent more detailed design.

After this first design had been analysed, a 15-run BoxBehnken design was implemented with the significant factors found in the screening design. The presence of three levels of each factor allows calculation of quadratic effects in addition to the main effects. Once this design had been analysed, only "extraction time" and "ionic strength" proved to be significant factors. Figure 5 shows two representative estimated response surfaces as a function of the significant factors. The most polar analytes (e.g. propoxur, $\log P_{\text {ow }}=1.56$ ) showed an increased extraction yield with increasing ionic strength (salting-out effect). For the less polar analytes (e.g. methiocarb, $\log P_{\text {ow }}=3.08$ ) extraction was observed to reach a maximum value, and then to decrease with further increase in salt concentration. This behaviour can be explained [33] by considering two simultaneously occurring processes. Initially, there is a decrease in the solvation of the analyte, which is therefore more amenable to extraction by the fibre. However, as the ionic strength increases, the interaction between the salt ions and the analytes predominates, and hence the capacity of the latter to move onto the fibre decreases.

Finally, the conditions chosen for further measurements were as follows: extraction temperature, $25^{\circ} \mathrm{C}$; ionic strength, $60 \% \mathrm{v} / \mathrm{v}$ of brine; extraction time, $120 \mathrm{~min}$; and desorption temperature, $300^{\circ} \mathrm{C}$.

\subsection{Analytical characteristics of proposed methods}

For determination of the carbamates studied, different analytical methods were developed, using spiked ultrapure water. In all of them, the linearity of the analytical signal as a function of concentration, as well as the precision of the proposed procedure and the detection limit for each analyte, were evaluated. To determine the method detec-

(C) 2005 WILEY-VCH Verlag GmbH \& Co. KGaA, Weinheim 

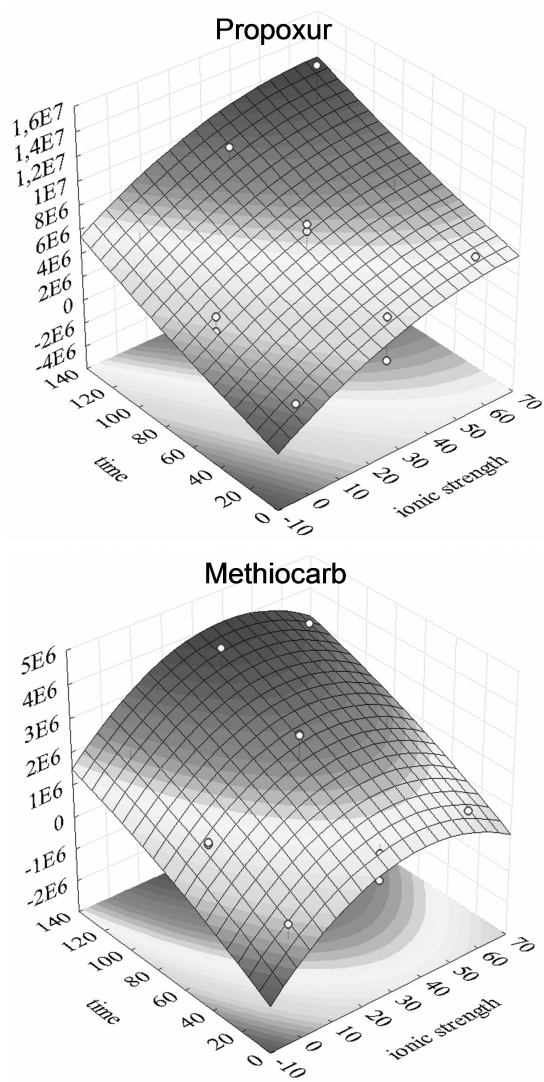

Figure 5. Representative response surfaces (signal area) as a function of significant variables (ionic strength and extraction time), fixing extraction temperature at its mean level. tion limit (MDL) the MDL $=t \cdot s$ criterion was used, where $s$ is the standard deviation of the calculated concentrations of $n$ samples with a concentration close to the estimated detection limit, and $t$ is Student's $t$ for $n-1$ degrees of freedom and a given level of significance [34].

\subsubsection{GC-MS method with SPME as the preconcentration step}

Table 3 shows the analytical characteristics of the method when a prior preconcentration step by SPME was applied.

The relative standard deviations ranged from 10 to $17 \%$. The limits of detection obtained ranged between $0.6 \mu \mathrm{g} \mathrm{L}^{-1}$ for methiocarb and $19 \mu \mathrm{g} \mathrm{L}^{-1}$ for carbetamide. The MDL values obtained indicate that this SPME-GCMS method is suitable for the determination of propoxur, carbofuran, carbaryl, and methiocarb in surface waters when destined for the production of drinking water, since current legislation (Council Directive 75/440/EEC) stipulates a range of between 1 and $5 \mu \mathrm{g} \mathrm{L}^{-1}$, depending on the further treatment of such waters.

\subsubsection{GC-MS method with SPE and SPME as preconcentration steps}

With a view to proposing a suitable method for the evaluation of these carbamates in drinking water, we studied the possibilities of using a preconcentration step by SPE prior to preconcentration by SPME. C-18 was employed as sorbent, obtaining recoveries between $(64 \pm 12) \%$ for carbofuran, and $(85 \pm 12) \%$ for aldicarb. Previous publications had shown that $\mathrm{C}-18$ is a proven good sorbent for this kind of analyte [13-20].

Table 4 shows the analytical characteristics of the method with the SPE and SPME steps. The values of the relative standard deviation are lower than $20 \%$ (with the exception of methiocarb), which is acceptable taking into account the concentration levels at which they were determined

Table 4. Analytical characteristics for the SPE followed by SPME-GC-MS method.

\begin{tabular}{|l|c|r|r|r|c|}
\hline Pesticide & $\begin{array}{c}\text { Intercept } \\
10^{4} \text { counts s }\end{array}$ & $\begin{array}{c}\text { Slope } \\
\text { counts s L } \mu g^{-1}\end{array}$ & $r^{2}$ & $\begin{array}{c}\mathrm{RSD}^{\mathrm{a}}(\%)[\text { concen- } \\
\left.\text { tration/ } / \mathrm{g} \mathrm{L}^{-1}\right]\end{array}$ & $\begin{array}{c}\mathrm{MDL}^{\mathrm{b})} \\
\mu \mathrm{L} \mathrm{L}^{-1}\end{array}$ \\
\hline Aldicarb & $0.3 \pm 0.3$ & $(0.5 \pm 0.1) \times 10^{4}$ & 0.994 & $10[0.59]$ & 0.29 \\
\hline Carbetamide & $1 \pm 2$ & $(1.7 \pm 0.6) \times 10^{4}$ & 0.987 & $13[0.87]$ & 0.46 \\
\hline Propoxur & $0.4 \pm 2$ & $(17 \pm 5) \times 10^{4}$ & 0.991 & $17[0.10]$ & 0.06 \\
\hline Carbofuran & $0.3 \pm 0.9$ & $(5.0 \pm 1.8) \times 10^{4}$ & 0.986 & $20[0.10]$ & 0.08 \\
\hline Carbaryl & $2 \pm 8$ & $(7 \pm 2) \times 10^{5}$ & 0.991 & $18[0.09]$ & 0.05 \\
\hline Methiocarb & $7 \pm 12$ & $(10 \pm 4) \times 10^{5}$ & 0.986 & $21[0.07]$ & 0.05 \\
\hline Pirimicarb & $-0.3 \pm 2$ & $(7 \pm 1) \times 10^{4}$ & 0.997 & $20[0.32]$ & 0.23 \\
\hline
\end{tabular}

a) RSD, relative standard deviation $(n=4)$ determined for the concentration level indicated in brackets.

b) $\mathrm{MDL}=t \cdot s$ (method detection limit; $t$ is Student's $t$ value for $4-1$ degrees of freedom and a significance level of $\alpha=0.05 ; s$ is the standard deviation calculated with the same measurements employed for RSD). 
Table 5. Analytical characteristics for the SPE plus GC-MS method.

\begin{tabular}{|c|c|c|c|c|c|}
\hline Pesticide & $\begin{array}{c}\text { Intercept } \\
10^{4} \text { counts } s\end{array}$ & \begin{tabular}{|c|} 
Slope \\
$10^{4}$ counts $\mathrm{L} L \mathrm{~g}^{-1}$
\end{tabular} & $r^{2}$ & $\begin{array}{c}\mathrm{RSD}^{\mathrm{a}}(\%) \text { [concen- } \\
\text { tration } / \mu \mathrm{g} \mathrm{L}^{-1} \text { ] }\end{array}$ & $\begin{array}{l}\mathrm{MDL}^{\mathrm{b})} \\
\mu \mathrm{g} \mathrm{L}^{-1}\end{array}$ \\
\hline Aldicarb & $-2 \pm 1$ & $16 \pm 6$ & 0.976 & $15[0.10]$ & 0.020 \\
\hline Carbetamide & $-1 \pm 2$ & $26 \pm 4$ & 0.986 & $15[0.09]$ & 0.038 \\
\hline Pirimicarb & $-2 \pm 3$ & $87 \pm 6$ & 0.998 & $15[0.10]$ & 0.028 \\
\hline
\end{tabular}

a) $\mathrm{RSD}$, relative standard deviation $(n=7)$ determined for the concentration level indicated in brackets.

b) $\mathrm{MDL}=t \cdot s$ (method detection limit; $t$ is Student's $t$ value for $7-1$ degrees of freedom and a significance level of $\alpha=0.05 ; s$ is the standard deviation calculated with the same measurements employed for RSD).

and the fact that the method includes two preconcentration steps. The limits of detection obtained for the carbamates propoxur, carbofuran, carbaryl, and methiocarb are lower than the values established by current legislation for individual pesticides in drinking water $\left(0.1 \mu \mathrm{g} \mathrm{L}^{-1}\right)$. However, the limits of detection for aldicarb, carbetamide, and pirimicarb are higher than this value because these pesticides showed a low degree of preconcentration in the SPME step.

\subsubsection{GC-MS method with SPE as the preconcentration step}

As indicated above, aldicarb, carbetamide, and pirimicarb gave rise to reproducible signals when the samples were injected directly into the chromatograph. Accordingly, for these carbamates a method is proposed that includes a single preconcentration step with SPE and later direct injection.

Table 5 shows the analytical characteristics of the SPE followed by GC-MS method. Detection limits ranging between 0.020 and $0.038 \mu \mathrm{g} \mathrm{L}^{-1}$ were obtained for the three pesticides evaluated with this method, allowing its application for the determination of these pesticides in drinking water.

\section{Conclusions}

The gas chromatographic behaviour of seven carbamate pesticides was studied as a function of variables such as the solvent and mode of injection, the chemical nature of the pesticide in question, and the age of the chromatographic column. An SPME preconcentration step is proposed as a means to obtain reproducible decomposition of thermally labile carbamates.

Several analytical methods were tested with different preconcentration configurations using ultrapure water as solvent, viz. SPME-GC-MS, SPE followed by SPME-GCMS, and SPE followed by GC-MS. The first configuration was suitable for the determination of phenyl $\mathrm{N}$-methyl carbamates (propoxur, carbofuran, carbaryl, and methiocarb) in surface waters. For their determination in drinking water SPE followed by SPME-GC-MS is recommended.

J. Sep. Sci. 2005, 28, 2130-2138 www.jss-journal.de
However, preconcentration of aldicarb, carbetamide, and pirimicarb by SPME was not favourable, and thus for these carbamates the most suitable configuration was SPE followed by GC-MS.

\section{Acknowledgements}

The Dirección General de Investigación, Ministerio de Ciencia y Tecnología (MCYT-DGI, Project BQU200202314) and the Junta de Castilla y León (Project SA-044) are gratefully acknowledged for financial support for this work. Special thanks are due to C. Raposo (Servicio General de Espectrometría de Masas, Universidad de Salamanca) for technical support.

\section{References}

[1] EPA 531.1 method. Methods for the Determination of Organic Compounds in Drinking Water-Supplement III (EPA/600/R-95-131) 1989.

[2] EPA 531.2 method. Measurement of $N$-Methyl-carbamoyloximes and $\mathrm{N}$-Methyl-carbamates in Water by Direct Aqueous Injection HPLC with Post Column Derivatization 2001.

[3 Pogačnik, L., Franko, M., Biosensors Bioelectronics 2003, 18,1-9.

[4] Wigfield, Y. Y., Grant, R., Snider, N., J. Chromatogr. A 1993, 657, 219-222.

[5] Trehy, M. L., Yost, R. A., McCreary, J. J., Anal. Chem. 1984, $56,1281-1285$.

[6] Zrostlíková, J., Hajšlová, J., Godula, M., Maštovská, K., J. Chromatogr. A2001, 937, 73-86.

[7] Maštovská, K., Lehotay, S. J., Hajšlová, J., J. Chromatogr. A 2001, 926, 291-308.

[8] Amirav, A., Gordin, A., Tzanami, N., Rapid Commun. Mass Spectrom. 2001, 15, 811-820.

[9] Climent, M. J., Miranda, M. A., J. Chromatogr. A 1996, 738, 225-231.

[10] Samanidou, V., Fytianos, K., Pfister, G., Bahadir, M., Sci. Total Environm. 1988, 76, 85-92.

[11] Santos Delgado, M. J., Rubio Barroso, S., Toledano Fernández-Tostado, G., Polo-Díez, L. M., J. Chromatogr. A 2001, 921, 287-296.

[12] Liska, I., Krupcik, J., Leclercq, P. A., J. High Resol. Chromatogr. 1989, 12, 577-590.

[13] Jourdan, S. W., Scutellaro, A. M., Fleeker, J. R., Herzog, D. P., Rubio, F. M., J. Agric. Food Chem. 1995, 43, 27842788.

[14] Chiron, S., Valverde, A., Fernández-Alba, A., Barceló, D., J. AOAC Int. 1995, 78, 1346-1352.

(C) 2005 WILEY-VCH Verlag GmbH \& Co. KGaA, Weinheim 
[15] Moore, K. M., Jones, S. R., James, C., Wat. Res. 1995, 29, 1225-1230.

[16] Giraud, D., Ventura, A., Camel, V., Bermond, A., Arpino, P., J. Chromatogr. A 1997, 777, 115-125.

[17] Vassilakis, I., Tsipi, D., Scoullos, M., J. Chromatogr. A 1998, 823, 49-58.

[18] Eitzer, B. D., Chevalier, A., Bull. Environ. Contam. Toxicol. 1999, 62, 420-427.

[19] Primus, T. M., Kohler, D. J., Avery, M., Bolich, P., Way, M. O., Johnston, J. J., J. Agr. Food Chem. 2001, 49, 57065709.

[20] Soriano, J. M., Jiménez, B., Font, G., Moltó, J. C., Crit. Rev. Anal. Chem. 2001, 31, 19-52.

[21] Belardi, R., Pawliszyn, J., Water Pollut. Res. J. Can. 1990, 24, 179-191.

[22] López-Blanco, M. C., Cancho-Grande, B., Simal-Gándara, J., J. Chromatogr. A2002, 963, 117-123.

[23] Gou, Y., Pawliszyn, J., Anal. Chem. 2000, 72, 2774-2779.

[24] Gou, Y., Eisert, R., Pawliszyn, J., J. Chromatogr. A 2000, $873,137-147$.
[25] Carabias Martínez, R., García Hermida, C., Rodríguez Gonzalo, E., Soriano Bravo, F. E., Hernández Méndez, J., J. Chromatogr. A2003, 1002, 1-12.

[26] Salafranca, J., Domeño, C., Fernández, C., Nerín, C., Anal. Chim. Acta 2002, 477, 257-267.

[27] Rodil, R., Carro, A. M., Lorenzo, R. A., Abuín, M., Cela, R., J. Chromatogr. A2002, 963, 313-323.

[28] Dron, J., García, R., Millán, E., J. Chromatogr. A 2002, 963, 259-264.

[29] García-Jares, C., Llompart, M., Polo, M., Salgado, C., Macías, S., Cela, R., J. Chromatogr. A2002, 963, 137-148.

[30] Batlle, R., Sánchez, C., Nerín, C., Anal. Chem. 1999, 71, 2417-2422.

[31] Bouaid, A., Ramos, L., González, M. J., Fernández, P., Cámara, C., J. Chromatogr. A 2001, 939, 13-21.

[32] González-Barreiro, C., Lores, M., Casais, M. C., Cela, R., J. Chromatogr. A2000, 896, 373-379.

[33] Pawliszyn, J., Ed., Applications of Solid Phase Microextraction, RSC Chromatography Monographs, Royal Society of Chemistry, UK, 1999, p. 440-443.

[34] Glaser, J. A., Foerst, D. L., McKee, G. D., Quave, S. A., Budde, W. L., Env. Sci. Tech. 1981, 15, 1426-1435. 



Rita Carabias-Martínez'
Encarnacion Rodríguez-Gonzal
Norman W. Smith ${ }^{2}$
Luis Ruano-Miguel'

'Departamento de Química Analítica,
Nutrición y Bromatología,
Facultad de Ciencias Químicas,
Universidad de Salamanca,
Salamanca, Spain
'Micro Separations Group,
Pharmaceutical Science
Research Division,
King's College,
London, UK

Received April 10, 2006

Revised June 20, 2006

Accepted June 22, 2006

\section{Research Article}

\section{Use of a polar-embedded stationary phase for the separation of tocopherols by CEC}

A polar-embedded stationary phase (ULTIMA C18) has been investigated for the separation of $\alpha-, \beta-, \gamma$ - and $\delta$-tocopherols by CEC in comparison with commercially available $\mathrm{C}_{18}$ and $\mathrm{C}_{30} n$-alkyl RPs. The behavior of this stationary phase was tested for different mobile phases based on methanol, $\mathrm{ACN}$, or mixtures thereof and different separation parameters such as retention factors and resolution were evaluated. The main feature of this stationary phase is the improved selectivity for the separation of $\beta$ - and $\gamma$-tocopherols (positional isomers) when compared with the pure $n$-alkyl $\mathrm{C}_{18}$ material, which was unable to resolve these compounds. Additionally, it is possible to observe a reversal in the elution order of the $\beta$ - and $\gamma$-tocopherol isomers with respect to that obtained on the $\mathrm{C}_{30}$ column. The resulting data indicate that the enhanced selectivity obtained with the polar-embedded stationary phase, with respect to the conventional $\mathrm{C}_{18}$ material, is due to the participation of both hydrophobic and polar interactions: these latter are of the hydrogen bridge type with the amide group of the polar-embedded stationary phase, which increases the retention of the tocopherols and facilitates the discrimination between the $\beta$ - and $\gamma$-isomers. Adequate separation of the four tocopherols was obtained by CEC using the polar-embedded stationary phase and $95: 5 \mathrm{v} / \mathrm{v}$ methanol/water ( $5 \mathrm{mM}$ Tris, final concentration) as the mobile phase.

Keywords: CEC / Isomers / Polar-embedded phase / Tocopherols / Vitamin E

DOI 10.1002/elps.200600223

\section{Introduction}

Vitamin $E$ is a liposoluble vitamin of importance owing to its numerous health benefits. The generic term 'Vitamin E' designates a series of compounds naturally present in vegetable oils, designated $\alpha$-, $\beta$-, $\gamma$ - and $\delta$-tocopherols. These molecules have closely related structures (they are commonly named isomers, even though they are not) that differ only in the number and position of the methyl substituents in the phenolic ring (see Fig. 1A). Owing to their important nutritional value, health benefits, different antioxidant properties, structural similarity and diverse ratios in different types of oil, evaluation of their compositional

Correspondence: Dr. Encarnacion Rodríguez-Gonzalo, Departamento de Química Analítica, Nutrición y Bromatología, Facultad de Ciencias Químicas, Universidad de Salamanca, Plaza de la Merced s.n., E-37008 Salamanca, Spain

E-mail: erg@usal.es

Fax: $+34-923-294483$

Abbreviation: PFPS, pentafluorophenylsilica distribution in foods, and hence, the chromatographic isolation and separation of these substances, has been of much interest in the food industry, in the quality control of the important agricultural products, and to investigators in general.

CEC is a well-known separation technique that was first introduced by Pretorius et al. [1] in 1974. CEC is considered a hybrid technique between HPLC and CE. The mobile phase is driven by EOF through a capillary column containing a stationary phase. The use of EOF generates a flat flow profile and a more uniform flow velocity distribution among all channels, which leads to much higher efficiencies. In the last 10 years, CEC has proved to be a good alternative to HPLC owing to its high-efficiency separations, and the possibility of performing high-speed microanalyses with minimal solvent consumption.

The literature contains several recent references to the separation of tocopherols by CEC with $\mathrm{C}_{8}$ [2], $\mathrm{C}_{18}$ [2-6] or $\mathrm{C}_{30}[3,4]$ alkyl silica-based phases. Although these 
A<smiles>[R2]c1c(C)c2c(c([R])c1O)CCC(C)(CCCC(C)CCCC(C)CCCC(C)C)O2</smiles>

B

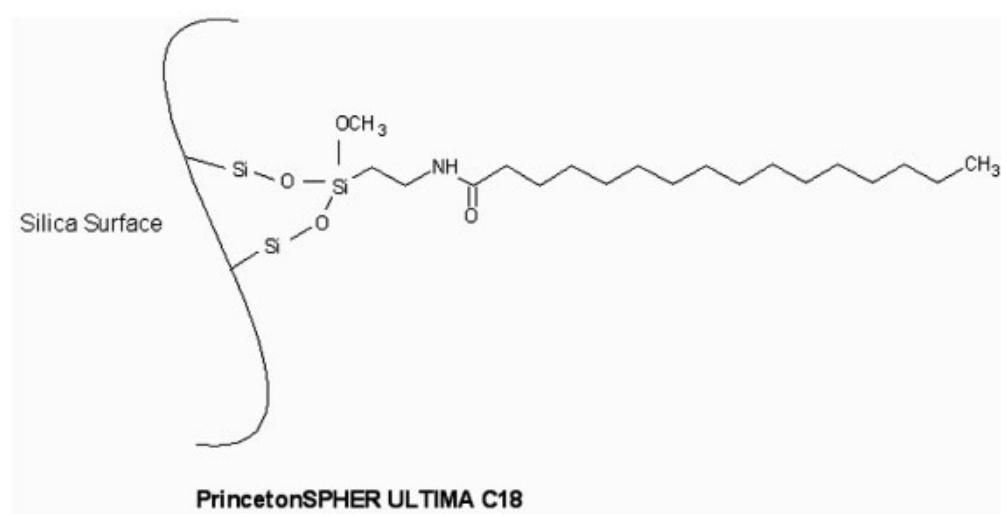

Figure 1. (A) Chemical structure of tocopherols. (B) Structure of the ULTIMA C18 polarembedded stationary phase, kindly provided by Princeton Chromatography. stationary phases have been used to separate a broad variety of compounds, $\mathrm{C}_{18}$ alkyl chains and smaller ones have difficulty in separating extremely hydrophobic and isomeric compounds. HPLC and CEC separations of tocopherols using octadecyl stationary phases do not have sufficient selectivity, resolving only two of the four forms, with the true isomers $\beta$ - and $\gamma$-tocopherols (positional isomers) coeluting $[7,8]$.

Several recent papers have addressed the characterisation and comparison of novel polar-embedded stationary phases [9-13]. These stationary phases contain a polar functionality, such as an amide, carbamate, urea, sulphonamide or phenyl ether group, directly linked to the alkyl chain in close proximity to the silica surface. Polarembedded groups were originally designed to deactivate silanol interactions with basic molecules in order to obtain good peak symmetries for these analytes. The retention and selectivity characteristics of the embedded-polargroup bonded phases are well described in the literature $[14,15]$; these stationary phases have been observed to exert an enhanced retention of phenolic compounds (i.e. hydrogen donors) as a result of their hydrogen-bonding capacity $[16,17]$. They have also found application as stable phases for highly aqueous mobile phases and can also be used to enhance selectivity in the separation of low-molecular-weight acids and highly hydrophobic compounds. 
In the present study, we report the suitability of a polarembedded stationary phase called ULTIMA C18 for the separation and resolution of the four tocopherols 'isomers' using CEC and its comparison with $\mathrm{C}_{18^{-}}$and $\mathrm{C}_{30^{-}}$ bonded phases. The ULTIMA C18 stationary phase is formed by an amide group embedded between a spacer and a 15-carbon atom chain; the structure of this phase is shown in Fig. 1B, kindly provided by the manufacturer Princeton Chromatography. For comparative purposes, all three stationary phases were packed in fused-silica capillaries of $100 \mu \mathrm{m}$ id.

\section{Materials and methods}

\subsection{Reagents and chemicals}

The following compounds and chemicals were used: $\alpha$-tocopherol (>98\%), $\gamma$-tocopherol and $\delta$-tocopherol (90\%; Sigma, Alcobendas, Madrid, Spain), $\beta$-tocopherol (Merck, Darmstadt, Germany). HPLC-grade ACN was obtained from Rathburn Chemicals (Walkerburn, Scotland). HPLC-grade methanol, acetone and Tris buffer were obtained from BDH (UK). The standard stock solutions of tocopherols were prepared in $\mathrm{MeOH}(1 \mathrm{~g} / \mathrm{L})$ and stored at $4^{\circ} \mathrm{C}$. Fused-silica capillaries $(100 \mu \mathrm{m}$ id, $375 \mu \mathrm{m}$ od) were from Composite Metals (llkley, W. Yorkshire, UK). The ULTIMA C18 (5 $\mu \mathrm{m}$ particle size) and Spherisorb ODS1 ( $3 \mu \mathrm{m}$ particle size) stationary phases were kind gifts from Dr. Walton Caldwell (Princeton Chromatography, Cranbury, NJ, USA), and Professor Peter Myers of Xtec (Wirral, UK), respectively, whilst the $\mathrm{C}_{30}$ phase ( $3 \mu \mathrm{m}$ particle size) was a gift from Dr. Frank Moffatt of Syngenta (UK). Frits were formed using an Innovatech frit former (Innovatech, Stevenage, Herts, UK). All CEC experiments were performed on a HewlettPackard HP ${ }^{3 D}$ CE instrument supplied by Agilent (Waldbronn, Germany).

\subsection{Column packing procedure}

All phases were packed in a similar manner to standard silica-based particulate phases, using the procedure and ultrasonic probe described by Boughtflower et al. [18]. Briefly, the particles were slurried in acetone and sonicated for $15 \mathrm{~min}$ in order to eliminate clusters and aggregates prior to placing them in the ultrasonic chamber. An end frit was made by sintering silica particles with the Innovatech frit former, after which the fused-silica capillaries $(100 \mu \mathrm{m}$ id) were pressure-packed using a highpressure packing pump at $8000 \mathrm{psi}$, with acetone as the pumping solvent and an ultrasonic probe to ensure homogenous packing.
The columns were flushed with water and a second frit was made directly from the stationary phase particles with the frit former, with the detection window formed immediately after this second frit. The capillary columns $(100 \mu \mathrm{m}$ id $\times 24.5 \mathrm{~cm}$ effective length) were subsequently conditioned with mobile phase in the CEC instrument.

\subsection{CEC experiments}

Experiments were carried out using a Hewlett-Packard $\mathrm{HP}^{3 \mathrm{D}} \mathrm{CE}$ instrument equipped with an UV-visible DAD and an air-cooled oven compartment.

Columns were conditioned with mobile phase by applying a pressure of 8 bar on both sides, while a voltage program was run as follows: SkV was applied first for $10 \mathrm{~min}$, after which the voltage was raised from 5 to $30 \mathrm{kV}$ for $40 \mathrm{~min}$ and left at $30 \mathrm{kV}$ for a further $30 \mathrm{~min}$ or until the current and baseline were stable. This conditioning method was used whenever a new mobile phase was employed.

Both the outlet and inlet vials were pressurized at 8 bar during the CEC experiments in order to avoid bubble formation. The detection wavelength chosen was $205 \mathrm{~nm}$, and separations were carried out at $30 \mathrm{kV}$ and $30^{\circ} \mathrm{C}$.

The buffer salt content of all the mobile phases was $5 \mathrm{mM}$ Tris ( $\mathrm{pH}$ unadjusted). These solutions were prepared by diluting 20-fold a solution of $100 \mathrm{mM}$ Tris buffer in $\mathrm{MeOH}$ with the appropriate solvent $(\mathrm{MeOH}, \mathrm{ACN}$ or water). Mobile phases were prepared daily and ultrasonicated for $10 \mathrm{~min}$ before use.

Working standard solutions were prepared daily by making a ten-fold dilution of the stock solutions with methanol $(1 \mathrm{~g} / \mathrm{L}$ in methanol). Thiourea was added as an EOF marker. All samples were injected under pressure (8 bar for $0.5 \mathrm{~min}$ ) followed by a plug of mobile phase ( 8 bar for $0.3 \mathrm{~min})$.

All analytical data (retention factors, retention time and resolution) came from at least three replicate injections of each analysis. Retention factors $(k)$ were determined from the equation $k=\left(t-t_{0}\right) / t_{0}$, with $t$ being the average retention time and $t_{0}$ the retention time of thiourea (EOF marker). The resolution between two consecutive peaks ( $\mathrm{A}$ and $\mathrm{B}$ ) was calculated from the equation $R_{\mathrm{S}}=(2.35 / 2)$ $\left[\left(t_{\mathrm{B}}-t_{\mathrm{A}}\right) /\left(W_{\mathrm{A}}+W_{\mathrm{B}}\right)\right]$, using the software of the CEC instrument (HP ChemStation), where $W_{\mathrm{A}}$ and $W_{\mathrm{B}}$ are the peak widths of species $A$ and $B$, respectively, at their half height. 


\section{Results and discussion}

3.1 Separation of $\alpha-, \gamma$-, and $\delta$-tocopherols. Effect of the composition of the mobile phase

The stationary phases tested were the polar-embedded ULTIMA C18, and the linear, nonendcapped alkyl silica phases ODS1 $\left(\mathrm{C}_{18}\right)$ and $\mathrm{C}_{30}$. A study of the influence of the mobile phase on the separation of $\alpha-, \gamma-$, and $\delta$-tocopherols was carried out with nonaqueous mixtures of
$\mathrm{MeOH} / \mathrm{ACN}$ at different ratios, keeping the salt content constant (5 mM Tris). Figure 2 shows the plots of the retention times, retention factors and resolution versus the composition of the mobile phase.

In CEC systems, the driving force for the mobile phase is the EOF. Since the EOF depends on the $\varepsilon / \eta$ ratio (dielectric constant/viscosity) of the mobile phase, an increase in EOF would be expected to follow an increase in the percentage of $\mathrm{ACN}$ in the $\mathrm{ACN} / \mathrm{MeOH}$ mixture because the $\varepsilon / \eta$ ratio is greater for $A C N$ than for methanol. As may be

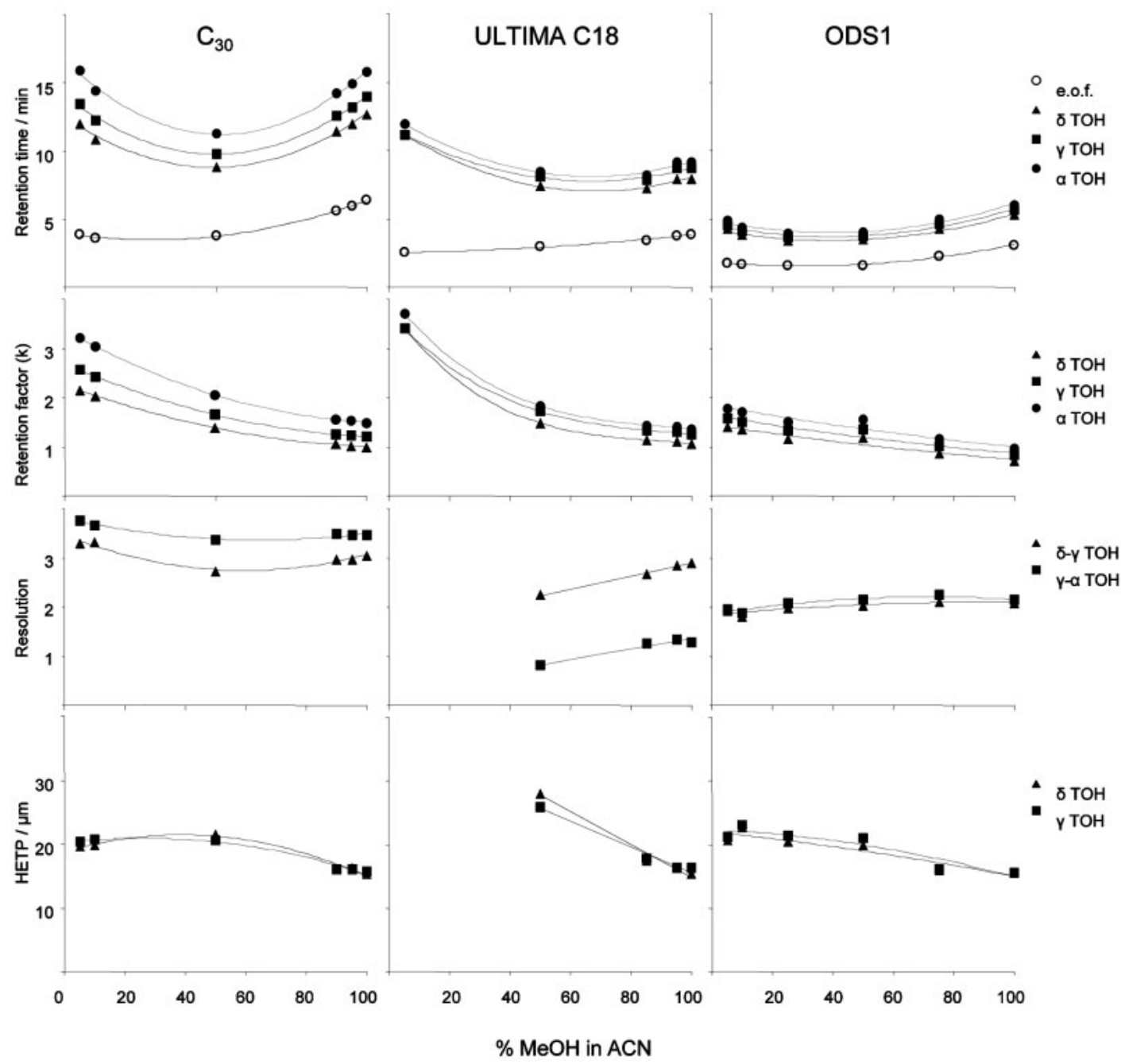

Figure 2. Effect of mobile phase composition (MeOH/ACN) on the retention time, retention factor, resolution and efficiency of the three stationary phases in the separation of $\alpha$-, $\gamma$ - and $\delta$-tocopherols. 
seen in Fig. 2, the value of the retention time of the EOF marker (thiourea) decreased upon increasing the percentage of $\mathrm{ACN}$ in the mobile phase, which indicates that a greater EOF is generated in these media. However, experimentally (Fig. 2) we observed an increase in the retention time of all the compounds studied on using ACN percentages higher than $50-60 \%$ for the three stationary phases tested. Similar results have been reported by Fanali et al. [5, 19] and Abidi et al. [4].

By using linear $\mathrm{C}_{18}$ and $\mathrm{C}_{30}$ phases, the change from methanol to ACN did not involve a loss of resolution and the resolution values remained approximately constant throughout the range studied (Fig. 2), allowing the separation of the three tocopherols at any solvent ratio. As expected, the retention times and the resolution parameters among compounds were higher when the $C_{30}$ phase was used.

In contrast, for the ULTIMA C18 polar-embedded phase, a significant difference between both the solvents was observed. When ACN was employed as the main solvent in the mobile phase instead of $\mathrm{MeOH}$, the peaks were less reproducible, ill-defined and broader, with only two overlapping peaks being observed for the three compounds. Efficiency and resolution improved significantly as the content of $\mathrm{MeOH}$ was increased, and a good separation of the three tocopherols with well-shaped peaks was achieved at an ACN content of less than $50 \%$. The retention times with the ULTIMA C18 phase were midway between the $\mathrm{C}_{30}$ and $\mathrm{C}_{18}$ phases, the minimum retention time being found at methanol contents higher than for the alkyl phases. Interestingly, with the polar-embedded phase these nonpolar compounds were more strongly retained than with a common $\mathrm{C}_{18}$ phase. This may be attributed to additional interactions with the polar-embedded amide group, in addition to the hydrophobic interactions, which are present in alkyl-bonded phases. It has been reported that polar-embedded phases show enhanced retention of phenolic compounds (i.e. hydrogen donors) as a result of their hydrogen-bonding capacity $[16,17]$. Another difference in the CEC behavior of the ULTIMA C18 phase with respect to the ODS1 material is that the resolution between the $\gamma$ - and $\alpha$-isomers, which was possible using the ODS1 phase, was never obtained with the ULTIMAC18 phase with these nonaqueous mobile phases.

All three phases reached the same maximum efficiency (minimum height of equivalent theoretical plates (HETP) value of $15 \mu \mathrm{m}$ ) with $100 \% \mathrm{MeOH}$. Figure 3 shows a chromatogram of each stationary phase when $100 \% \mathrm{MeOH}$ was used as the mobile phase.

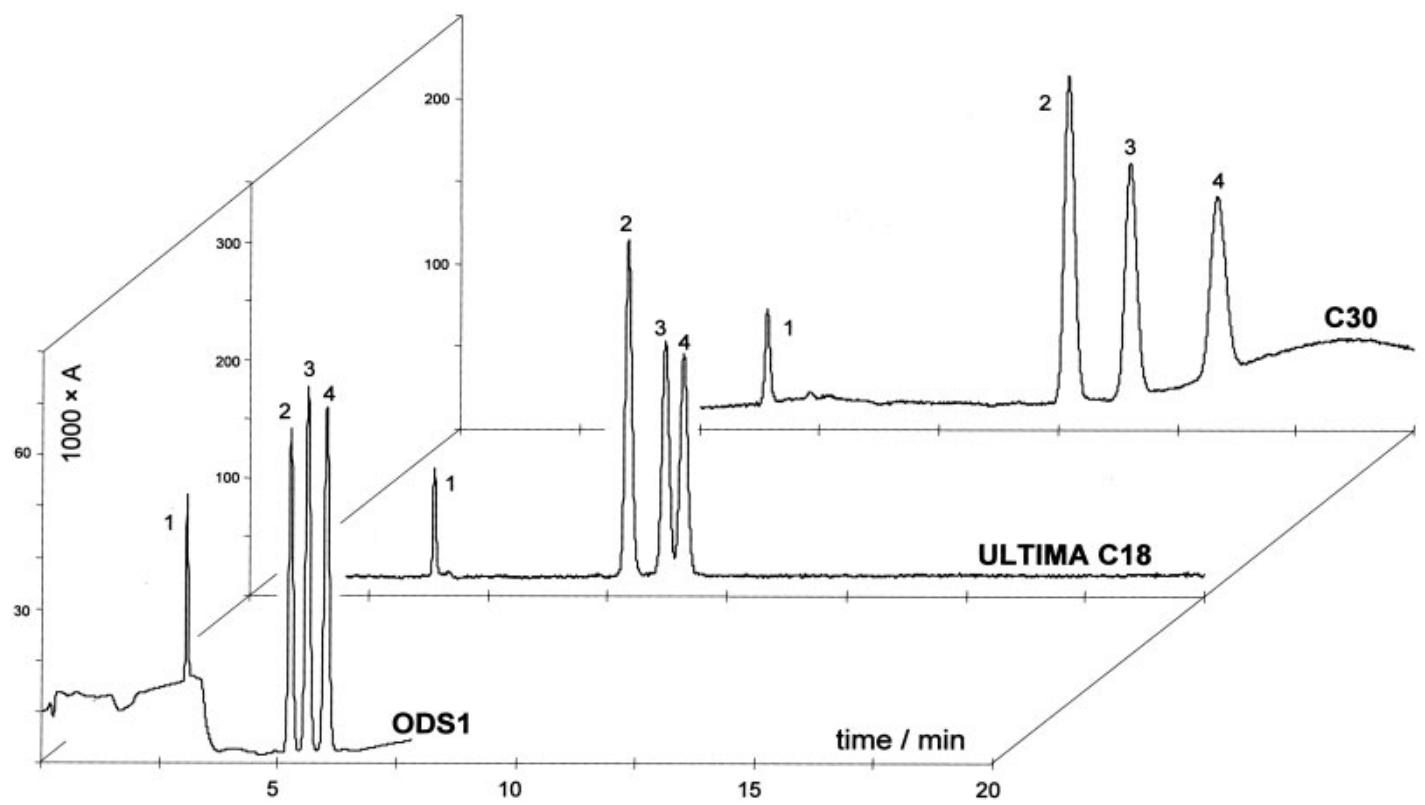

Figure 3. Separation of $\alpha-, \delta$ - and $\gamma$-tocopherols with the ODS-1, ULTIMA C18 and $\mathrm{C}_{30}$ stationary phases. Mobile phase: $100 \% \mathrm{MeOH}, 5 \mathrm{mM}$ Tris. Separation at $30 \mathrm{kV}, 30^{\circ} \mathrm{C}$. Injection: 8 bar for $0.5 \mathrm{~min}$. Peaks: $1=$ thiourea; $2=\delta$-tocopherol; $3=$ $\gamma$-tocopherol; $4=\alpha$-tocopherol. 
In general, it may be concluded that although ACN seems to be a good choice as a mobile phase for CEC because it provides higher EOFs, this solvent is a poorer eluent than methanol in the three columns evaluated. Thus, the retention times for tocopherols increased at higher ACN contents, but a similar increase in the retention time of the EOF marker was not observed. Furthermore, this effect was much more pronounced on the ULTIMA C18 polarembedded phase than ODS1, probably because for this type of polar RP material, methanol is a better eluent of polar interactions, as suggested by the values of the solvent strength parameter on alumina $\left(\varepsilon^{\circ}\right)$ for both solvents (0.65 for ACN and 0.95 for methanol) [20].

\subsection{Separation of $\beta$ - and $\gamma$-isomers with the ULTIMA C18 stationary phase}

Usually, the two compounds hardest to resolve when common RP materials are used, are the positional isomers $\beta$ - and $\gamma$-tocopherols. It has been reported that these isomers are not easily separated on conventional alkyl linear $\mathrm{C}_{8}$ or $\mathrm{C}_{18}$ phases $[7,8]$.

Here, standard solutions containing $\alpha-, \beta-, \gamma$ - and $\delta$-tocopherols were used to check the ability of the ULTIMA C18 polar-embedded phase for the separation of these four compounds, especially the $\beta$ - and $\gamma$-isomers. The same experiments were carried out on the $\mathrm{C}_{30}$ phase for comparative purposes.

First, nonaqueous mobile phases based on $\mathrm{MeOH} / \mathrm{ACN}$ mixtures were used. Table 1 compares the resolution between $\beta$ - and $\gamma$-tocopherols versus the composition of the mobile phase (MeOH/ACN mixtures). As reported above, the presence of high percentages of ACN on the ULTIMA C18 stationary phase gave rise to a deterioration in the separation of the tocopherols, preventing calculation of the resolution values for percentages of $\mathrm{ACN}$ higher than $50 \%$. The resolution obtained with $\mathrm{C}_{30}$ was better than that of ULTIMA C18, although the elution times were also longer.

Table 1. Comparison of resolution $\left(R_{\mathrm{s}}\right)$ between $\beta$ - and $\gamma$-tocopherols with the ULTIMAC18 and $\mathrm{C}_{30}$ stationary phases (mobile phase: $\mathrm{MeOH} / \mathrm{ACN}$ at different ratios; $5 \mathrm{mM}$ Tris final concentration)

\begin{tabular}{|c|c|c|c|c|c|c|c|}
\hline & \multicolumn{6}{|c|}{$\% \mathrm{MeOH}$ in $\mathrm{ACN}$} \\
\hline & & 5 & 10 & 50 & 90 & 95 & 100 \\
\hline $\mathrm{C}_{30}$ & $R_{\mathrm{s}}(\gamma-\beta)$ & 0.95 & 0.87 & 0.71 & 0.80 & 0.86 & 0.84 \\
\hline ULTIMA C18 & $R_{\mathrm{s}}(\beta-\gamma)$ & $\mathrm{NM}^{\mathrm{a})}$ & $\mathrm{NM}^{\mathrm{a})}$ & $N M^{a)}$ & 0.52 & 0.49 & 0.57 \\
\hline
\end{tabular}

a) NM: not measurable.
When a $100 \% \mathrm{MeOH}$ was used as the mobile phase, the results revealed that the ULTIMA C18 polar-embedded phase showed certain selectivity for the $\beta$ - and $\gamma$-tocopherols, resulting in two partially resolved peaks for these compounds (see Fig. 4A). Although both the ULTIMA C18 and the $\mathrm{C}_{30}$ stationary phases showed partial separation between the $\beta$ - and $\gamma$-tocopherols, the order of elution of the two compounds differed for both phases: $t_{\mathrm{R}}(\beta)>t_{\mathrm{R}}(\gamma)$ for the $\mathrm{C}_{30}$ material, whereas $t_{\mathrm{R}}(\gamma)>t_{\mathrm{R}}(\beta)$ for the ULTIMA C18 phase (Figs. 4A and B). This behavior confirms the participation of additional retention mechanisms apart from the purely hydrophobic ones, which predominate on the pure $\mathrm{C}_{30}$ alkyl-bonded phase.

In an attempt to achieve baseline separation of the four tocopherols, several experiments were carried out, gradually increasing the water content in a mobile phase based upon pure methanol. A good separation of the four isomers was achieved within a reasonable time (less than $30 \mathrm{~min}$ ) with a mobile phase composed of $95: 5 \mathrm{v} / \mathrm{v} \mathrm{MeOH} /$ $\mathrm{H}_{2} \mathrm{O}$; it should be noted that the addition of a small amount of water enhanced the selectivity but tripled the retention times as compared with the pure methanol mobile phase. Under these conditions, an $R_{\mathrm{s}}(\beta-\gamma)$ value of 1.2 was obtained. A typical chromatogram is shown in Fig. 5.

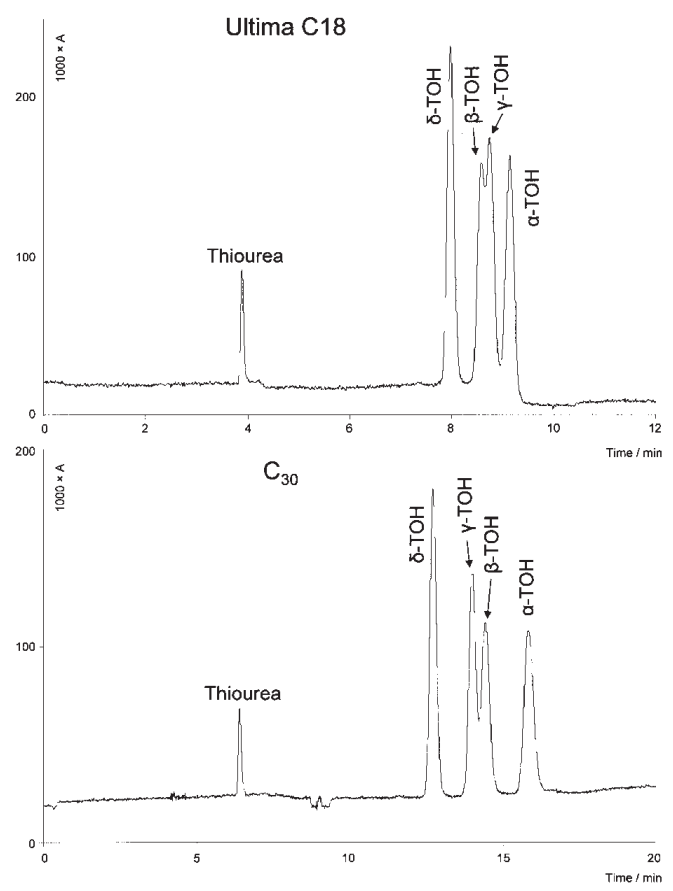

Figure 4. Separation of $\alpha-, \beta-, \gamma$ - and $\delta$-tocopherols with the ULTIMA C18 (A) and $\mathrm{C}_{30}$ (B) stationary phases. Experimental conditions as in Fig. 3. 


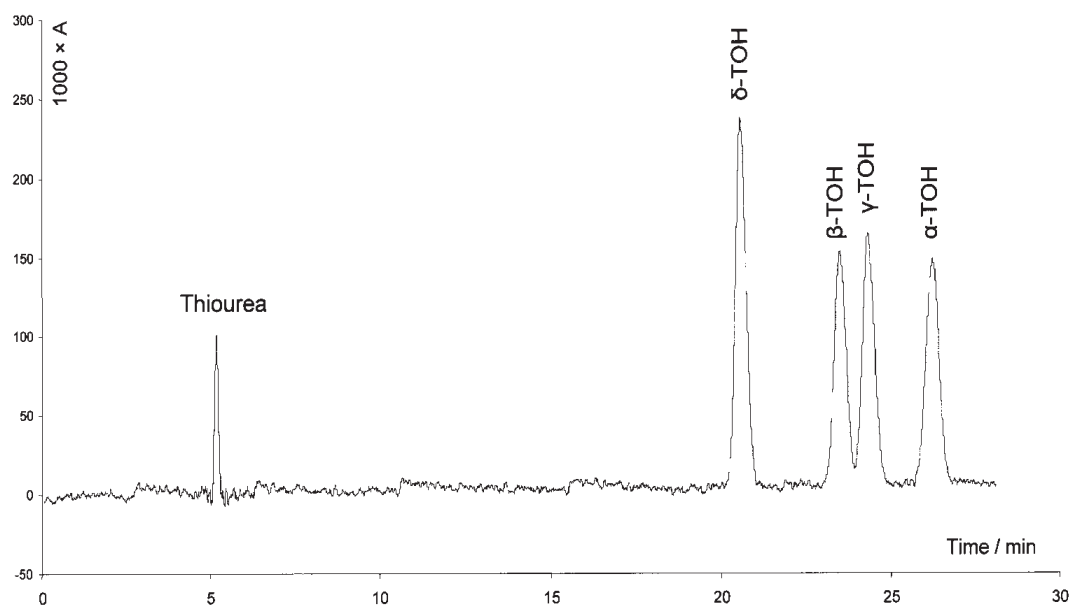

Figure 5. Separation of $\alpha-, \beta-, \gamma$ - and $\delta$-tocopherols on ULTIMA C18 stationary phase using 95:5 MeOH/ $/ \mathrm{H}_{2} \mathrm{O} ; 5 \mathrm{mM}$ Tris final concentration. Other conditions as in Fig. 4.

\subsection{Selectivity of polar-embedded ULTIMA C18 versus $\mathrm{C}_{30}$ for the separation of $\beta$ - and $\gamma$-tocopherols}

As described above, in the CEC experiments with a $\mathrm{C}_{30}$ stationary-phase the $\beta$-isomer appeared to be more hydrophobic than the $\gamma$-isomer since the former was more strongly retained on this type of stationary phase, i.e. $t_{\mathrm{R}}(\beta)>t_{\mathrm{R}}(\gamma)$. These results are in agreement with previously published findings [3]. When the CEC experiments were carried out with the ULTIMAC18 stationary phase, the elution order of the $\beta$ - and $\gamma$ - pair was reversed (Fig. 4); i.e. $t_{\mathrm{R}}(\beta)<t_{\mathrm{R}}(\gamma)$. The same order of elution $\left(k_{\beta}<k_{\gamma}\right)$ was described by Richheimer et al. [21] for the separation of tocopherols by RP HPLC on a pentafluorophenylsilica (PFPS) stationary phase. Abidi et al. reported the same elution order with both an octadecyl polyvinyl alcohol phase (ODPVA) [7] and the polar PFPS phase in HPLC and CEC separations [4].

The common characteristic of these RP stationary phases (PFPS, ODPVA and ULTIMA C18) in which the order of elution was $-t_{\mathrm{R}}(\beta)<t_{\mathrm{R}}(\gamma)$ - is that all of them exhibited some type of polar functionality. It should be borne in mind that this order of elution $-t_{R}(\beta)<t_{R}(\gamma)-$ is the one that has traditionally been observed for these two isomers when normal-phase chromatography is carried out. Accordingly, the retention of the $\beta$ - and $\gamma$-pair seems to be linked to their facility for interacting with the polar group of these polar reversed-stationary phases.
The position of the methyl groups in the chromanol ring is what distinguishes the $\beta$ - and $\gamma$-isomers (Fig. 1A). In the case of $\beta$-tocopherol, the two methyl groups are at positions 5 and 8 of the chromanol head (the 'para' position), and they act as a shield for the polar zone of the molecule (the - $\mathrm{OH}$ group), favouring its hydrophobicity and hence a longer retention in the $\mathrm{C}_{30}$ column - where $t_{\mathrm{R}}(\beta)>t_{\mathrm{R}}(\gamma)$. This shielding effect of the hydroxyl group would in turn hinder the interaction of the $\beta$-isomer with the amide-group of the Ultima C18 stationary phase, and hence its retention in this column would be disfavored. In contrast, in the case of $\gamma$-tocopherol the two methyl groups are at positions 7 and 8 in the chromanol head (the 'ortho' position), such that the shielding effect does not occur. Accordingly, the formation of hydrogen bridge bonds with the Ultima C18 polarembedded phase should be favored, explaining its longer retention in this type of column - where $t_{R}(\beta)<t_{R}(\gamma)$.

These observations suggest that although the $\mathrm{C}_{30}$ and ULTIMA C18 columns show sufficient selectivity for resolving the pair of isomers, the way in which they do so differs. According to Sander and Wise's group [22-24], the 'shape selectivity' for alkyl stationary phases increases with increased alkyl chain length in the stationary phase as the conformational order increases with alkyl chain length. However, in the case of the ULTIMA C18 polar-embedded stationary phase, with an alkyl chain very similar in length to the conventional $\mathrm{C}_{18}$, it has a selectivity for the separation of tocopherols similar to that obtained in long-chain phases, such as $\mathrm{C}_{30}$; the enhancement of shape selectivity in this case seems to be related to the accessibility for interaction with the polar group of the stationary phase. 


\section{Concluding remarks}

This study represents the first separation of Vitamin $E$ isomers using a packed polar-embedded stationary phase for CEC. The suitability of this stationary phase for such a task is demonstrated, obtaining an improved resolution and selectivity for the $\gamma$ - and $\beta$-isomers that is not attained using conventional $\mathrm{C}_{18}$ phases for these closely related structures. CEC with a polar-embedded stationary phase should allow complete separation of all the components, with good peak symmetries and retention times. A strong dependence on the organic modifier in the mobile phase was also apparent in the behaviour of these compounds, which does not exist for alkyl-bonded phases. Replacing methanol with ACN in this stationary phase resulted in a loss of resolution and efficiency, as well as in selectivity. The results indicate that the elution behaviour obtained with polar RP stationary phases is notably affected by both the hydrophobic and polar properties of the analytes.

This work was supported by the MEC-DGI (project CTQ2005-00292) and by the Junta de Castilla y León (project SA007A05). It was carried out in the Micro Separations Group, at King's College, London. The authors wish to acknowledge the kind gift of the ULTIMA C18 stationary phase from Dr. Walton Caldwell (Princeton Chromatography Inc.).

\section{References}

[1] Pretorius, V., Hopkins, B. J., Schieke, J. D., J. Chromatogr. 1974, 99, 23-30.

[2] Abidi, S. L., Rennick, K. A., J. Chromatogr. A 2001, 913, 379386.
[3] Henry, C. W., III, Fortier, C. A., Warner, I. M., Anal. Chem. 2001, 73, 6077-6082.

[4] Abidi, S. L., Thiam, S., Warner, I. M., J. Chromatogr. A 2002, 949, 195-207.

[5] Fanali, S., Catarcini, P., Quaglia, M. G.,Camera, E. et al., J. Pharm. Biomed. Anal. 2002, 29, 973-979.

[6] Aturki, Z., D’Orazio, G., Fanali, S., Electrophoresis 2005, 26, 798-803.

[7] Abidi, S. L., Mounts, T. L., J. Chromatogr. A 1997, 782, 2532.

[8] Gliszczynska-Swiglo, A., Sikorska, E., J. Chromatogr. A 2004, 1048, 195-198.

[9] Layne, J., J. Chromatogr. A 2002, 957, 149-164.

[10] Le Mapihan, K., Vial, J., Jardy, A., J. Chromatogr. A 2005, 1088, 16-23.

[11] Euerby, M. R., Petersson, P., J. Chromatogr. A 2005, 1088, $1-15$.

[12] Marín, A., Barbas, C., J. Pharm. Biomed. Anal. 2006, 40, 262-270.

[13] Ruderisch, A., Iwanek, W., Pfeiffer, J., Fischer, G. et al., J. Chromatogr. A 2005, 1095, 40-49.

[14] O'Gara, J., Walsh, D. P., Phoebe, C. H., Jr., Alden, B. A. et al., LC. GC 2001, 19, 632-642.

[15] Majors, R. E., Przybyciel, M., LC.GC 2002, 20, 584-593.

[16] Wilson, N. S., Gilroy, J., Dolan, J. W., Snyder, L. R., J. Chromatogr. A 2004, 1026, 91-100.

[17] O'Gara, J., Alden, B., Walter, T., Petersen, J. et al., Anal. Chem. 1995, 67, 3809.

[18] Boughtflower, R. J., Underwood, T., Maddo, J., Chromatographia 1995, 41, 398-402.

[19] Fanali, S., Catarcini, P., Quaglia, M. G., Electrophoresis 2002, 23, 477-485.

[20] Poole, C. F., Schuette, S. A., Contemporary Practice of Chromatography, Elsevier, Amsterdam 1984, p. 257.

[21] Richheimer, S. L., Kent, M. C., Bernat, M. W., J. Chromatogr. A 1994, 677, 75-80.

[22] Sander, L. C., Wise, S. A., Anal. Chem. 1987, 59, 2309-2313.

[23] Bell, C. M., Sander, L. C., Fetzer, J. C., Wise, S. A., J. Chromatogr. A 1996, 753, 37-45.

[24] Sander, L. C., Lippa, K., Wise, S. A., Anal. Bioanal. Chem. 2005, 382, 646-668. 


\section{Encarnación Rodríguez- \\ Gonzalo \\ Javier Domínguez-Álvarez \\ Luis Ruano-Miguel \\ Rita Carabias-Martínez \\ Departamento de Química \\ Analítica, \\ Nutrición y Bromatología \\ Facultad de Ciencias Químicas, \\ Universidad de Salamanca, \\ Salamanca, Spain}

Received March 3, 2008

Revised April 30, 2008

Accepted May 2, 2008
Research Article

\section{In-capillary preconcentration of pirimicarb and carbendazim with a monolithic polymeric sorbent prior to separation by CZE}

\begin{abstract}
CZE was assayed for the separation of carbamate pesticides susceptible to protonation (Pirimicarb, Carbendazim). Different electrophoretic media with high organic contents were explored, adequate separation and resolution being achieved when a BGE based on ACN with acetic acid in the presence of SDS as an ionic additive was used. With a view to increasing the sensitivity of the method, an in-capillary SPE step prior to the electrophoretic separation was developed. We employed a monolithic polymer formed in situ within the capillary as a medium for analyte retention. The synthesized monolithic bed exhibited high porosity and allowed samples to be loaded at flow rates of about $65 \mu \mathrm{L} /$ min by applying a pressure of $12 \mathrm{bar}$. A $5-\mathrm{cm}$ length of monolithic sorbent was used to preconcentrate the target analytes from aqueous samples. The analytes retained were eluted from the polymeric phase directly in the separation capillary with the same electrophoretic medium used for their further separation by CZE. For a 15-min preconcentration time, the in-line SPE-CZE approach proposed here permitted the determination of these pesticides in drinking water at a concentration level of $0.1 \mu \mathrm{g} / \mathrm{L}$, as demanded by current EU legislation.
\end{abstract}

\section{Keywords:}

Carbamate pesticides / CZE / In-capillary SPE / Monolithic polymeric sorbent

DOI 10.1002/elps.200800277

\section{Introduction}

Carbamate pesticides have been available commercially since the 1950s and are currently widely used in pest control owing to their low persistence, high effectiveness, and the possibility of using them in broadly varying applications (insecticides, fungicides, herbicides, nematocides, etc.). The characteristics of carbamate pesticides are their polarity, their solubility in water, and their thermal instability. Although GC and HPLC are the methods most commonly used for the detection of pesticides in environmental samples, HPLC methods are preferred over GC methods for carbamate pesticides [1] since most of these are thermally labile.

Correspondence: Dr. Encarnación Rodríguez-Gonzalo, Departamento de Química Analítica, Nutrición y Bromatología, Facultad de Ciencias Químicas, Universidad de Salamanca, Plaza de la Merced s/n, 37008 Salamanca, Spain

E-mail: erg@usal.es

Fax: +34-923294483

Abbreviations: BMA, butyl methacrylate; CBZ, carbendazim; $\gamma$-MAPS, $\gamma$-methacryloxypropyltrimethoxysilane; $\mathrm{MeOH}$, methanol; PMC, pirimicarb
In recent decades, $\mathrm{CE}$ has been used as an alternative to methods of chromatographic separation (HPLC and GC). CE techniques such as micellar electrokinetic chromatography have been described for the analysis of carbamate pesticides [2, 3] in neutral form. However, in the case of charged carbamates, CZE have received little attention $[4,5]$.

Nevertheless, conventional CE techniques usually suffer from poor sensitivity, especially when spectrophotometric detection is carried out. To improve the limited sensitivity observed in CE, different strategies have been developed. One approach involves the use of more sensitive detection systems or the use of preconcentration strategies based on concentrating the sample injected into the capillary by modifications to the electrophoretic velocity of the analytes (stacking by field amplification, stacking through the injection of large sample volumes, pH-mediated stacking, sweeping, isotachophoresis, etc.). These on-line electrophoretic preconcentration strategies have been extensively reviewed $[6,7]$.

Another approach involves application of preconcentration steps such as liquid-phase microextraction, solid-phase microextraction and SPE prior to CE separation. For liquidphase microextraction $[8,9]$ and solid-phase microextraction [10-13] combined with CE, several off-line procedures have been described, some of them dealing with the determination of pesticides [11-13], but few works addressing on-line 
approaches have been reported $[14,15]$. Currently, SPE is the preconcentration technique most widely applied in combination with $\mathrm{CE}$, as is reflected by the large number of publications and reviews addressing the issue [16-18]. There are different ways in which SPE can be integrated with CE: off-, at-, on-, and in-line [16]. The best integration can be achieved with in-line coupling of SPE with CE, in which the preconcentration sorbent is placed directly inside the electrophoretic separation capillary [19-21]. In this mode, once preconcentration has been performed, the amount eluted is subjected to electrophoretic separation.

In recent years, numerous papers have been published reporting in-line SPE-CE methods for the preconcentration and analysis of analytes such as peptides, proteins, drugs, etc. [22-25] in biological samples (urine, blood). In most such studies, small packed-bed columns were prepared in which the particle beads of sorbent material were packed in a short section near the injection end of the electrophoretic capillary and held in place by retaining frits. Some drawbacks related to the presence of these frits have been reported: they may lead to increases in backpressure, longer analysis times, and irreproducible EOFs [20, 26]. Alternatively, open-tubular columns, with the sorbent attached to the inner wall of the capillary, and membrane-based SPE devices (i.e. disks or membranes impregnated with a sorbent) have also been proposed; these do not require the use of a retainer to hold the chromatographic material in place. The main limitation of these setups is the low sample capacity.

Another approach is the use of porous monolithic (continuous-bed) columns [27] prepared by in situ polymerization of a mixture of monomers inside a capillary tube. The most frequent application of monolithic polymers is as the stationary phase [28] in capillary electrochromatography and micro-liquid chromatography. However, their use as sorbents in extraction-preconcentration steps is also beginning to expand [29] because this type of phase has the advantages of ease of manufacture, low cost, and the possibility of designing phases with customized polarity and selectivity for a large variety of analytes.

The application of a monolithic sorbent to preconcentration directly in the separation capillary in CE was reported by Baryla and Toltl [19], who used monolithic methacrylate polymers for the preconcentration of S-propranolol In this case, a single analyte was used and no subsequent separation was reported. Later, different strategies have been applied successfully for efficient preconcentration and later separation by $\mathrm{CE}$ in the determination of proteins [30], amino acids [31], antidepressants [32], neurotransmitters [33], etc. Most published works about SPE-CE mechanisms have focused on the handling of biological samples. The literature referring to environmental applications is still rather scarce.

Here, we report the electrophoretic behaviour of two carbamate pesticides and the optimization of their separation using CZE in a BGE with a high organic content. Analysis of these pesticides in natural waters requires an efficient sample preparation step for current legal limits to be reached. Thus, in this work we also describe the development of an in-capillary SPE procedure for the preconcentration of these compounds based on a monolithic polymeric sorbent synthesized directly at the inlet end of the same capillary used for the electrophoretic separation. The high organic content of the BGE assayed for the CZE separation allowed us to use it as a solvent for analyte desorption. The performance of the in-line SPE-CZE configuration was investigated and its analytical characteristics were assessed. Its application to natural waters is also reported.

\section{Materials and methods}

\subsection{Chemicals}

The pesticides were purchased from Riedel-de Haën (SeelzeHannover, Germany) and were used without further purification (minimum purity greater than 98\%). The pesticides studied were as follows: Pirimicarb (PMC) [23103-98-2], Carbendazim (CBZ) [10605-21-7], Diquat [23136-7], Paraquat [4685-14-7], Ametryn [834-12-8], Prometryn [7287-19-6], and Terbutryn [886-50-0]. Standard stock solutions of the pesticides $(200 \mathrm{mg} / \mathrm{L})$ were prepared by weighing and dissolving the compounds in methanol (MeOH). These stock solutions were stored at $4^{\circ} \mathrm{C}$ and, when needed were suitably diluted to obtain the working standard solutions.

SDS was purchased from Fluka (Madrid, Spain). The HPLC-grade organic solvents - ACN, $\mathrm{MeOH}$, and acetone were from Merck (Darmstadt, Germany). Acetic acid (HPLC grade) and sodium chloride, lithium perchlorate, and ammonium acetate (analytical reagent grade) and were purchased from Scharlau (Barcelona, Spain).

The reagents used for the synthesis of monolithic polymer were as follows: divinylbenzene (technical, 80\%), butyl methacrylate (BMA, 99\%), and ethylene glycol dimethacrylate $(98 \%)$ were purchased from Aldrich (Madrid, Spain); 2,2'-Azobis(2-methyl-propionitrile), AIBN, used as an initiator was from Acros Organics (Geel, Belgium); $\gamma$-methacryloxypropyltrimethoxysilane $(\gamma$-MAPS, 98\%) used for derivatizing the capillary was from Sigma (Madrid, Spain); and 1-octanol, 1-propanol and 1,4-butanediol (reagent grade, 99\%) and 2-acryloylamido-2-methylpropanesulfonic acid $(98 \%)$ were from Fluka.

Fused-silica capillaries (75 $\mu \mathrm{m}$ i.d., $375 \mu \mathrm{m}$ o.d.) from Polymicro Technologies (Phoenix, AZ, USA), supplied by Composite Metal Services (West Yorkshire, UK), were used in the work.

\subsection{CE experiments}

All experiments were carried out using a Hewlett-Packard $\mathrm{HP}^{3 \mathrm{D}} \mathrm{CE}$ instrument equipped with a UV-visible DAD and an air-cooled oven compartment supplied by Agilent (Waldbronn, Germany). The detection wavelengths chosen 
were 220, 241, and $281 \mathrm{~nm}$. Electrophoretic separations were carried out at $30 \mathrm{kV}$ and $30^{\circ} \mathrm{C}$. The total capillary length was $58.5 \mathrm{~cm}$ and the effective length was $50 \mathrm{~cm}$.

All new capillaries were conditioned before use. They were treated for $10 \mathrm{~min}$ with BGE. This was also applied as a daily start-up procedure. After each run, the capillary was rinsed for 2 min with fresh BGE. Samples were introduced into the capillary under pressure $(50 \mathrm{mbar}$ for $4 \mathrm{~s})$. The BGE used was $2 \% \mathrm{v} / \mathrm{v}$ water in $\mathrm{ACN}$ with $1 \mathrm{M}$ acetic acid $(5.7 \% \mathrm{v} / \mathrm{v})$, and $15-20 \mathrm{mM}$ SDS, and a voltage of $30 \mathrm{kV}$ was applied for the electrophoretic separation. Normal polarity (detector at the cathode end of the capillary) was used for all the electrophoretic separations. All samples were in aqueous media, with residual $\mathrm{MeOH}$ from the dilution of the corresponding stock solutions. Thiourea was used as an EOF marker. BGE solutions were refreshed prior to each run in order to achieve reproducible results devoid of the effects of electrolysis.

\subsection{Preparation of the monolithic polymeric beds}

In order to maintain the continuous bed stable inside the capillary column, preventing the monolith from being flushed away, the inner wall of the capillary should be treated with the bifunctional coupling agent $\gamma$-MAPS, which reacts with the silanol of the inner wall of the capillary and also provides grafting of the anchor sites of the polymer to the silica surface. Bare capillaries were washed in the CE instrument with $1 \mathrm{M} \mathrm{NaOH}$ for $10 \mathrm{~min}$, water for $10 \mathrm{~min}$, $0.1 \mathrm{M} \mathrm{HCl}$ for $10 \mathrm{~min}$, again with water for $10 \mathrm{~min}$, and finally with acetone for $10 \mathrm{~min}$. In all cases, a pressure of 4 bar was applied. The capillary was dried by air from an empty vial for $5 \mathrm{~min}$ and then the solution of $\gamma$-MAPS in acetone $(2 / 10 \mathrm{v} / \mathrm{v})$ was passed through the system for $15 \mathrm{~min}$. The capillary was left overnight at room temperature and then washed with acetone $(10 \mathrm{~min})$, water $(10 \mathrm{~min})$ and air (10 min), all at 4 bar.

For synthesis of the monolithic polymer, $3.0 \mathrm{~g}$ of 1-octanol and $1.0 \mathrm{~g}$ of the monomer divinylbenzene (at a proportion of $75 / 25 \mathrm{w} / \mathrm{w}$ ) were weighed in a vial together with $10 \mathrm{mg}$ of the AIBN initiator $(1 \% \mathrm{w} / \mathrm{w}$ with respect to the monomers). The solution was placed in an ultrasound bath for 15 min to dissolve the AIBN and degas the solution. The desired length of the capillary was filled by means of a syringe, and both ends were sealed with two silicone septa. The capillary was placed in a water bath at $60^{\circ} \mathrm{C}$ for $16 \mathrm{~h}$. After withdrawal of the polymerized capillary from the bath, a detection window was made at $8.5 \mathrm{~cm}$ from the empty end. The capillary was then washed with $\mathrm{MeOH}$, applying a pressure of 1 bar in the CE device, until a stable baseline was achieved. Finally, the polymerized end of the capillary was cut at the desired length.

Polymers made of BMA were also assayed. The composition of the porogenic mixture was $75 / 25 \mathrm{w} / \mathrm{w}$, solvent/monomer with a monomer composition of 59.7/40/ 0.3 (BMA/ethylene glycol dimethacrylate/2-acryloylamido-2 methylpropanesulfonic acid) and that of the solvents of
10/62/28 (water/1-propanol/1,4-butanediol), with 1\% AIBN with respect to the monomers. This polymerization procedure is equivalent to the one described above but in this case the polymerization time was $1 \mathrm{~h}$.

\subsection{In-capillary SPE procedure}

A capillary of $75 \mu \mathrm{m} \times 50 \mathrm{~cm}$, with $5 \mathrm{~cm}$ of monolith sorbent at the inlet end was used. This end was joined to a piece of empty capillary with a length of $7.5 \mathrm{~cm}$, using a $1.5-\mathrm{cm}$ long $350 \mu \mathrm{m}$ i.d. Teflon tube to do so. All samples were filtered through nylon filters $(0.22 \mu \mathrm{m})$ to prevent obstruction of the monolithic sorbent. The process of retention, elution, and electrophoretic separation can be described in the following steps: (i) washing of the monolith with the separation medium ( 2 bar for $1 \mathrm{~min}$ ) and conditioning with water ( 2 bar for $1 \mathrm{~min}$ ); (ii) passing of the aqueous sample through the monolith at a pressure of 12 bar for 1-30 min; (iii) washing the capillary with UHQ water to eliminate the unbound sample and remove the ionic species present ( 2 bar over $1 \mathrm{~min}$ ); (iv) elution of the sample with BGE from the outlet to the inlet end of the capillary, applying a negative voltage of $-15 \mathrm{kV}$ until a current value of $70 \%$ of the maximum intensity is obtained. In this step, both the inlet and outlet vials contain BGE, used later for the electrophoretic separation, (v) reversal of the voltage to a positive value $(+30 \mathrm{kV})$ and electrophoretic separation takes place at the usual polarity (cathode at the outlet end).

\subsection{Analysis of natural waters}

The samples of drinking water were analysed without previous treatment. The river water samples were taken from the River Tormes in the city of Salamanca (Spain). All river water samples were filtered through sintered glass filters (No. 5) prior to analyses.

\section{Results and discussion}

\subsection{Electrophoretic separation of PMC and CBZ}

CZE in BGEs with high organic contents was assayed for the separation of PMC and CBZ. Preliminary experiments were carried out in $100 \% \mathrm{ACN}$ with $15 \mathrm{mM}$ perchloric acid as BGE. Under these conditions, the two carbamates should be in a cationic protonated form since they are both weak bases ( $\mathrm{p} K_{\mathrm{a}} 4.5$ and 4.2 for PMC and CBZ, respectively). By injecting a standard mixture of PMC and CBZ dissolved in BGE, a single electrophoretic peak was obtained. Individual injection of each standard analyte confirmed that both analytes co-migrated at the same time and hence their protonated cationic forms must exhibit electrophoretic mobilities of similar magnitude. A similar electropherogram was obtained when a much higher concentration of acetic 
acid (1 M) was employed instead of perchloric acid in the BGE. In this case, no differences in the electrophoretic signals of the pesticides were obtained either.

The addition of SDS to the BGE as an ion-pairing reagent was checked. This additive has previously been applied successfully for the electrophoretic separation of compounds that differ only slightly in their electrophoretic mobilities [34, 35]. Since the solubility of SDS in ACN is low, the addition of a small amount of water to the BGE allows larger amounts of SDS to be solubilized. Accordingly, it was decided to use $5 \% \mathrm{v} / \mathrm{v}$ of water in $\mathrm{ACN}$, always in the presence of $1 \mathrm{M}$ of acetic acid. When SDS was added to this BGE, two well-resolved peaks were obtained (Fig. 1A). The possibility of injecting aqueous samples directly into this BGE with a high organic content was also assayed. In this experiment, the peak corresponding to PMC showed a strong degree of peak compression, while that of CBZ eluted with normal efficiency (Fig. 1B). This type of behaviour occurred as long as the injection sample was essentially aqueous, but it disappeared when the proportion of $\mathrm{ACN}$ in the sample was $60 \% \mathrm{v} / \mathrm{v}$ or superior.

In the above BGE, the sharp peak was observed only for PMC. Different separation media were screened and the same effect was observed for CBZ when the BGE was ACN with $1 \mathrm{M}$ acetic acid and $5 \mathrm{mM}$ SDS (Fig. 1C). In this BGE, the EOF obtained was greater $\left(t_{\mathrm{EOF}} \approx 4.6 \mathrm{~min}\right)$ and the current intensity recorded was lower $(I \approx 8 \mu \mathrm{A})$ than that obtained with the previous BGE, with $5 \%$ water. Moreover, this current showed a more pronounced decrease during the electrophoretic separation, although it recovered the initial value after the appearance of the EOF signal (Fig. 1C). As in previous assays, the sharp peak for CBZ was observed only when aqueous samples were injected in the non-aqueous BGE.

The appearance of these sharp peaks seems to be related to the so-called "system peaks", which occur when there is coincidence in the migration of an analyte zone with a "system zone", a disturbance due to the introduction of a sample into the originally uniform composition of the BGE. Several authors have made detailed studies addressing the appearance of system peaks as a function of the composition (the number of co-ions) in the BGE used for CE separation $[36,37]$. When the mobility of a system zone is other than zero, in some electrolytic systems the zone can move along the separation channel and, on reaching the position of the detector, it can cause a system peak.

Although the presence of a system zone coinciding in mobility with the migration of an analyte generates these anomalous system peaks, it should be noted that the peaks obtained in the present work were extremely narrow (with a half-height peak width of $0.3-0.4 \mathrm{~s}$ ), unlike most system peaks reported in the literature, which appear broadened or distorted.

\subsubsection{The effect of water content of the separation medium}

The injection of aqueous blank samples in BGEs based on $\mathrm{ACN}$ with different water contents (range $0-8 \% \mathrm{v} / \mathrm{v}$ ) was checked (Fig. 2). In all cases, an extremely sharp baseline disturbance appeared, which moved to shorter migration times when the water content of the BGE was increased. For comparative purposes, electropherograms corresponding to the injection of an aqueous standard sample containing both carbamates are also depicted in Fig. 2. It may be seen that the appearance of narrow peaks occurred when the disturbance of the baseline coincided in time with the migration of the analyte. Thus, when BGE was $100 \%$ ACN, the disturbance coincided with the migration time of the CBZ peak. For water percentages in the $0-5 \% \mathrm{v} / \mathrm{v}$ range, the disturbance appeared between both analytes and did not affect either of them. As expected, a sharp peak for PMC was observed when the BGE was $5 \% \mathrm{v} / \mathrm{v}$ water in $\mathrm{ACN}$, but for water percentages above $6 \% \mathrm{v} / \mathrm{v}$ the baseline disturbance appeared at a time shorter than for PMC, and therefore this was not affected.

It is worth noting the small magnitude of the signal corresponding to the baseline disturbance and the fact that this signal decreased as the water content in the separation medium became higher. Moreover, it occurred within an extremely narrow time window.

\subsubsection{Behaviour of different analytes}

In order to check whether system peaks affected the separation of other analytes that can migrate in the separation medium, the behaviour of several analytes different in nature to PMC and CBZ was also evaluated. The analytes selected were two quaternary ammonium herbicides - diquat and paraquat - and three methylthiotriazine herbicides ametryn, prometryn, and terbutryn. Diquat and paraquat are doubly charged cations, such that they were expected to show elevated electrophoretic mobility. In the BGE with $5 \%$ water in $\mathrm{ACN}$, both migrated separately at times lower than $\mathrm{PMC}$, without undergoing any anomalous peak shape alteration (Fig. 3A). In the same medium, the methylthiotriazines (weak bases with $\mathrm{p} K_{\mathrm{s}}$ of about 4.5) migrated at times slightly higher than CBZ, although, like this latter, they did not undergo a compression effect in this medium either. When the BGE used was $100 \%$ ACN, the methylthiotriazines behaved like the CBZ, a single sharp peak being seen (Fig. 3B). This corresponded to the three triazines and CBZ, but with no separation (a complete loss of resolution). This type of behaviour is similar to that reported by Kenndler and co-workers [38, 39] for the electrophoretic separation of proteins with SDS in the sample zone, not in the BGE. Those authors suggested that the system was behaving as an unintentional-isotachophoresis system under conditions aimed at carrying out zone electrophoresis. They concluded that this effect was simply an artefact.

In light of the observed behaviour, it may be concluded that the most suitable BGE for the separation of PMC and CBZ is $2 \% \mathrm{v} / \mathrm{v}$ water in $\mathrm{ACN}$ with $1 \mathrm{M}$ acetic acid and $15 \mathrm{mM}$ SDS; in this medium, the perturbation due to the existence of system zones does not affect any of the analytes. 

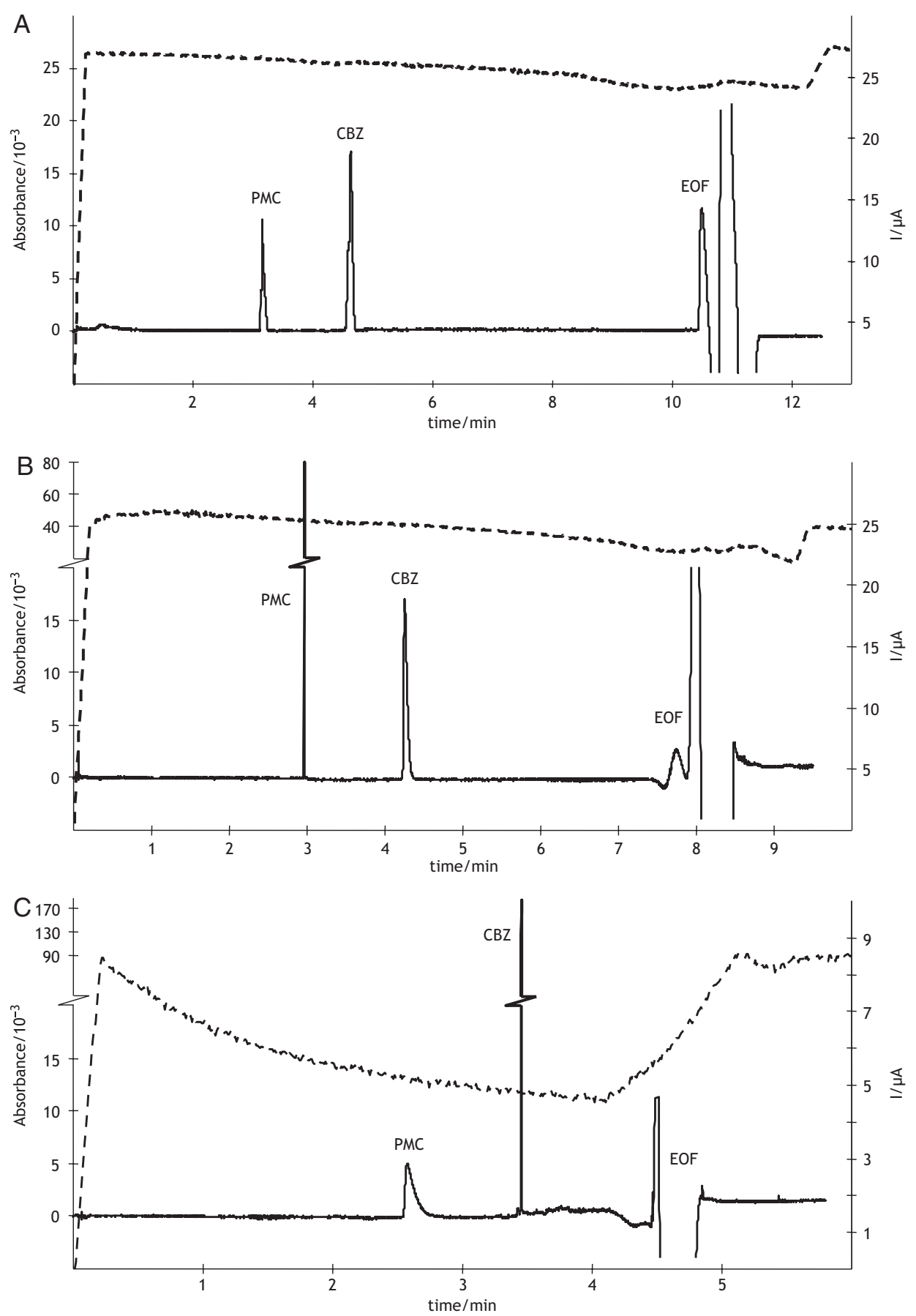

Figure 1. Separation of $P M C$ and $C B Z$ by CZE. BGEs used: (A) and (B) $5 \% \mathrm{v} / \mathrm{v}$ water in ACN with $1 \mathrm{M}$ acetic acid and $15 \mathrm{mM}$ SDS; (C) ACN with $1 \mathrm{M}$ acetic acid and $5 \mathrm{mM}$ SDS. Injected sample: carbamate pesticides dissolved in ACN (A) and dissolved in aqueous medium (B) and (C). Pesticide concentration, $10 \mathrm{mg} / \mathrm{L}$ each; detection at $220 \mathrm{~nm}$. 
Blank sample
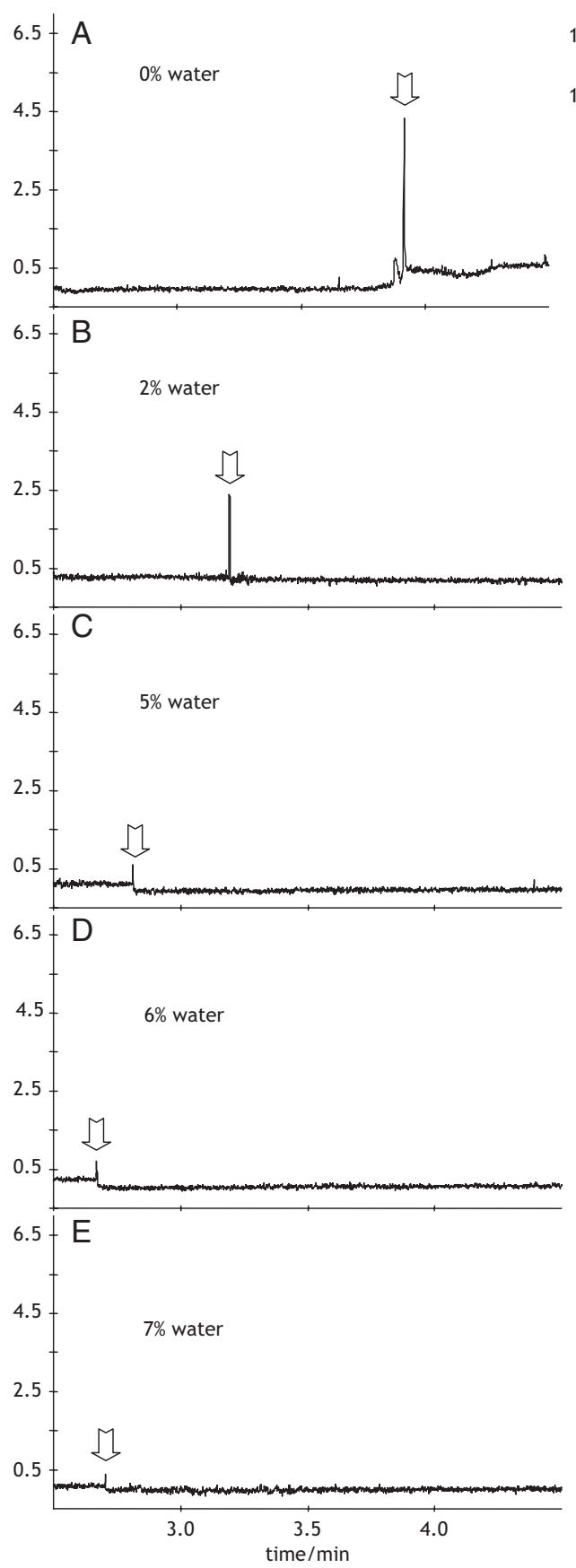

Pesticide sample
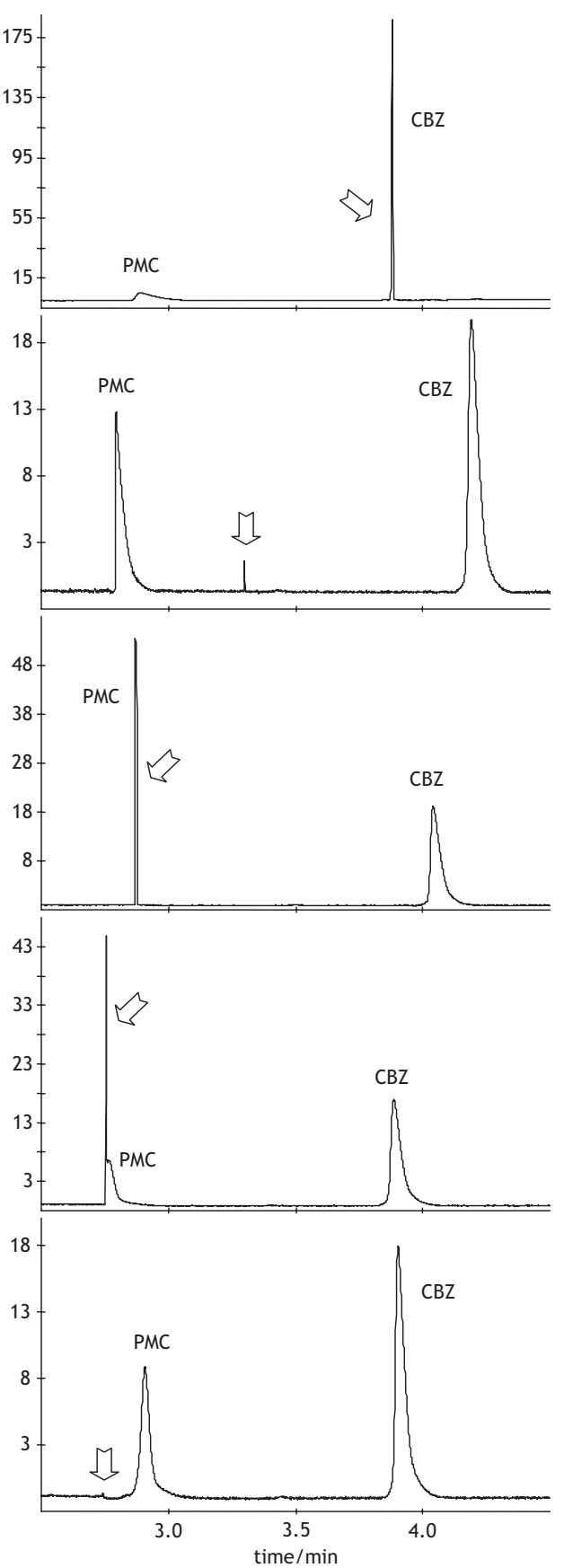

Figure 2. Influence of the content of water in $\mathrm{ACN}(\%, \mathrm{v} / \mathrm{v})$ in BGE. Injection of blank samples (left-hand side) and pesticide samples (right-hand side); arrows indicate the baseline disturbance. (A) $5 \mathrm{mM}$ SDS; (B)-(D) $15 \mathrm{mM}$ SDS were added to BGE. Pesticide concentration, $10 \mathrm{mg} / \mathrm{L}$ each; detection at $220 \mathrm{~nm}$. 

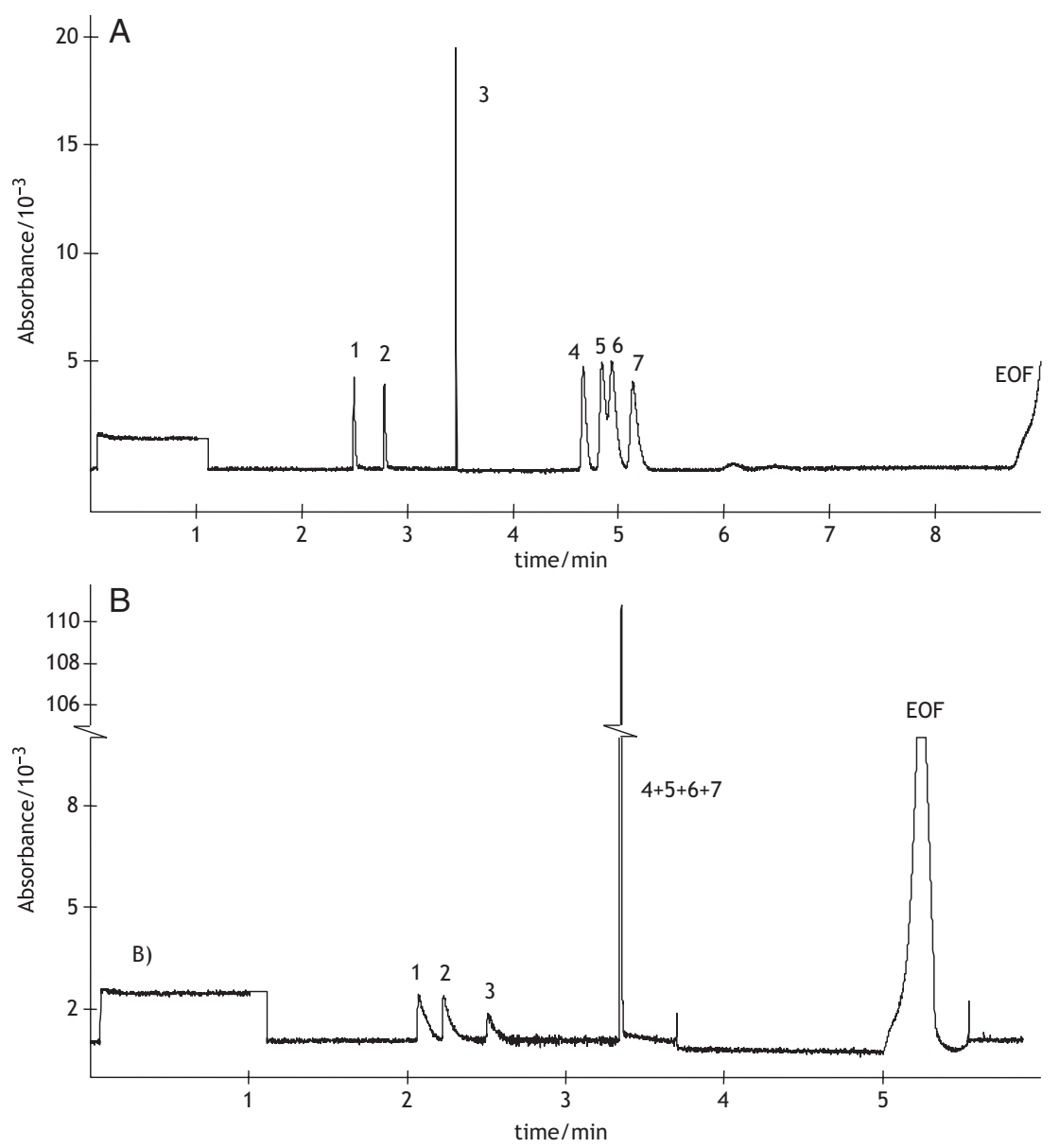

Figure 3. CZE separation of several charged analytes in different BGEs: (A) $5 \% \mathrm{v} / \mathrm{v}$ water in $\mathrm{ACN}$ with $1 \mathrm{M}$ acetic acid and $15 \mathrm{mM}$ SDS; (B) $100 \%$ $\mathrm{ACN}$ with $1 \mathrm{M}$ acetic acid and $5 \mathrm{mM}$ SDS. Signals: 1, Paraquat $(10 \mathrm{mg} / \mathrm{L})$; 2, Diquat $(10 \mathrm{mg} / \mathrm{L}) ; 3$, PMC $(10 \mathrm{mg} / \mathrm{L}) ; 4$, CBZ $(10 \mathrm{mg} / \mathrm{L}) ; \quad 5$, Ametryn $(20 \mathrm{mg} / \mathrm{L}) ; 6$, Prometryn $(20 \mathrm{~g} / \mathrm{L}) ; \quad 7$, Terbutryn $(20 \mathrm{mg} / \mathrm{L})$. Detection at $281 \mathrm{~nm}$.

\subsection{In-capillary SPE-CZE for PMC and CBZ}

With a view to increasing the sensitivity of the method, we developed a preconcentration step based on SPE prior to the electrophoretic separation. We employed monolithic polymers formed in situ within the capillary as a medium for sample preconcentration; thus, preconcentration and separation occurred in-line in the same capillary.

Initially, different assays were carried out previously in off-line mode, performing a preconcentration in monolithic capillaries with different polymeric materials; after the sample had been passed through the capillary, elution was carried out with $0.5 \mathrm{~mL}$ of $\mathrm{MeOH}$ and the extract thus obtained was injected into the electrophoretic system. In these assays, monoliths obtained from BMA and divinylbenzene monomers were compared. The results revealed that for the preconcentration of these analytes, the most suitable polymer was that obtained from divinylbenzene.
With these monoliths, higher sample flow rates were obtained and thus, for a fixed preconcentration time and applied pressure, the amount of sample loaded on the sorbent was higher than that loaded on BMA polymers. Under the same experimental conditions, divinylbenzene monoliths afforded 24-fold higher analytical signals than those obtained with BMA sorbents. These findings are in agreement with the fact that divinylbenzene polymers have a specific surface area greater than that of derivatives of acrylic acid and its esters [29]. Later studies were therefore performed with divinylbenzene monoliths.

Porous monolithic material was prepared from commercial divinylbenzene by in situ polymerization at the inlet end of a fused-silica capillary. For desorption of the analytes from the monolith and further electrophoretic separation, the procedure described in Section 2.4 was followed.

Assays were carried out with a 16-cm length of monolith sorbent synthesized in situ at the inlet end of the electro- 
phoretic capillary (total length of $58.5 \mathrm{~cm}$ and effective length of $50 \mathrm{~cm}$ ). A standard aqueous sample with both analytes $(0.1 \mathrm{mg} / \mathrm{L}$ each) was used to check the in-line SPE-CZE configuration. The sample was loaded through the capillary column by applying a pressure of 12 bar for $1 \mathrm{~min}$ and the elution of analytes from the sorbent and their further CZE separation were carried out with the same BGE. The electropherogram obtained showed broad peaks and the current was not very stable. These results suggested that the length of the polymer bed was excessively large, requiring a high volume of elution solvent to extract the compounds and thus affording broad signals with tails. Ensuing experiments aimed at achieving a sequential reduction in the length of the monolithic sorbent from 16 to $2 \mathrm{~cm}$; it was observed that $5 \mathrm{~cm}$ was an appropriate length, since, under these conditions well-defined electrophoretic peaks were obtained and the current was stable.

The most critical part of the in-line preconcentration procedure was to control the moment at which the transition between the desorption step and electrophoretic separation took place: the moment at which a change in the polarity of the voltage applied occurred. During the desorption step, it is necessary to ensure that the capillary will be filled with only one-column volume of BGE, since if the BGE volume is insufficient to fill the whole monolith bed, partial desorption of the retained analytes will occur; in contrast, if the filling volume, exceeds one capillary volume, there is a risk that the analytes will be discharged from the capillary at the inlet end.

Monitoring of the current passing through the circuit during the desorption step (when a negative voltage is being applied) affords a parameter that indicates when the capil- lary is filled with only one-column volume; at this time the analytes have been desorbed from the monolith and the voltage must be reversed to initiate their electrophoretic separation. Initially, the current recorded was very small because the capillary was full of water; then, it increased rapidly until a constant value was reached, indicating that the capillary was full of BGE. Thus, this recording allows it to be decided at what time the reversal in the polarity of the system should be performed, and hence the transition between the elution step (negative voltage) and the electrophoretic separation step (positive voltage).

Figure 4 shows the variation in the peak area of each analytes against the $i / i_{\max }$ ratio (expressed as \%), where the reference value of $i_{\max }$ was determined by applying $-15 \mathrm{kV}$ to a capillary filled with BGE. It may be seen that with $i / i_{\max }$ values lower than $20 \%$ the BGE has still not arrived at the monolith phase and hence the analytes have not been extracted from the sorbent. For $i / i_{\max }$ above $90 \%$, the peak areas decrease sharply because the analytes are expelled from the inlet end of the capillary. It may also be seen that the migration time of each analyte increases slightly, since the distance they have to run until they reach the detection window becomes slightly longer as migration begins at points increasingly closer to the inlet end. In light of the results observed, it was decided to reverse the polarity of the system and begin the electrophoretic separation at a current value of $70 \%$ with respect to $i_{\max }$ for which the highest peak area values were obtained. In any case, in order to avoid possible analyte losses through the inlet end of the capillary during the elution process, this end was coupled to a piece of empty capillary $(7.5 \mathrm{~cm}$ long) of the same i.d. by means of a $7.5-\mathrm{cm}$ long Teflon tube with an i.d. of $350 \mu \mathrm{m}$.

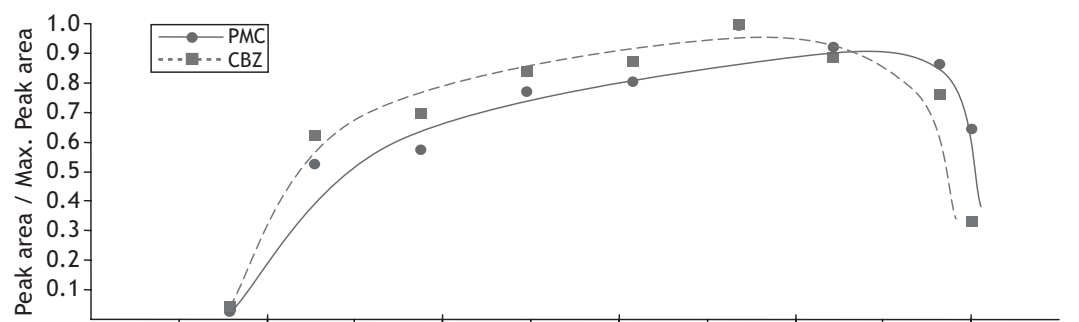

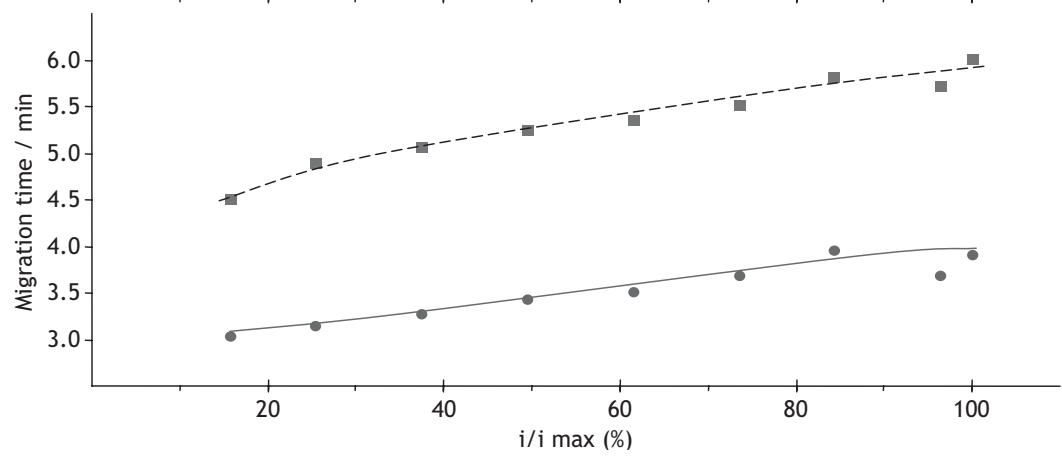

Figure 4. Variation in peak area and migration times as a function of the intensity selected to reverse the voltage (expressed as $i / i_{\max }$ ratio) and begin CZE separation under normal polarity (at $+30 \mathrm{kV}$ ). 
Figure 5 shows two electropherograms corresponding to a $1 \mathrm{mg} / \mathrm{L}$ sample injected hydrodynamically into the CZE system and a $1 \mu \mathrm{g} / \mathrm{L}$ sample preconcentrated according to the in-line SPE-CZE procedure for $15 \mathrm{~min}$ at $12 \mathrm{bar}$ in a capillary with $5 \mathrm{~cm}$ of monolithic sorbent. In order to compare the separation efficiency, the plate numbers $(N)$ were evaluated. Under conventional CZE conditions (Fig. 5B) the values obtained were $13.2 \times 10^{4}$ and $6.7 \times 10^{4}$ for PMC and CBZ, respectively. When the preconcentration process was performed with the in-line SPE-CZE system proposed here (Fig. 5A), the $N$ values were $12.7 \times 10^{4}$ and $4.7 \times 10^{4}$ for PMC and CBZ, respectively. These observations indicate that the separation efficiency is not substantially modified by the incorporation of the continuous monolithic bed into the electrophoretic capillary.

It should be mentioned that at all times it was possible to observe the existence of the system peak described above, which in this BGE appeared at migration times intermediate between those of the two analytes. It was also observed that the shape of the peaks corresponding to CBZ and PMC was sharp when the BGEs used were those described in Fig. 1.

The reproducibility and repeatability of the in-line preconcentration procedure was assessed by performing repeat analyses on the same day, using a polymerized capillary and a $1 \mu \mathrm{g} / \mathrm{mL}$ sample preconcentrated for 1 min (10 experiments), and on three consecutive days with three different capillaries (10 experiments on the

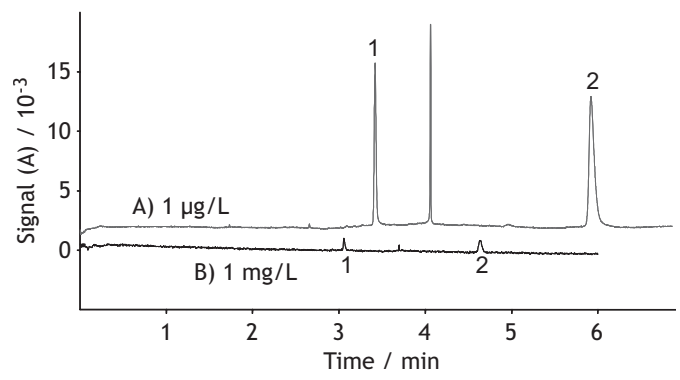

Figure 5. Electropherograms corresponding to: (A) in-line SPECZE applied to a standard carbamate sample at a concentration of $1 \mu \mathrm{g} / \mathrm{L}$ each, preconcentrated for $15 \mathrm{~min}$ at $12 \mathrm{bar}$; (B) CZE separation (without preconcentration) of a standard sample at $1 \mathrm{mg} / \mathrm{L}$ each, with direct hydrodynamic injection for $4 \mathrm{~s}$ at 25 mbar. first day; 6 experiments on each of the other two days; a total of 22 experiments) The precision obtained in the migration times and the corrected peak area had acceptable values (Table 1).

\subsection{Analytical characteristics of the in-capillary SPE-CZE method for the determination of PMC and $\mathrm{CBZ}$}

To check the ability of the sorbent to retain the analytes studied, preconcentration times ranking between 7 and $30 \mathrm{~min}$ were assayed, applying a pressure of $12 \mathrm{bar}$, for a sample with a concentration of $1 \mu \mathrm{g} / \mathrm{L}$ on a monolith sorbent $5 \mathrm{~cm}$ long. Although in the case of PMC no sorbent saturation was observed and the response obtained (peak area) was linear with the preconcentration time, for CBZ saturation was observed for $30 \mathrm{~min}$ of preconcentration. Accordingly, it was decided to use $15 \mathrm{~min}$ as the time suitable for the preconcentration of both analytes.

The analytical characteristics (precision, linear range, LODs) were determined (Table 2). It should be noted that within the concentration range assayed, $0.1-5 \mu \mathrm{g} / \mathrm{L}$, no saturation of the monolith sorbent was observed for a preconcentration time of $15 \mathrm{~min}$, and the calibration curves obtained showed good linearity.

The amount of sample preconcentrated in the in-line SPE-CZE system depends on the flow rate through the monolith bed and in turn this is related to the porosity obtained in the polymerization process. Control of the polymerization conditions guarantees acceptable reproducibility of the behaviour of the monolith. For $15 \mathrm{~min}$ preconcentration at $12 \mathrm{bar}$, with $5 \mathrm{~cm}$ of sorbent, the amount of sample loaded was $0.97 \mathrm{~g} \pm 0.09 \mathrm{~g}$ with two different capillaries (seven experiments in all). In all experiments performed, the real amount of sample loaded was determined by weighing the vial before and after the preconcentration process. Thus, the data provided in Table 2, corresponding to the in-line SPE-CZE system, are normalized for $1 \mathrm{~g}$ of preconcentrated sample.

Table 2 also shows a comparison with conventional CZE with hydrodynamic injection, performed with a capillary of the same dimensions. With the approach described here, sensitivity enhancement factors of $10^{4}$-fold in terms of the relationship between the slopes of the calibration lines under preconcentration and non-preconcentration

Table 1. Standard deviations (SD) of migration times and corrected peak areas for the in-line SPE-CZE method

\begin{tabular}{|c|c|c|c|c|}
\hline & \multicolumn{2}{|c|}{ Intra-day } & \multicolumn{2}{|c|}{ Inter-day $y^{b)}$} \\
\hline & Area $\pm S D / 10^{-3}$ & $t_{\text {migration }} \pm \mathrm{SD} / \mathrm{min}$ & Area $\pm S D / 10^{-3}$ & $t_{\text {migration }} \pm \mathrm{SD} / \mathrm{min}$ \\
\hline PMC & $0.39 \pm 0.04$ & $3.2 \pm 0.1$ & $0.36 \pm 0.05$ & $3.5 \pm 0.3$ \\
\hline CBZ & $0.63 \pm 0.07$ & $6.1 \pm 0.4$ & $0.67 \pm 0.08$ & $6.3 \pm 0.8$ \\
\hline
\end{tabular}

a) $n=10$, the same day with the same capillary.

b) $n=22,3$ days and 3 different capillaries. 
conditions were found for each of the analytes. LODs of $0.01 \mu \mathrm{g} / \mathrm{L}$ were obtained in a total analysis time of $30 \mathrm{~min}$.

The main advantage of the in-line configuration lies in the fact that the preconcentrated sample is transferred directly to the separation section of the capillary and no sample handling steps are involved in this transfer. Thus, in

Table 2. Analytical characteristics for CZE (without preconcentration) and in-line SPE-CZE conditions. BGE: $2 \% \mathrm{v} / \mathrm{v}$ water in ACN with $1 \mathrm{M}$ acetic acid and $15 \mathrm{mM}$ SDS. Amount of sample preconcentrated: $1 \mathrm{~g}$

\begin{tabular}{|c|c|c|}
\hline & $\operatorname{PMC}(\lambda=240 \mathrm{~nm})$ & $\operatorname{CBZ}(\lambda=220 \mathrm{~nm})$ \\
\hline \multicolumn{3}{|l|}{ CZE } \\
\hline Linearity (mg/L) & $1-20$ & \\
\hline \multicolumn{3}{|l|}{ Calibration curve $^{\text {a) }}$} \\
\hline Slope $(A U \mu g / L)$ & $(7.11 \pm 0.08) \times 10^{-9}$ & $(11.0 \pm 0.2) \times 10^{-9}$ \\
\hline Intercept (AU) & $(-1.8 \pm 0.6) \times 10^{-6}$ & $(-2.3 \pm 0.1) \times 10^{-6}$ \\
\hline$R^{2}$ & 0.9997 & 0.9995 \\
\hline $\operatorname{RSD}(\%)^{b)}$ & 6.0 & 5.1 \\
\hline LODs $(\mathrm{mg} / \mathrm{L})^{\mathrm{c})}$ & 0.10 & 0.19 \\
\hline \multicolumn{3}{|l|}{$S P E-C Z E$} \\
\hline Linearity ( $\mu \mathrm{g} / \mathrm{L})$ & $0.1-5$ & \\
\hline \multicolumn{3}{|l|}{ Calibration curve $\mathrm{e}^{\mathrm{a})}$} \\
\hline Slope $(A U / \mu g / L)$ & $(77 \pm 6) \times 10^{-6}$ & $(124 \pm 7) \times 10^{-6}$ \\
\hline Intercept (AU) & $(-1 \pm 14) \times 10^{-6}$ & $(-7 \pm 18) \times 10^{-6}$ \\
\hline$R^{2}$ & 0.9981 & 0.9993 \\
\hline $\operatorname{RSD}(\%)^{\mathrm{d})}$ & $12.5 \%$ & $6.3 \%$ \\
\hline LODs $(\mu \mathrm{g} / \mathrm{L})^{c)}$ & 0.01 & 0.01 \\
\hline \multicolumn{3}{|c|}{ Sensitivity enhancement ${ }^{\mathrm{e})}$} \\
\hline$m_{\mathrm{SPE}-\mathrm{CZE}} / m_{\mathrm{CZE}}$ & $13.6 \times 10^{3}$ & $7.8 \times 10^{3}$ \\
\hline
\end{tabular}

a) Corrected peak area (absorbance units, AU) versus concentration $(\mu \mathrm{g} / \mathrm{L})$ of the analyte.

b) RSD, relative standard deviation for consecutive measurements $(n=8)$ at $10.9 \mathrm{mg} / \mathrm{L}$ for PMC and $11.6 \mathrm{mg} / \mathrm{L}$ for CBZ (at a concentration level of $10 \mathrm{mg} / \mathrm{L}$ ).

c) LODs, limits of detection for a signal-to-noise ratio of 3 .

d) RSD, relative standard deviation at a concentration level of $0.5 \mu \mathrm{g} / \mathrm{L}$ for two consecutive days and with two different capillaries (total experiments $n=7$ ).

e) Slope ratio for peak height calibration curves. the method proposed here, analyte retention, desorption, separation, and quantification can be accomplished automatically. Table 3 shows a comparison of the enrichment factors obtained with different SPE-CE systems reported in the literature.

\subsection{Application to natural water samples}

The in-capillary SPE-CZE method was applied to the analysis of natural water samples: tap and river water. The presence of the pesticides was not detected in the samples analysed and hence they were spiked with different amounts of the analytes. Figure 6A shows the electropherogram obtained on analysing drinking water spiked at $0.1 \mu \mathrm{g} / \mathrm{L}$ : the level established by European legislation as the maximum limit permitted for individual pesticides in drinking water. Figure 6B shows the electropherograms obtained when the same procedure was applied to a river water sample spiked at a level five times higher: $0.5 \mu \mathrm{g} / \mathrm{L}$. For river water, the relationships between the slopes of the calibration lines under preconcentration and non-preconcentration conditions $\left(m_{\mathrm{SPE}-\mathrm{CZE}} / m_{\mathrm{CZE}}\right)$ were $2.1 \times 10^{3}$ and $3.8 \times 10^{2}$ for PMC and CBZ, respectively. Thus, a sevenfold reduction in the sensitivity enhancement factor was observed for PMC, while in the case of CBZ the decrease in that factor was 20-fold. It may be seen that in these matrices there was a clear matrix effect, which was more marked for CBZ.

Upon analysing tap water, it was observed that the monolithic columns could be used 10-12 times with no loss of precision in the analytical signal. In contrast, on analysing river water samples a darkening of the inlet end of the capillary was observed after 4-5 samples had been assayed. This phenomenon leads to a decrease in the flow of sample passing through the capillary and hence in the analytical signal. Reproducible results were obtained by making the cut at approximately $1 \mathrm{~mm}$ of the sorbent. Cutting the capillary rectifies the loss of flow and the capillary can be used again. Another way of prolonging the useful life of the capillary would be to treat the river water samples prior to their introduction into the system.

Table 3. Comparison of the characteristics of several SPE-CE methods described in the literature

\begin{tabular}{lllll}
\hline Sorbent & Analyte & Preconcentration time (min) & Enrichment factor & Reference \\
\hline $\mathrm{C}_{18}$ & $\begin{array}{l}\text { Progesterone, } \beta \text {-estradiol } \\
\text { Chlorophenols (two) }\end{array}$ & - & $>600$ & {$[20]$} \\
& Opioid peptides (six) & 100 & 4000 & {$[21]$} \\
& & $100-10000$ & {$[25]$} \\
Polymeric monoliths & Amino acids & 20 & 300 & {$[31]$} \\
& Antidepressants (three) & - & 500 & {$[32]$} \\
& Dopamine, epinephrine & 10 & 462 & {$[33]$} \\
& PMC & 15 & $13600(2100)^{\text {a) }}$ & This work \\
& CBZ & & $7800(380)^{\text {a) }}$ & \\
\end{tabular}

a) Values obtained for river waters. 


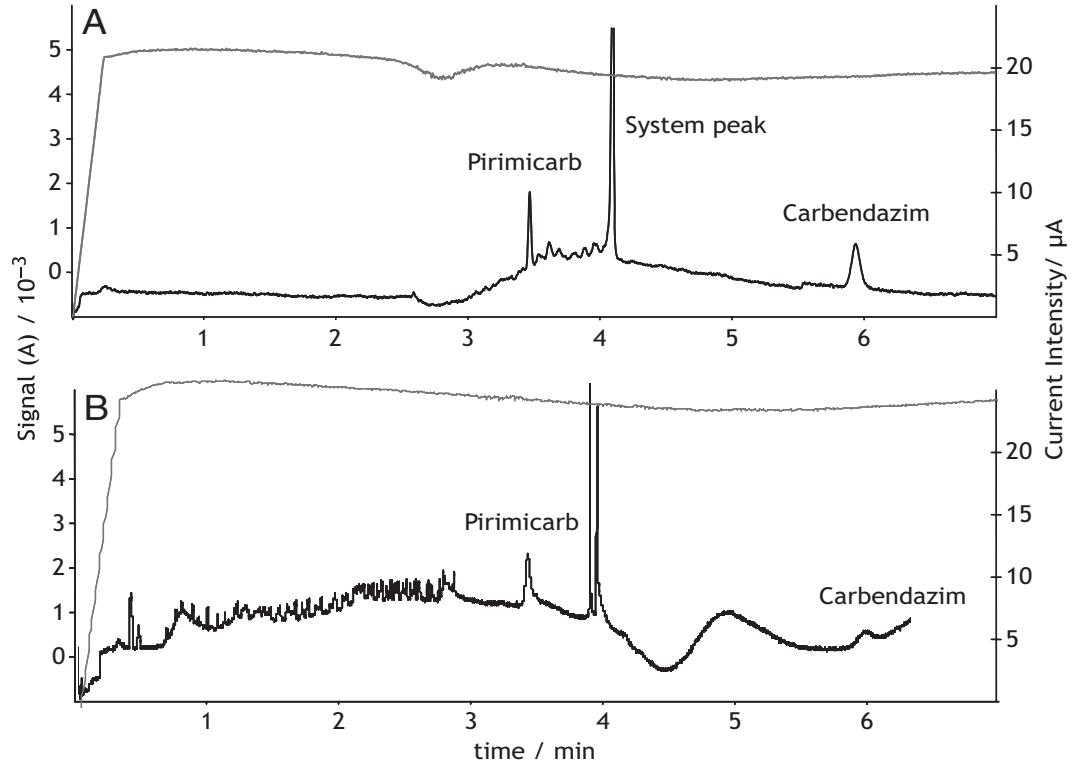

Figure 6. Electropherograms corresponding to the in-line SPE-CZE system applied to natural waters: (A) tap water at a concentration of $0.1 \mu \mathrm{g} / \mathrm{L}$ each and (B) river water at $0.5 \mu \mathrm{g} / \mathrm{L}$.

\section{Concluding remarks}

CZE has been explored in media with high organic contents explored within the context of the separation of two carbamate derivatives used as pesticides: PMC and CBZ. Very sharp peaks were observed when aqueous samples were injected into the highly organic electrophoretic medium. Although such peaks are not fully understood, they seem to be related to the development of system zones that are induced in the separation medium during the electrophoretic run. The perturbation due to the existence of system zones does not affect any of the analytes when BGE was $2 \% \mathrm{v} / \mathrm{v}$ water in $\mathrm{ACN}$ with $1 \mathrm{M}$ acetic acid and $15 \mathrm{mM}$ SDS.

A sensitive method based on in-line preconcentration SPE followed by CZE has been developed for the analysis of these carbamate herbicides. Monolith polymers obtained from divinylbenzene monomers were found to be more suitable for the preconcentration of these analytes than those obtained from BMA. A monolithic bed of $5 \mathrm{~cm}$ length, formed in situ at the inlet end of the electrophoretic capillary, allowed preconcentration of the QJ;target analytes from aqueous samples; the analytes retained could be eluted directly in the separation capillary with no intermediate step. The incorporation of the continuous monolithic bed into the electrophoretic capillary did not have a significant effect on separation efficiency, and the peak shape and separation resolution of the pesticides were similar to those obtained with conventional CZE. The main feature of the in-capillary SPE-CZE method developed here is that it allows rapid and easy determination of these pesticides in drinking waters in accordance with current legislation.

This work was supported by the MEC (Project CTQ-200500292) and by the Junta de Castilla y León (Project SA007A05).

The authors have declared no conflict of interest.

\section{References}

[1] US EPA method 8318A, N-Methylcarbamates by highperformance liquid chromatography, Rev. 12007.

[2] Arráez-Román, D., Segura-Carretero, A., Cruces-Blanco, C., Fernández-Gutiérrez, A., Pest Manag. Sci. 2004, 60, 675-679.

[3] Molina, M., Wiedmer, S. K., Jussila, M., Silva, M., Riekkola, M.-L., J. Chromatogr. A. 2001, 927, 191-202.

[4] Kaltsonoudis, C. K., Lamari, F. N., Prousalis, K. P., Karamanos, N. K., Tsegenidis, T., Chromatographia 2003, 57, 181-184.

[5] García, A. J., Font, G., Picó, Y., Electrophoresis 2005, 26, 1550-1561.

[6] Timerbaev, A. R., Hirokawa, T., Electrophoresis 2006, 27, 323-340.

[7] Malá, Z., Krivánková, L., Gebauer, P., Boček, P., Electrophoresis 2007, 28, 243-253.

[8] Psilakis, E., Kalogerakis, N., Trends Analyt. Chem. 2003, 22, 565-574. 
[9] Lambropoulou, D. A., Albanis, T. A., J. Biochem. Biophys. Methods 2007, 70, 195-228.

[10] Fang, H., Liu, M., Zeng, Z., Talanta 2006, 68, 979-986.

[11] Hernández-Borges, J., Rodríguez-Delgado, M. A., García-Montelongo, F. J., Cifuentes, A., Electrophoresis 2004, 25, 2065-2076.

[12] Hernández-Borges, J., Cifuentes, A., García-Montelongo, F. J., Rodríguez-Delgado, M. A., Electrophoresis 2005, 26, 980-989.

[13] Ravelo-Pérez, L. M., Hernández-Borges, J., BorgesMiquel, T. M., Rodríguez-Delgado, M. A., J. Chromatogr. A 2008, 1185, 151-154.

[14] Guzman, N. A., Electrophoresis 2003, 24, 3718-3727.

[15] Santos, B., Simonet, B. M., Rios, A., Valcárcel, M., Electrophoresis 2007, 28, 1312-1318.

[16] Veraart, J. R., Lingeman, H., Brinkman, U. A. Th., J. Chromatogr. A 1999, 856, 483-514.

[17] Puig, P., Borrull, F., Calull, M., Aguilar, C., Trends Analyt. Chem. 2007, 26, 664-678.

[18] Saavedra, L., Barbas, C., J. Biochem. Biophys. Methods 2007, 70, 289-297.

[19] Baryla, N. E., Toltl, N. P., Analyst 2003, 128, 1009-1012.

[20] Xie, R., Oleschuk, R., Electrophoresis 2005, 26, 4225-4234.

[21] Zhang, L.-H., Zhang, Ch.-J., Chen, X., Feng, Y.-Q., Wu, X.-Z., Electrophoresis 2006, 27, 3224-3232.

[22] Knudsen, C. B., Beattie, J. H., J. Chromatogr. A 1997, 792, 463-473.

[23] Ping, G., Zhang, Y., Zhang, W., Zhang, L. et al., Electrophoresis 2004, 25, 421-427.

[24] Saavedra, L., Maeso, N., Cifuentes, A., Barbas, C., J. Pharm. Biomed. Anal. 2007, 44, 471-476.
[25] Hernández, E., Benavente, F., Sanz-Nebot, V., Barbosa, J., Electrophoresis 2007, 28, 3957-3965.

[26] Wolfe, K. A., Breadmore, M. C., Ferrance, J. P., Power, M. E. et al., Electrophoresis 2002, 23, 727-733.

[27] Xie, S., Svec, F., Fréchet, J. M. J., Chem. Mater. 1998, 10, 4072-4078.

[28] Gusev, I., Huang, X., Horváth, C., J. Chromatogr. A 1999, 855, 273-290.

[29] Svec, F., J. Chromatogr. B 2006, 841, 52-64.

[30] Armenta, J. M., Gu, B., Humble, P. H., Thulin, C. D., Lee, M. L., J. Chromatogr. A 2005, 1097, 171-178.

[31] Breadmore, M. C., Anal. Chim. Acta 2006, 556, 121-126.

[32] Schaller, D., Hilder, E. F., Haddad, P. R., Anal. Chim. Acta 2006, 556, 104-111.

[33] Thabano, J. R. E., Breadmore, M. C., Hutchinson, J. P., Johns, C., Haddad, P. R., J. Chromatogr. A 2007, 1175, 117-126.

[34] Carabias-Martínez, R., Rodríguez-Gonzalo, E., Domínguez-Álvarez, J., Hernández-Méndez, J., Anal. Chem. 1997, 69, 4437-4444.

[35] Carabias-Martínez, R., Rodríguez-Gonzalo, E., Domínguez-Álvarez, J., Hernández-Méndez, J., Electrophoresis 2002, 23, 494-501.

[36] Beckers, J., Boček, P., Electrophoresis 1999, 20, 518-524.

[37] Gas, B., Hruska, V., Dittman, M., Bek, F., Witt, K., J. Sep. Sci. 2007, 30, 1435-1445.

[38] Kenndler, E., Schmith-Beiwl, K., J. Chromatogr. A 1992 545, 397-402.

[39] Kremser, L., Bilek, G., Kenndler, E., Electrophoresis 2007, 28, 3684-3690. 
From: elpho@wiley-vch.de

To: erg@usal.es

Cc:

Subject: ELECTROPHORESIS - Decision on Manuscript \# elps-2008-00699.R1

Body:

08-Jan-2009

Dear Dr. Rodriguez-Gonzalo,

I am pleased to inform you that your manuscript, "In-capillary microextraction using monolithic polymers. Application to preconcentration of carbamate pesticides prior to their separation by micellar electrokinetic capillary chromatography.", is now acceptable for publication in ELECTROPHORESIS.

With the acceptance of your manuscript the final uploaded version in MS-Central will be used for copy-editing and the subsequent production process, so please do not send a new text file.

Please find below a list of required material for production:

- $\quad$ Please complete and return the attached "Copyright Transfer Agreement" and the "Color and Page Charge Agreement". Note: even if you do not wish to have any figures printed in color, we require this form to be completed to cover any page charges that might accrue (see Instructions to Authors on the journal homepage).

- If you would like to submit any color illustration as potential cover artwork (free of charge) please feel free to do so.

- Any permission statements, where applicable.

Please send this material to the Managing Editor at:

Fax: 6201-606-172

E-mail: elpho@wiley-vch.de

After we have received this material, your paper will go into production and you will receive a galley proof by e-mail in due course. Once you have corrected the proof, the paper will then be published on-line via Wiley InterScience ahead of its appearance in the printed journal.

Thank you for supporting ELECTROPHORESIS. I look forward to seeing more of your work in the future.

Sincerely,

Prof. Ziad El Rassi

Editor-in-Chief, ELECTROPHORESIS 


\section{(1) ELECTROPHORESIS}

In-capillary microextraction using monolithic polymers. Application to preconcentration of carbamate pesticides prior to their separation by micellar electrokinetic capillary chromatography.

\begin{tabular}{|r|l|}
\hline Journal: & Electrophoresis \\
\hline Manuscript ID: & elps-2008-00699 \\
\hline Wiley - Manuscript type: & Research Paper \\
\hline Author: & 28-Oct-2008 \\
\hline Complete List of Authors: & $\begin{array}{l}\text { Rodriguez-Gonzalo, Encarnacion; Universidad de Salamanca, } \\
\text { Quimica Analitica, Nutricion y Bromatologia } \\
\text { Ruano Miguel, L.; Universidad de Salamanca, Química Analítica, } \\
\text { Nutrición y Bromatología } \\
\text { Carabias-Martínez, Rita; Universidad de Salamanca, Química } \\
\text { Analítica, Nutrición y Bromatología }\end{array}$ \\
\hline Keywords: & $\begin{array}{l}\text { MEKC, in-capillary microextraction, monolithic polymers, carbamate } \\
\text { pesticides }\end{array}$ \\
\hline &
\end{tabular}

\section{s scholarONE" \\ Manuscript Central}




\section{In-capillary microextraction using monolithic polymers.}

\section{Application to preconcentration of carbamate pesticides prior to their separation by micellar electrokinetic capillary chromatography.}

Abbreviations: MTM, Metomyl; ASL, Asulam; CBZ, Carbendazim; ADC, Aldicarb; CBM, Carbetamide; PPX, Propoxur; PMC, Pirimicarb; CBR, Carbaryl; CBF; Carbofuran, MTC, Methiocarb; ASO, Aldicarb sulphoxide; IPP, 2-isopropoxyphenol; NAP, $\alpha$-naphthol; $\gamma$-MAPS, $\gamma$ methacryloxypropyltrimethoxysilane; AMPS, 2-acryloylamido-2-methylpropanesulfonic acid;

Keywords: micellar electrokinetic capillary chromatography, in-capillary microextraction; monolithic polymers, carbamate pesticide. 


\begin{abstract}
In the present work we report a novel procedure for in-capillary microextraction using a monolithic polymeric sorbent. In the proposed methodology, sample treatment takes place in the CE instrument but in a different capillary from that used for the electrophoretic separation. The sorbent employed was a poly(ethylvinylbenzene-divinylbenzene) monolithic polymer formed in situ inside the capillary $(16 \mathrm{~cm} \times 100 \mu \mathrm{m} \mathrm{ID})$. The usefulness of the proposed procedure was checked for the determination of carbamate pesticides (Metomyl, Asulam, Carbendazim, Aldicarb, Carbetamide, Propoxur, Pirimicarb, Carbaryl, Carbofuran and Methiocarb) and three of their degradation compounds (Aldicarb sulphoxide, 2-isopropoxyphenol and $\alpha$-naphthol) using micellar electrokinetic chromatography (MEKC). The optimisation of the MEKC is reported, a good separation of the 13 analytes being obtained in less than $6 \mathrm{~min}$. The analytical method using in-capillary microextraction was validated in terms of linearity, repeatability, precision (RSD $\leq 18 \%$ for $50 \mu \mathrm{g} / \mathrm{L}$ ), and LODs (1$16 \mu \mathrm{g} / \mathrm{L}$ ), and it revealed the usefulness of this in-capillary preconcentration procedure for the determination of analytes of intermediate polarity.
\end{abstract}




\section{Introduction}

CE techniques usually suffer from poor sensitivity, especially when spectrophotometric detection is carried out. To improve their limited sensitivity, different strategies have been developed. Besides approaches based on concentrating analytes by modifications of their electrophoretic mobility (stacking, sweeping, isotachophoresis, etc [1-4]), owing to its high concentration factors and versatility SPE is probably the technique most widely used.

Given the characteristics of CE instruments, full automatic coupling of the SPE step to the separation step is not easy and often requires the use of complex interfaces. There are different ways in which SPE can be integrated with CE: namely, at-, on-, and in-line [5, 6].

Ideal coupling is achieved with in-line approaches, where the preconcentration sorbent (a monolithic polymer or packed beads) is placed directly inside the electrophoretic separation capillary and once preconcentration has been performed the sample eluted is subjected to electrophoretic separation. Even though in recent years several authors [7-12] have addressed inline SPE-CE, to our knowledge none of them have employed MEKC as the separation mode owing to the destruction of the micellar media in the organic solvents commonly employed to elute the analytes.

At-line coupling of SPE and CE involves interfaces in which an empty vial is filled with a fraction of the eluate from the SPE step containing the analytes, either by means of a robotic arm, or a replenishment device $[13,14]$, and it usually requires a relatively high amount of sample. On-line coupling involves a physical connection and continuity between the effluent from the SPE column and the separation capillary and does allow the preconcentration of microsamples. However, this latter kind of coupling necessitates rather complex interfaces, including valves [15], FIA systems [16] or T-splits [17].

Although several materials have been employed as sorbents in the coupling of SPE to CE, those based on $\mathrm{C}_{18}$ silica are the most widely used. Monolithic preconcentration columns have not yet found widespread use in on- and at-line approaches. Furthermore, in most of the SPE-CE systems proposed in the literature, CZE has been used for the electrophoretic separation of analytes eluted from SPE sorbents; this is because of the requirement that the solvent used in the elution step must be compatible with the electrophoretic media used for the further separation. Other modes of $\mathrm{CE}_{2}$ such as MEKC, have been little used in SPE-CE couplings because the elution solvents may not be compatible with the micellar media employed in MEKC.

Carbamate pesticides are derived from carbamic acid and are widely used as insecticides, although also as fungicides, herbicides and nematocides. Their main characteristics are their high 
acute toxicity and their elevated polarity and solubility in water. HPLC methods are preferred over GC methods for the analysis of carbamate pesticides owing to their thermal lability [18, 19]. Electrophoretic techniques offer an alternative to chromatographic methods and, since most carbamate pesticides are neutral, MEKC is the most frequently described electrophoretic technique employed for their analysis [20-25].

In this paper we propose a new way of carrying out sample enrichment that is compatible with coupling to MEKC. The approach reported involves a microextraction step on a monolithic polymeric sorbent synthesised in a silica capillary. Sample enrichment is performed by using the $\mathrm{CE}$ instrument. After the sample has been loaded onto the sorbent, elution with methanol is performed into an empty vial. When the microextraction step has finished, the preconcentration capillary cartridge is then replaced by the separation cartridge, and CE is performed by injecting the eluate collected in the elution step. This mode allows the preconcentration of samples of small volume ( $250 \mu \mathrm{L}$ in the optimum approach). In the present work, the application of this in-capillary microextraction to the preconcentration of carbamate pesticides prior to their separation by MEKC was investigated. Different monomers were assayed and the performance and the effectiveness of the polymeric bed were investigated in terms of length and sample flow rate. The analytical characteristics of the method were assessed and the preconcentration factors were calculated.

\section{Material and methods}

\subsection{Reagents and chemicals}

The pesticides were purchased from Riedel-de Haën (Seelze-Hannover, Germany) and were used without further purification (minimum purity greater than 98\%). The pesticides were as follows: Metomyl (MTM, CAS RN 16752-77-5), Asulam (ASL, CAS RN 3337-71-1), Carbendazim (CBZ, CAS RN 10605-21-7), Aldicarb (ADC, CAS RN 116-06-3), Carbetamide (CBM, CAS RN 16118-49-3), Propoxur (PPX, CAS RN 114-26-1), Pirimicarb (PMC, CAS RN 23103-98-2), Carbaryl (CBR, CAS RN 63-25-2), Carbofuran (CBF, CAS RN 1563-66-2) and Methiocarb (MTC, CAS RN 2032-65-7), and three of their degradation compounds Aldicarb sulphoxide (ASO, CAS RN 1646-87-3), 2-isopropoxyphenol (IPP, CAS RN 4812-20-8), and $\alpha$ naphthol (NAP, CAS RN 90-15-3). Standard stock solutions of the pesticides (200 $\mathrm{mg} \mathrm{L}^{-1}$ ) were prepared by weighing and dissolving the compounds in methanol. These stock solutions were stored at $4{ }^{\circ} \mathrm{C}$ and suitably diluted when needed to obtain the working standard solutions.

The reagents used for the synthesis of the monolithic polymer were as follows: divinylbenzene (DVB, technical, 80\%), butyl methacrylate (BMA, 99\%), ethylene glycol dimethacrylate (EGDMA, 
98\%) were purchased from Sigma-Aldrich (Madrid, Spain); 2,2'-azobis(2-methyl-propionitrile) (AIBN), used as initiator, was obtained from Acros Organics (Geel, Belgium). $\gamma$ methacryloxypropyltrimethoxysilane ( $\gamma$-MAPS, 98\%) used for derivatizing the capillary was from Sigma. 1-octanol, 1-propanol and 1,4-butanediol (reagent grade, min 99\%) and 2-acryloylamido-2methylpropanesulfonic acid (AMPS, 98\%) were purchased from Fluka (Sigma-Aldrich).

SDS was purchased from Fluka. HPLC-grade Organic solvents (methanol and acetonitrile) were from Merck (Darmstadt, Germany). Water was obtained using an Elgastat UHQ purification system. The other chemicals were all of analytical reagent grade and were obtained from Scharlau (Barcelona, Spain).

\subsection{Instruments}

All CE experiments were routinely carried out using a Hewlett-Packard $\mathrm{HP}^{3 \mathrm{D}} \mathrm{CE}$ instrument equipped with a UV-visible DAD and an air-cooled oven compartment supplied by Agilent (Waldbronn, Germany).

Fused-silica capillaries (75, 100, 200 and $400 \mu \mathrm{m}$ ID) from Polymicro Technologies (Phoenix, AZ, USA) supplied by Composite Metal Services Ltd (West Yorkshire, UK) were used.

An immersion thermostat as well as common laboratory equipment —automatic pipettes, ultrasound bath, consumables, etc- - were employed for the polymerisation of the sorbents.

Design-Expert, version 7.0.0 of Stat Ease, Inc., was employed for the optimisation of the separation by MEKC.

\subsection{Procedures}

\subsubsection{MEKC separation}

Separations were performed in $75 \mu \mathrm{m}$ ID capillaries of $58.5 \mathrm{~cm}$ total length and $50 \mathrm{~cm}$ effective length. All new separation capillaries were conditioned before use. They were flushed at 1 bar for $20 \mathrm{~min}$ with $0.1 \mathrm{M} \mathrm{NaOH}$, and then for $10 \mathrm{~min}$ with separation medium, followed by application of $30 \mathrm{kV}$ for 2 min to check current stability. This procedure was also applied as a daily start-up protocol.

The separation medium used was an aqueous solution of $60 \mathrm{mM}$ SDS and $5 \mathrm{mM}$ sodium tetraborate (borate buffer concentration: $20 \mathrm{mM}$ ). All separations were carried out at $30 \mathrm{kV}$ and $30{ }^{\circ} \mathrm{C}$. Injections were performed hydrodynamically ( $25 \mathrm{mbar}$ for $4 \mathrm{~s}$ ). The samples injected for the optimisation of MEKC separation were aqueous samples with residual methanol from the dilution

$$
\begin{gathered}
5 \\
\text { Wiley-VCH }
\end{gathered}
$$


of the stock solutions. In the procedure for the in-capillary microextraction, the samples injected were hydroalcoholic since they contained the methanol used in the elution step and the water present in the capillary. Analysis time was $6 \mathrm{~min}$, followed by a 2 min rinsing step with fresh separation medium.

The detection wavelengths chosen were as follows: $200 \mathrm{~nm}$ for ADC, ASO, IPP, CBM, NAP, PPX, MTC and CBF; $234 \mathrm{~nm}$ for MTM; $284 \mathrm{~nm}$ for CBZ; $255 \mathrm{~nm}$ for ASL; $222 \mathrm{~nm}$ for CBR; and $246 \mathrm{~nm}$ for PMC. UV spectra obtained from the electropherogram were stored for confirmation purposes.

\subsubsection{Preparation of the monolithic polymeric sorbents $\underline{\text { Inner wall derivatisation }}$}

The inner wall of the capillary must be treated with the bifunctional coupling agent $\gamma$-MAPS, which reacts with the silanol of the inner wall of the capillary and also provides grafting of the anchor sites of the polymer to the silica surface. $\gamma$-MAPS was applied as follows: $3 \mathrm{~m}$ long capillaries were flushed in the $\mathrm{CE}$ instrument at 4 bar with $1 \mathrm{M} \mathrm{NaOH}$ for $10 \mathrm{~min}$, water for $10 \mathrm{~min}$, $0.1 \mathrm{M} \mathrm{HCl}$ for $10 \mathrm{~min}$, again with water for $10 \mathrm{~min}$, and finally with acetone for $10 \mathrm{~min}$. The capillary was dried with air from an empty vial for $5 \mathrm{~min}$, after which a solution of $\gamma$-MAPS/acetone $(2 / 8, \mathrm{v} / \mathrm{v})$ was passed through the system for $15 \mathrm{~min}$. The capillary was left overnight at room temperature and then treated with acetone $(10 \mathrm{~min})$, water $(10 \mathrm{~min})$ and air $(10 \mathrm{~min})$, all at 4 bar. Capillaries treated in this way were sealed with silicone septa and stored until required.

\section{Polymerisation}

Divinylbenzene and 1-octanol at a proportion of 75/25 (w/w) were weighed in a vial together with the AIBN initiator at a proportion of $1 \%(\mathrm{w} / \mathrm{w})$ with respect to the monomers. The solution was placed in an ultrasound bath for 15 min to dissolve the AIBN and degas the solution. By means of a syringe, the desired length of a treated capillary was filled and both ends were sealed with two silicone septa. The capillary was placed in a water bath at $60{ }^{\circ} \mathrm{C}$ for $16 \mathrm{~h}$. The polymerised capillary was cooled with water and a detection window was made at $8.5 \mathrm{~cm}$ from the empty end. The capillary was then washed with methanol, applying a pressure of 1 bar in the CE device, until a stable baseline was achieved. Finally, the polymerised end of the capillary was cut to the desired length. 
Polymers made of butyl methacrylate were also assayed. The composition of the porogenic mixture was 75/25 (w/w), solvent/monomer with a monomer composition of 59.7/40/0.3 (BMA/EGDMA/AMPS) and that of the solvents of 10/62/28 (water/1-propanol/1,4-butanediol), with $1 \%$ of AIBN with respect to the monomers. This polymerisation procedure was equivalent to the one described above but in this case the polymerisation time was $1 \mathrm{~h}$.

\subsubsection{In-capillary polymeric microextraction and separation by MEKC}

A capillary of $100 \mu \mathrm{m} \times 40 \mathrm{~cm}$, with $16 \mathrm{~cm}$ of monolith bed at the inlet end was used. All samples and solvents were passed through nylon filters $(0.22 \mu \mathrm{m})$ to prevent obstruction of the monolithic sorbent.

The process of retention and elution can be described in the following steps (See also Table 1): (a) Washing of the monolith with methanol to remove compounds from previous analyses (1 min, 12 bar). (b) Conditioning of the monolith with water (1 min, 12 bar). (c) Microextraction, passing the aqueous sample through the monolith (12 bar) for 1-30 min, depending on the analyte concentration. (d) Washing the monolith with UHQ water (1 min, 12 bar). (e) Elution of the retained sample with methanol at 1 bar into an empty $100 \mu \mathrm{L}$ vial; elution is stopped when the absorbance monitored falls to $10 \%$ of the peak observed (using capillaries of $100 \mu \mathrm{m}$, the volume of methanol was approximately $2.5 \mu \mathrm{L}$ ). Once the microextraction step has finished, the preconcentration capillary cartridge is then replaced by the one used in separation, and MEKC is performed injecting the eluate collected in the elution step.

\section{Results}

\subsection{Separation of carbamate pesticides by MEKC}

Preliminary experiments for the MEKC separation were carried out with $10 \mathrm{mM}$ phosphate buffer and $60 \mathrm{mM}$ SDS as micelle-forming agent. Although the buffer concentrations were varied between 5 and $30 \mathrm{mM}$ and those of surfactant between 20 and $80 \mathrm{mM}$, no satisfactory results were obtained. Upon working at a higher $\mathrm{pH}$ (borate buffer $\mathrm{pH}$ 9.2) the electropherograms obtained showed well defined signals at migration times of between 5 and $10 \mathrm{~min}$. However, not all the analytes were well resolved. 


\subsubsection{Optimisation of the MEKC separation}

Separation was optimised using a design-of-experiment approach [26, 27]. A two-level fractional factorial design was applied, the borate buffer concentration, the SDS concentration, the applied voltage, the temperature and the presence of an organic modifier $(\mathrm{MeOH})$ being the variables under study (the levels for each factor are shown in Table 2). The total number of runs was 19 (16 plus three replicates of the central point). The response was evaluated in terms of the resolution of critical groups of peaks; the responses were $\boldsymbol{R}_{\mathbf{1}}$, the resolution between CBZ and ADC; $\boldsymbol{R}_{\mathbf{2}}$, the geometric mean of the resolution between three consecutive IPP, CBM and PPX peaks, whose relative migration orders changed depending on the conditions used, and $\boldsymbol{R}_{\mathbf{3}}$, the resolution between CBR and PMC, whose migration order was dramatically affected by the presence of methanol.

The experimental data were fitted by least squares to the simplest model not showing a lack of fit. No interactions between the factors or symptoms of curvature were found, and hence only linear terms were included in the model. Table 1 shows the effects of all the factors for each response.

It may be seen that for the separation between $\mathrm{CBZ}$ and $\mathrm{ADC}-\boldsymbol{R}_{\mathbf{1}}$ response - the concentration of SDS is of special importance, as are the voltage applied and the separation temperature, although to a lesser extent. All three factors affected the separation in a positive fashion. Regarding the separation of IPP, CBM and PPX $-\boldsymbol{R}_{\mathbf{2}}$ response- the concentration of SDS affected this positively and that of methanol negatively. Moreover, the resolution between CBR and PMC $-\boldsymbol{R}_{\mathbf{3}}$ response - was mainly affected by the presence of methanol in the separation medium, in the sense that it altered the order of migration of these two analytes and a good separation was achieved in the two extreme levels of the design.

A desirability function was maximised, with values of 1 assigned to the responses higher than two, and values of 0 to those lower than 1 . Several optimum conditions were found with the mathematical software employed, among which the most suitable ones were assayed (lower analysis times and current intensities below $100 \mu \mathrm{A}$ ).

The final conditions selected were as follows: $30{ }^{\circ} \mathrm{C}$ for temperature, $30 \mathrm{kV}$ for the separation voltage, $60 \mathrm{mM}$ SDS, $20 \mathrm{mM}$ borate buffer and without methanol in the BGE. A good separation in less than 5.5 min was obtained with these conditions and no further optimisation studies were carried out. An example of the separation obtained can be seen in Figure 3. 


\subsection{In-capillary preconcentration using monolithic polymers}

As reported in the Introduction, preconcentration prior to CE in the in-line approach, is carried out in the same capillary as the one in which separation takes place. However, the micellar media employed in separations using MEKC are not compatible with the organic eluting solvent. In our own case, all attempts to perform preconcentration and separation in the same capillary required a highly organic solvent to elute the analytes and, in all cases, after preconcentration the separation by MEKC resulted in a single peak of unresolved compounds due to the absence of micelles in the plug where the analytes were eluted.

Here we propose a new procedure for in-capillary preconcentration prior to electrophoretic separation by MEKC. Preconcentration takes place on a monolithic polymeric sorbent synthesised in a silica capillary placed in the CE instrument. This procedure initially permits sample preconcentration and collection of the elution volume in different microvials, using this capillary modified with the monolithic bed. After the microextraction step has been completed, the preconcentration capillary cartridge is then replaced by the one used for the separation, and MEKC is performed by injecting the eluate collected in the elution step. A scheme of the procedure is shown in Figure 1 and the steps to be followed are shown in Table 1. Different studies were carried out using polymers of butyl methacrylate (BMA) and of poly(ethylvinylbenzene-divinylbenzene), (PEVB-DVB). The polymers of BMA were obtained using 1,4-butanodiol and 1-propanol as porogenic solvents. The proportion of solvents was $75 \%(\mathrm{w} / \mathrm{w})$, instead of the $50-55 \%$ usually used in the manufacture of these polymers for use in CEC columns [28-30]. With the proportion of solvents employed, a polymer monolith was obtained that allowed the passage of sample and washing solvents at an adequate flow rate with the pressures applied by the CE apparatus employed here (up to 12 bar).

Figure 2 shows the variations in the spectrophotometric signals during the preconcentration, washing and elution steps in a BMA-based polymer. It also shows the pressure applied to the system during the different steps. In the preconcentration step the signal increased rapidly, due to the effect of the arrival of the sample front at the detection window, a constant value being reached that later decreased when the capillary was washed with water. This behaviour indicates that the analytes were not completely retained in the preconcentration step on the BMA polymer, and hence a spectrophotometric signal was generated when the analytes passed through the detector. In the elution step with methanol, a transient signal was obtained with time; its magnitude can be used to optimise the volume of methanol to be used for analyte elution. It was observed that the most suitable elution time, using methanol, was when the spectrophotometric signal was $10 \%$ of the maximum transient signal (Fig. 1). 
Working with BMA, and injecting the extract obtained in the elution step, the preconcentration of more polar analytes (ASO, MTM and ASL) did not occur; in the case of the other analytes studied signals approximately $50 \%$ more reduced than those obtained by injecting the sample directly were obtained.

In light of these observations, capillaries filled with PEVB-DVB were constructed. These materials are highly porous and have been described to have a large specific surface area [31, 32] and are thus able to retain different compounds through adsorption phenomena. Additionally, the sample flow that can be used with this type of polymer is relatively high (approximately between 1 and $5 \mathrm{~mL} / \mathrm{h}$ ), whereas with BMA a maximum of $0.3 \mathrm{~mL} / \mathrm{h}$ is usual, which allows much more sample to be preconcentrated in shorter times. With these polymers, in the preconcentration step, the spectrophotometric signal is almost absent, indicating that under these conditions the analytes are completely retained in PEVB-DVB. Figure 3 shows the electropherograms of a standard solution at approx $35 \mathrm{mg} / \mathrm{L}$ injected directly (Fig. 3-A), and after preconcentration for $5 \mathrm{~min}$ at a pressure of 6 bar (Fig. 3-B); for comparative purposes, Fig. 3-C shows the electropherogram of a standard sample at $0.35 \mathrm{mg} / \mathrm{L}$ preconcentrated for $30 \mathrm{~min}$ at 12 bar. Studies performed with thicker capillaries (250 and $400 \mu \mathrm{m}$ ID) revealed that under the working conditions employed the capillaries that provided maximum sensitivity and resolution were those of PEVB-DVB with $100 \mu \mathrm{m}$ ID.

\subsubsection{Characterisation of the monolithic polymers}

In order to relate the observed behaviour of the monolithic polymers to their morphology, micrographs were taken with a scanning electron microscope (SEM). Figure 4 shows the micrographs of BMA and PEVB-DVB when $100 \mu \mathrm{m}$ capillaries were used. In the micrographs of the PEVB-DVB polymers it may be seen that the polymer does not fill the section of the capillary in a uniform way, leaving open spaces. However, it does completely line the wall of the capillary. This might lead the polymer to behave in a way similar to that of an open tubular capillary, with the wall covered with the stationary phase, thus allowing high flow rates for the sample loading. In contrast, in the different micrographs obtained with capillaries filled with BMA, the monolith is spread evenly throughout the capillary section. Also, BMA is formed by irregular nodules with a size of approximately $0.5 \mu \mathrm{m}$, while those of PEVB-DVB are made up of larger $(1 \mu \mathrm{m})$ spherical nodules. These characteristics of PEVB-DVB polymers, together with the fact that they have a high specific surface area [31,32] may account for their greater retention capacity. 


\subsubsection{Optimisation of polymeric bed length and preconcentration time}

The length of the sorbent bed increases its retention capacity, but owing to the greater resistance that it offers to the passage of fluids the flow rate is reduced. In contrast, if the length is short it is possible to use higher sample flow rates per unit time. Despite this, if the flow rate is too high this may prevent an adequate interaction between the polymer and the analytes. To optimise these effects, a study was performed varying the length of the polymeric bed and the preconcentration time. The lengths of the sorbent bed studied were 25,16 and $8 \mathrm{~cm}$. The whole study was performed in the same monolithic column, first with a length of $25 \mathrm{~cm}$ and then cutting it successively until the desired length was reached. The different preconcentration times were 7, 15 and $30 \mathrm{~min}$ (total, 9 experiments). Although all the samples were filtered, the entrance to the capillary became progressively obstructed, probably due to swelling. When this occurred, cutting a few millimetres off the capillary solved the problem. The variation in the length was almost negligible and the polymer maintained its characteristics.

The amount of sample that can be preconcentrated is a function of time and the length of the monolithic sorbent bed. The maximum amount of preconcentrated sample was achieved with short monolithic polymers and long preconcentration times (Fig. 5). Flow rate was decreased upon increasing the length of the monolithic polymer. Thus, values of $4.9 \pm 1.3,3.1 \pm 0.5$ and $1.5 \pm 0.09$ $\mathrm{mL} / \mathrm{h}$ were obtained for PEVB-DVB polymer monolith with bed lengths of 8,16 and $25 \mathrm{~cm}$, respectively. The variability in the flow rate affected the amount of sample to be loaded and hence analyte quantification; however this effect was corrected with the use of an internal standard.

The signals obtained $v s$. the amount of sample preconcentrated for each of the three lengths of monolith were seen to depend on the polarity of the analytes (Fig. 6). The more polar analytes, ASO and ASL, were not detected in any of the assays, such that it may be concluded that the PEVB-DVB polymer is not suitable for their concentration. Methomyl (MTM), with a value of $\log K_{\mathrm{OW}}=0.60$, was poorly retained and with the 8 and $16 \mathrm{~cm}$ monolithic polymer the signal decreased as the preconcentration time increased. When the preconcentration time was increased, the analytes of intermediate polarity, $\mathrm{ADC}\left(\log K_{\mathrm{OW}}=1.13\right)$; $\mathrm{CBZ}\left(\log K_{\mathrm{OW}}=1.52\right)$; $\mathrm{PPX}\left(\log K_{\mathrm{OW}}=1.52\right)$ and CBM $\left(\log K_{\mathrm{OW}}=1.63\right)$, showed a decrease in the signal in the shorter monolith $(8 \mathrm{~cm})$, whereas when longer polymers were employed the signal tended towards a constant value. This behaviour is due to the breakthrough phenomenon and indicates that for analytes of intermediate polarity, with short columns, the analytical signal is not a linear function of the amount of sample passed through the monolithic polymer. For the most apolar analytes (log $\left.K_{\mathrm{OW}}>1.7\right)$ PMC, IPP, CBR, CBF, NAP and MTC, the amount of analyte retained increased with the increase in the amount of sample loaded for all three monolithic polymer lengths considered. For these compounds, maximum 
sensitivity was obtained with capillaries with an $8 \mathrm{~cm}$ monolith bed and preconcentration times of $30 \mathrm{~min}$.

\subsection{Analytical characteristics}

The analytical characteristics (precision, linear range and LODs) were determined for the incapillary microextraction procedure prior to MEKC separation. We used a monolithic sorbent bed of $16 \mathrm{~cm}$ length and a preconcentration time of $15 \mathrm{~min}$ at $12 \mathrm{bar}$. $\alpha$-naphthol at $74 \mu \mathrm{g} / \mathrm{L}$ was used as internal standard. Good linear relationships between analytical signal and analyte concentration were obtained for all the compounds studied. The regression parameters of the calibration straight lines are shown in Table 3, as well as the sensitivity enhancement factors as a means of comparison with conventional MEKC performed without any preconcentration step. The enhancement factors were determined from the ratio between the slopes of the calibration lines obtained under preconcentration and non-preconcentration conditions; values in the 44-72 range were obtained, except for MTM, a polar compound that is very sparingly retained in the polymeric sorbent employed. LODs ranging from 1 to $16 \mu \mathrm{g} / \mathrm{L}$ were obtained, implying a considerable increase in sensitivity with respect to MECK alone, with a total analysis time of less than $20 \mathrm{~min}$. Additionally, it was possible to reduce the LODs by increasing the preconcentration time. Fig. 7 shows an electropherogram obtained for a sample at a concentration level of $10-20 \mu \mathrm{g} / \mathrm{L}$ preconcentrated for $30 \mathrm{~min}$.

The main advantage of the proposed semi-automatized method is that it is possible to preconcentrate sample volumes of $250 \mu \mathrm{L}$ using a PEVB-DVB monolithic bed without the need for microvalves, external connectors or T-splits. Additionally, the manufacture of capillaries with monolithic polymers is easy and such capillaries afford suitable efficiency in the preconcentration step. This methodology can be performed using only the CE instrument, controlling the flow of sample in the preconcentration step and following the spectrophotometric signal in the elution step. Table 4 shows a comparison of the analytical characteristics of the different methods proposed, with on-line and at-line couplings, reported in the literature.

\section{Conclusions}

Employing MEKC, good separation of carbamate pesticides and some of their metabolites was achieved in less than 6 min. An in-line preconcentration step in a polymeric sorbent synthesised in the same separation capillary was tested, but the micellar medium was not compatible with the 
high percentage of organic solvent required for the elution of the analytes from the polymeric sorbent.

A novel and sensitive method for in-capillary monolithic polymer microextraction followed by MEKC separation has been developed. The approach described here uses two different capillaries, one for the preconcentration step and the other one for the electrophoretic separation, the whole process being carried out with the CE equipment. This method permits the preconcentration of microsamples in a capillary column containing a bed of monolithic sorbent, later changing the capillary for the electrophoretic separation.

The proposed method is easy to implement and does not require microvalves, external connectors or T-splits. The monolithic polymers obtained from divinylbenzene monomers were found to be more suitable for the preconcentration of carbamates than those obtained from butyl methacrylate. A monolithic bed of $16 \mathrm{~cm}$ length, formed in situ at the inlet end of the capillary, allows the preconcentration of the target analytes from aqueous samples with a mean preconcentration factor of 60 . The enrichment step affords increased sensitivity that overcomes the lack of sensitivity typical of electrophoretic techniques, offering an alternative method to LC separations for this family of pesticides.

\section{Acknowledgements}

The Ministerio de Ciencia e Innovación, Spain, (Project CTQ 2008-02200/BQU) and the Junta de Castilla y León (Project SA017A08) are gratefully acknowledged for financial support of this work. 


\section{References}

[1] Kim, J.-B., Terabe, S., J. Pharm. Biomed. Anal., 2003, 30, 1625-1643.

[2] Timerbaev, A.R., Hirokawa, T., Electrophoresis, 2006, 27, 323-340.

[3] Malá, Z., Křrivánková L., Gebauer, P., Boček, P., Electrophoresis, 2007, 28, 243-253.

[4] Juan-García, A., Font, G., Picó, Y., J. Chromatogr. A, 2007, 1153, 104-113.

[5] Veraart, J.R., Lingeman, H., Brinkman, U.A. Th., J. Chromatogr. A, 1999, 856, 483-514.

[6] Puig, P., Borrull, F., Calull, M., Aguilar, C., Trends Anal. Chem., 2007, 26, 664-678.

[7] Baryla, N.E., Toltl, N.P., Analyst 2003, 128, 1009-1012.

[8] Xie, R., Oleschuk, R., Electrophoresis, 2005, 26, 4225-4234.

[9] Zhang, L.-H., Zhang, C.-J., Chen, X., Feng, Y.-Q., Wu, X.-Z., Electrophoresis, 2006, 27, $3224-$ 3232.

[10] Jarmalaviciene, R., Szumski, M., Kornyšova, O., Kłodzinska, E., Westerlund, D., Krawczyk, S., Mickevicius, D., Buszewski, B., Maruška, A., Electrophoresis, 2008, 29, 1753-1760.

[11] Macià, A., Borrull, F., Calull, M., Benavente, F., Hernández, E., Sanz-Nebot, V., Barbosa, J., Aguilar, C., J. Sep. Sci., 2008, 31, 872-880.

[12] Rodríguez-Gonzalo, E., Domínguez-Álvarez, J., Ruano-Miguel, L., Carabias-Martínez, R., Electrophoresis, 2008, 29, 4066-4077.

[13] Santos, B., Simonet, B.M., Ríos, A., Valcárcel, M., Trends Anal. Chem., 2006, 25, 968-976.

[14] Santos B., Lista, A., Simonet, B.M., Ríos, A., Valcárcel, M., Electrophoresis, 2005, 26, 1567 1575.

[15] Tempels, F.W.A., Underberg, W.J.M., Somsen, G.W., de Jong, G.J., Electrophoresis, 2007, 28, 1319-1326.

[16] Han, F., He, Y.-Z., Yu, C.-Z., Talanta, 2008, 74, 1371-1377.

[17] Puig, P., Tempels, F.W.A., Borrull, F., Calull, M., Aguilar, C., Somsen, G.W., de Jong, G.J., J. Chromatogr. B, 2007, 856, 365-370.

[18] US EPA method 531.2, Measurement of N-methylcarbamoyloximes and N-methylcarbamates in water by direct aqueous injection HPLC with post column derivatisation, 2001. Rev. 1.

[19] US EPA method 8318A, N-Methylcarbamates by High-Performance Liquid Chromatography, 2007. Rev. 1. 
[20] Arráez-Román, D., Segura-Carretero, A., Cruces-Blanco, C., Fernández-Gutiérrez, A., Pest Manag. Sci., 2004, 60, 675-679.

[21] Rossi, M., Rotilio, D., J. High Resol. Chromatogr. 1997, 20, 265-269.

[22] Molina, M., Wiedmer, S.K., Jussila, M., Silva, M., Riekkola, M.-L., J. Chromatogr. A, 2001, 927, 191-202.

[23] Wu, Y.S., Lee, H.K., Li, S.F.Y., J. Microcol. Sep. 1998, 10, 239

[24] Saavedra, L., Barbas, C., J. Biochem. Biophys. Methods, 2007, 70, 289-297.

[25] Molina, M., Pérez-Bendito, D., Silva, M., Electrophoresis, 1999, 20, 3439-3449.

[26] He, Y., Lee, H.K., J. Chromatogr. A, 1998, 793, 331-340.

[27] Kuo, C.H., Sun, S.W., Anal. Chim. Acta, 2003, 482, 47-58.

[28] Peters, E. C., Petro, M., Svec, F., Fechet, J. M. J., Anal. Chem., 1997, 69, 3646-3649.

[29] Peters, E. C., Petro, M., Svec, F., Fechet, J. M. J., Anal. Chem. 1998, 70, 2288-2295.

[30] Jiang, T., Jiskra, J., Claessens, H. A., Cramers, C. A., J. Chromatogr. A, 2001, 923, 215-227.

[31] Xie, S., Svec, F. Frechet, J.M.J., Chem. Mater., 1998, 10, 4072-4078.

[32] Svec, F., J. Chromatogr. B, 2006, 841, 52-64.

[33] Tempels, F. W. A., Teeuwsen, J., Kyriakou, I. K., Theodoridis, G., Underberg, W. J. M., Somsen, G. W., de Jong, G. J., J. Chromatogr. A, 2004, 1053, 263-268.

[34] Hinsmann, P., Arce, L., Ríos, A., Valcárcel, M., J. Chromatogr. A, 2000, 866, 137-146.

[35] Suárez, B., Simonet, B. M., Cárdenas, S., Valcárcel, M., J. Chromatogr. A, 2007, 1159, $203-$ 207.

[36] Suárez, B., Santos, B., Simonet, B. M., Cárdenas, S., Valcárcel, M., J. Chromatogr. A, 2007, $1175,127-132$.

[37] Priego Capote F., Luque de Castro, M. D., Electrophoresis 2007, 28, 1214-1220.

[38] Zhang, M., Wei, F., Zhang, Y.- F., Nie, J., Feng, Y.-Q., J. Chromatogr. A, 2006, 1102, $294-$ 301. 


\section{Figure Legends}

Figure 1.- General scheme of the preconcentration process.

Figure 2.- Signal monitored during the successive passage of a standard solution $(5 \mathrm{mg} / \mathrm{L}$, each compound), water and methanol through a BMA polymeric sorbent $(25 \mathrm{~cm} \times 100 \mu \mathrm{m} \mathrm{ID})$.Applied pressure: 6 bar in preconcentration and washing steps, and 1 bar in the elution step.

Figure 3.- Comparison of electropherograms of a solution of pesticides injected directly and after preconcentration in $25 \mathrm{~cm} \times 100 \mu \mathrm{m}$ of a PEVB-DVB. Peaks: 1, ASO; 2. MTM; 3, ASL; 4, CBZ; 5 , ADC; 6, IPP; 7, CBM; 8, PPX; 9, CBF; 10, NAP; 11, CBR; 12, PMC 13, MTC.

Figure 4.- SEM micrographs of monolithic capillary cross-sections employed in this work.

Figure 5.- Sample amount preconcentrated as a function of monolithic bed length and of preconcentration time.

Figure 6.- Peak areas as a function of monolithic bed length and of preconcentration time.

Figure 7.- Electropherogram of a pesticide solution with concentrations between 10 and $20 \mu \mathrm{g} / \mathrm{L}$. Microextraction with a monolithic bed of $16 \mathrm{~cm} \times 100 \mu \mathrm{m}$ of a PEVB-DVB for $30 \mathrm{~min}$. Numbers on peaks as in Fig. 3. 
Table 1. General steps for the in-capillary microextraction prior MEKC procedure.

\begin{tabular}{lllllll}
\hline & Step & Inlet & \multicolumn{2}{l}{ Outlet } & & \\
\hline & 1 & Washing & MeOH & Waste & $12 \mathrm{bar}$ & $1 \mathrm{~min}$ \\
& 2 & Washing & Water & Waste & $12 \mathrm{bar}$ & $1 \mathrm{~min}$ \\
$\begin{array}{l}\text { Preconcentration } \\
\text { capillary }\end{array}$ & 3 & Microextraction & Sample & Waste & $12 \mathrm{bar}$ & $1-30 \mathrm{~min}$ \\
& 4 & Washing & Water & Waste & $12 \mathrm{bar}$ & $1 \mathrm{~min}$ \\
& 5 & Elution & MeOH & $100 \mu \mathrm{L}$ vial & 1 bar & \\
\hline \multirow{3}{*}{ Separation capillary } & 6 & Injection & Eluted sample & BGE & $25 \mathrm{mbar}$ & $4 \mathrm{~s}$ \\
& 7 & Separation & BGE & BGE & $30 \mathrm{kV}$ & \\
\hline
\end{tabular}


Table 2. Factors and levels employed during the MEKC optimisation and regression coefficients of coded factors.

\begin{tabular}{|c|c|c|c|c|c|c|c|c|}
\hline & \multicolumn{2}{|c|}{ Level } & \multicolumn{6}{|l|}{ Effect $(p)$} \\
\hline & Low & High & $R_{1}$ & & $R_{2}$ & & $R_{3}$ & \\
\hline$T\left({ }^{\circ} \mathrm{C}\right)$ & 25 & 35 & $0.6 \pm 0.6^{a}$ & $(0.0417)$ & $0.0 \pm 0.2$ & $(0.7253)$ & $0.8 \pm 0.6$ & $(0.0377)$ \\
\hline$V(\mathrm{kV})$ & 20 & 30 & $0.9 \pm 0.6$ & $(0.0062)$ & $0.0 \pm 0.2$ & $(0.9292)$ & $0.7 \pm 0.6$ & $(0.0822)$ \\
\hline SDS (mM) & 40 & 100 & $1.8 \pm 0.6$ & $(<0.0001)$ & $0.3 \pm 0.2$ & $(0.0113)$ & $-0.1 \pm 0.6$ & $(0.2037)$ \\
\hline Buffer (mM) & 8 & 48 & $0.5 \pm 0.6$ & $(0.0856)$ & $0.1 \pm 0.2$ & $(0.5320)$ & $0.1 \pm 0.6$ & $(0.5999)$ \\
\hline $\mathrm{MeOH}(\%)$ & 0 & 9,6 & $-0.3 \pm 0.6$ & $(0.2918)$ & $-0.7 \pm 0.2$ & $(<0.0001)$ & $-2.6 \pm 0.6$ & $(<0.0001)$ \\
\hline Lack of fit & & & $(0.0858)$ & & $(0.0612)$ & & $(0.0941)$ & \\
\hline$r^{2}$ & & & 0.849 & & 0.789 & & 0.885 & \\
\hline
\end{tabular}

${ }^{a}$ Confidence levels at $95 \%$; significative factors in bold $(\mathrm{p}<0.05)$. 
Table 3. Analytical characteristics for in-capillary microextraction prior to MEKC separation ${ }^{a}$. Preconcentration time, $15 \mathrm{~min}$ at 12 bar; PEVB-DVB monolith of $16 \mathrm{~cm}$ length.

\begin{tabular}{|c|c|c|c|c|c|c|c|c|c|}
\hline \multirow[b]{2}{*}{ MTM } & \multicolumn{3}{|c|}{$\begin{array}{c}\text { Intercept }^{b} \\
\left(\mathbf{1 0}^{-\mathbf{1}}\right)\end{array}$} & \multicolumn{2}{|c|}{$\begin{array}{c}\text { Slope } \\
\left(10^{-3} \mathrm{~L} / \mu \mathrm{g}\right)\end{array}$} & \multirow{2}{*}{$\begin{array}{c}\boldsymbol{r}^{2} \\
0.94\end{array}$} & \multirow{2}{*}{$\begin{array}{c}\mathbf{R S D}^{c} \\
-\end{array}$} & \multirow{2}{*}{$\begin{array}{c}\mathbf{L O D}^{d} \\
(\boldsymbol{\mu g} / \mathbf{L})\end{array}$} & \multirow{2}{*}{$\begin{array}{c}\begin{array}{c}\text { Sensitivity } \\
\text { enhacement }^{e}\end{array} \\
16\end{array}$} \\
\hline & 3 & \pm & 4 & 0.5 & \pm 0.2 & & & & \\
\hline CBZ & 0.3 & \pm & 0.6 & 5.2 & \pm 0.4 & 0.997 & 13 & 7 & 65 \\
\hline $\mathrm{ADC}$ & 0 & \pm & 1 & 4.3 & \pm 0.4 & 0.996 & 18 & 16 & 72 \\
\hline IPP & 0 & \pm & 1 & 12.5 & \pm 0.7 & 0.998 & 11 & 4 & 56 \\
\hline $\mathrm{CBM}$ & 1.2 & \pm & 0.4 & 9.4 & \pm 0.2 & 0.9997 & 15 & 7 & 58 \\
\hline PPX & 1 & \pm & 2 & 9 & \pm 1 & 0.993 & 15 & 8 & 59 \\
\hline $\mathrm{CBF}$ & 1 & \pm & 2 & 12 & \pm 1 & 0.996 & 12 & 6 & 59 \\
\hline CBR & 0 & \pm & 4 & 23 & \pm 2 & 0.995 & 5 & 1 & 61 \\
\hline PMC & 0 & \pm & 1 & 7.3 & \pm 0.6 & 0.996 & 15 & 4 & 44 \\
\hline MTC & 0 & \pm & 2 & 12.3 & \pm 0.9 & 0.997 & 9 & 3 & 50 \\
\hline
\end{tabular}

${ }^{a}$ Studied interval between 19 and $314 \mu \mathrm{g} / \mathrm{L}$, except MTM $(188-2820 \mu \mathrm{g} / \mathrm{L})$ and ADC (38$627 \mu \mathrm{g} / \mathrm{L}$ ), with $C$ as abscissas (in $\mu \mathrm{g} / \mathrm{L}$ ) and $A_{\mathrm{i}} / A_{\text {IS }}$ as ordinates (dimensionless). $A_{\mathrm{i}}$, analyte peak area; $A_{\mathrm{IS}}$, internal standard peak area.

${ }^{b}$ Confidence levels at $95 \%$.

${ }^{c}$ Consecutive measurements $(n=8)$ at $50 \mu \mathrm{g} / \mathrm{L}$.

${ }^{d}$ Limits of detection for a signal-to-noise ratio of 3 .

${ }^{e}$ Slope ratio for peak height calibration curves between MEKC with and without the incapillary microextraction procedure. 
Table 4. Comparison of the characteristics of several on-line and at-line couplings reported in the literature.

\begin{tabular}{|c|c|c|c|c|c|c|c|c|}
\hline Mode & Sorbent & Separation & Analytes & $\begin{array}{l}\text { Sample } \\
\text { volume }\end{array}$ & Eluent & $\begin{array}{l}\text { Preconcentration } \\
\text { factor }\end{array}$ & LODs $(\mu \mathrm{g} / \mathrm{L})$ & Ref. \\
\hline On-line & $\mathrm{C}_{18}$ & CZE-UV & Peptides & $250 \mu \mathrm{L}$ & $260 \mathrm{~nL} \mathrm{ACN}$ & 200 & 5 & [33] \\
\hline On-line & $\mathrm{C}_{18}$ & & Peptides & $100 \mu \mathrm{L}$ & $425 \mathrm{~nL} \mathrm{ACN}$ & - & 0.5 & {$[15]$} \\
\hline On-line & $\mathrm{C}_{18}$ & CZE-UV & $\begin{array}{l}\text { Cephalosporins: } \\
\text { Cefoperazone, } \\
\text { Ceftiofur }\end{array}$ & $250 \mu \mathrm{L}$ & $426 \mathrm{~nL} \mathrm{ACN}$ & - & 100 & [17] \\
\hline On-line & $\mathrm{C}_{18}$ & & Parabens & $1800 \mu \mathrm{L}$ & $\begin{array}{l}150 \mu \mathrm{L} 40 / 60 \\
\text { buffer } 20 \\
\text { mM/ethanol }\end{array}$ & 65 & $70-100$ & [16] \\
\hline At-line & $\mathrm{C}_{18}$ & & Pesticides & $25 \mathrm{~mL}$ & $30 \% \mathrm{ACN}$ & 12 & $10-30$ & [34] \\
\hline At-line & Carbon nanotubes & CZE-MS & Organic analytes & $5 \mathrm{~mL}$ & $200 \mu \mathrm{L} \mathrm{MeOH}$ & - & 1.6 & [35] \\
\hline At-line & Carbon nanotubes & CZE-MS & Tetracyclines & $10 \mathrm{~mL}$ & $\begin{array}{l}200 \mu \mathrm{L} \\
\mathrm{ACN} / \mathrm{HAcO} \\
90 / 10 \mathrm{v} / \mathrm{v}\end{array}$ & - & 0.3 & [36] \\
\hline At-line & $\mathrm{C}_{18} 2.5 \mathrm{~cm} \times 100 \mu \mathrm{m}$ & CZE-UV & Quinolone antibiotics & $2 \mu \mathrm{L}$ & $\begin{array}{l}125 \mathrm{~nL} 5 \% \\
\text { ammonia in } \\
86 / 14 \mathrm{v} / \mathrm{v} \\
\mathrm{MeOH} / \mathrm{H} 2 \mathrm{O}\end{array}$ & 10.4 & $20-80$ & [37] \\
\hline $\begin{array}{l}\text { Polymeric } \\
\text { monolithic } \\
\text { microextraction }\end{array}$ & $\begin{array}{l}\text { Monolithic polymer } \\
2 \mathrm{~cm} \times 530 \mu \mathrm{m}\end{array}$ & CZE-UV & $\begin{array}{l}\text { Angiotensin II } \\
\text { receptor antagonist }\end{array}$ & $2 \mathrm{~mL}$ & $50 \mu \mathrm{L} \mathrm{ACN}$ & - & 20 & [38] \\
\hline $\begin{array}{l}\text { In-capillary } \\
\text { microextraction }\end{array}$ & $\begin{array}{l}\text { Monolithic polymer } \\
16 \mathrm{~cm} \times 100 \mu \mathrm{m}\end{array}$ & MEKC & Carbamates & $250 \mu \mathrm{L}$ & $2.5 \mu \mathrm{L} \mathrm{MeOH}$ & $44-72$ & $1-16$ & this work \\
\hline
\end{tabular}

Wiley-VCH 


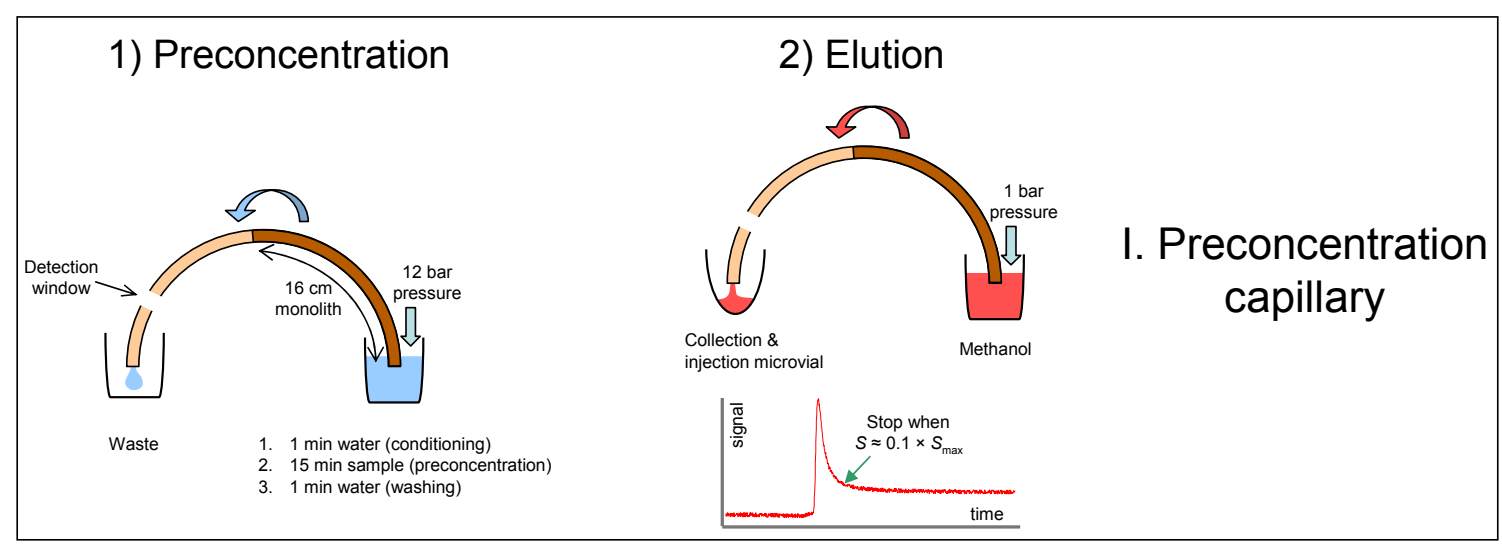

3) Separation

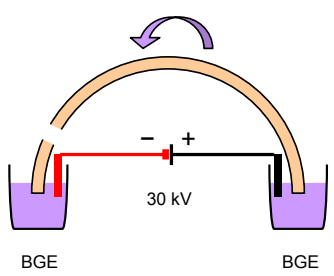

II. Separation capillary 


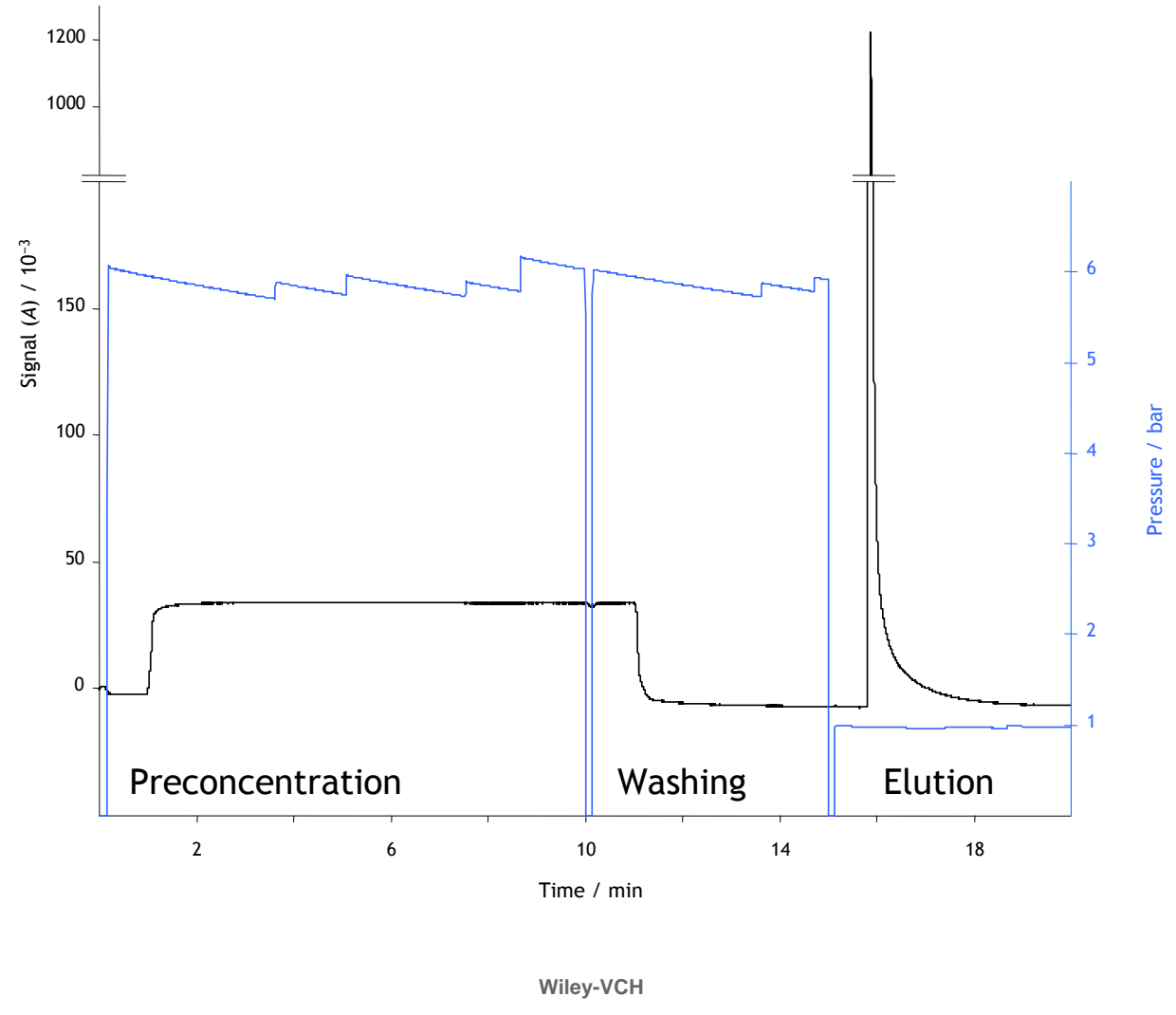




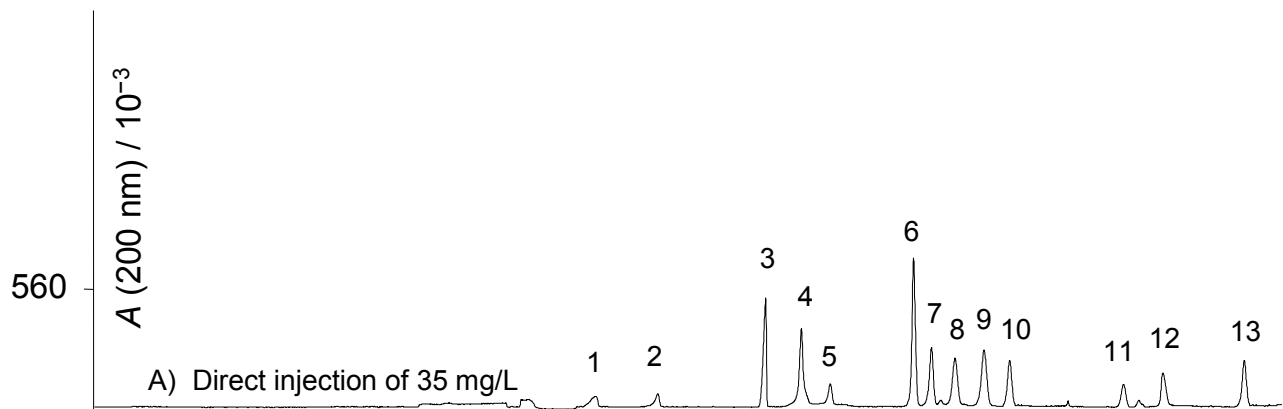

460

360

B) Preconcentration of $35 \mathrm{mg} / \mathrm{L}$ 5 min, 6 bar

160

6

260
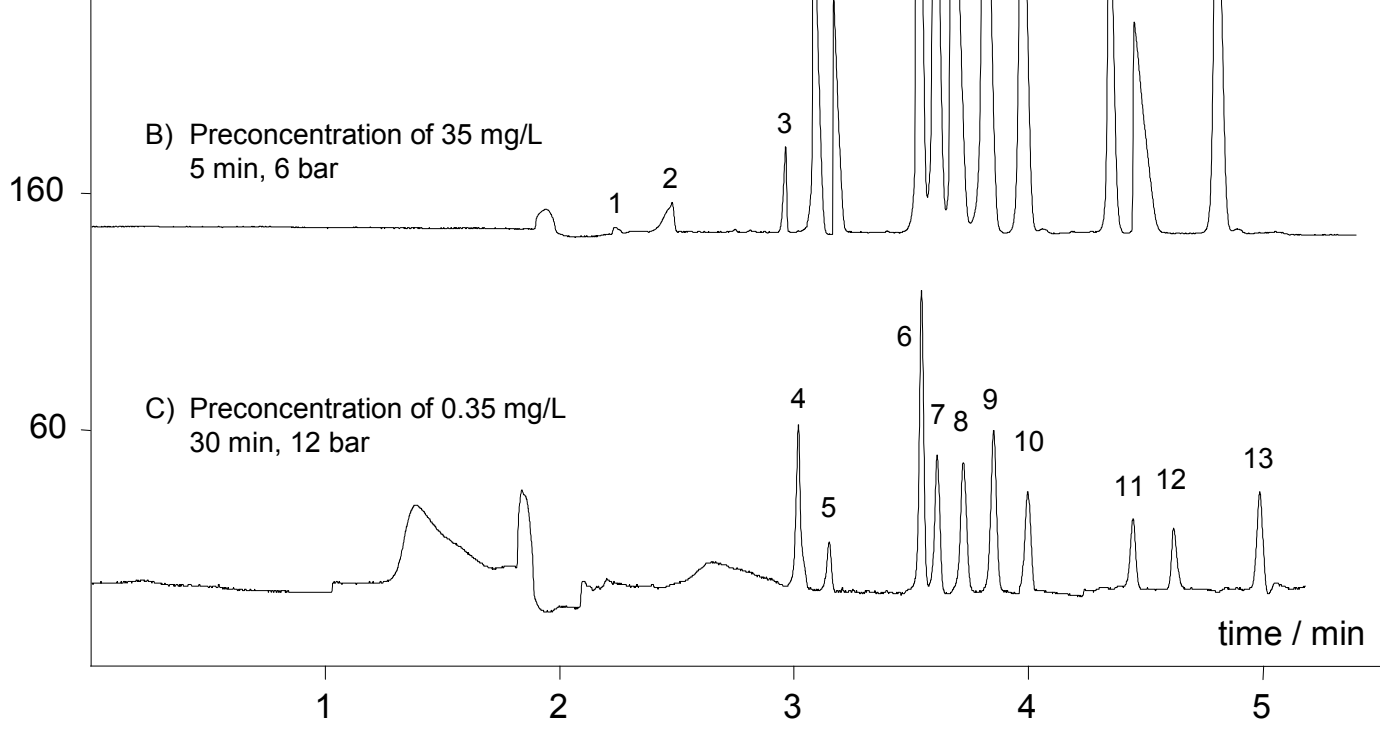

Wiley-VCH 


\section{Poly(ethylvinylbenzene-divinylbenzene)}
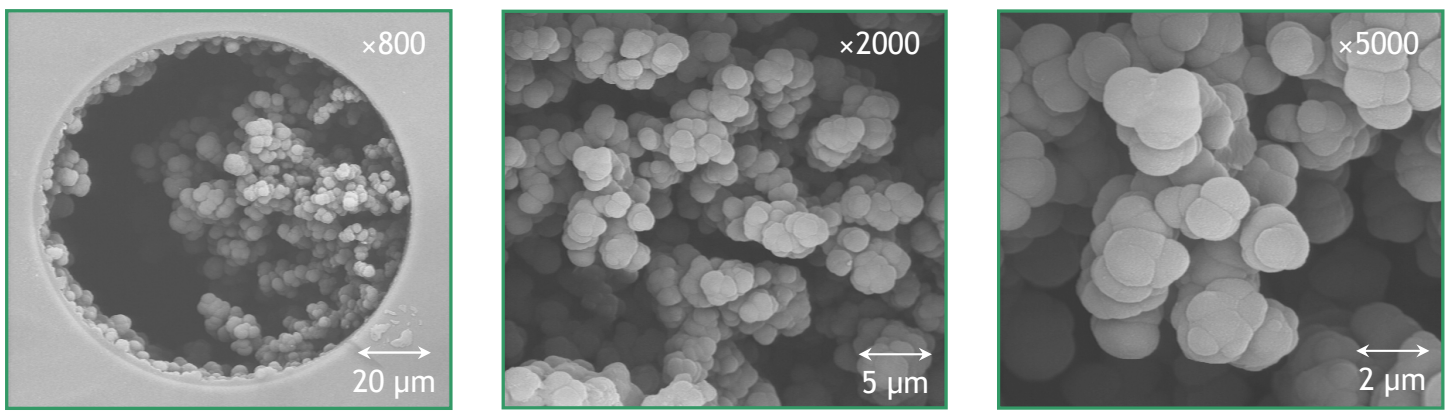

\section{Butylmethacrylate-based polymer}
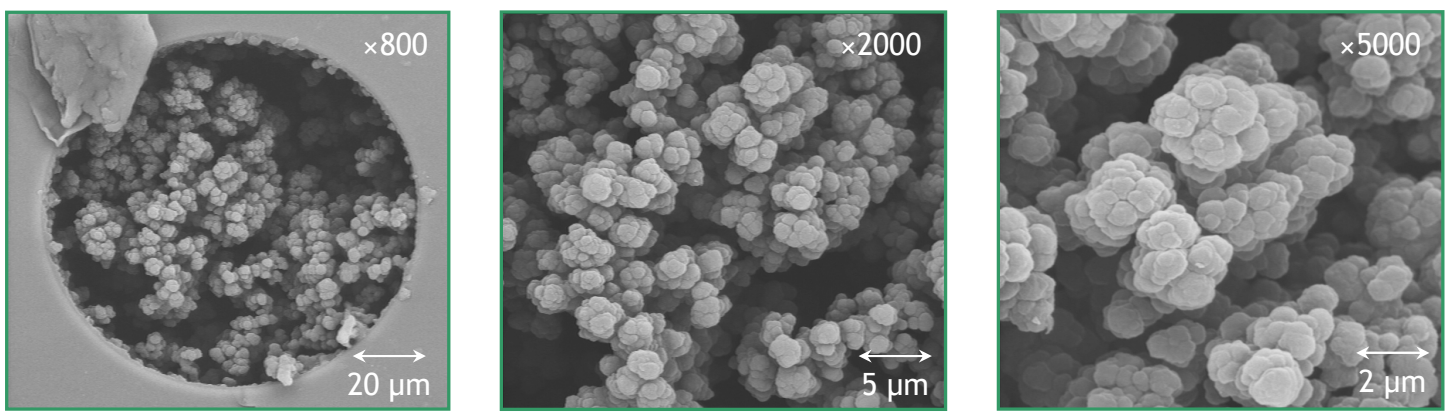

Wiley-VCH 


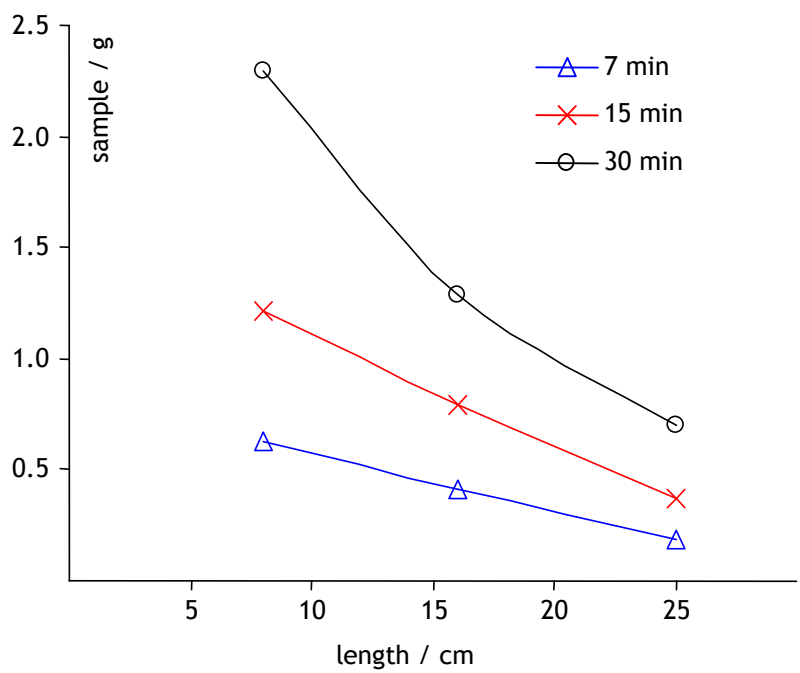

Wiley-VCH 


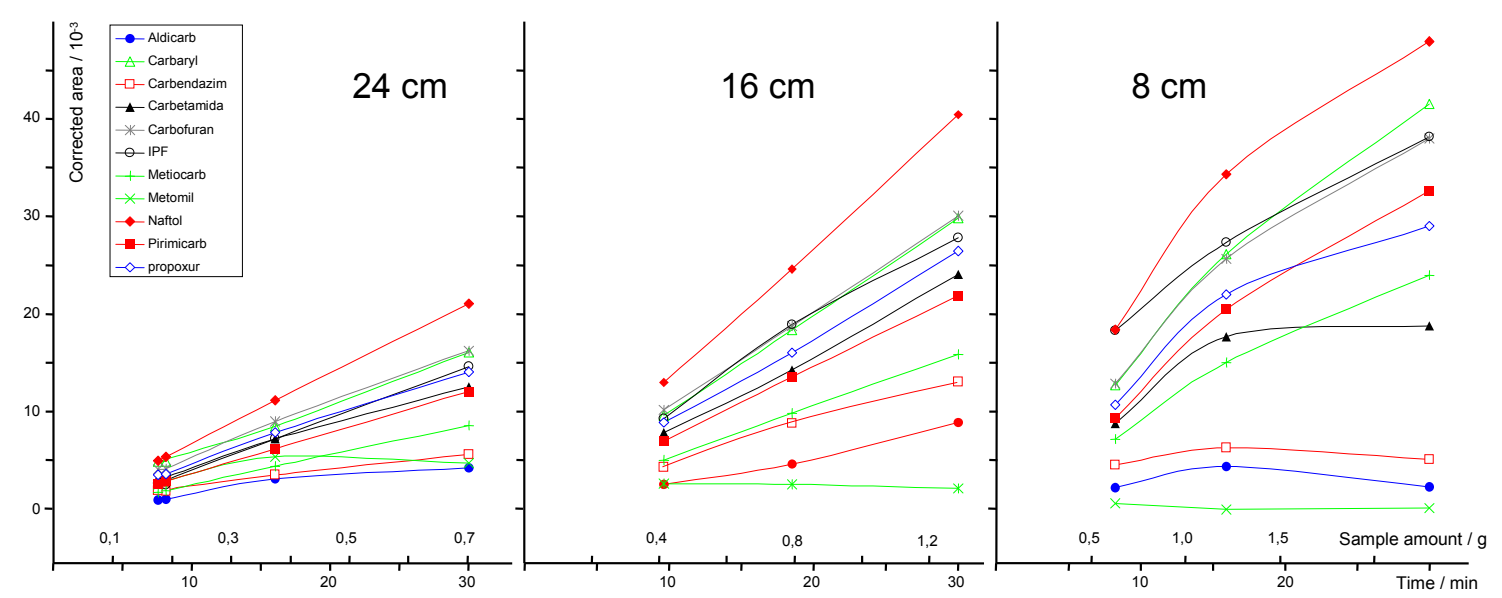

Wiley-VCH 


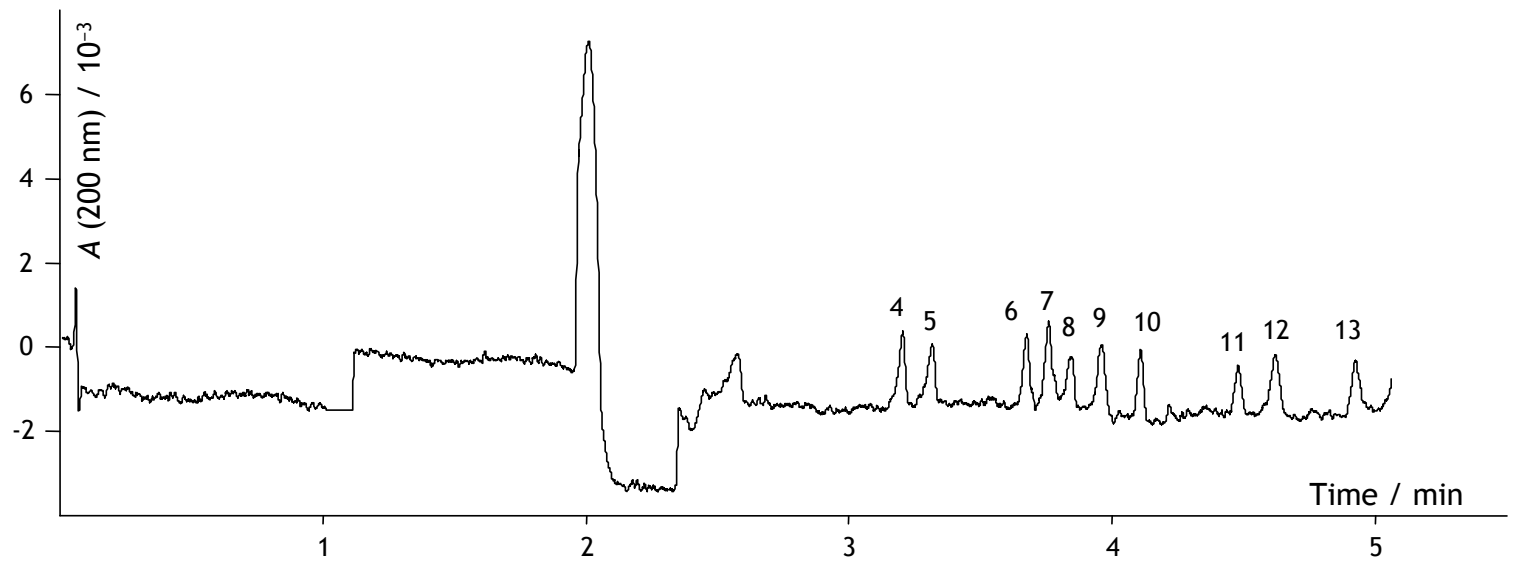

